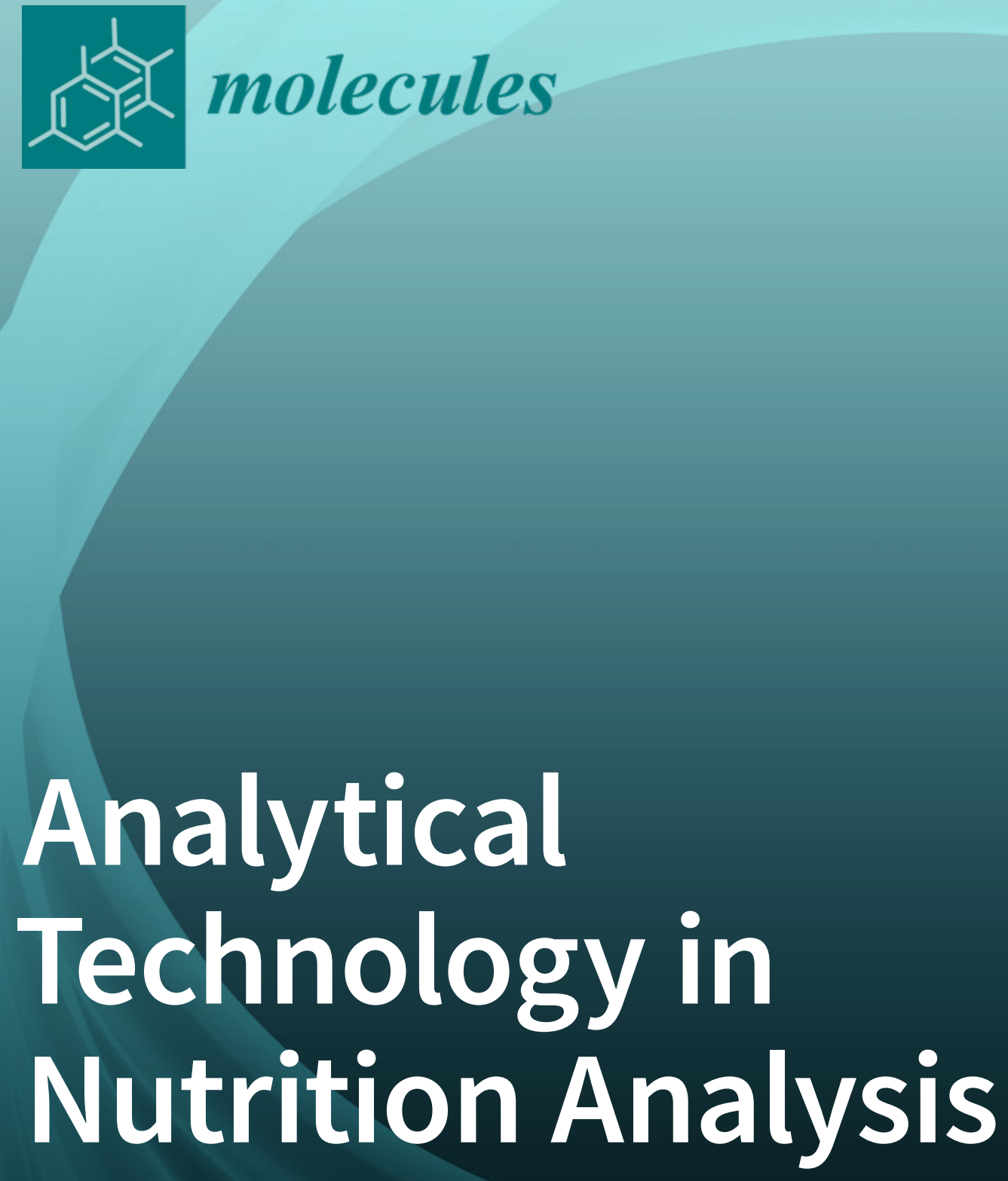

Edited by Jose M. Miranda Printed Edition of the Special Issue Published in Molecules 


\section{Analytical Technology in Nutrition Analysis}





\section{Analytical Technology in Nutrition Analysis}

Special Issue Editor

Jose M. Miranda 
Special Issue Editor

Jose M. Miranda

Universidade de Santiago de Compostela

Spain

\section{Editorial Office}

MDPI

St. Alban-Anlage 66

4052 Basel, Switzerland

This is a reprint of articles from the Special Issue published online in the open access journal Molecules (ISSN 1420-3049) (available at: https:/ /www.mdpi.com/si/molecules/Nutrition_analysis).

For citation purposes, cite each article independently as indicated on the article page online and as indicated below:

LastName, A.A.; LastName, B.B.; LastName, C.C. Article Title. Journal Name Year, Article Number, Page Range.

ISBN 978-3-03928-764-2 (Hbk)

ISBN 978-3-03928-765-9 (PDF)

(C) 2020 by the authors. Articles in this book are Open Access and distributed under the Creative Commons Attribution (CC BY) license, which allows users to download, copy and build upon published articles, as long as the author and publisher are properly credited, which ensures maximum dissemination and a wider impact of our publications.

The book as a whole is distributed by MDPI under the terms and conditions of the Creative Commons license CC BY-NC-ND. 


\section{Contents}

About the Special Issue Editor $\ldots \ldots \ldots \ldots \ldots \ldots \ldots \ldots$ vii

Jose M. Miranda

Analytical Technology in Nutrition Analysis

Reprinted from: Molecules 2020, 25, 1362, doi:10.3390/molecules25061362 _ . . . . . . . . 1

Larissa Gabrielly Barbosa Lima, Julia Montenegro, Joel Pimentel de Abreu,

Millena Cristina Barros Santos, Talita Pimenta do Nascimento, Maiara da Silva Santos,

Antônio Gilberto Ferreira, Luiz Claudio Cameron, Mariana Simões Larraz Ferreira and

Anderson Junger Teodoro

Metabolite Profiling by UPLC-MS ${ }^{\mathrm{E}}$, NMR, and Antioxidant Properties of Amazonian Fruits:

Mamey Apple (Mammea Americana), Camapu (Physalis Angulata), and Uxi (Endopleura Uchi)

Reprinted from: Molecules 2020, 25, 342, doi:10.3390/molecules25020342 _ . . . . . . . . . 5

Ahmidin Wali, Atikan Wubulikasimu, Sharafitdin Mirzaakhmedov, Yanhua Gao,

Adil Omar, Amina Arken, Abulimiti Yili and Haji Akber Aisa

Optimization of Scorpion Protein Extraction and Characterization of the Proteins'

Functional Properties

Reprinted from: Molecules 2019, 24, 4103, doi:10.3390/molecules24224103 . . . . . . . . . . 23

Emmanuel Martinez, Jose A. Rodriguez, Alicia C. Mondragon, Jose Manuel Lorenzo and Eva M. Santos

Influence of Potato Crisps Processing Parameters on Acrylamide Formation and Bioaccesibility

Reprinted from: Molecules 2019, 24, 3827, doi:10.3390/molecules24213827 . . . . . . . . . . 39

Yonghang Ma, Zhengcheng Zeng, Lingchang Kong, Yuanxin Chen and Pingli He

Determination of $\mathrm{N}$-Carbamylglutamate in Feeds and Animal Products by High Performance

Liquid Chromatography Tandem Mass Spectrometry

Reprinted from: Molecules 2019, 24, 3172, doi:10.3390/molecules24173172 _ . . . . . . . . . . 4 9

Alexis Ayala-Ni no, Gabriela Mariana Rodr'íguez-Serrano, Luis Guillermo Gonz'alez-Olivares, Elizabeth Contreras-López, Patricia Regal-López and Alberto Cepeda-Saez

Sequence Identification of Bioactive Peptides from Amaranth Seed Proteins

(Amaranthus hypochondriacus spp.)

Reprinted from: Molecules 2019, 24, 3033, doi:10.3390/molecules24173033

Li Duan, Chenmeng Zhang, Chenjing Zhang, Zijing Xue, Yuguang Zheng and Long Guo Green Extraction of Phenolic Acids from Artemisia argyi Leaves by Tailor-Made Ternary Deep Eutectic Solvents

Reprinted from: Molecules 2019, 24, 2842, doi:10.3390/molecules24152842 _ . . . . . . . . . 7

Thomas Rosemary, Abimannan Arulkumar, Sadayan Paramasivam,

Alicia Mondragon-Portocarrero and Jose Manuel Miranda

Biochemical, Micronutrient and Physicochemical Properties of the Dried Red Seaweeds

Gracilaria edulis and Gracilaria corticata

Reprinted from: Molecules 2019, 24, 2225, doi:10.3390/molecules24122225 . . . . . . . . . . . . 89 
Gretel Dovale-Rosabal, Alicia Rodríguez, Elyzabeth Contreras, Jaime Ortiz-Viedma, Marlys Muñoz, Marcos Trigo, Santiago P. Aubourg and Alejandra Espinosa

Concentration of EPA and DHA from Refined Salmon Oil by Optimizing the Urea-Fatty Acid

Adduction Reaction Conditions Using Response Surface Methodology

Reprinted from: Molecules 2019, 24, 1642, doi:10.3390/molecules24091642

Aroa Lopez-Santamarina, Jose Manuel Miranda, Alicia del Carmen Mondragon,

Alexandre Lamas, Alejandra Cardelle-Cobas, Carlos Manuel Franco and Alberto Cepeda

Potential Use of Marine Seaweeds as Prebiotics: A Review

Reprinted from: Molecules 2020, 25, 1004, doi:10.3390/molecules25041004 . . . . . . . . . . . 115

Marcos Flores, Carolina Saravia, Claudia E. Vergara, Felipe Avila, Hugo Valdés and

Jaime Ortiz-Viedma

Avocado Oil: Characteristics, Properties, and Applications

Reprinted from: Molecules 2019, 24, 2172, doi:10.3390/molecules24112172 


\section{About the Special Issue Editor}

Jose M. Miranda (Ph.D.) Prior to his academic and scientific activities, he worked for several years as a health inspector. Currently, he is working as assistant professor in the University of Santiago de Compostela (Spain). He has published over 100 scientific articles in indexed journals. His areas of expertise are food safety, food chemical analysis, characterization of compounds with nutritional interest, and metagenomics. 



\title{
Analytical Technology in Nutrition Analysis
}

\author{
Jose M. Miranda \\ Laboratorio de Higiene Inspección y Control de Alimentos, Departamento de Química Analítica, Nutrición y \\ Bromatología, Universidade de Santiago de Compostela, 27002 Lugo, Spain; josemanuel.miranda@usc.es; \\ Tel.: +34-982-252-231 (ext. 22407); Fax: +34-982-254-592
}

Received: 9 March 2020; Accepted: 11 March 2020; Published: 17 March 2020

The great challenge facing humanity in the coming decades is to secure food for the 9.8 billion people who are expected to inhabit the planet by around 2050 and 11.2 billion in 2100 [1]. To increase the food production by traditional methods to meet this demand for food is very difficult. Additionally, traditional methods of food production, both of plant and animal origin, present specific problems that make it difficult for them to meet such an ambitious increase target.

In this sense, terrestrial agriculture presents a problem because fresh water (an essential resource) is an increasingly scarce commodity, and progressive desertification of the Earth's surface is taking place and will probably be aggravated in the future by global warming. About $45 \%$ of the world's land surface is currently considered drylands, while 12 million hectares of land are degraded yearly through a lack of water and related processes. According to the Food and Agriculture Organization of the United Nations [2], agricultural productivity is persistently declining at over 1\% per year.

With respect to food production of animal origin, this also presents specific challenges, such as the fact that intensive production methods require large amounts of land, water and feed, and some livestock (such as ruminants) produce high levels of greenhouse gas emissions. Thus, intensive methods of animal production have serious drawbacks from the point of view of environmental care. In order to properly feed such a large population, it will be necessary to increase food production while respecting ecosystems and natural resources. The current high demand for animal proteins requires that livestock is reared in large numbers over diminishing land resource which is not possible and, therefore, alternative substitutes for animal proteins needs to be embraced to overcome this problem [3].

The abovementioned fact means that demand for food produced from non-traditional sources is expected to rise in the coming decade [4]. Fortunately, nowadays increasing acceptance for novel foods is also being observed, not only in developing but also in developed countries, which is mainly influenced by consumer awareness of the nutritional benefits linked to these kinds of foods [3]. As it can be seen in Figure 1, the investigation about novel foods has experienced a dramatic increase in the last decade (about three-fold).

In addition to the need for an increase in food production, nowadays, in most countries of the world, there is a growing prevalence of chronic non-communicable diseases, many of which are diet-related [5]. As a result, there is widespread consumer demand for foods with a nutritional composition more in line with current nutritional guidelines, and which include a greater proportion of the nutrients that have a potential beneficial effect on human health, or fewer of those components that have a negative effect on human health [6]. Therefore, both because of the need to ensure food safety in food, especially in those that do not have a history of safe use. In addition, there is also a need for analytical methodologies to reliably determine both the presence of specific nutrition-related components in foods, and the effects of these dietary components on human health, in areas as diverse as lipidomics, proteomics, transcriptomics, genomics, epigenomics, or metagenomics $[7,8]$.

To meet these needs, it is essential that we in the international scientific community work intensively to ensure safe, effective and honest food production and to protect the health of consumers. 
For this reason, from Molecules it was recognized the need to propose the Special Issue "Analytical Technologies in Nutrition Analysis". This Special Issue was aimed to offer an appropriate opportunity to all the contributors to make their results and techniques more visible, and to present the most recent findings.

\section{Documents by year}

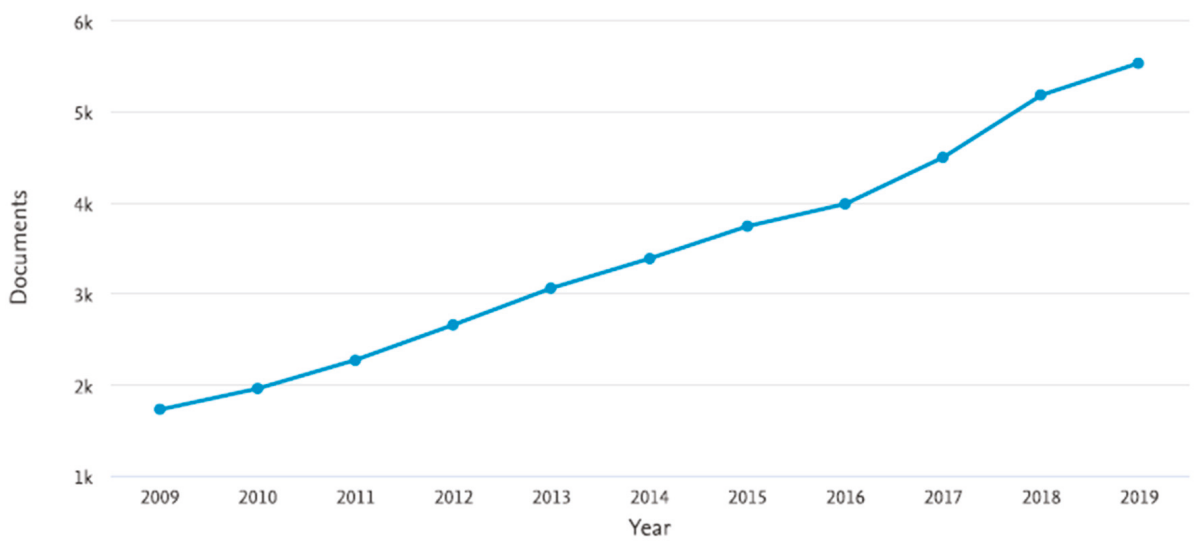

Figure 1. Results analysis for Scopus query "novel foods" in title, keywords or abstract section of the articles between 2009 and 2019.

This Special Issue has received remarkably positive feedback, with many contributions submitted by numerous geographically diverse scientists, resulting in a collection of 10 publications, including two exhaustive review articles [9-18]. Among the contributing authors, authors can be found from Asia (China, India, and Uzbekistan), Europe (Spain), South America (Brazil and Chile) and North America (Mexico). The published articles include findings related to the comprehensive bioactive compound profile and antioxidant capacities of mamey apple (Mammea americana), camapu (Physalis angulata), and uxi (Endopleura uchi) that can contribute to their economic exploitation [9].

Another article described the multifunctional activity of amaranth (Amaranthus hypochondriacus spp.) proteins, opening the possibility that amaranth hydrolyzed with alcalase and flavourzyme to be used as a value-added ingredient with multi-functional bioactive properties [10]. Another article aimed to find an efficient extraction method and investigate some of physical and chemical parameters, like water solubility, emulsification, foaming properties, and oil-holding capacity of obtained scorpion proteins. The results obtained suggest that scorpion proteins can be considered as an important ingredient and raw material for the creation of water-soluble supramolecular complexes for drugs [11].

A fractional factorial design was used to evaluate the effects of temperature, frying time, blanching treatment and the thickness of potato slices on a very relevant potential toxic compound (acrylamide) content in crisps. The findings obtained demonstrate that acrylamide concentration remained at $70 \%$ in fried chips, and reductions took place, mainly at the intestinal phase, as a result of reaction with nucleophilic compounds [12]. $N$-carbamylglutamate, a synthetic analogue of $N$-acetylglutamate, is an activator of blood ammonia conversion and endogenous arginine synthesis. This study will provide a solid foundation for the evaluation of availability and metabolic mechanism of $\mathrm{N}$-carbamylglutamate in animals [13].

The Artemisia argyi leaf has been used as a traditional medicine and food supplement in Asian countries for hundreds of years. Phytochemical studies disclosed that Artemisia argyi leaf contains various bioactive constituents, mainly phenolic acids, which have great potential as possible alternatives to those organic solvents in health-related areas such as food and pharmaceuticals [14]. Regarding the use of seaweeds as alternative dietary fibre sources to terrestrial vegetables, in this Special Issue 
an article is presented evaluating the nutritional composition and physicochemical properties of two dried commercially interesting edible red seaweeds, Gracilaria corticata and G. edulis. In view of the results, both G. corticata and G. edulis contain important nutrients for human health and are possible natural functional foods [15]. More generally, a wide review about the current knowledge surrounding the impacts of seaweeds and their derived polysaccharides on the human microbiota is also presented, in which potential benefits against chronic non-transmissible diseases were discussed [16].

Finally, two articles describing potentially beneficial food sources of fat for humans are presented. In one on them, it was concluded that refined commercial salmon oil can be transformed into a profitable source of eicosapentaenoic and docosapentaenoic acids, thus leading to a product with higher commercial value, and that this process can be optimized by using response surface methodology [17]. The last article of the Special Issue consists of a review article about avocado oil, including discussion about the extraction methods, chemical composition, and various applications of avocado oil in the food and medicine industries. Based on the available data, avocado oil has established itself as an oil that has a very good nutritional value at low and high temperatures, with multiple technological applications that can be exploited for the benefit of its producers [18].

This Special Issue is accessible thought the following link: https://www.mdpi.com/journal/ molecules/special_issues/Nutrition_analysis.

As Guest Editor for this Special Issue, I would like to thank all the authors and co-authors for their contributions and all the reviewers for their effort in carefully and rapid evaluating the manuscripts. Last but not least, I would like to appreciate the hard work done by the editorial office of the Molecules journal, as well as their kind assistance in preparing this Special Issue.

Funding: This research received no external funds.

Conflicts of Interest: The author declares no conflict of interest.

\section{References}

1. United Nations, Department of Economics and Social affairs, Population Division. World Population Prospects 2019: Highlights; United Nations: New York, NY, USA, 2019.

2. FAO. The Future of Food and Agriculture-Trends and Challenges; Food and Agriculture Organization of the United Nations: Rome, Italy, 2017.

3. Imathiu, S. Benefits and food safety concerns associated with consumption of edible insects. NFS J. 2020, 18, 1-11. [CrossRef]

4. Selenius, O.; Korpela, J.; Salminen, S.; Gallego, C.G. Effect of chitin and chitooligosaccharide on in vitro growth of Lactobacillus rhamnosus GG and Escherichia coli TG. Appl. Food Biotechnol. 2018, 5, 163-172.

5. Miranda, J.M.; Anton, X.; Redondo-Valbuena, C.; Roca-Saavedra, P.; Rodriguez, J.A.; Lamas, A.; Franco, C.M.; Cepeda, A. Egg and egg-derived foods: Effects on human health and use as functional foods. Nutrients 2015, 7, 706-709. [CrossRef] [PubMed]

6. Roca-Saavedra, P.; Mendez-Vilabrille, V.; Miranda, J.M.; Nebot, C.; Cardelle-Cobas, A.; Franco, C.M.; Cepeda, A. Food additives, contaminants and other minor components: Effects on human gut microbiota-A review. J. Physiol. Biochem. 2018, 74, 69-83. [CrossRef] [PubMed]

7. Lamas, A.; Regal, P.; Vázquez, B.I.; Miranda, J.M.; Franco, C.M.; Cepeda, A. Transciptomics: A powerful tool to evaluate the behavior of foodborne pathogens in the food production chain. Food Res. Int. 2019, 15, 108543. [CrossRef] [PubMed]

8. Ramon Vidal, D. Model organisms and "OMIC" technologies: New tools for the development of healthy foods. Curr. Opin. Biotechnol. 2013, 24, S19. [CrossRef]

9. Barbosa Lima, L.G.; Montenegro, J.; de Abreu, J.P.; Barros santos, M.C.; Pimenta do Nascimento, T.; da Silva santos, M.; Ferreira, A.G.; Cameron, L.C.; Larraz Ferreira, M.S.; Teodoro, A.J. Metabolite Profiling by UPLC-MSE, NMR, and Antioxidant Properties of Amazonian Fruits: Mamey Apple (Mammea Americana), Camapu (Physalis Angulata), and Uxi (Endopleura Uchi). Molecules 2020, 25, 342. [CrossRef] [PubMed] 
10. Ayala-Niño, A.; Rodríguez-Serrano, G.M.; González-Olivares, L.G.; Contreras-López, E.; Regal-López, P.; Cepeda-Sáez, A. Sequence identification of bioactive peptides from Amaranth seed proteins (Amaranthus hypochondriacus spp.). Molecules 2019, 24, 3033. [CrossRef] [PubMed]

11. Wali, A.; Wubulikasimu, A.; Mirzaakhmedov, S.; gao, Y.; Omar, A.; Arken, A.; Yili, A.; Aisa, H.A. Optimization of Scorpion protein extraction and characterization of the proteins' functional properties. Molecules 2019, 24, 4103. [CrossRef] [PubMed]

12. Martinez, E.; Rodriguez, J.A.; Mondragon, A.C.; Lorenzo, J.M.; Santos, E.M. Influence of potato crisps processing parameters on acrylamide formation and bioaccesibility. Molecules 2019, 24, 3827. [CrossRef] [PubMed]

13. Ma, Y.; Zeng, Z.; Kong, L.; Chen, Y.; He, P. Determination of N-carbamylglutamate in feeds and animal products by high performance liquid chromatography tandem mass spectrometry. Molecules 2019, $24,3172$. [CrossRef] [PubMed]

14. Duan, L.; Zhang, C.; Zhang, C.; Xue, Z.; Zheng, Y.; Guo, L. Green extraction of phenolic acids from Artemisia argyi leaves by Tailor-made ternary deep eutectic solvents. Molecules 2019, 24, 2842. [CrossRef] [PubMed]

15. Rosemary, T.; Arulkumar, A.; Paramasivam, S.; Mondragon-Portocarrero, A.; Miranda, J.M. Biochemical micronutrient and physicochemical properties of the dried red seaweeds Gracilaria edulis and Gracilaria corticata. Molecules 2019, 24, 2225. [CrossRef] [PubMed]

16. Lopez-Santamarina, A.; Miranda, J.M.; Mondraon, A.C.; Lamas, A.; Cardelle-Cobas, A.; Franco, C.M.; Cepeda, A. Potential use of marine seaweeds as prebiotics: A review. Molecules 2020, 25, 1004. [CrossRef] [PubMed]

17. Dovale-Rosabal, G.; Rodriguez, A.; Contreras, E.; Ortiz-Viedma, J.; Muñoz, M.; Trigo, M.; Aubourg, S.P.; Espinosa, A. Concentration of EPA and DHA acid adduction reaction conditions using response surface methodology. Molecules 2019, 24, 1642. [CrossRef] [PubMed]

18. Flores, M.; saravia, C.; Vergara, C.E.; Avila, F.; Valdés, H.; Ortiz-Viedma, J. Avocado oil: Characteristics, properties, and applications. Molecules 2019, 24, 2172. [CrossRef] [PubMed]

(C) 2020 by the author. Licensee MDPI, Basel, Switzerland. This article is an open access article distributed under the terms and conditions of the Creative Commons Attribution (CC BY) license (http://creativecommons.org/licenses/by/4.0/). 
Article

Metabolite Profiling by UPLC-MS ${ }^{\mathrm{E}}$, NMR, and Antioxidant Properties of Amazonian Fruits: Mamey Apple (Mammea Americana), Camapu (Physalis Angulata), and Uxi (Endopleura Uchi)

Larissa Gabrielly Barbosa Lima ${ }^{1}$, Julia Montenegro ${ }^{1}$, Joel Pimentel de Abreu ${ }^{1}$, Millena Cristina Barros Santos 2,3, Talita Pimenta do Nascimento ${ }^{2,3}$, Maiara da Silva Santos 4 , Antônio Gilberto Ferreira ${ }^{5}$, Luiz Claudio Cameron ${ }^{3}$, Mariana Simões Larraz Ferreira ${ }^{2,3}$ and Anderson Junger Teodoro ${ }^{1, *}$

1 Laboratory of Functional Foods, Nutrition Biochemistry Core, Food and Nutrition Graduate Program, Federal University of the State of Rio de Janeiro, UNIRIO. Av. Pasteur, 296, Rio de Janeiro 22290-240, Brazil; larissagabrielly_lima@hotmail.com (L.G.B.L.); juliamontenegro95@gmail.com (J.M.); pimenabreu@gmail.com (J.P.d.A.)

2 Laboratory of Bioactives, Nutrition Biochemistry Core, Food and Nutrition Graduate Program, UNIRIO. Av. Pasteur, 296, Rio de Janeiro 22290-240, Brazil; barrosmillena@gmail.com (M.C.B.S.); talitapiment@gmail.com (T.P.d.N.); mariana.ferreira@unirio.br (M.S.L.F.)

3 Center of Innovation in Mass Spectrometry, Laboratory of Protein Biochemistry, UNIRIO. Av. Pasteur, 296, Rio de Janeiro 22290-240, Brazil; cameron@unirio.br

4 Fluminense Federal Institute of Education, Science and Technology, IFF, Av. Dário Viêira Borges, 235-Lia Márcia, Bom Jesus do Itabapoana, Rio de Janeiro 28360-000, Brazil; maiarasantos@yahoo.com.br

5 Laboratory of NMR, Department of Chemistry, Federal University of São Carlos, UFSCar. Washington Luiz, s/n, São Carlos 13565-905, SP, Brazil; giba_04@yahoo.com.br

* Correspondence: atteodoro@gmail.com; Tel.: +55-21-25427236; Fax: +55-21-25427752

Received: 1 October 2019; Accepted: 12 December 2019; Published: 15 January 2020

\begin{abstract}
The metabolite profiling associated with the antioxidant potential of Amazonian fruits represents an important step to the bioactive compound's characterization due to the large biodiversity in this region. The comprehensive bioactive compounds profile and antioxidant capacities of mamey apple (Mammea americana), camapu (Physalis angulata), and uxi (Endopleura uchi) was determined for the first time. Bioactive compounds were characterized by ultra-performance liquid chromatography coupled to high resolution mass spectrometry (UPLC-MS ${ }^{\mathrm{E}}$ ) in aqueous and ethanolic extracts. Globally, a total of 293 metabolites were tentatively identified in mamey apple, campau, and uxi extracts. The main classes of compounds in the three species were terpenoids (61), phenolic acids (58), and flavonoids (53). Ethanolic extracts of fruits showed higher antioxidant activity and total ion abundance of bioactive compounds than aqueous. Uxi had the highest values of phenolic content (701.84 mg GAE/100 g), ABTS (1602.7 $\mu$ mol Trolox $\left.\mathrm{g}^{-1}\right)$, and ORAC $\left(15.04 \mu \mathrm{mol}\right.$ Trolox g $\left.{ }^{-1}\right)$. Mamey apple had the highest results for DPPH $\left(1168.42 \mu \mathrm{mol} \mathrm{TE} \mathrm{g}^{-1}\right)$ and FRAP $\left(1381.13 \mu \mathrm{mol} \mathrm{FSE} \mathrm{g}^{-1}\right)$. Nuclear magnetic resonance (NMR) spectroscopy results showed that sugars and lipids were the substances with the highest amounts in mamey apple and camapu. Data referring to chemical characteristics and antioxidant capacity of these fruits can contribute to their economic exploitation.
\end{abstract}

Keywords: Amazonian fruits; antioxidant; phenolic compounds; UPLC-MS ${ }^{\mathrm{E}}$; bioactive compounds

\title{
1. Introduction
}

The Amazonian region offers a wide variety of native fruits and most of them are typically obtained from nature or grown only for the local market supply in form of pulp or in natura. The economic 
exploitation is potentially of great importance for the region [1]. These native fruits have been studied as potential bioactive sources and many of them have shown high antioxidant capacity and elevated phenolic compounds content [2].

The antioxidant properties of Amazonian fruits have been the object of many researches, mainly due to the presence of natural antioxidants such as carotenoids and phenolic compounds. The group of antioxidant compounds found in fruits produced in Amazonian can protect the human body against toxic effects and preventing diseases such as chronic degenerative disorders, cardiovascular diseases, premature ageing, diabetes, and neurodegenerative diseases [3-5].

The Brazilian Amazonian region has a great biodiversity with approximately about 220 edible plant species producing fruit, representing $44 \%$ of native fruit diversity in Brazil. Some species such as mamey apple (Mammea americana), camapu (Physalis angulata), and uxi (Endopleura uchi) have widely appreciated flavors by Brazilian consumers, but still of moderate importance to the economy. They show potential for commercialization in both domestic and international markets [6].

Mamey apple (Mammea americana) is a fruit with a reddish yellow color, aromatic, and edible pulp, and is popularly known as abricó-do-pará, abricó, mammey apple or apricot from St. Domingo. This fruit has an important agroindustrial potential and this pulp can be used to produce different products such as syrup, juice, sherbet, jam, and pastes [7]. Physalis angulata L. is an herb indigenous of the Solanaceae family, and dispersed throughout tropical areas, including the Amazonian region [8]. This is popularly known as "camapu" and its juice is used as sedative, depurative, anti-rheumatic, and for the relief of earache, and is also used as a traditional medicine [9]. Uxi (Endopleura uxi) is an important fruit distributed in Pará and Amazonas, states of Northern Brazil. The only edible part of uxi presents a yellow-brownish color pulp with a rough-like texture, containing high content of fat (mainly oleic acid) and carotenoids, mostly trans- $\beta$-carotene, with an unique flavor [10].

Due to their peculiar biodiversity, knowledge of the species and functional property characterization of native Amazonian fruits such as mamey apple, camapu, and uxi present a major challenge to their appreciation, as many of these species are unexplored and their chemical properties remain unknown.

Few studies in the literature were found to provide a comprehensive metabolomic analysis of the bioactive compounds combined to antioxidant capacity of these fruits from the Amazonian biome. However, some studies have shown the metabolomic composition of Amazonian native fruits. Paz et al. [11] studied Clavija lancifolia Desf. using liquid chromatography mass spectrometry (LC-MS/MS) and found some compounds of flavonoids for which kaempferol was the main compound. Souza et al. [12] identified the phenolic compounds cyanidin 3-O-rutinoside, chlorogenic acid, and rutin in Oenocarpus distichus fruits, using high-performance liquid chromatography (HPLC). It has been reported the presence of catechin, caffeic acid, rutin, orientin, quercetin, apigenin, luteolin, and kaempferol in Mauritia flexuosa L. f. (Arecaceae), another fruit from Amazonian biome [13].

Concerning the importance of the characterization of bioactive compounds from Amazonian fruits, the aim of this study was to assess the phytochemical profile and the total antioxidant capacity of mamey apple (Mammea americana), camapu (Physalis angulata), and uxi (Endopleura uchi).

\section{Results and Discussion}

\subsection{Total Phenolic Compounds Content}

Mamey apple (MA), camapu (C), and uxi (U) were submitted for analysis of total phenolic compounds from extractions submitted with different vehicles solvents (water $(\mathrm{W})$ and ethanol (E)) to determine the most efficient extraction solvent of the mentioned compounds. The results showed that the ethanolic extracts (MAE and UE) of the different Amazonian fruits showed a greater quantity of phenolic compounds when compared to the aqueous extracts (MAW and UW) (Figure 1). The preparation and extraction from this wide range of samples depends mostly on the nature of the sample matrix and the chemical properties of the phenolics, including molecular structure, polarity, 
concentration, number of aromatic rings, and hydroxyl groups. Conventional solid-liquid using organic solvent extraction is the main method used to extract phenolics. The sample preparation, polarity of the solvent used, the technique employed and temperature are factors that can influence the extraction and contents of these compounds [14].

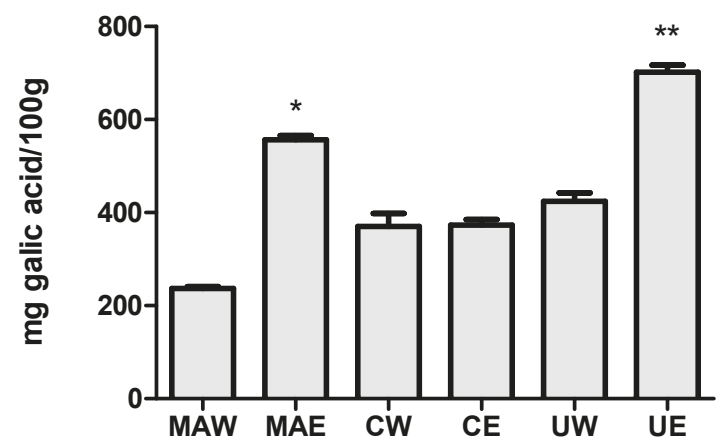

Figure 1. Total phenolic content in aqueous mamey apple (MAW), ethanolic mamey apple (MAE), aqueous camapu (CW), ethanolic camapu (CE), aqueous uxi (UW), and ethanolic uxi (UE) extracts. Results are expressed by mean \pm SD $(n=3)$ and were compared by the one-way ANOVA test with post-test Tukey's $\left({ }^{*} p<0.01 ;{ }^{* *} p<0.001\right)$.

Uxi ethanolic extract (UE) showed the highest phenolic compound content (701.839 mg GAE/100 g), followed by mamey apple (MAE) (556.105 mg GAE/100 g), and camapu (CE) (237.39 mg GAE/100 g). The aqueous extracts of mamey apple (MAW) and uxi (UW) showed significant difference $(p<0.05)$ when compared to the respective ethanolic extracts. No significant differences $(p>0.05)$ were observed in the content of phenolic compounds between the aqueous and ethanolic extracts in the camapu sample.

Aqueous and ethanolic extract showed similar fruits yield extracts, being dependent on the moisture percentage of each fruit. Uxi yield was significantly higher (UE-28.82\% and UW-29.42\%), followed by mamey apple (MAE-14.04\% and MAW-13.13\%) and camapu (CE-10.50\% and CW- $11.10 \%$ ). Considering these results, the levels of phenolic compounds per mass of fruits for the highest yield would be 202.27, 78.08, and $24.92 \mathrm{mg}$ GAE/100 $\mathrm{g}$ for uxi, mamey apple, and camapu, respectively.

Péroumal et al. [15] studied the pulp of six mamey apple accessions and found values for total phenolic content between 90 and $143 \mathrm{mg} \mathrm{GAE} / 100 \mathrm{~g}$. It can be observed that the results obtained for uxi ethanolic extracts in this work are higher than some Amazonian fruits such as araça-boi (87.2 $\pm 3.0 \mathrm{mg} \mathrm{GAE} / 100 \mathrm{~g})$ and araça $(129.1 \pm 9.3 \mathrm{mg} \mathrm{GAE} / 100 \mathrm{~g})$, and lower than camu-camu (1797.2 $\pm 37.7 \mathrm{mg} \mathrm{GAE} / 100 \mathrm{~g}$ ) reported by Genovese et al. [16]. Comparing the results of this study with fruits from the Brazilian Cerrado biome, the Amazonian fruits present lower phenolic compounds in relation to sweet passion fruit $(245.36 \pm 3.70 \mathrm{mg} \mathrm{GAE} / 100 \mathrm{~g})$, soursop $(281 \pm 5.40 \mathrm{mg} \mathrm{GAE} / 100 \mathrm{~g})$, murici (334.37 $\pm 9.07 \mathrm{mg} \mathrm{GAE} / 100 \mathrm{~g}$ ), and marolo (739.37 $\pm 7.92 \mathrm{mg} \mathrm{GAE} / 100 \mathrm{~g}$ ) [17]. According to the classification proposed by Vasco et al. [18], MAE, uxi extracts were classified as fruits as having with medium phenolic content (100-500 mg GAE/100 g).

\subsection{Phytochemical Profile by UPLC-MS ${ }^{E}$}

For the first time, bioactive compounds of Amazonian fruits like mamey apple, camapu, and uxi were elucidated by UPLC-MS ${ }^{\mathrm{E}}$ metabolomic approach. Globally, 293 compounds were tentatively identified from aqueous and ethanolic extracts of these fruits (Table S1) and relatively quantified taking account all extracts based on ion counting. Table 1 shows the number of identified compounds and their classification into eight chemical classes according to Phenol Explorer database [19]: phenolic acid, flavonoids, chalcones, coumarins, amino acid related compounds, fatty acid, and terpene related compounds. The main bioactive compounds in the three species were terpenoids $(n=61 ; 21 \%)$, 
phenolic acids $(n=58 ; 20 \%)$, and flavonoids $(n=53 ; 18 \%)$. Other metabolites were also identified such as other polyphenols $(n=50 ; 17 \%)$, including lignans, coumarins and tannins, and also other metabolites $(n=56 ; 19 \%)$ such as amino acid related, alkaloids and polyketides, showing the extraction and LC-MS methods were suitable to characterize different polarities compounds.

Table 1. Number of bioactive compounds distributed by classes and other compounds identified in aqueous (W) and ethanolic (E) extracts of mamey apple, camapu, and uxi.

\begin{tabular}{|c|c|c|c|c|c|c|}
\hline Compounds (\%) & \multicolumn{2}{|c|}{ Mamey Apple } & \multicolumn{2}{|c|}{ Camapu } & \multicolumn{2}{|c|}{ Uxi } \\
\hline Phenolic Acid & $43(20.57 \%)$ & $37(19.68 \%)$ & $44(24.04 \%)$ & $40(21.51 \%)$ & $38(23.17 \%)$ & $35(21.21 \%)$ \\
\hline Chalcones & $2(0.96 \%)$ & $2(1.06 \%)$ & $2(1.09 \%)$ & $2(1.08 \%)$ & $3(1.83 \%)$ & $3(1.82 \%)$ \\
\hline Coumarins & $16(7.66 \%)$ & $15(7.98 \%)$ & $14(7.65 \%)$ & $14(7.53 \%)$ & $8(4.88)$ & $9(5.45 \%)$ \\
\hline Fatty acids related compounds & $22(10.53 \%)$ & $22(11.70 \%)$ & $11(6.01 \%)$ & $12(6.45 \%)$ & $14(8.54 \%)$ & $15(9.09 \%)$ \\
\hline Terpenoids & $46(22.01 \%)$ & $43(22.87 \%)$ & $39(21.31 \%)$ & $39(20.97 \%)$ & $39(23.78 \%)$ & $35(21.21 \%)$ \\
\hline Total of compounds & $209(100 \%)$ & $188(100 \%)$ & $183(100 \%)$ & $186(100 \%)$ & $164(100 \%)$ & $165(100 \%)$ \\
\hline
\end{tabular}

The identification of different phenolic compounds in this study makes it relevant, since the presence of these compounds has a range of bioactivities, as already reported in vitro and in vivo studies [20]. In a recent study, extracts of phenolic compounds from jatobá-do-cerrado can inhibit $\alpha$-amylase and $\alpha$-glycosidase after in vitro digestion and modulate the glucose metabolism [21].

Mamey apple was characterized by high number of bioactive compounds. Among the identified metabolites, $209(71 \%)$ and $188(64 \%)$ were found in aqueous and ethanolic extracts of mamey apple, respectively. Furthermore, $183(62 \%)$ and $186(63 \%)$ compounds were found in the aqueous extract ethanolic extracts of camapu, respectively. In uxi, $164(56 \%)$ and $165(56 \%)$ compounds were tentatively identified in the aqueous and ethanolic extracts, respectively. Notably, $50(17 \%)$ compounds were found only in mamey apple (e.g., droserone, norlichexanthone, procyanidin C1, 3,4-leucopelargonidin II, and piquerol A). Piquerol A is a sesquiterpene with low stability in nature and has only previously been tested as an insecticide and as an inhibitor of metabolism in cell cultures [22]. About $43(15 \%)$ were tentatively identified only in camapu (e.g., myristicin, 11-deoxocucurbitacin, synapic acid I, and pseudopurpurin). Medina et al. [23] reported the presence of sinapic acid in Passiflora edulis Sims. Furthermore, about $36(12 \%)$ compounds were found exclusively in the uxi extract (e.g., 4-coumaroylchiquimate, ferulic acid I, kaempferol II, jacareubin, 6-deoxyjacareubin, vanylactic acid II, nigakilactone A, and jasmonic acid). Kaempferol is an important flavonol identified in other fruits like hybrid grapes by Rosso et al. [24].

These metabolites are antioxidant inhibitors of mutagenic and carcinogenic compounds and are considered neuroprotective agents in neurodegenerative disorders, such as Parkinson's and Alzheimer's diseases [25].

The acid phenolic profiling was the most abundant subclass of phenolic compounds in all extracts evaluated, as shown in the Tables 1 and 2. Aqueous and ethanolic camapu extracts (CW and CE) showed about 24 and $22 \%$ of phenolic acids, respectively, followed by mamey apple aqueous (MAW) and ethanolic (MAE) extracts. In addition to phenolic acids, flavonoids showed high number of identification as well as elevated abundance relative. 
Table 2. Flavonoids tentatively identified in mamey apple, camapu, and uxi extracts.

\begin{tabular}{|c|c|c|c|c|c|c|c|c|c|c|c|}
\hline \multirow{2}{*}{$\begin{array}{c}\text { Possible } \\
\text { Identifications }\end{array}$} & \multirow{2}{*}{ CAS } & \multirow{2}{*}{$m / z \operatorname{Exp}$} & \multirow{2}{*}{$\begin{array}{c}\mathrm{RT} \\
(\mathrm{min})\end{array}$} & \multirow{2}{*}{ Fragment $m / z$} & \multirow{2}{*}{$\begin{array}{l}\text { Error } \\
(\mathrm{ppm})\end{array}$} & \multicolumn{2}{|c|}{ Mamey } & \multicolumn{2}{|c|}{ Camapu } & \multicolumn{2}{|c|}{ Uxi } \\
\hline & & & & & & W & $\mathrm{E}$ & W & $E$ & W & $\mathrm{E}$ \\
\hline Genistin & $529-59-9$ & 431.0978 & 4.55 & $133.0294(10.20)$ & -1.23 & - & - & - & - & $x$ & $\mathrm{x}$ \\
\hline Eriodictiol I & $552-58-9$ & 287.0552 & 3.05 & $\begin{array}{l}81.0338 \text { (5.46); } \\
93.0339 \text { (78.57); } \\
119.0496(100) ; \\
155.0342 \text { (10.19); } \\
163.0395 \text { (60.20) }\end{array}$ & -2.86 & $x$ & $x$ & - & - & - & - \\
\hline Hesperidin & $520-26-3$ & 609.1875 & 0.43 & $\begin{array}{l}79.0188 \text { (0.66); } \\
369.0671 \text { (50.27); } \\
488.1618 \text { (10.04) }\end{array}$ & 8.37 & $x$ & $x$ & $X$ & $x$ & $x$ & $x$ \\
\hline Narirutin & $14259-46-2$ & 579.1775 & 0.43 & $\begin{array}{l}72.9924 \text { (78.62); } \\
79.0188 \text { (0.58); } \\
\text { 117.0187 (26.50); } \\
\text { 135.0294 (87.65); } \\
357.1033 \text { (3.92); } \\
369.0671 \text { (44.06); } \\
\text { 535.1514 (21.08) }\end{array}$ & 9.66 & $x$ & $x$ & $X$ & $x$ & $x$ & $x$ \\
\hline Pomiferin I & $572-03-2$ & 419.1505 & 2.62 & nd & 1.21 & $x$ & $x$ & $x$ & $x$ & $x$ & $x$ \\
\hline Ononin & $486-62-4$ & 429.1170 & 2.02 & nd & -4.89 & $x$ & $x$ & $x$ & $x$ & & \\
\hline Mammeisin & $18483-64-2$ & 405.1677 & 4.01 & $\begin{array}{l}109.0653(0.46) \\
154.0615(0.72)\end{array}$ & -7.30 & $x$ & $x$ & & & & \\
\hline Quercitrin & $522-12-3$ & 447.0923 & 3.48 & $\begin{array}{l}151.0030(2.20) \\
285.0393(5.36)\end{array}$ & -2.09 & $x$ & $x$ & $x$ & & & \\
\hline$\underset{\text { 3-galactoside }}{\text { Quercetin }}$ & $482-36-0$ & 463.0875 & 3.47 & $\begin{array}{l}151.0030 \text { (2.97); } \\
\text { 255.0291 (5.58); } \\
\text { 271.0241 (16.99); } \\
\text { 285.0393 (7.25); } \\
300.0266 \text { (31.67) }\end{array}$ & -1.44 & $x$ & $x$ & $X$ & $X$ & $x$ & $x$ \\
\hline Kaempferol I & $520-18-3$ & 285.0396 & 4.90 & nd & -2.70 & $x$ & $x$ & & & & $x$ \\
\hline Dihydroquercetin & $480-18-2$ & 303.0505 & 1.42 & $147.0120(100)$ & -1.65 & $x$ & $x$ & & & & \\
\hline Luteoforol & $24897-98-1$ & 289.0733 & 0.56 & $109.0289(12.30)$ & 5.54 & $x$ & $x$ & $X$ & $x$ & $x$ & $\mathrm{x}$ \\
\hline
\end{tabular}

Terpenes were between the most abundant bioactive classes in all extracts. About 46 and 43 terpenes, representing 22\% of identifications, were found in the MAW and MAE extracts, respectively. In UE extracts, $39(23 \%)$ terpenes were tentatively identified too. Terpenoids are important secondary metabolites of plants and are extremely chemically diversified, being estimated at more than 40,000 substances. Its use has been described as flavoring agents, in addition to providing benefits to human health through its antioxidant potential [26,27].

Although the number of identifications between the extracts of the same fruit was not significantly different, the ethanolic extracts showed a greater relative abundance of compounds in relation to the aqueous extracts in all fruits studied (Figure 2). This fact can be explained by the large variability of the structures of these bioactive compounds and the proportion of organic solvents with water is required for better extraction.

The principal component analysis (PCA) and hierarchical cluster analysis (HCA) were applied to explain possible difference among extracts (Figures 3 and 4). First, the PCA biplot represented both loading (metabolites) and scores (extracts). Such parameters distinguished the profile of bioactive compounds among the fruits evaluated in all extracts. Principal components (PC1 and PC2) demonstrated that the fruits extracts have different composition of bioactive compounds, but the use of aqueous and ethanolic extractors did not favor the removal of distinct metabolite profile in the species. The two major principal components (PC1 and PC2) explained more than $72 \%$ of the variance pattern (Figure 3). Discriminatory metabolites, which showed maximum variance (eigenvalues) among 
extracts, were observed mainly in the PC2, including the following bioactive compounds bryophyllin A II, 1-O-2'-hydroxy-4'-methoxycinnamoyl-b-D-glucose I, mammeisin II, eriodictiol II, justicidin A, hallactone B II, 7,2'-dihydroxy-4'-methoxy-isoflavanol, eleganin I, 5-hydroxyferulic acid methyl ester II, lancerin II, 6-methoxytaxifolin II, zapoterin, salvinorin A, meconic acid, benzoic acid II, auriculoside, leucocyanidin II, lophophorine, lancerin I, vernodalol, visnagin, sinapic acid II, sinapyl alcohol II, 6-methoxytaxifolin I, isobrucein A, and syringin I.

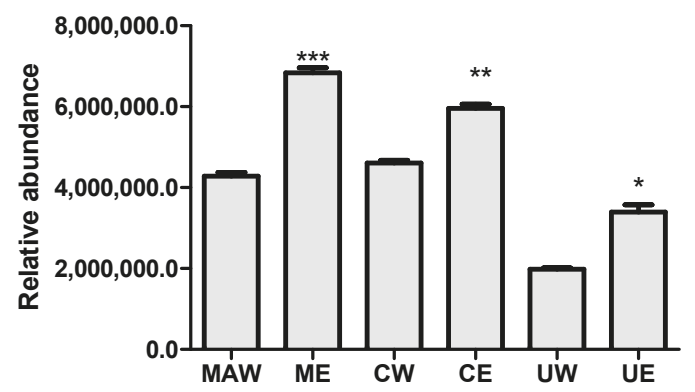

Figure 2. Relative abundance based on total ion counting of identified compounds from aqueous mamey apple (MAW), ethanolic mamey apple (MAE), aqueous camapu (CW), ethanolic camapu (CE), aqueous uxi (UW), and ethanolic uxi (UE) extracts. Results are expressed by mean \pm SD $(n=3)$ and were compared by the one-way ANOVA test with post-test Tukey's $\left({ }^{*} p<0.05\right.$; $\left.{ }^{* *} p<0.01 ; * * *<0.001\right)$.

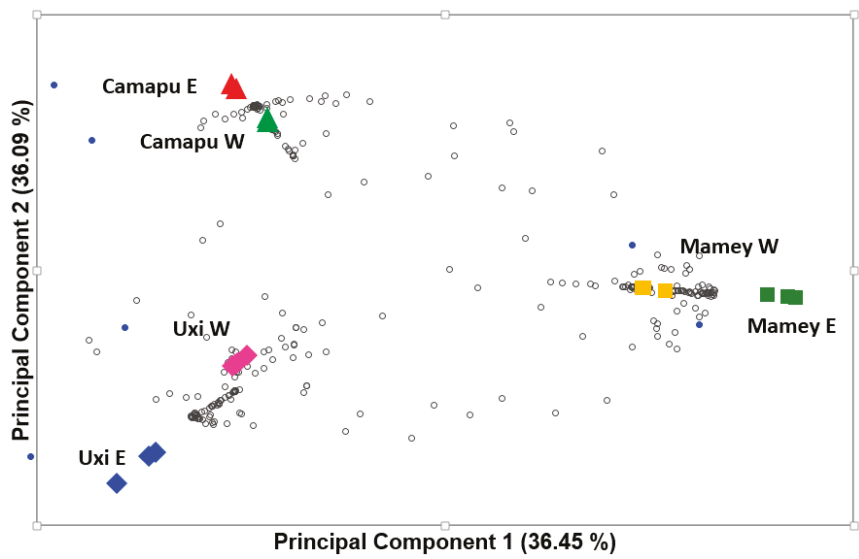

Figure 3. Principal component analysis (PCA) biplot (loadings and scores) of the bioactive compounds tentatively identified (loadings, empty circles) in the mamey (squares), camapu (triangles), and uxi (diamonds) fruits extracted with aqueous (W) and ethanolic (E) solvents.

Then, HCA was applied to observe the similarity/dissimilarity among the abundance of the discriminatory polyphenols (Figure 4) in order to understand the profile of composition among extracts. The heatmap indicated that metabolites (20) found in uxi extracts showed higher abundance in comparison to other extracts, especially in the ethanol extracts. Mamey also showed a distinguished bioactive profile, with six compounds found exclusively. Among them, sinapoyl alcohol II is an exclusive metabolite with high abundance in the mamey apple extracts. One of the metabolites with highest abundance in these extracts was syringin. This compound was determined and reported from fresh jaboticaba methanolic extract by Wu et al. [28] and implicated as immunomodulator having an anti-allergic effect [29]. 


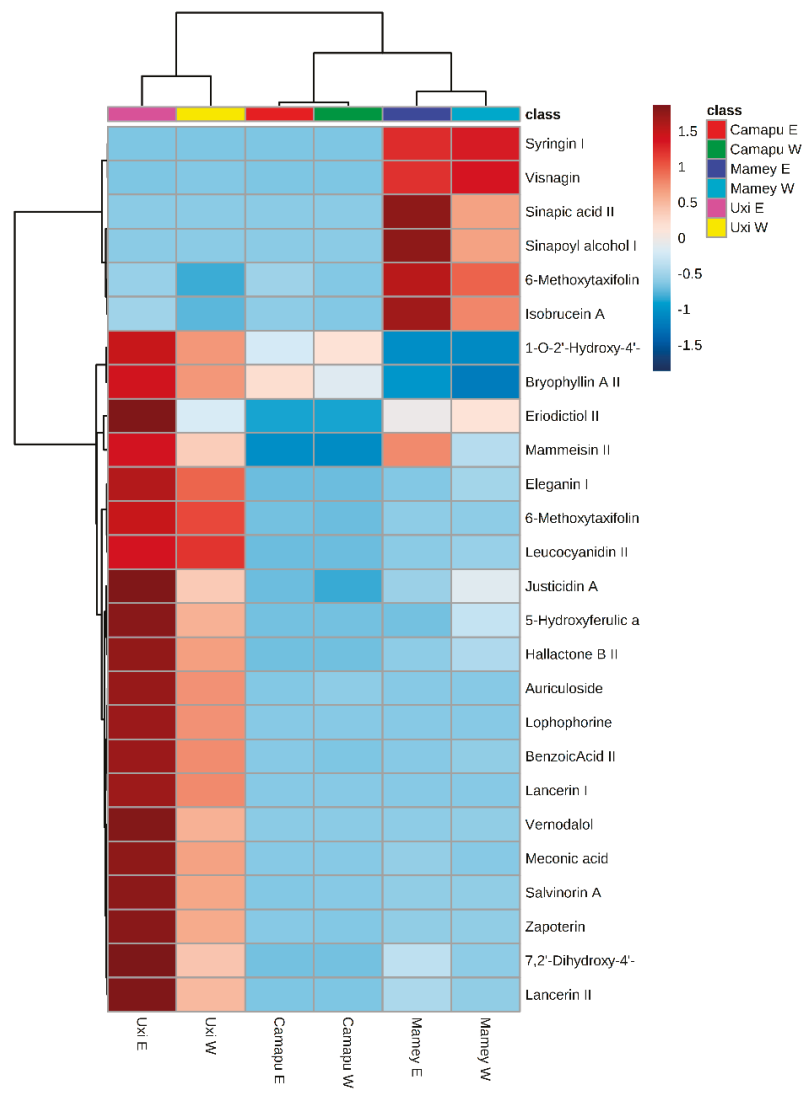

Figure 4. Hierarchical cluster analysis (HCA) and heatmap of the bioactive compounds in the mamey apple, camapu, and uxi fruits extracted with aqueous (W) and ethanolic (E) solvents, which showed maximum variance (eigenvectors) among extracts.

\subsection{In Vitro Antioxidant Activity}

Due to the multifunctional characteristics of the phenolic compounds found in Amazonian fruits, the effectiveness of measuring the antioxidant capacity of a pulp extract is better evaluated when using commonly accepted tests. The ethanolic and aqueous fruits extracts was determined by four different methods with different action mechanism (ABTS, DPPH, FRAP, and ORAC) (Table 3). According to Barros et al. [14], a single assay does not accurately account for all of the groups of antioxidant compounds, because of complexity of fruit matrices, and because of these methodologies can suffer interferences.

ABTS assay revealed values ranged between $263.67 \pm 23.90$ and $1602.7 \pm 30 \mu \mathrm{mol}$ Trolox $\mathrm{g}^{-1}$. The highest antioxidant capacity was presented in UE samples $\left(1602.7 \pm 30.16 \mu \mathrm{mol}\right.$ Trolox g $\left.{ }^{-1}\right)$. Freitas et al. [30] analyses fresh pulp of uxi and found $51.6 \mathrm{mg} \mathrm{TE} / 100 \mathrm{~g}$ for ABTS. In general, the ethanolic extracts of fruits showed the higher antioxidant capacity for this methodology. However, the aqueous extract from camapu fruit was an exception with a value of $432.74 \pm 16.17 \mu \mathrm{mol}$ Trolox $\mathrm{g}^{-1}$ (Table 3). Schiassi et al. [31] studied the activity antioxidant of methanolic extracts of araça $(10.92 \pm 0.11 \mu \mathrm{mol}$ Trolox $\left.\mathrm{g}^{-1}\right)$, buriti $\left(6.03 \pm 0.00 \mu \mathrm{mol}\right.$ Trolox $\left.\mathrm{g}^{-1}\right)$, cagaita $\left(29.32 \pm 0.69 \mu \mathrm{mol}_{\text {Trolox }}{ }^{-1}\right)$, yellow mombin $\left(5.55 \pm 0.01 \mu \mathrm{mol}\right.$ Trolox $\left.\mathrm{g}^{-1}\right)$, and marolo $\left(132.16 \pm 1.40 \mu \mathrm{mol}\right.$ Trolox $\left.\mathrm{g}^{-1}\right)$ and found values lower than the present study. 
Table 3. Antioxidant activity of the mamey apple, camapu, and uxi samples by ABTS, DPPH, FRAP, and ORAC assays.

\begin{tabular}{|c|c|c|c|c|c|c|}
\hline \multirow{2}{*}{ Assay } & \multicolumn{2}{|c|}{ Mamey Apple } & \multicolumn{2}{|c|}{ Camapu } & \multicolumn{2}{|c|}{ Uxi } \\
\hline & Aqueous & Ethanolic & Aqueous & Ethanolic & Aqueous & Ethanolic \\
\hline ABTS $\left(\mu \mathrm{mol}\right.$ Trolox $\left.\mathrm{g}^{-1}\right)$ & $263.67 \pm 23.90^{\mathrm{a}}$ & $937.66 \pm 218.49^{b}$ & $432.74 \pm 16.17^{c}$ & $419.43 \pm 18.55^{c}$ & $271.86 \pm 22.14^{\mathrm{a}}$ & $1602.7 \pm 30.16^{\mathrm{d}}$ \\
\hline DPPH ( $\mu \mathrm{mol}$ Trolox $\left.\mathrm{g}^{-1}\right)$ & $336.60 \pm 3.05^{\mathrm{a}}$ & $1168.42 \pm 218.56^{b}$ & $386.24 \pm 116.99^{c}$ & $705.77 \pm 100.74^{\mathrm{d}}$ & $46.95 \pm 17.17^{e}$ & $509.27 \pm 26.95^{f}$ \\
\hline ORAC $\left(\mu \mathrm{mol}\right.$ Trolox $\left.\mathrm{g}^{-1}\right)$ & $5.17 \pm 0.56^{\mathrm{a}}$ & $8.88 \pm 0.52^{b}$ & $12.30 \pm 1.15^{c}$ & $11.15 \pm 0.42^{c}$ & $14.33 \pm 1.36^{\mathrm{d}}$ & $15.04 \pm 0.84^{\mathrm{d}}$ \\
\hline
\end{tabular}

Results are expressed as mean \pm standard deviation. Different letters on the same line show significant difference.

Results were compared by the One-way ANOVA test with Tukey post-test $(p<0.05)$

Antioxidant capacity was also evaluated by DPPH ${ }^{\bullet}$ radical scavenging method (Table 3 ) and expressed in aqueous and ethanolic extract concentration $\mu$ mol Trolox $\mathrm{g}^{-1}$ sample. The highest activity was found in MAE $\left(1168.42 \mu \mathrm{mol}\right.$ Trolox $\left.\mathrm{g}^{-1}\right)$, followed by CE $\left(705.771 \mu \mathrm{mol}\right.$ Trolox $\left.\mathrm{g}^{-1}\right)$ and UE (509.68 $\mu \mathrm{mol}$ Trolox $\mathrm{g}^{-1}$ ). According to Huchin et al. [32], the DPPH method can analyze hydrophilic and lipophilic compounds, and ethanol is one of the most used solvents for bioactive compounds extraction due, because proposes some benefits, such as low toxicity, good extraction produce, it is safe for human consumption and allows the extracts to be used in the food industry [33].

Antioxidant activity by FRAP method followed the same pattern of the DPPH analysis, where higher values were found for the ethanolic extracts. It is probable that the antioxidant compounds of the samples detected by FRAP are the same with those evaluated by DPPH. MAE also presented the highest activity $\left(1381.13 \mu \mathrm{mol}\right.$ ferrous sulphate $\left.\mathrm{g}^{-1}\right)$ These results was lower than obtained by Barros et al. [14] for aqueous extracts of achachairu $\left(712.35 \pm 6.61 \mu \mathrm{mol}\right.$ ferrous sulphate $\left.\mathrm{g}^{-1}\right)$, araça-boi $\left(798.92 \pm 1.52 \mu \mathrm{mol}\right.$ ferrous sulphate $\left.\mathrm{g}^{-1}\right)$, and bacaba $\left(6567.45 \pm 4.25 \mu \mathrm{mol}\right.$ ferrous sulphate $\left.\mathrm{g}^{-1}\right)$.

Regarding to ORAC assay, the results revealed that UE and UW obtained the highest value $\left(15.04 \pm 0.84\right.$ and $14.33 \pm 1.36 \mu \mathrm{mol}$ Trolox $\left.\mathrm{g}^{-1}\right)$, followed by CE and CW (11.15 \pm 0.42 and $12.30 \pm 1.15 \mu \mathrm{mol}$ Trolox $\left.\mathrm{g}^{-1}\right)$. No significant differences $(p>0.05)$ were observed between the aqueous and ethanolic extracts of uxi and camapu sample. MAE $\left(8.88 \pm 0.52 \mu \mathrm{mol}\right.$ Trolox $\left.\mathrm{g}^{-1}\right)$ and MAW $(5.17 \pm$ $\left.0.56 \mu \mathrm{mol} \mathrm{Trolox} \mathrm{g}^{-1}\right)$ showed the lowest values $(p>0.05)$ between extracts. Santos et al. [34] reported to Amazonian fruits such as bacaca $\left(195.00 \pm 10.00 \mu \mathrm{mol}\right.$ Trolox $\left.\mathrm{g}^{-1}\right)$, buriti $\left(83.00 \pm 6.00 \mu \mathrm{mol}\right.$ Trolox g $\left.{ }^{-1}\right)$, inajá $\left(26.00 \pm 2.00 \mu \mathrm{mol}\right.$ Trolox $\left.\mathrm{g}^{-1}\right)$, pupunha $\left(94.00 \pm 1.00 \mu \mathrm{mol}\right.$ Trolox $\left.^{-1}\right)$, and tucumã $\left(64.00 \pm 4.00 \mu \mathrm{mol}\right.$ Trolox $\left.\mathrm{g}^{-1}\right)$ results higher than camapu, mamey apple and uxi extracts.

\subsection{Correlation between Total Phenolic Compounds and Antioxidant Capacity}

The results of Pearson correlation coefficients $(r)$ between total phenolic compounds and antioxidant capacity of aqueous and methanolic extracts suggest that the total phenolic compounds contributed to the in vitro antioxidant capacity of the extracts according to the method used. The aqueous extract showed a good association of total phenolic compounds with ABTS $(r=0.843)$ and ORAC $(r=0.752)$ for camapu fruit. ORAC assay has been largely applied to the assessment of free radical scavenging capacity of pure antioxidant compounds and antioxidant plant extracts [35]. The radical cation ABTS [2,29-]azinobis-(3-ethylbenzothiazoline-6-sulfonic acid) is one of the spectrophotometric methods used to measure water-soluble as well as lipid-soluble antioxidants, pure compounds, and food extracts. The pre-formed radical monocation of 2,29-azinobis-(3-ethylbenzothiazoline-6-sulfonic acid) $\left(\mathrm{ABTS}^{\bullet 1}\right)$ is generated by oxidation of ABTS with potassium persulfate and is reduced in the presence of such hydrogen-donating antioxidants [36]. 1-O-2'-Hydroxy-4'-methoxycinnamoyl-b-D-glucose, a compound present in CW (Figure 4), this compound belongs to the sub class of organic compounds known as hydroxycinnamic acid glycosides. Hydroxycinnamic acids are natural antioxidants found in fruits, vegetables, and cereals [37].

Regarding to mamey-apple, the ethanolic extract presented positive correlation with total phenolic compounds in relation to DPPH assay $(r=0.910)$. The 2,2-diphenylpicrylhydrazyl (DPPH) assay is widely used in plant biochemistry to evaluate their properties for scavenging free radicals. The method 
is based on the spectrophotometric measurement of DPPH concentration change resulting from the reaction with an antioxidant [38].

According to Figure 4, the acids syrigin I and visnagin were components with high relative abundancy. Visnagin is an antioxidant furanocoumarin derivative and is a furanochromone that is furo [3,2-g]chromen-5-one which is substituted at positions 4 and 7 by methoxy and methyl groups, respectively. Syringic acid is a dimethoxybenzene that is 3,5-dimethyl ether derivative of gallic acid. It has a role as a plant metabolite, a member of benzoic acids, and derives from a gallic acid. Previous reports described that hydroxybenzoic acids itself and its derivatives showed antioxidant properties against different type of free radicals and can prevent or decrease overproduction of reactive species. The main structural feature responsible for the antioxidative and free radical scavenging activity in the case of phenolic derivatives is the phenolic hydroxyl group. Phenols are able to donate the hydrogen atom of the phenolic $\mathrm{OH}$ to the free radicals, thus stopping the propagation chain during the oxidation process. This effect is modulated by the ring substituents, so that electron-withdrawing groups increase the bond-dissociation enthalpy, due to the stabilization of the phenol by a polar structure that leaves a positive charge on the $\mathrm{OH}$ group [39-41].

In uxi ethanolic extract, some bioactive compounds were identified with great relative abundance, such as auriculoside, that is a flavan glycoside. Most natural flavans are lipid-soluble and prominent in fruit skin or peel and leaf surfaces, and are usually found at higher concentrations in immature fruits compared to mature fruits [42]. Lancerin a plant metabolite found in UE is a member of xanthones, a C-glycosyl compound and a polyphenol. Among the polyphenols, the xanthones derivatives comprise an important class of the oxygenated heterocycles with a diversity of substitution patterns that have been described for their antioxidant activity, show to act as metal chela-tors, free radical scavengers, as well as inhibitors of lipid peroxidation [43]. The presence of these compounds may have contributed to the strong correlation $(r=0.910)$ found between total phenolic compounds and ORAC assay.

These results demonstrate the importance of do different methods to available the antioxidant activity, above all in complex matrices. The positive correlation between compound phenolics and ORAC, can be explained due to this assay may be considered a more exact method, because it uses a biologically relevant radical source (peroxyl) and allows the measurement of total antioxidant capacity through the combination of the antioxidant capacity of hydrophilic and lipophilic fractions [44]. According to the methodology used, these results suggest that phenolic compounds may be one of the main factors responsible for the antioxidant capacity of mamey apple, camapu, and uxi.

\subsection{NMR Profile}

Table 4 described the identified compounds for each fruit, with the chemical shift and signal multiplicity, as well as coupling constant $(J)$, and the quantification in $\mathrm{mg} / \mathrm{g}$ of freeze-dried fruit. Camapu had the greatest number of different compounds, indicating that it has a large variety of nutrients and metabolites, even more than could be extracted and identified. Uxi had the least amount, probably due to the great quantity of lipophilic compounds that could not be extracted, so this result does not mean that there are few compounds in uxi.

Sugars were most abundant compounds in those fruits. Camapu showed the highest amount of sucrose, and mamey apple showed the highest amount of fructose and glucose, both $\alpha$ and $\beta$. In the uxi extracts no sugars were found. This result indicates that mamey apple and camapu are sweeter than $u x i$, and probably would be more accepted by consumers. The sugars present in mamey apple were sucrose $(1.50 \pm 0.10 \mathrm{mg} / \mathrm{g})$, fructose $(0.85 \pm 0.03 \mathrm{mg} / \mathrm{g}), \alpha$-glucose, and $\beta$-glucose $(0.49 \pm 0.02$ and $0.40 \pm 0.01 \mathrm{mg} / \mathrm{g}$, respectively). The sugars found in camapu were sucrose $(4.09 \pm 0.46 \mathrm{mg} / \mathrm{g})$, followed by fructose, $\alpha$-glucose, and $\beta$-glucose $(0.11 \pm 0.00,0.04 \pm 0.00$, and $0.04 \pm 0.00 \mathrm{mg} / \mathrm{g}$ respectively).

Fruit and vegetable flavor depend upon taste (given by sweetness, sourness, acidity, and astringency) and aroma (concentrations of odor-active volatile compounds). Sweetness is determined by the concentrations of the predominant sugars, which are ranked relative to sucrose (fructose $>$ sucrose $>$ glucose). Sourness or acidity is determined by the predominant organic acids, which 
are ranked relative to citric acid (citric $>$ malic $>$ tartaric). Some amino acids, such as aspartic and glutamic, may also contribute to sourness. In general, consumer acceptance is related to soluble solids concentration (sugars, organic acids, soluble pectin, some phenolic compounds, and ascorbic acid) or the ratio of soluble solids to titratable acidity [45].

Table 4. NMR fingerprinting identification and quantification of mamey apple, camapu, and uxi.

\begin{tabular}{|c|c|c|c|c|}
\hline Fruit & Compound & $\delta^{1} \mathbf{H}(\mathrm{ppm})$ & Multiplicity (J) & Mass (mg/g) \\
\hline \multirow{8}{*}{ Mamey Apple } & Formic acid & 8.44 & s & $0.01 \pm 0.00$ \\
\hline & Shikimic acid & 6.48 & $\mathrm{~m}$ & $0.11 \pm 0.01$ \\
\hline & Sucrose & 5.42 & $\mathrm{~d}(3.88)$ & $1.51 \pm 0.11$ \\
\hline & $\alpha$-glucose & 5.22 & $\mathrm{~d}(3.76)$ & $0.49 \pm 0.02$ \\
\hline & $\beta$-glucose & 4.64 & $\mathrm{~d}(7.94)$ & $0.40 \pm 0.02$ \\
\hline & Fructose & 4.10 & d (3.42) & $0.85 \pm 0.04$ \\
\hline & Choline & 3.19 & s & $0.01 \pm 0.00$ \\
\hline & Ethanol & 1.18 & $\mathrm{t}(7.09)$ & $0.01 \pm 0.00$ \\
\hline \multirow{13}{*}{ Camapu } & Formic acid & 8.44 & $\mathrm{~s}$ & $0.01 \pm 0.00$ \\
\hline & Sucrose & 5.42 & $\mathrm{~d}(3.91)$ & $4.09 \pm 0.46$ \\
\hline & $\alpha$-glucose & 5.23 & $\mathrm{~d}(3.73)$ & $0.04 \pm 0.01$ \\
\hline & $\beta$-glucose & 4.65 & $\mathrm{~d}(7.92)$ & $0.04 \pm 0.01$ \\
\hline & Fructose & 4.11 & $\mathrm{~d}(3.42)$ & $0.12 \pm 0.01$ \\
\hline & Choline & 3.20 & $\mathrm{~s}$ & $0.01 \pm 0.00$ \\
\hline & Aspartic acid & 2.82 & dd $(17.4 ; 3.78)$ & $0.04 \pm 0.01$ \\
\hline & Acetic acid & 1.94 & $\mathrm{~S}$ & $0.01 \pm 0.00$ \\
\hline & GABA & 1.89 & quin (7.44) & $0.02 \pm 0.01$ \\
\hline & Alanine & 1.47 & $\mathrm{~d}(7.2)$ & $0.02 \pm 0.01$ \\
\hline & Lactic acid & 1.33 & $\mathrm{~d}(6.68)$ & $0.01 \pm 0.00$ \\
\hline & Ethanol & 1.18 & $\mathrm{t}(7.09)$ & $0.02 \pm 0.001$ \\
\hline & Valine & 1.04 & $\mathrm{~d}(7.07)$ & $0.01 \pm 0.00$ \\
\hline \multirow{5}{*}{ Uxi } & Linoleic acid & 5.32 & M & $1.79 \pm 0.11$ \\
\hline & Acetic acid & 1.94 & S & $0.16 \pm 0.01$ \\
\hline & Alanine & 1.45 & $\mathrm{~d}(7.20)$ & $0.04 \pm 0.01$ \\
\hline & Ethanol & 1.16 & $\mathrm{t}(7.10)$ & $0.15 \pm 0.02$ \\
\hline & Valine & 1.05 & $\mathrm{~d}(7.05)$ & $0.05 \pm 0.001$ \\
\hline
\end{tabular}

It has been shown that mamay apple has ethanol $(0.01 \pm 0.00 \mathrm{mg} / \mathrm{g})$, which is possibly a fruit sugar fermentation product. It was also found choline $(0.01 \pm 0.00 \mathrm{mg} / \mathrm{g})$ and organic acids, such as formic acid and shikimic acid $(0.01 \pm 0.00$ and $0.11 \pm 0.00 \mathrm{mg} / \mathrm{g})$ in mamey apple. Shikimic acid (3,4,5-trihydroxy-1-cyclohexene-1-carboxylic acid) is natural acid from the plant metabolism and common in berries fruits. It is a precursor for the biosynthesis of primary metabolites such as aromatic amino acids and folic acid, and a great many other aromatic compounds. The benzene ring is formed through the shikimate pathway, and shikimic acid is an extremely essential compound in plants and microbes. Shikimic acid has been found to occur in many tissues of a variety of plants, with a sufficiently high percentage. Moreover, its content and accumulation in different tissues depends on the rate of metabolic processes taking place in them. Shikimic acid is utilized for industrial synthesis of the oseltamivir (antiviral), zeylenone (employed as a preparation for chemotherapy of cancer), and monopalmityloxy shikimic acid (anticoagulant activity). In addition, shikimic acid derivatives represent a great interest for agriculture because many of them are used as herbicides and antibacterial agents [46].

Choline is a natural amine that can be synthesized in human body, but this production usually is not enough to meet human needs in men and postmenopausal women. Some important functions of choline are it is a part of the neurotransmitter acetylcholine; it is a part of the predominant phospholipids in membranes; it forms betaine, which is an important osmolyte in the kidney glomerulus and helps with the reabsorption of water from the kidney tubule. Eggs and liver are the main sources of choline, but many other foods contain significant amounts of choline and esters of choline [47]. 
Ethanol $(0.02 \pm 0.00 \mathrm{mg} / \mathrm{g})$ was also present in camapu, indicating fermentation. The organic acids found in camapu were lactic acid, acetic acid and formic acid $(0.01 \pm 0.00,0.01 \pm 0.00$, and $0.01 \pm 0.00)$. Besides those organic acids, it was found $\gamma$-amino butyric acid (GABA) in camapu $(0.02 \pm 0.00 \mathrm{mg} / \mathrm{g})$. GABA is a four-carbon nonprotein amino acid and is widespread in bacteria, animals, and plants. GABA is naturally present in small quantities in plants, and is produced in response to anaerobic conditions, $\gamma$-radiation, low $\mathrm{pH}$, low or high temperatures, and darkness, and by mechanical manipulation. Some functions of GABA in plants are: regulation of cytosolic $\mathrm{pH}$, protection against oxidative stress, defense against insects, and the regulation of pollen tube growth and guidance [48]. In vertebrates is a neurotransmitter that is deficient in the brain of people with Alzheimer disease [49]. Camapu has been shown to be effective in delaying the development of this disease and in its treatment, by increasing the proliferation of neural stem cells in vivo [50] and also shown an anxiolytic effect [51] which the authors suppose is due to the presence of GABA agonists. Several amino acids such as aspartic acid, alanine, and valine $(0.03 \pm 0.00,0.02 \pm 0.00$, and $0.01 \pm 0.08 \mathrm{mg} / \mathrm{g})$ and choline $(0.01 \pm 0.00 \mathrm{mg} / \mathrm{g})$ were also present in camapu in sufficient quantities to be identified.

For uxi, the compound with in the highest amount was linoleic acid $(1.79 \pm 0.10 \mathrm{mg} / \mathrm{g})$, which is the main fatty acid of $\omega-6$ group. This result shows that there are fatty acids that are sufficient to appear in a spectrum of fingerprints, even though other lipids may not have been completely extracted from the sample. There is probably a low amount of sugar in uxi fruit because there are high amounts of lipids and usually sugar and lipids in the pulp of fruits are inversely proportional. However, it was found ethanol $(0.15 \pm 0.01 \mathrm{mg} / \mathrm{g})$, indicating that some sugar that was present before it was fermented. It was also found enough amount of acetic acid $(0.15 \pm 0.00 \mathrm{mg} / \mathrm{g})$ valine and alanine amino acids $(0.05 \pm 0.00$ and $0.04 \pm 0.00 \mathrm{mg} / \mathrm{g}$, respectively).

\section{Material and Methods}

\subsection{Standards and Chemicals}

2,2-Diphenyl-1-picrylhydrazyl ( $\left.\mathrm{DPPH}^{\bullet}\right), 2$,2'-azino-bis (3-ethylbenzothiazoline-6-sulfonic acid) diammonium salt (ABTS), gallic acid, quercetin, $2^{\prime}, 7^{\prime}$-dichlorofluorescin diacetate (DCFH-DA), L-(+)-ascorbic acid (AA). Phenolic standards (caffeic acid, (+)-catechin, ellagic acid, (-)-epicatechin, gallic acid, gentisic acid, 4-hydroxybenzoic acid, myricetin, pyrogallol, quercetin, and quercetin 3-O-glucoside) were purchased from Sigma-Aldrich (St. Louis, MO, USA). All the solvents used for the UPLC-MSE analysis were of LC-MS purity grade and were also purchased from Sigma-Aldrich (St. Louis, MO, USA).

\subsection{Samples}

The fruits in natura of mamey apple (Mammea americana), camapu (Physalis angulata), and uxi (Endopleura uchi) were obtained from producing regions of Pará State, in the months of January and February 2017. They were transported in vacuum plastic containers to Federal University of the State of Rio de Janeiro (UNIRIO, RJ, Brazil) and stored at $-18^{\circ} \mathrm{C}$. The part of the fruit used for extraction was carried out according to their consumption, for mamey apple only pulp, for camapu the whole fruit and for uxi pulp and bark.

\subsection{Sample Preparation}

Samples were extracted by means of 2 extraction solvents: (I) ethanol $70 \%$ and (II) water, from $5 \mathrm{~g}$ of sample and $100 \mathrm{~mL}$ of extraction solvent, followed by homogenization at room temperature $\left(-20^{\circ} \mathrm{C}\right)$ in a homogenizer TE-420 (Tecnal, São Paulo, Brazil) for $10 \mathrm{~min}$ in the absence of light. The samples were then centrifuged (Thermo Fisher Scientific, Bartlesville, CA, USA) $\left(5000 \times g, 5 \mathrm{~min}, 20^{\circ} \mathrm{C}\right)$ and filtered through analytical filter paper. The extraction solvents were evaporated using a rotary evaporator under vacuum (Savant, Thermo Scientific) and the extracts were then frozen at $-80^{\circ} \mathrm{C}$ in an ultra-freezer 
and lyophilized (Terroni ${ }^{\circledR}$ LD 300, São Carlos, SP, Brazil) for $24 \mathrm{~h}$. After this process, extracts were frozen at $-20^{\circ} \mathrm{C}$ until use in the experiments.

For UPLC-MS ${ }^{\mathrm{E}}$ analysis, the extraction solvents were evaporated using a rotary evaporator under vacuum (Savant, Thermo Scientific, USA) at $40{ }^{\circ} \mathrm{C}$ and thereafter ressuspended in methanol/acetonitrile/water $(2: 5: 93 ; v / v)$. Stock solutions $(500 \mathrm{ppm})$ of 11 standards (caffeic acid, (+)-catechin, ellagic acid, (-)-epicatechin, gallic acid, gentisic acid, 4-hydroxybenzoic acid, myricetin, pyrogallol, quercetin and quercetin 3-O-glucoside from Sigma-Aldrich were prepared individually by dissolving accurately weighed amounts of standards in aqueous methanol an aliquot of each stock solution was mixed to achieve a mixed standard solution with a final concentration of $10 \mathrm{mg} / \mathrm{L}$ for each compound. Finally, extracts and standards were filtered through a $0.22 \mu \mathrm{m}$ syringe filter and stored at $-80^{\circ} \mathrm{C}$ until UPLC-MS ${ }^{\mathrm{E}}$ analysis.

\subsection{Quantification of Total Phenolic Compounds}

Total phenolic content was determined by the Folin-Ciocalteu method, which was adapted from Rocchetti et al. [52]. The extract and $2.5 \mathrm{~mL}$ Folin-Ciocalteu reagent solution $10 \%$ were combined and then mixed well using a Vortex. The mixture was allowed to react for $5 \mathrm{~min}$ then $2 \mathrm{~mL}$ of sodium carbonate $4 \%$ solution was added and mixed well the solution was incubated at room temperature $\left(25^{\circ} \mathrm{C}\right)$ in the dark for $2 \mathrm{~h}$. The absorbance was measured at $750 \mathrm{~nm}$ using a spectrophotometer (Turner ${ }^{\circledR} 340$, Haverhill, MA, USA) and the results were expressed in mg gallic acid equivalents (GAE) per $100 \mathrm{~g}$ of extract using a gallic acid $(2,5-50 \mu \mathrm{g} / \mu \mathrm{L})$ standard curve [53].

\subsection{Phytochemical Profile Characterization by UPLC-MS ${ }^{E}$}

The UPLC-MS ${ }^{\mathrm{E}}$ analyses were carried out according to Santos et al. (2018) [54] with slightly modifications. Two uL of extracts and standards were injected in triplicate into an Acquity UPLC (Waters, Milford, MA, USA) coupled to Xevo G2-S QTOF-MS/MS (Waters, Manchester, UK) system equipped with an electrospray ionization source (ESI) operating in negative ion mode. The column used was a UPLC HSS T3 C18 (100 mm $\times 2.1 \mathrm{~mm}, 1.8 \mu \mathrm{m}$ ) (Waters, Wexford, Ireland). The flow rate was $0.6 \mathrm{~mL} / \mathrm{min}$ and the mobile phase gradient elution consisted of acidified water $(5 \mathrm{mM}$ ammonium formate and $0.3 \%$ formic acid, v/v) (pump A) and acetonitrile containing 0.3\% formic acid (pump B), as follows: $97 \%$ A at $0 \mathrm{~min}$, $50 \% \mathrm{~A}$ at $6.8 \mathrm{~min}, 15 \% \mathrm{~A}$ at 7.4-8.5 min, followed by an additional equilibration step 97\% A at $9.1-12 \mathrm{~min}$. Data were acquired using a multiplexed MS/MS acquisition in the extended mode with alternating low and high energy acquisition (MS ${ }^{\mathrm{E}}$ ) $30-55 \mathrm{eV}$ using ultra-high pure argon (Ar). The capillary and cone voltage were set at $3.0 \mathrm{kV}$ and $30 \mathrm{~V}$, respectively. The desolvation gas $\left(\mathrm{N}_{2}\right)$ was set at $600 \mathrm{~L} / \mathrm{h}$ at $450{ }^{\circ} \mathrm{C}$, the cone gas was set at $50 \mathrm{~L} / \mathrm{h}$ and the source temperature at $120^{\circ} \mathrm{C}$. Data acquisition was performed by using MassLynx 4.1 (Waters Corporation, Milford, MA, USA). To ensure accuracy and reproducibility, all acquisitions were performed by infusing lock mass calibration with leucine-enkephaline (Waters Corporation, Milford, MA, USA) $(m / z 554.2615)$ at a concentration of $1.0 \mathrm{ng} / \mathrm{L}$ in acetonitrile: $\mathrm{H}_{2} \mathrm{O}$ (50:50, $v / v)$ with $0.1 \%(v / v)$ formic acid at a flow rate of $10 \mu \mathrm{L} / \mathrm{min}$.

The raw data of all replicates were processed with Progenesis QI v2.1 (Nonlinear Dynamics, Waters Corporation, UK) with the following conditions: centroid data, resolution full-width at half maximum (FWHM) of 50,000, deprotonated molecule $[\mathrm{M}-\mathrm{H}]^{-}$. The identification of phenolic compounds was performed by searching for polyphenols with MetaScope, using a customized database of polyphenol compounds from PubChemID by using the following parameters: precursor and fragment mass error tolerance ( 5 and $10 \mathrm{mg} / \mathrm{L}$, respectively), retention time limit $7.5 \mathrm{~min}$. Target analysis was also applied for identification of the phenolic compounds by comparing the run parameters of phenolic standards such as the retention time, exact mass, mass error, and the MS-MS spectra, besides the other above mentioned parameters. The processed data were exported to XLSTAT software (Addinsoft, Paris, France), where the values of relative abundance obtained from each compound based on ion mass spectra counting were used to relative quantification and then to the multivariate statistical evaluation where Principal Components Analysis (PCA) biplot was elaborated. The Metaboanalyst 3.0 web server 
was used for analysis of multivariate data (HCA, hierarchical cluster analysis and heat map) where the eigenvectors of the correlation matrix was used to select the discriminatory bioactive compounds between the samples analyzed.

\subsection{Analysis by Nuclear Magnetic Resonance Spectroscopy}

For the NMR analyses, samples were prepared in triplicate. It was done by weighing $30.0( \pm 0.5) \mathrm{mg}$ of freeze-dried samples (for each repetition), which was subjected during $10 \mathrm{~min}$ to shaking in a vortex with $0.8 \mathrm{~mL}$ of extractor solvent $\left(\mathrm{D}_{2} \mathrm{O}\right.$ for abrico and camapu; methanol-d4 for uxi), with TMSP-d4 at concentration $0.02 \%(\mathrm{~m} / \mathrm{v})$ as internal reference and mass standard and, after, to ultrasonic bath during $10 \mathrm{~min}$. Next, samples were centrifuged (13,000 RPM) at room temperature for more $10 \mathrm{~min}$. A $0.6 \mathrm{~mL}$ supernatant aliquot was analyzed.

The ${ }^{1} \mathrm{H}-\mathrm{NMR}$ spectra, as well as the 2D experiments, were conducted in the Bruker Avance III 9.4 Tesla (400 MHz for hydrogen frequency) spectrometer equipped with a PABBI probe $(5 \mathrm{~mm})$ and with an Automatic Tuning and Matching (ATMA) unit located in NMR Laboratory of the Chemistry Department at Federal University of São Carlos-UFSCar, Brazil. The TMSP-d4 was used to determine the 0 point in the chemical shift scale. $1 \mathrm{H}$ NMR spectra were registered at temperature of $300 \mathrm{~K}$ using $64 \mathrm{~K}$ data points and the standard Bruker pulse sequence (zgps).

All spectra were obtained through pre-saturation pulse sequence in order to suppress the residual water sign in the solvent. Spectra were acquired through 16 scans (NS), spectral window $15.0191 \mathrm{mg} / \mathrm{L}$ with 128,000 data points, receiver gain (RG) 80.6, relation delay of $50 \mathrm{~s}$ (D1) and acquisition time of $10.9 \mathrm{~s}$ (AQ). The exponential line broadening function value adopted for spectral apodization (LB) was $0.30 \mathrm{~Hz}$.

The NMR data was analyzed in TopSpin Brucker Software. Quantification was performed by comparison of the compound's signals area and the area of the TMSP-d4 signal to find out the compound's mass since the TMSP-d4 mass is known. The equation used was: analyte mass $=$ (analyte area $\times$ TMSP-d $4{ }^{1} \mathrm{H} \mathrm{N}^{\mathrm{o}} \times$ TMSP-d 4 mass $\times$ analyte MM)/(TMSP- $\mathrm{d} 4$ area $\times$ analyte ${ }^{1} \mathrm{H} \mathrm{N}^{\circ} \times$ TMSP- $\mathrm{d} 4$ $\mathrm{MM})$. The quantification is expressed in $\mathrm{mg} / \mathrm{g}$ of freeze-dried fruit.

\subsection{ABTS}

For ABTS assay, the procedure followed the method of Thaipong et al. [55]. The stock solutions included $7.0 \mathrm{mM}$ ABTS solution and $140 \mathrm{mM}$ potassium persulfate solution. The working solution was then prepared by mixing the two stock solutions, $5 \mathrm{~mL}$ ABTS solution in $88 \mu \mathrm{L}$ potassium persulfate solution, and allowing them to react for $16 \mathrm{~h}$ at room temperature in the dark. The solution was then diluted by mixing $1 \mathrm{~mL}$ ABTS solution with ethanol necessary to obtain an absorbance of $0.709-0.701$ units at $734 \mathrm{~nm}$ using the spectrophotometer (Turner ${ }^{\circledR} 340$, Haverhill, MA, USA). The fruits extracts were allowed to react with $2.5 \mathrm{~mL}$ of the ABTS solution for $6 \mathrm{~min}$ in a dark condition. The standard curve was linear between 0 and $2000 \mu \mathrm{M}$ Trolox equivalents. Results are expressed in $\mu \mathrm{M}$ Trolox equivalents $\mathrm{g}^{-1}$ of extract.

\section{8. $\mathrm{DPPH}$}

The antioxidant activity of all fruits extracts in relation to the DPPH (2,2-diphenyl-1-picrilidrazil) radical was quantified by using a protocol described by Brand-Williams and Berset [56], using wave $515 \mathrm{~nm}$ in spectrophotometer (Turner ${ }^{\circledR} 340$, Haverhill, MA, USA). The working solution was obtained by dissolving $2.4 \mathrm{mg}$ DPPH reagent with $100 \mathrm{~mL}$ methanol and stored in the dark until needed. The extracts were allowed to react with $2.5 \mathrm{~mL}$ of the DPPH solution for $30 \mathrm{~min}$ in the dark. The standard curve was linear between $0 \mu \mathrm{M}$ and $2000 \mu \mathrm{M}$ Trolox. Results are expressed in $\mu \mathrm{mol}$ Trolox $\mathrm{g}^{-1}$ of extract. 


\subsection{FRAP}

The FRAP assay was done according to Thaipong et al. [55]. The stock solutions included $0.3 \mathrm{M}$ acetate buffer, $\mathrm{pH}$ 3.6, $10 \mathrm{mM}$ TPTZ (2,4,6-tripyridyl-s-triazine) solution, and $20 \mathrm{mM}$ ferric chloride solution. The fresh working solution was prepared by mixing $25 \mathrm{~mL}$ acetate buffer, $2.5 \mathrm{~mL}$ TPTZ solution, and $2.5 \mathrm{~mL}$ ferric chloride solution. Fruits extracts were allowed to react with $2.7 \mathrm{~mL}$ of the FRAP solution for $30 \mathrm{~min}$ in the dark condition and warmed at $37^{\circ} \mathrm{C}$. Readings of the colored product were then taken at $595 \mathrm{~nm}$ in spectrophotometer (Turner ${ }^{\circledR} 340$, Haverhill, MA, USA). The standard curve was linear between $500 \mu \mathrm{M}$ and $2000 \mu \mathrm{M}$ ferrous sulphate. Results are expressed in $\mu$ mol ferrous sulphate $\mathrm{g}^{-1}$ of extract.

\subsection{ORAC}

The ORAC procedure used an automated plate reader (SpectraMax i3x, Molecular Devices, USA) with 96-well plates [54-57]. Analyses were conducted in phosphate buffer $\mathrm{pH} 7.4$ at $37^{\circ} \mathrm{C}$. Peroxyl radical was generated using 2, 2'-azobis (2-amidino-propane) dihydrochloride which was prepared fresh for each run. Fluorescein was used as the substrate. Fluorescence conditions were as follows: excitation at $485 \mathrm{~nm}$ and emission at $520 \mathrm{~nm}$. The standard curve was linear between $1 \mu \mathrm{M}$ and $90 \mu \mathrm{M}$

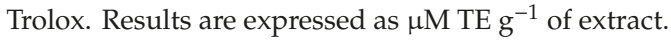

\subsection{Statistical}

Statistical comparisons were carried out by ANOVA and post hoc Tukey's test using Graph Pad Prism 5.0 and the differences were considered significant when $p<0.05$ in total phenolic content and relative abundance of identified compounds. The correlation coefficients between different results of evaluation antioxidant capacity of the samples, ABTS, DPPH, FRAP, ORAC and total phenolic compounds (PC) were obtained. Principal component analysis (PCA) and heatmap was used to interpret data, using Stat graphics software.

\section{Conclusions}

This work highlights the significantly concentration of phenolic compounds and antioxidant properties of Amazonian fruits. A total of 293 phenolic compounds were tentatively identified in mamey apple, camapu, and uxi by comparison with standards and by fragmentation patterns. Mamey apple extracts presented major number of phenolic compounds, being the phenolic acids and terpenoids the classes more identified. ABTS, DPPH, FRAP, and ORAC assays revealed that the ethanol extract presents a higher antioxidant activity and aqueous extract presents a high correlation with phenolic compounds content in Amazonian fruits. The findings of this study highlight the potential of mamey apple, camapu, and uxi as a valuable source of natural antioxidants.

Supplementary Materials: The following are available online. Table S1: Bioactive compounds detected and characterized in mamey apple, camapu and uxi fruits extracted with aqueous (W) and ethanolic (E) solvents.

Author Contributions: Conceptualization, L.G.B.L., A.G.F., L.C.C., M.S.L.F., and A.J.T.; methodology, L.G.B.L., J.M., J.P.d.A., M.C.B.S., T.P.d.N., M.d.S.S., A.G.F, M.S.L.F., and A.J.T. data curation, L.G.B.L., J.M., J.P.d.A., M.C.B.S., T.P.d.N., M.d.S.S., A.G.F, M.S.L.F., and A.J.T. writing—original draft preparation, L.G.B.L., J.M., M.C.B.S., T.P.d.N., M.d.S.S., M.S.L.F., and A.J.T. writing-review and editing, L.G.B.L., M.C.B.S., T.P.d.N., M.S.L.F., and A.J.T. All authors have read and agreed to the published version of the manuscript.

Funding: This research was funded by FAPERJ grant number 248660, 246295, 216954 and 246296.

Acknowledgments: This work was supported by Coordenação de Aperfeiçoamento de Pessoal de Nível Superior (CAPES), Conselho Nacional de Desenvolvimento Científico e Tecnológico (CNPq), Fundação de Amparo à Pesquisa do Estado do Rio de Janeiro (FAPERJ) and Foundation for Research Support of the State of São Paulo (FAPESP).

Conflicts of Interest: The authors declare no conflict of interest.

Availability of Data and Materials: All the processed data are presented in the article. Information on raw data and materials are available from the corresponding authors upon request. 


\section{References}

1. Ramos, A.S.; Souza, R.O.; Boleti, A.P.D.A.; Bruginski, E.R.; Lima, E.S.; Campos, F.R.; Machado, M.B. Chemical characterization and antioxidant capacity of the araçá-pera Psidium acutangulum: An exotic Amazon fruit. Food Res. Int. 2015, 75, 315-327. [CrossRef]

2. Cândido, T.L.N.; Silva, M.R.; Agostini-Costa, T.S. Bioactive compounds and antioxidant capacity of buriti (Mauritia flexuosa L.f.) from the Cerrado and Amazon biomes. Food Chem. 2015, 177, 313-319. [CrossRef] [PubMed]

3. Chisté, R.C.; Mercadante, A.Z. Identification and quantification, by HPLC-DAD-MS/MS, of carotenoids and phenolic compounds from the Amazonian fruit Caryocar villosum. J. Agric. Food Chem. 2012, 60, 5884-5892. [CrossRef] [PubMed]

4. Schulz, M.; Borges, G.D.S.C.; Gonzaga, L.V.; Seraglio, S.K.T.; Olivo, I.S.; Azevedo, M.S.; Nehring, P.; de Gois, J.S.; de Almeida, T.S.; Vitali, L.; et al. Chemical composition, bioactive compounds and antioxidant capacity of juçara fruit (Euterpe edulis Martius) during ripening. Food Res. Int. 2015, 77, 125-131. [CrossRef]

5. Bataglion, G.A.; da Silva, F.M.A.; Eberlin, M.N.; Koolen, H.H.F. Simultaneous quantification of phenolic compounds in buriti fruit (Mauritia flexuosa L.f.) by ultra-high performance liquid chromatography coupled to tandem mass spectrometry. Food Res. Int. 2014, 66, 396-400. [CrossRef]

6. Virgolin, L.B.; Seixas, F.R.F.; Janzantti, N.S. Composition, content of bioactive compounds, and antioxidant activity of fruit pulps from the Brazilian Amazon biome. Pesqui. Agropecu. Bras. 2017, 52, 933-941. [CrossRef]

7. Luís, E.; Ordóñez-Santos, G.M.; Martínez-Álvarez, A.M.V.-R. Effect of processing on the physicochemical and sensory properties of mammee apple (Mammea americana L.) fruit. Agrociencia 2014, 48, 377-385.

8. Sun, L.; Liu, J.; Liu, P.; Yu, Y.; Ma, L.; Hu, L. Immunosuppression effect of Withangulatin A from Physalis angulata via heme oxygenase 1-dependent pathways. Process Biochem. 2011, 46, 482-488. [CrossRef]

9. Hseu, Y.C.; Wu, C.R.; Chang, H.W.; Kumar, K.J.S.; Lin, M.K.; Chen, C.S.; Cho, H.J.; Huang, C.Y.; Huang, C.Y.; Lee, H.Z.; et al. Inhibitory effects of Physalis angulata on tumor metastasis and angiogenesis. J. Ethnopharmacol. 2011, 135, 762-771. [CrossRef]

10. Nunomura, R.C.S.; Oliveira, V.G.; Nunomura, S.M. Characterization of Bergenin in. Amazonia 2009, 20, 1060-1064.

11. Paz, W.H.P.; de Almeida, R.A.; Braga, N.A.; da Silva, F.M.A.; Acho, L.D.R.; Lima, E.S.; Boleti, A.P.A.; dos Santos, E.L.; Angolini, C.F.F.; Bataglion, G.A.; et al. Remela de cachorro (Clavija lancifolia Desf.) fruits from South Amazon: Phenolic composition, biological potential, and aroma analysis. Food Res. Int. 2018, 109, 112-119. [CrossRef] [PubMed]

12. de Brabo Sousa, S.H.; de Andrade Mattietto, R.; Campos Chisté, R.; Carvalho, A.V. Phenolic compounds are highly correlated to the antioxidant capacity of genotypes of Oenocarpus distichus Mart. fruits. Food Res. Int. 2018, 108, 405-412. [CrossRef] [PubMed]

13. Nonato, C.D.F.A.; Leite, D.O.D.; Pereira, R.C.; Boligon, A.A.; Ribeiro-filho, J.; Rodrigues, F.F.G.; Costa, J.G.M. Chemical analysis and evaluation of antioxidant and antimicrobial activities of fruit fractions of Mauritia flexuosa L.f. (Arecaceae). PeerJ 2018, 6, e5991. [PubMed]

14. Barros, R.G.C.; Andrade, J.K.S.; Denadai, M.; Nunes, M.L.; Narain, N. Evaluation of bioactive compounds potential and antioxidant activity in some Brazilian exotic fruit residues. Food Res. Int. 2017, 102, 84-92. [CrossRef] [PubMed]

15. Péroumal, A.; Adenet, S.; Rochefort, K.; Fahrasmane, L.; Aurore, G. Variability of traits and bioactive compounds in the fruit and pulp of six mamey apple (Mammea americana L.) accessions. Food Chem. 2017, 234, 269-275. [CrossRef] [PubMed]

16. Genovese, M.I.; Da Silva Pinto, M.; De Souza Schmidt Gonçalves, A.E.; Lajolo, F.M. Bioactive compounds and antioxidant capacity of exotic fruits and commercial frozen pulps from Brazil. Food Sci. Technol. Int. 2008, 14, 207-214. [CrossRef]

17. De Souza, V.R.; Pereira, P.A.P.; Queiroz, F.; Borges, S.V.; de Deus Souza Carneiro, J. Determination of bioactive compounds, antioxidant activity and chemical composition of Cerrado Brazilian fruits. Food Chem. 2012, 134, 381-386. [CrossRef]

18. Vasco, C.; Ruales, J.; Kamal-eldin, A. Total phenolic compounds and antioxidant capacities of major fruits from Ecuador pacific OCEAN. Food Chem. 2008, 111, 816-823. [CrossRef] 
19. Rothwell, J.A.; Perez-jimenez, J.; Neveu, V.; Medina-remo, A.; Manach, C.; Knox, C.; Eisner, R.; Hiri, N.M.; Garc1, P.; Wishart, D.S.; et al. Database Update Phenol-Explorer 3.0: A major update of the Phenol-Explorer database to incorporate data on the effects of food processing on polyphenol content. Database 2013, 2013, 1-8. [CrossRef]

20. Martins, N.; Barros, L.; Ferreira, I.C.F.R. In vivo antioxidant activity of phenolic compounds: Facts and gaps. Trends Food Sci. Technol. 2016, 48,1-12. [CrossRef]

21. da Silva, C.P.; Freitas, R.A.M.S.; Sampaio, G.R.; Santos, M.C.B.; do Nascimento, T.P.; Cameron, L.C.; Simões, M.; Arêas, J.A.G. Identification and action of phenolic compounds of Jatobá-do-cerrado (Hymenaea stignocarpa Mart.) on $\alpha$-amylase and $\alpha$-glucosidase activities and flour effect on glycemic response and nutritional quality of breads. Food Res. Int. 2019, 116, 1076-1083. [CrossRef]

22. Cruz-Reys, A.; Chavarin, C.; Arias, M.P.C.; Taboada, J.; Jímenez, E. The Molluscacide activity of piquerol A isolated from Piqueria trinervia (Compositae) on 8 species of pulmonate snails. Memórias Inst. Oswaldo Cruz 1989, 84, 35-40. [CrossRef]

23. Medina, S.; Collado-González, J.; Ferreres, F.; Londoño-Londoño, J.; Jiménez-Cartagena, C.; Guy, A.; Durand, T.; Galano, J.M.; Gil-Izquierdo, A. Quantification of phytoprostanes-bioactive oxylipins-and phenolic compounds of Passiflora edulis Sims shell using UHPLC-QqQ-MS/MS and LC-IT-DAD-MS/MS. Food Chem. 2017, 229, 1-8. [CrossRef] [PubMed]

24. De Rosso, M.; Tonidandel, L.; Larcher, R.; Nicolini, G.; Dalla Vedova, A.; De Marchi, F.; Gardiman, M.; Giust, M.; Flamini, R. Identification of new flavonols in hybrid grapes by combined liquid chromatography-mass spectrometry approaches. Food Chem. 2014, 163, 244-251. [CrossRef] [PubMed]

25. Mezni, F.; Slama, A.; Ksouri, R.; Hamdaoui, G.; Khouja, M.L.; Khaldi, A. Phenolic profile and effect of growing area on Pistacia lentiscus seed oil. Food Chem. 2018, 257, 206-210. [CrossRef] [PubMed]

26. Black, C.A.; Parker, M.; Siebert, T.E.; Capone, D.L.; Francis, I.L. Terpenoids and their role in wine flavour: Recent advances. Aust. J. Grape Wine Res. 2015, 21, 582-600. [CrossRef]

27. Vithana, M.D.K.; Singh, Z.; Johnson, S.K. Levels of terpenoids, mangiferin and phenolic acids in the pulp and peel of ripe mango fruit influenced by pre-harvest spray application of FeSO4 (Fe2+), MgSO4 (Mg2+) and MnSO4 (Mn2+). Food Chem. 2018, 256, 71-76. [CrossRef]

28. Wu, S.; Dastmalchi, K.; Long, C.; Kennelly, E.J. Metabolite Pro fi ling of Jaboticaba (Myrciaria cauli fl ora) and Other Dark-Colored Fruit Juices. J. Agric. Food Chem. 2012, 60, 7513-7525. [CrossRef]

29. Choi, J.; Shin, K.M.; Park, H.J.; Jung, H.J.; Kim, H.J.; Lee, Y.S.; Rew, J.H.; Lee, K.T. Anti-inflammatory and antinociceptive effects of sinapyl alcohol and its glucoside syringin. Planta Med. 2004, 70, 1027-1032. [CrossRef]

30. Freitas, F.; Avio, A.; de Araújo, R.C.; Soares, E.R.; Nunomura, R.C.S.; Silva, F.M.A.; da Silva, S.R.S.; da Souza, A.Q.L.; de Souza, A.D.L.; de Franco-Montalbán, F.; et al. Biological evaluation and quantitative analysis of antioxidant compounds in pulps of the Amazonian fruits bacuri (Platonia insignis Mart), ing a (Inga edulis Mart), and uchi (Sacoglottis uchi Huber) by UHPLC-ESI-MS/MS Fl. J. Food Biochem. 2018, 42, e12455. [CrossRef]

31. Schiassi, M.C.E.V.; Souza, V.R.; de Lago, A.M.T.; Campos, L.G.; Queiroz, F. Fruits from the Brazilian Cerrado region: Physico-chemical characterization, bioactive compounds, antioxidant activities, and sensory evaluation. Food Chem. 2018, 245, 305-311. [CrossRef] [PubMed]

32. Moo-Huchin, V.M.; Moo-Huchin, M.I.; Estrada-León, R.J.; Cuevas-Glory, L.; Estrada-Mota, I.A.; Ortiz-Vázquez, E.; Betancur-Ancona, D.; Sauri-Duch, E. Antioxidant compounds, antioxidant activity and phenolic content in peel from three tropical fruits from Yucatan, Mexico. Food Chem. 2015, 166, 17-22. [CrossRef] [PubMed]

33. Oroian, M.; Escriche, I. Antioxidants: Characterization, natural sources, extraction and analysis. Food Res. Int. 2015, 74, 10-36. [CrossRef] [PubMed]

34. Dos Santos, M.; Mamede, R.; Rufino, M.; de Brito, E.; Alves, R. Amazonian Native Palm Fruits as Sources of Antioxidant Bioactive Compounds. Antioxidants 2015, 4, 591-602. [CrossRef]

35. Dávalos, A.; Carmem, G.-C.; Bartolomé, B. Extending Applicability of the Oxygen Radical Absorbance Capacity (ORAC—Fluorescein) Assay. J. Agric. Food Chem. 2004, 52, 48-54. [CrossRef]

36. Re, R.; Pellegreni, N.; Proeggente, A.; Pannala, A.; Yang, M.; Rice-Evans, C. Antioxidant Activity Applying an Improved Abts Radical Cation Decolorization Assay. Free Radic. Biol. Med. 1999, 26, 1231-1237. [CrossRef] 
37. Kylli, P.; Nousiainen, P.; Biely, P.; Sipilã, J.; Tenkanen, M.; Heinonen, M. Antioxidant Potential of Hydroxycinnamic Acid Glycoside Esters. J. Agric. Food Chem. 2008, 56, 4797-4805. [CrossRef]

38. Pyrzynska, K.; Pekal, A. Application of free radical diphenylpicrylhydrazyl (DPPH) to estimate the antioxidant capacity of food samples. Anal. Methods 2013, 5, 4288-4295. [CrossRef]

39. Morales, J.C.; Lucas, R. Structure-Activity Relationship of Phenolic Antioxidants and Olive Components; Elsevier: Amsterdam, The Netherlands, 2010; ISBN 9780123744203.

40. Velika, B.; Kron, I. Original Article Antioxidant properties of benzoic acid derivatives against superoxide radical. Free Radic. Antioxid. 2012, 2, 62-67. [CrossRef]

41. Pasari, L.P.; Khurana, A.; Anchi, P.; Aslam Saifi, M.; Annaldas, S.; Godugu, C. Visnagin attenuates acute pancreatitis via $\mathrm{Nrf} 2 / \mathrm{NFKB}$ pathway and abrogates associated multiple organ dysfunction. Biomed. Pharmacother. 2019, 112, 108629. [CrossRef]

42. Swanson, B.G. Tannins and Polyphenols; Elsevier: Amsterdam, The Netherlands, 2003; p. 5729.

43. Cidade, H.; Rocha, V.; Palmeira, A.; Marques, C.; Tiritan, M.; Ferreira, H.; Lobo, J.S.; Almeida, I.F.; Sousa, M.E.; Pinto, M. In silico and in vitro antioxidant and cytotoxicity evaluation of oxygenated xanthone derivatives. Arab. J. Chem. 2016, 10,1-10. [CrossRef]

44. Dudonné, S.; Vitrac, X.; Coutière, P.; Woillez, M.; Mérillon, J.-M. Comparative Study of Antioxidant Properties and Total Phenolic Content of 30 Plant Extracts of Industrial Interest Using DPPH, ABTS, FRAP, SOD and ORAC Assays. J. Agric. Food Chem. 2009, 57, 1768-1774. [CrossRef]

45. Kader, A.A. Flavor quality of fruits and vegetables. J. Sci. Food Agric. 2008, 88, 1863-1868. [CrossRef]

46. Bochkov, D.V.; Sysolyatin, S.V.; Kalashnikov, A.I.; Surmacheva, I.A. Shikimic acid: Review of its analytical, isolation, and purification techniques from plant and microbial sources. J. Chem. Biol. 2012, 5, 5-17. [CrossRef]

47. Ross, A.C.; Caballero, B.; Cousins, R.J.; Tucker, K.L.; Ziegler, T.R. Modern Nutrition in Health and Disease, 11st ed.; Lippincott Williams \& Wilkins: Philadelphia, PA, USA, 2014.

48. Akihiro, T.; Koike, S.; Tani, R.; Tominaga, T.; Watanabe, S.; Iijima, Y.; Aoki, K.; Shibata, D.; Ashihara, H.; Matsukura, C.; et al. Biochemical Mechanism on GABA Accumulation During Fruit Development in Tomato. Plant Cell Physiol. 2008, 49, 1378-1389. [CrossRef]

49. Solas, M.; Puerta, E.J.; Ramirez, M. Treatment Options in Alzheimer's Disease: The GABA Story. Curr. Pharm. Des. 2015, 21, 4960-4971. [CrossRef] [PubMed]

50. Nascimento, M.V.L. Physalis Angulata Estimula Proliferação de Células-Tronco Neurais do Giro Denteado Hipocampal de Camundongos Adultos; Universidade Federal do Pará: Belém, Brazil, 2013.

51. Giorgetti, M.; Negri, G. Plants from Solanaceae family with possible anxiolytic effect reported on 19th century's Brazilian medical journal. Rev. Bras. Farmacogn. 2011, 21, 772-780. [CrossRef]

52. Rocchetti, G.; Chiodelli, G.; Giuberti, G.; Masoero, F.; Trevisan, M.; Lucini, L. Evaluation of phenolic profile and antioxidant capacity in gluten-free flours. Food Chem. 2017, 228, 367-373. [CrossRef] [PubMed]

53. Saeed, N.; Khan, M.R.; Shabbir, M. Antioxidant activity, total phenolic and total flavonoid contents of whole plant extracts Torilis leptophylla L. BMC Complement Altern. Med. 2012, 12, 221. [CrossRef]

54. Santos, B.M.C.; da Silva Lima, L.R.; Nascimento, F.R.; do Nascimento, T.P.; Cameron, L.C.; Ferreira, M.S.L. Metabolomic approach for characterization of phenolic compounds in different wheat genotypes during grain development. Food Res. Int. 2019, 124, 118-128. [CrossRef]

55. Thaipong, K.; Boonprakob, U.; Crosby, K.; Cisneros-Zevallos, L.; Hawkins Byrne, D. Comparison of ABTS, $\mathrm{DPPH}, \mathrm{FRAP}$, and ORAC assays for estimating antioxidant activity from guava fruit extracts. J. Food Compos. Anal. 2006, 19, 669-675. [CrossRef]

56. Brand-Williams, W.; Cuvelier, M.E.; Berset, C. Use of a free radical method to evaluate antioxidant activity. LWT Food Sci. Technol. 1995, 28, 25-30. [CrossRef] 
57. Prior, R.L.; Hoang, H.; Gu, L.; Wu, X.; Bacchiocca, M.; Howard, L.; Hampsch-Woodill, M.; Huang, D.; Ou, B.; Jacob, R. Assays for Hydrophilic and Lipophilic Antioxidant Capacity (oxygen radical absorbance capacity (ORAC FL)) of Plasma and Other Biological and Food Samples. J. Agric. Food Chem. 2003, 51, 3273-3279. [CrossRef] [PubMed]

Sample Availability: Samples of the compounds are not available from the authors.

(C) 2020 by the authors. Licensee MDPI, Basel, Switzerland. This article is an open access article distributed under the terms and conditions of the Creative Commons Attribution (CC BY) license (http://creativecommons.org/licenses/by/4.0/). 


\title{
Article \\ Optimization of Scorpion Protein Extraction and Characterization of the Proteins' Functional Properties
}

\author{
Ahmidin Wali ${ }^{1,2}$, Atikan Wubulikasimu ${ }^{1,2}$, Sharafitdin Mirzaakhmedov ${ }^{3}$, Yanhua Gao ${ }^{1}$, \\ Adil Omar ${ }^{1,2}$, Amina Arken ${ }^{1,2}$, Abulimiti Yili ${ }^{1, *}$ and Haji Akber Aisa ${ }^{1}$ \\ 1 Key Laboratory of Plant Resources and Chemistry in Arid Regions, Xinjiang Technical, \\ Institute of Physics and Chemistry, Chinese Academy of Sciences, Urumqi 830011, Xinjiang, China; \\ ahmidin@ms.xjb.ac.cn (A.W.); obuatikam@sina.com (A.W.); gaoyh@ms.xjb.ac.cn (Y.G.); \\ adilomar@126.com (A.O.); ak950208@163.com (A.A.); haji@ms.xjb.ac.cn (H.A.A.) \\ 2 University of Chinese Academy of Science, Beijing 100039, China \\ 3 Institute of Bioorganic Chemistry, Academy of Sciences of Uzbekistan, Tashkent 100125, Uzbekistan; \\ mirzaakhmedov@mail.ru \\ * Correspondence: abu@ms.xjb.ac.cn; Tel.: +86-991-3835679
}

Academic Editor: Jose M. Miranda

Received: 26 September 2019; Accepted: 6 November 2019; Published: 13 November 2019

\begin{abstract}
Scorpion has long been used in traditional Chinese medicine, because whole scorpion body extract has anti-cancer, analgesic, anti-thrombotic blood anti-coagulation, immune modulating, anti-epileptic, and other functions. The purpose of this study was to find an efficient extraction method and investigate some of physical and chemical parameters, like water solubility, emulsification, foaming properties, and oil-holding capacity of obtained scorpion proteins. Response surface methodology (RSM) was used for the determination of optimal parameters of ultrasonic extraction (UE). Based on single factor experiments, three factors (ultrasonic power $(\mathrm{w})$, liquid/solid $(\mathrm{mL} / \mathrm{g}$ ) ratio, and extraction time (min)) were used for the determination of scorpion proteins (SPs). The order of the effects of the three factors on the protein content and yield were ultrasonic power $>$ extraction time $>$ liquid/solid ratio, and the optimum conditions of extraction proteins were as follows: extraction time $=50.00 \mathrm{~min}$, ultrasonic power $=400.00 \mathrm{w}$, and liquid $/$ solid ratio $=18.00 \mathrm{~mL} / \mathrm{g}$. For the optimal conditions, the protein content of the ultrasonic extraction and yield were $78.94 \%$ and $24.80 \%$, respectively. The solubility, emulsification and foaming properties, and water and oil holding capacity of scorpion proteins were investigated. The results of this study suggest that scorpion proteins can be considered as an important ingredient and raw material for the creation of water-soluble supramolecular complexes for drugs.
\end{abstract}

Keywords: scorpion (Buthus martensii Karsch) protein; ultrasonic extraction; response surface methodology; scanning electron microscopy; functional properties

\section{Introduction}

Scorpions are Chelicerate arthropods and members of the class Arachnida. There are about 1500 known scorpion species, and only 30 among them produce venom considered potentially dangerous to humans, which might be lethal without medical treatment [1,2]. Scorpion venoms are rich sources of complex mixtures of substances, including toxic peptides, free amino acids, enzymes, nucleotides, lipids, amines, mucoproteins, heterocyclic components, and inorganic salts, which affect the ion channels of both excitable and non-excitable cells [3,4]; some scorpion venoms also contains bioactive compounds, like trimethylamine, nucleosides, and betaine. Therefore, it has anti-thrombosis, anticoagulant, fibrinolysis, analgesic, anti-tumor, anti-epileptic, and several pharmacological effects [5-8]. A number of studies indicate that scorpion venom is comprised of more than 300 toxins, most of which are less 
than $10 \mathrm{kDa}$ in molecular mass [9]. Scorpions have been used in traditional medicine in Asia and Africa for thousands of years, and large-scale commercial farming has achieved good social and economic benefits $[10,11]$. The body parts of scorpions are effective for the treatment of cancer [12-14]. In this work, our main attention is focused on investigating whole scorpion body extract, not directed to venomous part.

With the emergence of several novel methods for the study and identification of scorpion body parts and venom components, several bioactive peptides have been proved effective to treat a variety of diseases [15-17]. The whole body part of a scorpion is used as medicinal material in traditional Chinese medicine. Although there are previous studies on the extraction, isolation, and activity of scorpion toxin $[18,19]$, few reports are available on the extraction and functional evaluation of scorpion total protein. Scorpion bodies are a main medicinal recourse, but few studies on the bioactive peptides from scorpion proteins have been mentioned [20].

Most of the functional characteristics of proteins play a significant role in the protein's physical and chemical properties in the processing, storage, preparation, and sale phase at different areas of economy [21,22]. Many factors, such as the protein's size, $\mathrm{pH}$, temperature, protein's shape, ionic strength, structure, amino acid sequence, composition, and charge distribution are very important factors of protein functionality. The conditions of the proteins at extraction and each stage of purification and drying are factors that must be taken into consideration $[23,24]$. Therefore, the aim of this study was to investigate some of physical and chemical parameters, like water solubility, emulsification, foaming properties, and oil-holding capacity of scorpion proteins. In order to reach of this goal, response surface methodology for the optimization of three parameters of ultrasonic extraction (UE) - ultrasonic power, solid/liquid ratio, and extraction time- are also investigated.

\section{Materials and Methods}

\subsection{Materials and Chemicals}

Scorpions (Buthus martensii Karsch) were collected (about 1000 pieces) in April in the Turpan region, Xinjiang, China, and after killing, they were put into plastic bottles and kept in a refrigerator. A Pierce BCA Protein Assay Kit was purchased from Thermo Scientific; electrophoresis reagents ware purchased from Biosharp Corporation (Beijing, China). All other chemicals were purchased from local suppliers.

The freeze drier was an FDU-1110 (EYELA Company, Tokyo, Japan), the high-speed refrigerated centrifuge was a CR22N (Hitachi Koki Co., Ltd., Tokyo, Japan), the refrigerated centrifuge was an 5417R (Eppendorf, Germany), and the large-capacity oscillator was an HY-8A (Millipore, Burlington, MA, USA). A Spectra Max M5 enzyme labeling analyzer (Bio-Tec Co., Ltd., USA) was also used.

\subsection{Total Extraction of Proteins from Scorpion Bodies}

Ten grams of dried scorpion were ground and separated through a 40-mesh separator. After that, separated powders $(8.2 \mathrm{~g})$ were subjected to de-oiling by petroleum ether $(150 \mathrm{~mL})$ in a continuous soxhlet extractor, until the solvent became colorless. The final residue was collected and air-dried. According to the following procedure, scorpion proteins (SPs) were extracted by (1) distilled water, (2) sodium chloride $(0.5 \mathrm{M})$, (3) phosphate buffer (PBS; $50 \mathrm{mM}, \mathrm{pH}=8.0$ ), and (4) isoelectric precipitation (adjusted $\mathrm{pH}$ to 9.0 with $1.0 \mathrm{~N} \mathrm{NaOH}$, and adjusted $\mathrm{pH}$ to 4.5 with $1.0 \mathrm{~N} \mathrm{HCl}$ to precipitate SPs) using an ultrasonic extraction method and a stirring extraction method (as a comparison) for $1 \mathrm{~h}$, respectively. This method was used for the first time by us. Scorpion proteins were extracted with an ultrasonic generator, and the ultrasonic power was $200 \mathrm{w}$. The extraction steps were repeated three times and dialyzed against distilled water for $48 \mathrm{~h}$ at $4{ }^{\circ} \mathrm{C}$ (F0136-1 Dialysis Membrane, MWCO 1000Da, United States). The obtained dialysates were lyophilized using a freeze drier (FDU-1110, EYELA Company, Tokyo, Japan) and kept at $-20^{\circ} \mathrm{C}$ until use. 


\subsection{Methods for the Determination of Protein Extraction Indexes}

\subsubsection{Determination of Protein Contents (\%)}

The protein content of lyophilized SPs was determined by the BCA (bicinchoninic acid) method [25]. Bovine serum albumin (BSA) was used as a standard. A total of $1.0 \mathrm{~mL}$ of distilled water was used to dissolve $1.0 \mathrm{~g}$ of sample, which was clarified through centrifugation at $4500 \times \mathrm{g}$ for $15 \mathrm{~min}$ at $4{ }^{\circ} \mathrm{C}$. According to the specification of the BCA protein measuring kit, the absorbance was read by an enzyme labeling instrument (Spectra Max M5 enzyme labeling analyzer) at $562 \mathrm{~nm}$. The average value of three parallel measurements was used to calculate the protein content.

\subsubsection{Determination of Yields (\%)}

The yield of SPs was determined using Equation (1):

$$
\text { Yield }(\%)=\frac{m_{S e}}{m_{S d}} \times 100 \%
$$

where $m_{S e}$ is the weight of scorpion protein extraction $(\mathrm{mg})$, and $m_{S d}$ is the weight of the defatted scorpion (mg).

\subsection{Single-Factor Experiments}

The influence of ultrasonic power $(\mathrm{w})$, extraction time (min) and liquid/solid ratio $(\mathrm{mL} / \mathrm{g})$ on protein content and yield of the UE were investigated. Based on the ultrasonic extraction and stirring extraction experiments, scorpion protein was extracted with $0.5 \mathrm{M} \mathrm{NaCl}$ buffer by the ultrasonic extraction method. The ultrasonic extraction time $(20,30,40,50$, and $60 \mathrm{~min})$, liquid/solid ratio $(5,10$, $15,20$, and $25 \mathrm{~mL} / \mathrm{g})$, and ultrasonic power $(50,100,200,300$, and $400 \mathrm{w})$ were tested.

\subsection{Gel Electrophoresis Analysis}

Gel electrophoresis (SDS-PAGE) of the SPs was done using 15\% acrylamide gel (Bio-Rad Mini-PROREAN Tetra System) [26]. Gel electrophoresis was carried out at $10 \mathrm{v} / \mathrm{cm}$ constant voltage. Coomassie Brilliant Blue R-250 dye was used for staining the protein bands for $1.5 \mathrm{~h}$, which were then de-stained in a decoloring solution for $1.5 \mathrm{~h}$ via shaking by large capacity oscillator (HY-8A).

\subsection{Box-Behnken of RSM and Statistical Analysis}

RSM is a statistical tool for solving multivariable problems by using reasonable experimental design method and obtaining certain data through experiments, and by analyzing regression equations to determine the optimal technological parameters [27]. In this study, the RSM and Box-Behnken design was used to optimize the extraction conditions. Based on the single-factor experiment, the complete design was made up of 17 runs, and these were done in triplicate to optimize the levels of the selected variables (extraction time, ultrasonic power, and liquid/solid ratio). For the statistical analysis, the three independent variables were coded as $X_{1}, X_{2}$, and $X_{3}$, respectively using Equation (2):

$$
x_{i}=\frac{X_{i}-X_{0}}{\Delta X_{i}}
$$

where $x_{i}$ is the coded value of an independent variable, $X_{i}$ is the real value of an independent variable, $X_{0}$ is the real value of an independent variable at the center point, and $\Delta X_{i}$ is the step change value.

The quadratic equation of the variables is as follows:

$$
Y=\beta_{0}+\sum \beta_{i} x_{i}+\sum \beta_{i i} x_{i}^{2}+\sum \beta_{i j} x_{i} x_{j}
$$


where $Y$ is the predicted response variable; $B_{0}, \beta_{i}, \beta_{i i}$, and $\beta_{i j}$ are the constant regression coefficients of the model; and $x_{i}$ and $x_{j}(i=1,3 ; j=1,3, i \neq j)$ represent the independent variables.

The accuracy and fitness of the above model were evaluated by the coefficient of determination $\left(R^{2}\right)$ and the $F$-value. Based on the above results, the second order polynomial coefficients were undertaken using Design Expert (Version 8.0.6, USA) software. The model was performed to evaluate the analysis of variance (ANOVA).

\subsection{Functional Properties}

The functional properties of de-oiled scorpion flour (DSF), stirring extraction (SE), and ultrasonic extraction (UE) have been tested at the optimal conditions.

\subsubsection{Protein Solubility Analyses}

Using the method from [28], with slight modification, the solubility of the protein was determined. A total of $200 \mathrm{mg}$ of SP was dissolved in $20 \mathrm{~mL}$ deionized water, and the $\mathrm{pH}$ was adjusted to 2, 3, 4, 5, 6, $7,8,9,10,11$, and 12 by $1.0 \mathrm{~mol} / \mathrm{L} \mathrm{HCl}$ and $1.0 \mathrm{~mol} / \mathrm{L} \mathrm{NaOH}$. After the $\mathrm{pH}$ was stabilized, it was stirred for $0.5 \mathrm{~h}$ at a speed of $8000 \mathrm{rpm} / \mathrm{min}$ for $20 \mathrm{~min}$; centrifugation was done to obtain the supernatant. Using the Bradford method [29], the protein content of the supernatant was determined. The value of each sample was measured three times, and the average value was taken. Protein solubility was calculated using the following formula:

$$
\text { Protein Solubility \% }=\left(\frac{m}{m_{T}}\right) \times 100 \%
$$

where $m$ is the protein content of the supernatant $(\mathrm{mg} / \mathrm{g})$, and $m_{T}$ is the content of total protein in $\mathrm{SP}(\mathrm{mg} / \mathrm{g})$.

\subsubsection{Foaming Properties}

The foaming capacity (FC) and foaming stability (FS) were carried out using the methods described previously, with minor modifications [24,30]. Using these methods, $0.2 \mathrm{~g}$ of SP was dissolved in $20 \mathrm{~mL}$ of distilled water $(w / v=1.0 \%)$, and the solution $\left(V_{0}\right)$ was stirred for $2.0 \mathrm{~min}$. The mixture was transferred immediately into a $50 \mathrm{~mL}$ tube, the initial foam volume was measured $\left(V_{1}\right)$, and the foam volume after standing for $30 \mathrm{~min}$ was also measured $\left(V_{3}\right)$. The FC was calculated using Equation (5):

$$
\mathrm{FC}(\%)=\left(\frac{V_{1}+V_{2}-V_{0}}{V_{0}}\right) \times 100 \%
$$

where $V_{2}$ is the volume of the liquid remaining just after stirring.

FS is calculated using the following formula:

$$
\mathrm{FS}(\%)=\frac{V_{3}}{V_{1}} \times 100 \%
$$

\subsubsection{Water Absorption Capacity (WAC)}

Using the method from [31], with slight modifications, water absorption capacity (WAC) was determined. Here, $1 \mathrm{~g}\left(W_{0}\right)$ of SP was weighed together with the centrifugal tube $\left(W_{1}\right)$. Thereafter, $10 \mathrm{~mL}$ of distilled water was added in the tube and mixed. After being held at room temperature for $30 \mathrm{~min}$, the emulsion was centrifuged at $2100 \times \mathrm{g}$ for $15 \mathrm{~min}$. In the end, the supernatant was decanted, and the tube with sediment was weighed $\left(W_{2}\right)$. Using Equation $(7)$, the WAC was calculated:

$$
\mathrm{WAC}=\frac{W_{2}-W_{1}}{W_{0}}
$$




\subsubsection{Oil Absorption Capacity (OAC)}

The oil absorption capacity (OAC) was determined using the method reported previously [31], with minor modifications. One gram $\left(F_{0}\right)$ of SP was weighed together with a centrifugal tube $\left(F_{1}\right)$ and mixed with $5 \mathrm{~mL}$ of corn oil. The emulsion was incubated at room temperature for $30 \mathrm{~min}$, and then centrifuged (Eppendorf centrifuge 4530R, Germany) at $3500 \mathrm{rpm} / \mathrm{min}$ for $15 \mathrm{~min}$ under the same conditions. The tube was reweighed $\left(F_{2}\right)$ after the removal of the supernatant. The OAC was determined using Equation (8):

$$
\mathrm{OAC}=\frac{F_{2}-F_{1}}{F_{0}}
$$

\subsubsection{Emulsifying Properties}

The emulsifying activity (EA) of the UE and SE was determined by the method described by Wu et al. [32], with slight modification. Here, $1.0 \mathrm{~g}$ of each SP was weighed and dissolved in $20 \mathrm{~mL}$ of distilled water and $20 \mathrm{~mL}$ of corn oil, and mixed at a high speed for $1 \mathrm{~min}$ at room temperature. The mixture was centrifuged at $4000 \mathrm{rpm}$ for $5 \mathrm{~min}$. The EA was calculated using Equation (9):

$$
\mathrm{EA}(\%)=\frac{h}{H} \times 100 \%
$$

where $h$ is the height of the emulsified layer and $H$ is the height of the tube contents.

The emulsion stability (ES) of UE and SE were determined using the method from [30], with slight modifications. One gram of each SP was weighed and dissolved with $20 \mathrm{~mL}$ of distilled water and $20 \mathrm{~mL}$ of corn oil, and thereafter mixed at a high speed for $2 \mathrm{~min}$ at room temperature. The mixture was centrifuged at $4000 \mathrm{rpm}$ for $5 \mathrm{~min}$. After preparation, $30 \mathrm{~mL}$ of emulsions was then transferred into test tubes, and the emulsions were stored at room temperature; they separated into a top oil layer and a bottom serum layer over time. The ES was evaluated using Equation (10):

$$
\mathrm{ES}(\%)=\frac{H_{s}}{H_{t}} \times 100 \%
$$

where $H_{s}$ is the height of bottom serum layer $(\mathrm{mm})$ and $H_{t}$ is the total height of emulsion in the tube (mm).

\subsection{Scanning Electron Microscopy (SEM) Analysis}

To study the effect of scorpion protein extraction technology on protein content and yield, we analyzed SPs by scanning electron microscopy (SEM; SUPRA 55VP, ZEISS). The morphology and surface characteristics of the SPs were observed and recorded by SEM after the samples were fixed on silicon wafers and sputtered by gold.

\subsection{Statistical Analysis}

The experiments were performed with three independent trials, and all the determinations were triplicated. The results were represented as mean \pm standard deviation. Analysis of variance (ANOVA) was performed to identify significant differences $(p<0.05)$.

\section{Results and Discussion}

\subsection{Analysis of Scorpion Protein Extraction Method}

In this study, the effects of diverse buffer solutions for the extraction of scorpion protein were studied. Meanwhile, the effects of ultrasonic extraction (this method is used to increase the yield of protein), as well as stirring extraction of the yield (\%) and protein content (\%) were compared. Figure 1 and Table 1 show that the order of the effects of four buffer solutions on yield and protein 
content was $0.5 \mathrm{M} \mathrm{NaCl}>20 \mathrm{mM} \mathrm{PBS}>0.02 \mathrm{M} \mathrm{NaOH}>$ water. The $0.5 \mathrm{M} \mathrm{NaCl}$ buffer solution (yield $14.64 \pm 0.08 \%$, protein content $79.06 \pm 0.05 \%$ ) with ultrasonic was better than other buffers for extracting scorpion protein, followed by $20 \mathrm{mM}$ PBS (yield $18.29 \pm 0.05 \%$, protein content $60.98 \pm 0.07 \%$ ).

Stirring extraction

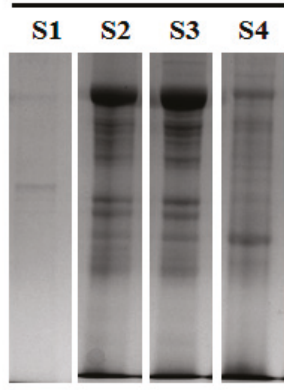

Ultrasonic extraction

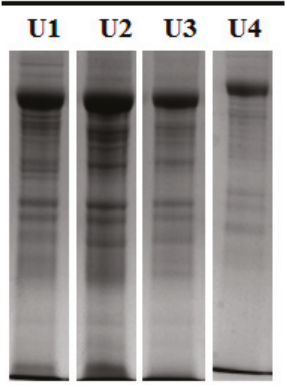

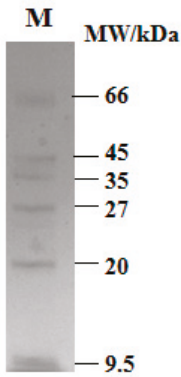

Figure 1. SDS-PAGE electrophoresis of scorpion proteins with different extractions and buffer conditions. $\mathrm{M}$ refers to the marker; S1, S2, S3, and S4 are scorpion proteins extracted by stirring with water, $0.5 \mathrm{M}$ $\mathrm{NaCl}, 20 \mathrm{mM}$ phosphate buffer (PBS), alkali extraction, and isoelectric precipitation, respectively; U1, $\mathrm{U} 2, \mathrm{U} 3$, and $\mathrm{U} 4$ are scorpion proteins extracted by ultrasonic with water, $0.5 \mathrm{M} \mathrm{NaCl}, 20 \mathrm{mM}$ PBS, alkali extraction, and isoelectric precipitation, respectively.

Table 1. Effects of ultrasonic and stirring methods on extraction of total proteins from scorpion body.

\begin{tabular}{lcccc}
\hline \multirow{2}{*}{ Extraction Method } & \multicolumn{2}{c}{ Yield (\%) } & \multicolumn{2}{c}{ Protein Content (\%) } \\
\cline { 2 - 5 } & Ultrasonic Extraction & Stirring Extraction & Ultrasonic Extraction & Stirring Extraction \\
\hline Water & $34.85 \pm 0.06$ & $34.15 \pm 0.09$ & $31.14 \pm 0.04$ & $18.08 \pm 0.06$ \\
$0.5 \mathrm{M} \mathrm{NaCl}$ & $14.64 \pm 0.08$ & $11.80 \pm 0.03$ & $79.06 \pm 0.05$ & $35.26 \pm 0.08$ \\
$20 \mathrm{mM} \mathrm{PBS}$ & $18.29 \pm 0.05$ & $13.45 \pm 0.10$ & $60.98 \pm 0.07$ & $37.25 \pm 0.09$ \\
$0.02 \mathrm{M} \mathrm{NaOH}$ & $7.70 \pm 0.11$ & $7.57 \pm 0.13$ & $50.87 \pm 0.07$ & $51.91 \pm 0.17$ \\
\hline
\end{tabular}

\subsection{Analysis of a Single Factor Results}

\subsubsection{Effect of Extraction Time on Yield and Protein Content}

Extraction time plays a key role in protein extraction [32]. In this experiment, the effect of extraction time on the yield and protein content is examined. For that, ultrasound power was $200 \mathrm{~W}$, the liquid/solid ratio was 15 , and extraction time was carried out in a range between $20-60 \mathrm{~min}$. The results obtained are shown in Figure 2A. Obtained data show that with the increase of ultrasonic extraction time, the yield and protein content rapidly increased and reached a maximum at $50 \mathrm{~min}$, at $17.95 \%$ and $66.35 \%$, respectively. A further increase of time did not affect the yield and amount of protein.
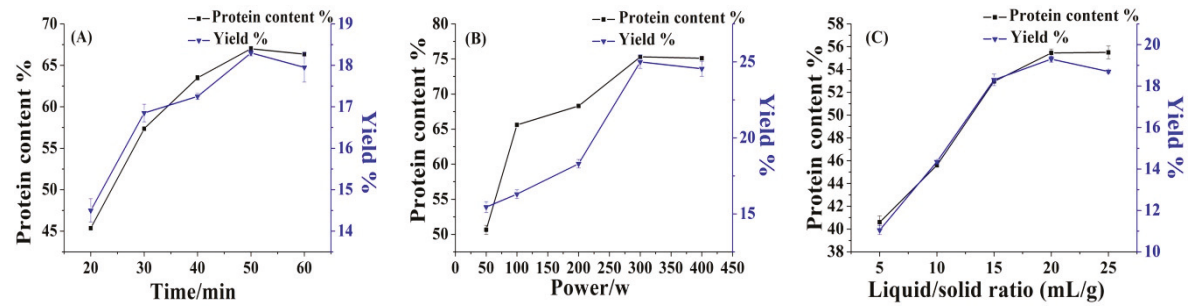

Figure 2. Effects of extraction time (A), ultrasonic power (B), and liquid/solid ratio (C) on yield and protein content. 


\subsubsection{Effect of Ultrasonic Power on Yield and Protein Content}

In this experiment, the effect of ultrasonic power on the yield and protein content was examined. For that, the extraction time was $50 \mathrm{~min}$, the liquid/solid ratio $(\mathrm{mL} / \mathrm{g})$ was 15 , and the ultrasonic power was evaluated in the range 50-400 w. The results obtained are shown in Figure 2B. The obtained data show that with an increase in power, the yield and protein content increased rapidly, and reached their maximums at $300 \mathrm{w}$, at $23.60 \%$ and $75.30 \%$, respectively; in addition, a further increase of time did not affect the yield and amount of protein.

\subsubsection{Effect of Liquid/Solid Ratio on Yield and Protein Content}

In this experiment, the effect of the liquid/solid ratio on the yield and protein content is examined. For that, ultrasound power was $200 \mathrm{w}$, extraction time was $50 \mathrm{~min}$, and the liquid/solid ratio was evaluated in the range between $5-25 \mathrm{~mL} / \mathrm{g}$. The results obtained are shown in Figure $2 \mathrm{C}$. The obtained data show that with the increase of liquid/solid ratio to the $15 \mathrm{~mL} / \mathrm{g}$ the yield, protein content rapidly increased, and when the ratio reached to $20 \mathrm{~mL} / \mathrm{g}$, a slower increase can be seen, reaching maximums of $19.21 \%$ and $55.32 \%$, respectively. A further increase of time did not affect the yield and amount of protein.

\subsection{Optimization of Extraction Parameters by RSM}

Table 2 shows that there was a significant change in protein content and yield at different values of the selected parameters. Using Equation (3), the results were analyzed. After multiple regressions fitting with Design-Expert V8.0.6 software, the regression model equation is as follows:

$$
\begin{aligned}
& Y_{1}=56.43+7.25 A+0.066 B+7.69 C+4.80 A B+4.97 A C+4.67 B C+2.14 A^{2}+1.28 B^{2}-3.18 C^{2} \\
& Y_{2}=19.46+0.86 A+0.75 B+1.93 C+1.14 A B+1.80 A C+1.72 B C+0.31 A^{2}-1.64 B^{2}-0.26 C^{2}
\end{aligned}
$$

where $Y_{1}$ and $Y_{2}$ are the predicted conversion (\%) of protein content and yield, respectively; and $A$, $B$, and $C$ are the extraction time $\left(X_{1}, \mathrm{~min}\right)$, liquid/solid ratio $\left(X_{2}, \mathrm{~mL} / \mathrm{g}\right)$, and ultrasonic power $\left(X_{3}\right.$, w), respectively.

When the factor sign is positive, it shows that the amount of the response variable increases with an increase in its value, and vice versa. Figure $3 \mathrm{~A}, \mathrm{C}$ can also be used to compare the model predicted and the experimental results. Figure $3 \mathrm{~B}, \mathrm{D}$ is the normal probability chart indicating that the points follow a narrow linear pattern. The analysis of variance of the regression equation is shown in Table 3. $F$ is the value of the regression model, where the protein content and yield were 17.49 and 34.12 and the $p$-values were 0.0005 and $<0.0001$, respectively. These values show that the model obtained was significant. The $F$-value and $p$-value for the lack of fit of the protein content and yield were 1.54 and 2.04 , respectively, and 0.3354 and 0.2506 , respectively, which shows that the equation has a good fitting degree and high reliability. In addition, the decision coefficients $\left(R^{2}\right)$ of the model were 0.9574 and 0.9777 , respectively, and the adjusted coefficients of determination (Adj- $R^{2}$ ) were 0.9027 and 0.9491 , respectively. The values of $R^{2}$ and adjusted $R^{2}$ for the models are shown in Table 3, which shows that the regression equation can predict the result of extracting scorpion protein accurately. 

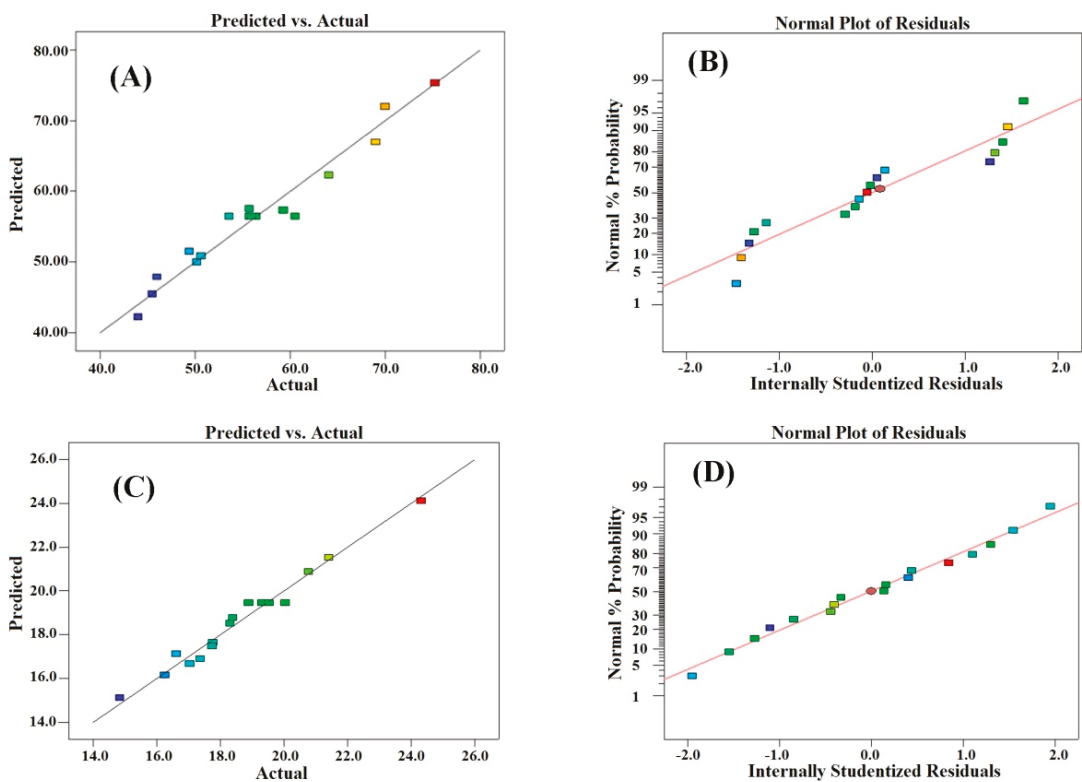

Figure 3. Standard statistical diagrams for model verification. (A,C) Model-predicted values versus actual data. This figure shows a comparison between the model-predicted values and the actual values that have been obtained by the experiments. (B,D) Normal probability plot of the residuals. Monotonous distribution and linearity of the data, which are obvious from these figures, confirm the validity of the model and its capability to predict the results.

Table 2. RSM experimental design and results for the three-factor/three-level Box-Behnken design (BBD).

\begin{tabular}{cccccc}
\hline Runs & $\begin{array}{c}\text { Extraction } \\
\text { Time }(\mathbf{m i n}) \boldsymbol{X}_{\mathbf{1}}\end{array}$ & $\begin{array}{c}\text { Liquid/Solid } \\
\text { Ratio }(\mathbf{m L} / \mathbf{g}) \boldsymbol{X}_{\mathbf{2}}\end{array}$ & $\begin{array}{c}\text { Ultrasonic } \\
\text { Power }(\mathbf{W}) \boldsymbol{X}_{\mathbf{3}}\end{array}$ & $\begin{array}{c}\text { Protein } \\
\text { Content/\% }\end{array}$ & Yield /\% \\
\hline 1 & 60 & 15 & 400 & 75.23 & 24.32 \\
2 & 40 & 20 & 400 & 69.01 & 21.41 \\
3 & 20 & 10 & 300 & 59.31 & 17.76 \\
4 & 40 & 15 & 300 & 55.98 & 19.53 \\
5 & 40 & 15 & 300 & 56.39 & 18.89 \\
6 & 60 & 10 & 300 & 64.09 & 16.62 \\
7 & 40 & 20 & 200 & 44.01 & 14.84 \\
8 & 40 & 10 & 200 & 49.4 & 16.25 \\
9 & 60 & 15 & 200 & 50.17 & 17.04 \\
10 & 40 & 10 & 400 & 55.70 & 17.74 \\
11 & 40 & 15 & 300 & 55.70 & 19.31 \\
12 & 60 & 20 & 300 & 70.00 & 20.78 \\
13 & 40 & 15 & 300 & 53.58 & 19.52 \\
14 & 20 & 20 & 300 & 46.01 & 17.37 \\
15 & 20 & 15 & 200 & 45.49 & 18.31 \\
16 & 20 & 15 & 400 & 50.66 & 18.39 \\
17 & 40 & 15 & 300 & 60.52 & 20.04 \\
\hline
\end{tabular}


Table 3. Least-squares fit and parameter estimates (significance of regression coefficient).

\begin{tabular}{lcccc}
\hline \multirow{2}{*}{ Source } & \multicolumn{2}{c}{ Protein Content } & \multicolumn{2}{c}{ Yield } \\
\cline { 2 - 5 } & $\boldsymbol{F}$-Value & $\boldsymbol{p}$-Value & $\boldsymbol{F}$-Value & $\boldsymbol{p}$-Value \\
\hline Model & 17.49 & 0.0005 & 34.12 & $<0.0001$ \\
$X_{1}$ & 53.50 & 0.0002 & 23.98 & 0.0018 \\
$X_{2}$ & 4.46 & 0.9486 & 18.15 & 0.0037 \\
$X_{3}$ & 60.17 & 0.0001 & 118.71 & $<0.0001$ \\
$X_{1} \times 2$ & 11.73 & 0.0111 & 20.67 & 0.0026 \\
$X_{1} \times 3$ & 12.57 & 0.0094 & 51.76 & 0.0002 \\
$X_{2} \times 3$ & 11.11 & 0.0125 & 25.77 & 0.0014 \\
$X_{1}{ }^{2}$ & 2.45 & 0.1617 & 1.67 & 0.2378 \\
$X_{2}{ }^{2}$ & 0.88 & 0.3800 & 45.25 & 0.0003 \\
$X_{3}{ }^{2}$ & 5.43 & 0.0526 & 1.12 & 0.3256 \\
Lack of Fit & 1.54 & 0.3354 & 2.04 & 0.2506 \\
$R^{2}$ & 0.9574 & & 0.9777 & \\
Adj- $R^{2}$ & 0.9027 & & 0.9491 & \\
\hline
\end{tabular}

3.3.1. Analysis of the Influence of Various Factors on the Extraction of Scorpion Proteins

The degree of influence of each factor on the test index can be compared by the $F$-value (Table 4 ): $F\left(X_{1}\right)=53.50,23.98 ; F\left(X_{2}\right)=4.46,18.15 ; F\left(X_{3}\right)=60.17,118.71$. These values indicate that the order of influence of each factor on the extraction of scorpion protein was ultrasonic power $(\mathrm{w})>$ extraction time $(\mathrm{min})>$ liquid/solid ratio $(\mathrm{mL} / \mathrm{g})$. The response surface can describe the interaction between variables and predict the optimal conditional values of each factor [33]. Figure 4A-F shows the effect of operational variables on protein content and yield protein content and yield. The effect of extraction time on the protein process is greater than that of the ratio of the liquid/solid, and that of ultrasonic power is greater than that of extraction time. According to the above analysis, the order of the influence of each variable on the extraction technology of scorpion protein was ultrasonic power $>$ extraction time $>$ liquid/solid ratio.

\subsubsection{Interactions of Variables}

Contour plots for each of the fitted models that display the effects of the three variables (to visualize the combined effects of the three factors on protein content and yield) were generated. Figure 4 illustrates the two-dimensional (2D) plots of the binary interactions of the variables on protein content and yield via the contour plots. The interaction between the extraction time and the liquid/solid ratio is shown in Figure 4A,D. This plot indicates that protein content and yield depend more on $X_{1}$ than on $X_{2}$. Figure $4 \mathrm{~A}, \mathrm{D}$ reveals that at low values of $X_{1}$, maximum protein content and yield occurs at higher values of $X_{2}$. However, at higher values of $X_{1}$, maximum protein content and yield occurs at lower values of $X_{2}$. As seen in Figure 4A,D, the interaction between the two factors is weak. The interaction between the extraction time and ultrasonic power is shown in Figure 4B,E. This plot indicates that protein content and yield depend more on $X_{3}$ than on $X_{1}$. In Figure 4C,F, the effect of the interaction between the liquid/solid ratio and ultrasonic power is depicted. Figure 4C,F shows that increasing the liquid/solid ratio at different ultrasonic power levels has no important effect on the protein content and yield, so the plot shows that protein content and yield depends more on $X_{3}$ than on $X_{2}$. Therefore, the optimum values of $X_{1}, X_{2}$, and $X_{3}$, as determined by the software, are $50 \mathrm{~min}, 400 \mathrm{w}$, and $18 \mathrm{~mL} / \mathrm{g}$, respectively. 

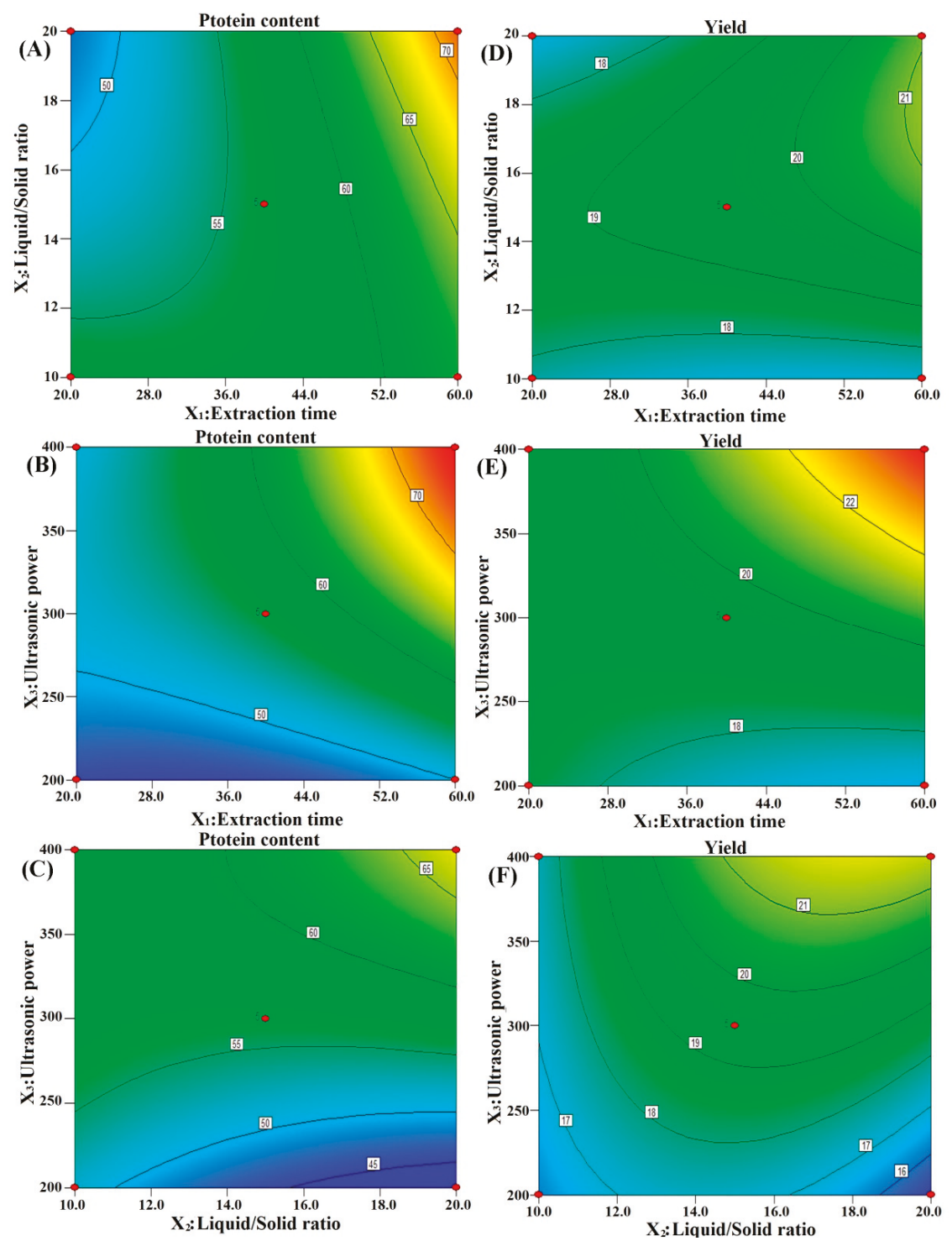

Figure 4. Effects of operational variables on protein content and yield. Interaction between (A) liquid/ solid ratio and extraction time, (B) ultrasonic power and extraction time, and (C) ultrasonic power and liquid/solid ratio to protein content. Also depicted are the interaction between the (D) liquid/solid ratio and extraction time, (E) ultrasonic power and extraction time, and (F) ultrasonic power and liquid/solid ratio to yield.

\subsubsection{Determination and Validation of Optimal Extraction Conditions}

Optimum conditions, which were obtained by Design-Expert V8.0.6 software, were as follows: extraction time $=47.68 \mathrm{~min}$; ultrasonic power $=395.84 \mathrm{w}$; and solid $/$ liquid ratios $=18.01 \mathrm{~mL} / \mathrm{g}$. In view of the feasibility of the experiment, the optimum conditions of extraction proteins were adjusted as follows: extraction time $=50.00 \mathrm{~min}$, ultrasonic power $=400 \mathrm{w}$, and solid/liquid ratio $=18.00 \mathrm{~mL} / \mathrm{g}$. 
After several tests $(n>3)$, the protein content and yield were $78.94 \%$, and $24.80 \%$, respectively. It is shown that the regression equation and the optimal conditions obtained by the response surface method are reliable.

\subsection{Functional Properties of Scorpion Proteins}

\subsubsection{Protein Solubility (PS)}

The protein solubility (PS) profiles of de-oiled scorpion flour (DSF), ultrasonic extraction (UE), and stirring extraction (SE) in the water at different $\mathrm{pH}$ ranges (2-12) are shown in Figure 5. The PS of DSF, UE, and SE were significantly different, and Figure 5 shows the same U-shaped curves. When the $\mathrm{pH}$ value is in the range of 2-4, the solubility of DSF, UE, and SE decreased; however, when in the $\mathrm{pH}$ range of 6-10, the solubility of DSF, UE, and SE significantly increased. The minimum protein solubility of DSF, UE, and SE were presented at $\mathrm{pH} 4$, with values of $8.05 \%, 15.25 \%$, and $18.75 \%$, respectively. The maximum protein solubility was presented at $\mathrm{pH} 12$, with values of $13.5 \%, 70.15 \%$, and $79.5 \%$, respectively. Therefore, results indicate that scorpion protein extracted by ultrasonic method shows exceptional solubility at an alkaline $\mathrm{pH}$.

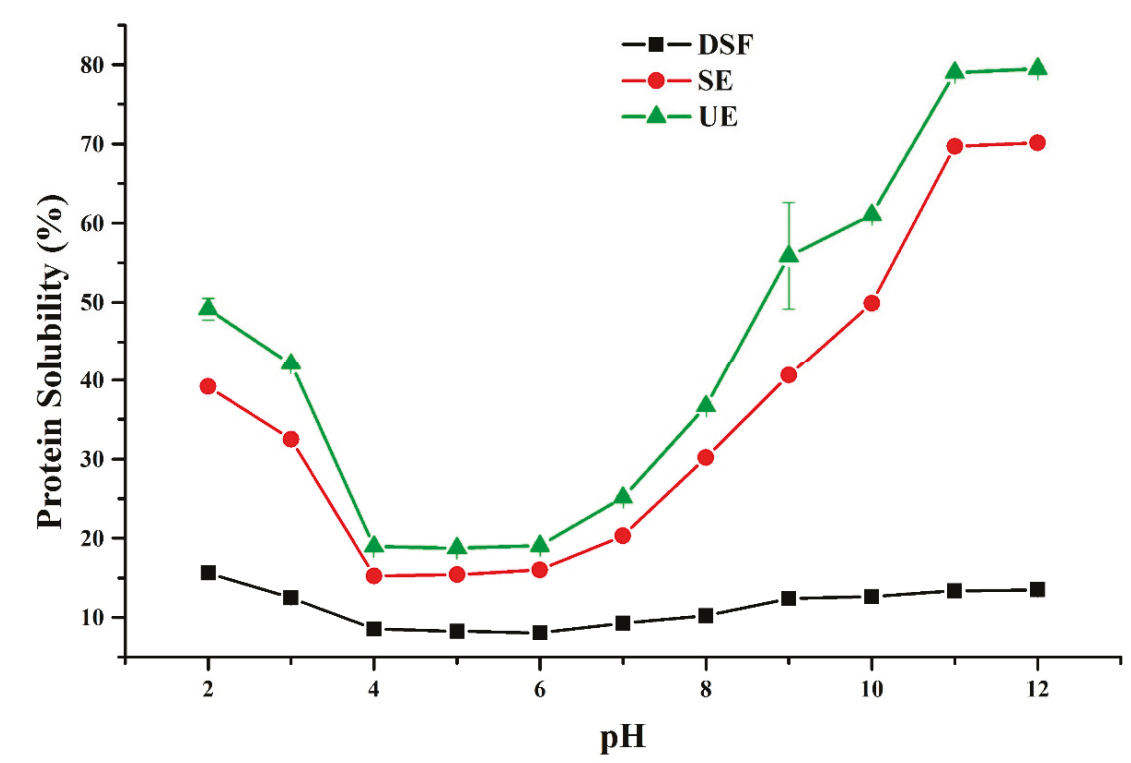

Figure 5. Protein solubility profiles of de-oiled scorpion flour (DSF), stirring extraction (SE), and ultrasonic extraction (UE) at different $\mathrm{pH}$ levels.

\subsubsection{Water and Oil Absorption Capacity}

The obtained results for the water absorption capacity (WAC) and oil absorption capacity (OAC) of proteins extracted by ultrasonic and stirring are presented in Table 4. The WAC and OAC from both methods were significantly different $(p<0.05)$, with UE having the higher WAC $(40.3 \pm 0.28 \mathrm{~g} / \mathrm{g})$ and $\mathrm{OAC}(27.70 \pm 0.14 \mathrm{~g} / \mathrm{g}$ ) than SE (with WAC $=33.45 \pm 0.07 \mathrm{~g} / \mathrm{g}$ and $\mathrm{OAC}=18.80 \pm 0.15 \mathrm{~g} / \mathrm{g}$ ) at $\mathrm{pH} 7.0$. 
Table 4. Functional properties of scorpion proteins.

\begin{tabular}{lcc}
\hline \multicolumn{1}{c}{ Properties } & Ultrasonic Extraction & Stirring Extraction \\
\hline Water holding capacity (g/g) & $25.25 \pm 0.21$ & $20.45 \pm 0.07$ \\
Oil holding capacity (g/g) & $38.50 \pm 0.14$ & $30.65 \pm 0.64$ \\
Emulsifying activity (\%) & $45.55 \pm 0.64$ & $40.25 \pm 0.07$ \\
Emulsion stability (\%) & $85.50 \pm 0.28$ & $69.45 \pm 0.35$ \\
Foam capacity (\%) & $40.30 \pm 0.28$ & $33.45 \pm 0.07$ \\
Foam stability (\%) & $21.70 \pm 0.14$ & $18.80 \pm 0.15$ \\
\hline
\end{tabular}

\subsubsection{Emulsifying Properties}

Charged or non-charged polar amino acids in proteins can affect the proteins' emulsifying and surfactant properties. Results of emulsifying properties of UE and SE are shown in Table 4. At pH 7.0, the emulsifying properties of UE and SE were significantly different from one another, with values of $45.55 \pm 0.64 \%$ and $40.25 \pm 0.07 \%$, respectively. However, the emulsifying property of UE was significantly different and was higher $(85.50 \pm 0.28 \%)$ than that of SE $(69.45 \pm 0.35 \%)$. The UE had pronounced effects on the emulsifying properties, since it might be exposing more hydrophobic groups to the water and oil interface, giving rise to increased emulsifying capacity and more stable emulsion.

\subsubsection{Foaming Properties}

Foam formation is similar to emulsion formation. In foam formation, water molecules surround air droplets, which is a nonpolar phase. At pH 7, the foam capacity (FC) of UE was considerably higher than that of SE, with values of $40.30 \pm 0.28 \%$ and $33.45 \pm 0.07 \%$, respectively. The foam stability (FS) of UE was significantly higher than that of SE, with values of $21.70 \pm 0.14 \%$ and $18.80 \pm 0.15 \%$, respectively (Table 4). The results obtained show that the UE, compared to SE, has more flexible protein structure in aqueous solution, and forms more stable foams for stronger interaction on the air-water interface. The variations in foaming properties of UE and SE might be explained with the difference in their protein concentrations. A high protein concentration will improve foam capacity and stability, increasing the viscosity and promoting the formation of the interfacial multilayer membrane [34].

\subsection{Scanning Electron Microscopy Analysis}

Protein samples obtained using various extraction methods were investigated by the SEM method. Figure 6 shows the surface states of protein samples extracted from whole-body, de-oiled protein (DSF) powder, stirred extraction (SE), and ultrasonic extraction (UE). These studies focused on the study of the surface layer of protein molecules. Accordingly, in Figure 6A, adhesive surface layers of protein molecules in dried DSF can be seen. This state has a collapsed form, which shows the density of protein molecules in relation to one other; therefore, these molecules have a higher crystalline degree than other states, and this will result in lower water solubility. In Figure 6B, on the surface of dried SE protein layers, a plurality of elements similar to "wood shavings" can be seen, in contrast to Figure 6A. These elements formed as a result of separation from the collapsed surface. This means that during drying after SE, from the crystalline state shown in Figure 6A, the protein molecules transition from a crystalline to amorphous state, as shown in Figure 6B; the outcome of this results in an increase in the solubility of the protein molecules in water. Also, in Figure 6C, you can see the results of the drying of protein molecules obtained after UE. This picture clearly shows the increase the number of "wood shavings" on the surface, compared to Figure 6B, and how the transformation collapse forms into thin film pieces. Therefore, UE leads to the formation of scorpion protein molecules from a crystalline state to an amorphous one, which results in an increase of their water solubility. 

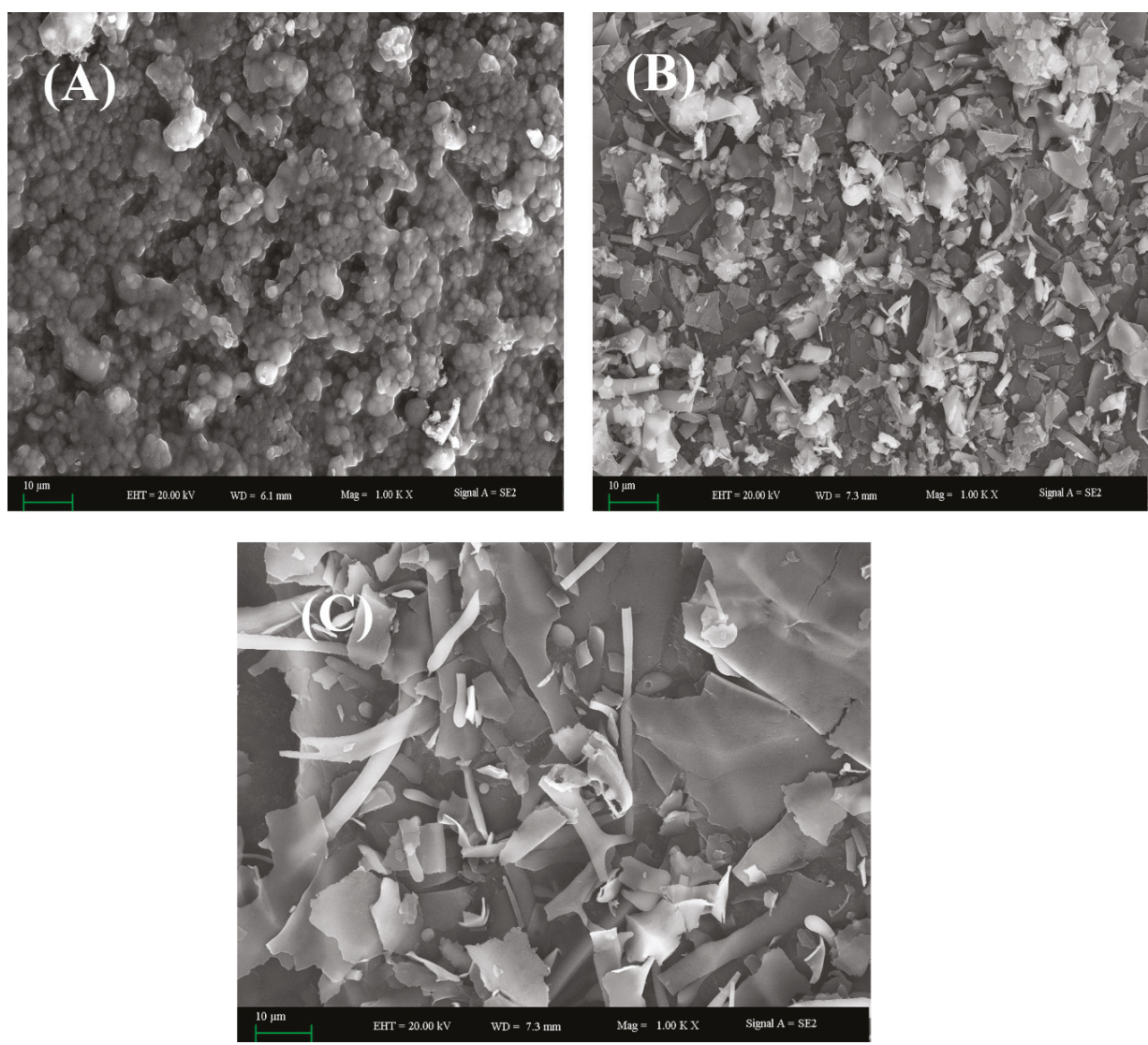

Figure 6. Scanning electron microscope images of (A) DSF, (B) SE, and (C) UE. (1.00 KX magnifications, bar $10 \mu \mathrm{m})$.

\section{Conclusions}

Studies have shown that the sum of proteins extracted from scorpion bodies had good emulsifying and foaming properties. At the same time, when they were subjected to extraction under different conditions, UE was found to be the best way to obtain the sum of proteins with improved water solubility. According to SEM analysis, the improvement of water solubility of the sum of protein components is accompanied by the transition of these macromolecules from the collapsed and crystalline form to a more amorphous and friable phase. For the extraction of scorpion body parts, some simple ways, i.e., cold water, hot water, and ethanol extraction methods used previously $[35,36]$ were used, and SPs obtained by these methods were physiologically effective for the treatment of various diseases. However, we think that using hot water or ethanol solvents may generally result in the denaturation of native compounds and reduce the real activities of the extracted SPs. Therefore, using UE in an alternative way, at the optimal conditions of UE (i.e., $X_{1}, X_{2}$, and $X_{3}$ are $50 \mathrm{~min}, 400 \mathrm{w}$, and $18 \mathrm{~mL} / \mathrm{g}$, respectively) resulted in increased water solubility and improvement of its emulsifying and foaming properties. In our opinion, the SPs obtained by the UE way should keep a number of their above-mentioned activities, and will be planned for use in creating medicines on that basis in TCM. On the other hand, UE could be the basis for the creation of water-soluble supramolecular complexes for those drugs that are poorly soluble in water. Obtaining such drugs in this way will contribute in the 
future to (1) an increase the drugs' water solubility, (2) a reduction their therapeutic doses, (c) increase pharmacological action, and (d) reduce toxicity and side effects. Since the sum of proteins from the scorpion body are not individual components, it might be promising, if created in their base gel drug forms, that they could be used through the skin.

Author Contributions: Project administration, A.Y., H.A.A.; Investigation, A.W.(Ahmidin Wali), A.A. and A.O.; Methodology, A.W.(Atikan Wubulikasimu) and Y.G.; Formal analysis, S.M.

Funding: This research was funded by the Program for National Science and Technology Major Project of China, grant number 2017ZX09301045 and "the light of the western" talent training plan: Planting of Hotan Rose and Its Polyphenols Application, Standardized Planting Techniques of Repellent Vernonia and Its Collection, Preservation and Popularization; It is also supported by the PIFI Fund of the Chinese Academy of Sciences for invited scientists, grant number 2019VBA0013 and Central Asian Drug Research and Development Center of the Chinese Academy of Sciences.

Conflicts of Interest: The authors declare no conflict of interest.

\section{References}

1. Cologna, C.T.; Silvana, M.; Giglio, J.R.; Soares, A.M.; Arantes, E.C. Tityus serrulatus scorpion venom and toxins: An overview. Protein Pept. Lett. 2009, 16, 920-932. [CrossRef]

2. Asmari, A.K.A.; Zahrani, A.G.A.; Said, A.J.; Mohammed, A. Clinical aspects and frequency of scorpion stings in the Riyadh Region of Saudi Arabia. Saudi Med. J. 2012, 33, 852-858. [PubMed]

3. Shi, L.; Zhang, T.X.; Du, C.Y.; Yuan, R.; Wang, C.C.; Li, F. Research Progress on Chemical Constituents, Pharmacological Effects and Clinical Applications of Scorpio. J. Liaoning Univ. Tradit. Chin. Med. 2015, 4, 31.

4. Yu, M.; Liu, S.L.; Sun, P.B.; Pan, H.; Tian, C.L.; Zhang, L.H. Peptide toxins and small-molecule blockers of BK channels. Acta Pharmacol. Sin. 2016, 37, 56-66. [CrossRef] [PubMed]

5. Machado, R.J.A.; Estrela, A.B.; Nascimento, A.K.L.; Melo, M.M.A.; Torres-Rêgo, M.; Lima, E.O.; Rocha, H.A.O.; Carvalho, E.; Silva-Junior, A.A.; Fernandes-Pedrosa, M.F. Characterization of TistH, a multifunctional peptide from the scorpion Tityus stigmurus: Structure, cytotoxicity and antimicrobial activity. Toxicon Off. J. Int. Soc. Toxinol. 2016, 119, 362-370. [CrossRef]

6. Ortiz, E.; Gurrola, G.B.; Schwartz, E.F.; Possani, L.D. Scorpion venom components as potential candidates for drug development. Toxicon 2015, 93, 125-135. [CrossRef]

7. Melo, E.T.D.; Estrela, A.B.; Santos, E.C.G.; Machado, P.R.L.; Farias, K.J.S.; Torres, T.M.; Carvalho, E.; Lima, J.P.M.S.; Silva-Júnior, A.A.; Barbosa, E.G. Structural characterization of a novel peptide with antimicrobial activity from the venom gland of the scorpion Tityus stigmurus: Stigmurin. Peptides 2015, 68, 3-10. [CrossRef]

8. Amorim, F.G.; Cordeiro, F.A.; Pinheiro-Júnior, E.L.; Boldrini-França, J.; Arantes, E.C. Microbial production of toxins from the scorpion venom: Properties and applications. Appl. Microbiol. Biotechnol. 2018, 102, 6319-6331. [CrossRef]

9. Pimenta, A.M.; StöCklin, R.; Favreau, P.; Bougis, P.E.; Martin-Eauclaire, M.F. Moving pieces in a proteomic puzzle: Mass fingerprinting of toxic fractions from the venom of Tityus serrulatus (Scorpiones, Buthidae). Rapid Commun. Mass Spectrom. Rcm 2010, 15, 1562-1572. [CrossRef]

10. Shao, J.; Rong, Z.; Xin, G.; Yang, B.; Zhang, J. Analgesic Peptides in Buthus martensii Karsch: A Traditional Chinese Animal Medicine The Analgesic Peptides in Scorpion Venoms. Asian J. Tradit. Med. 2007, 2, 45-50.

11. Pei, W.; Jie, T.; Yi, Z. Recombinant Expression and Functional Characterization of Martentoxin: A Selective Inhibitor for BK Channel $(\alpha+\beta 4)$. Toxins 2014, 6, 1419-1433.

12. Goudet, C.; Chi, C.W.; Tytgat, J. An overview of toxins and genes from the venom of the Asian scorpion Buthus martensi Karsch. Toxicon 2002, 40, 1239-1258. [CrossRef]

13. Gupta, S.D.; Debnath, A.; Saha, A.; Giri, B.; Tripathi, G.; Vedasiromoni, J.R.; Gomes, A.; Gomes, A. Indian black scorpion (Heterometrus bengalensis Koch) venom induced antiproliferative and apoptogenic activity against human leukemic cell lines U937 and K562. Leuk. Res. 2007, 31, 817-825. [CrossRef] [PubMed]

14. Díaz-García, A.; Morier-Díaz, L.; Frión-Herrera, Y.; Rodríguez-Sánchez, H.; Caballero-Lorenzo, Y.; Mendoza-Llanes, D.; Riquenes-Garlobo, Y.; Fraga-Castro, J.A. In vitro anticancer effect of venom from Cuban scorpion Rhopalurus junceus against a panel of human cancer cell lines. J. Venom Res. 2013, 4, 5-12. 
15. Guo, X.; Ma, C.; Du, Q.; Wei, R.; Wang, L.; Zhou, M.; Chen, T.; Shaw, C. Two peptides, TsAP-1 and TsAP-2, from the venom of the Brazilian yellow scorpion, Tityus serrulatus: Evaluation of their antimicrobial and anticancer activities. Biochimie 2013, 95, 1784-1794. [CrossRef]

16. He, Y.; Zhao, R.; Di, Z.; Li, Z.; Xu, X.; Hong, W.; Wu, Y.; Zhao, H.; Li, W.; Cao, Z. Molecular diversity of Chaerilidae venom peptides reveals the dynamic evolution of scorpion venom components from Buthidae to non-Buthidae. J. Proteom. 2013, 89, 1-14. [CrossRef]

17. Ali, S.A.; Alam, M.; Abbasi, A.; Kalbacher, H.; Schaechinger, T.J.; Hu, Y.; Zhijian, C.; Li, W.; Voelter, W. Structure-Activity Relationship of a Highly Selective Peptidyl Inhibitor of Kv1.3 Voltage-Gated $\mathrm{K}^{+}$-Channel from Scorpion (B. sindicus) Venom. Int. J. Pept. Res. 2014, 20, 19-32. [CrossRef]

18. Hoang, N.A.; Maksimov, G.V.; Berezin, B.B.; Piskarev, V.E.; Yamskov, I.A. Isolation of toxins from buthus occitanus sp. scorpion and their action on excitability of myelinated nerve. Bull. Exp. Biol. Med. 2001, 132, 953-955. [CrossRef]

19. Hoang, N.A.; Berezin, B.B.; Lakhtin, V.M.; Yamskov, I.A. Isolation and partial characterization of lectin from the venom of vietnamese scorpion buthus occitanussp. Appl. Biochem. Microbiol. 2001, 37, 534-537. [CrossRef]

20. Ren, Y.; Wu, H.; Lai, F.; Yang, M.; Li, X.; Tang, Y. Isolation and identification of a novel anticoagulant peptide from enzymatic hydrolysates of scorpion (buthus martensii karsch) protein. Food Res. Int. 2014, 64, 931-938. [CrossRef]

21. Ma, T.; Zhu, H.; Jing, W.; Qiang, W.; Yu, L.; Sun, B. Influence of extraction and solubilizing treatments on the molecular structure and functional properties of peanut protein. Lwt Food Sci. Technol. 2017, 79, 197-204. [CrossRef]

22. Ahmedna, M.; Prinyawiwatkul, W.; Rao, R.M. Solubilized wheat protein isolate: Functional properties and potential food applications. J. Agric. Food Chem. 1999, 47, 1340-1345. [CrossRef] [PubMed]

23. Zhang, Y.; Zhang, J.; Sheng, W.; Wang, S.; Fu, T.J. Effects of heat and high-pressure treatments on the solubility and immunoreactivity of almond proteins. Food Chem. 2015, 199, 856-861. [CrossRef] [PubMed]

24. Thaiphanit, S.; Anprung, P. Physicochemical and emulsion properties of edible protein concentrate from coconut (Cocos nucifera L.) processing by-products and the influence of heat treatment. Food Hydrocoll. 2016, 52, 756-765. [CrossRef]

25. Feng, X.L.; Liu, H.Z.; Shi, A.M.; Liu, L.; Wang, Q.; Adhikari, B. Effects of transglutaminase catalyzed crosslinking on physicochemical characteristics of arachin and conarachin-rich peanut protein fractions. Food Res. Int. 2014, 62, 84-90. [CrossRef]

26. Jeong, H.J.; Park, J.H.; Lam, Y.; de Lumen, B.O. Characterization of lunasin isolated from soybean. J. Agric. Food Chem. 2003, 51, 7901-7906. [CrossRef]

27. Lin, X.S.; Wen, Q.; Huang, Z.L.; Cai, Y.Z.; Halling, P.J.; Yang, Z. Impacts of ionic liquids on enzymatic synthesis of glucose laurate and optimization with superior productivity by response surface methodology. Process. Biochem. 2015, 50, 1852-1858. [CrossRef]

28. Mao, X.; Hua, Y. Composition, Structure and Functional Properties of Protein Concentrates and Isolates Produced from Walnut (Juglans regia L.). Int. J. Mol. Sci. 2012, 13, 1561-1581. [CrossRef]

29. Arcan, I.; Yemenicioğlu, A. Effects of controlled pepsin hydrolysis on antioxidant potential and fractional changes of chickpea proteins. Food Res. Int. 2010, 43, 140-147. [CrossRef]

30. Chityala, P.K. Effect of xanthan/enzyme-modified guar gum mixtures on the stability of whey protein isolate stabilized fish oil-in-water emulsions. Food Chem. 2016, 212, 332-340. [CrossRef]

31. Gong, K.J.; Shi, A.M.; Liu, H.Z.; Liu, L.; Hu, H.; Adhikari, B.; Wang, Q. Emulsifying properties and structure changes of spray and freeze-dried peanut protein isolate. J. Food Eng. 2016, 170, 33-40. [CrossRef]

32. Wu, H.; Wang, Q.; Ma, T.; Ren, J. Comparative studies on the functional properties of various protein concentrate preparations of peanut protein. Food Res. Int. 2009, 42, 343-348. [CrossRef]

33. Jianmei, Y.; Mohamed, A.; Ipek, G. Peanut protein concentrate: Production and functional properties as affected by processing. Food Chem. 2007, 103, 121-129.

34. Kadam, S.U.; Tiwari, B.K.; Álvarez, C.; O’Donnell, C.P. Ultrasound applications for the extraction, identification and delivery of food proteins and bioactive peptides. Trends Food Sci. Technol. 2015, 46, 60-67. [CrossRef] 
35. Liu, T.H.; Zhang, C.X.; Zhuang, F..; Xu, X.P.; Chi, Y.S. A Review on the Chemical Components and the Edible and Medicinal Value of Scorpion. Hans. J. Food Nutr. Sci. 2017, 6, 165-174. [CrossRef]

36. Wu, F.L.; Dong, Q.H.; Wang, H.; Tan, J.; Lin, H.Q.; Li, P.Y.; Li, Y.J. Research Progress of Chinese Scorpion. J. Liaoning Univ. TCM 2018, 20, 108-111.

Sample Availability: Samples of the compounds are available from the authors.

(C) 2019 by the authors. Licensee MDPI, Basel, Switzerland. This article is an open access article distributed under the terms and conditions of the Creative Commons Attribution (CC BY) license (http://creativecommons.org/licenses/by/4.0/). 


\title{
Article \\ Influence of Potato Crisps Processing Parameters on Acrylamide Formation and Bioaccesibility
}

\author{
Emmanuel Martinez ${ }^{1}$, Jose A. Rodriguez ${ }^{1}$, Alicia C. Mondragon ${ }^{2}$, Jose Manuel Lorenzo ${ }^{3}$ and \\ Eva M. Santos ${ }^{1, *}$ \\ 1 Area Academica de Quimica, Universidad Autonoma del Estado de Hidalgo, Carr. Pachuca-Tulancingo Km. \\ 4.5, Mineral de la Reforma, 42184 Hidalgo, Mexico; qaemmanuel@gmail.com (E.M.); \\ josear@uaeh.edu.mx (J.A.R.) \\ 2 Laboratorio de Higiene, Inspeccion y Control de Alimentos, Departamento de Quimica Analitica, Nutricion \\ y Bromatologia, Facultad de Veterinaria, Universidad de Santiago de Compostela, 27002 Lugo, Spain; \\ alicia.mondragon@deinal.es \\ 3 Meat Technology Centre of Galicia, Rúa Galicia Nº 4, Parque Tecnológico de Galicia, San Cibrao das Viñas, \\ 32900 Ourense, Spain; jmlorenzo@ceteca.net \\ * Correspondence: emsantos@uaeh.edu.mx
}

Academic Editor: Jose M. Miranda

Received: 24 September 2019; Accepted: 21 October 2019; Published: 23 October 2019

\begin{abstract}
A fractional factorial design was used to evaluate the effects of temperature, frying time, blanching treatment and the thickness of potato slices on acrylamide content in crisps. The design was used on freshly harvested and four-month stored potatoes. The critical factors found were temperature and frying time, and the interaction between blanching treatment and slice thickness. Once frying conditions were selected, an acrylamide content of 725 and $1030 \mathrm{mg} \mathrm{kg}^{-1}$ was found for non-stored and 4-month stored tubers, with adequate textural parameters in both cases. The difference in concentration is related to storage conditions, which must be controlled in order to control acrylamide levels. Bioaccesibility studies demonstrated that acrylamide concentration remained at $70 \%$, and reductions took place mainly at the intestinal phase, as a result of reaction with nucleophilic compounds.
\end{abstract}

Keywords: acrylamide; crisps; temperature; frying time; blanching; thickness

\section{Introduction}

Acrylamide, a thermal processing contaminant with a low molecular weight, which is soluble in water, is formed when carbohydrate-rich foods are subjected to temperatures above $120{ }^{\circ} \mathrm{C}$ in low-moisture conditions, such as frying, roasting or baking. Several studies consider Maillard reactions to be the main pathway for acrylamide, 5 hydroxymethylfurfural, methylglyoxal-lysine dimers, $\mathrm{N} \varepsilon$-carboxymethyl-lysine and pyrraline formation in processed foods, particularly reactions between the carbonyl group of reducing sugars and amino acids [1,2]. Initial reports showed relatively high concentrations of acrylamide in high-carbohydrate foodstuffs, such as crispy bread, breakfast cereals, pastries, coffee, French fries and crisps. In general, potato products present higher acrylamide contents (250-4000 $\left.\mu \mathrm{g} \mathrm{kg}^{-1}\right)$ compared to other food products, because of the higher concentration of asparagine in potato tubers $[3,4]$.

Acrylamide has been classified by the Agency for Research on Cancer as "probably carcinogenic to humans" (Group 2A) and, in the latest report from the European Food Safety Authority Expert Panel on Contaminants in the Food Chain (CONTAM, 2015), the margins of exposure for acrylamide lead to concerns regarding their neoplastic effects, based on animal evidence [5]. Therefore, the European Commission recently established "indicative" levels for the presence of acrylamide in food, suggesting 
a limit of $750 \mu \mathrm{g} \mathrm{kg}^{-1}$ for crisps [6]. Previously, the European Union and FDA had encouraged food industries to reduce the presence of this contaminant.

In response to this, the food industry has been forced to apply different strategies to reduce acrylamide formation, applying processing modifications according to recommendations published by the European Food and Drink Federation in the document "Acrylamide Toolbox", which includes the following variables: temperature and time during frying, blanching treatment, and thickness of potato slices [7]. However, the main challenge for the food industries is in producing potato chips with low acrylamide levels without affecting their sensory properties [8].

Although it is important to evaluate the effect of pre-treatments on the frying process on acrylamide mitigation, it is also necessary to determine their influence on its bioavailability. Potato chips are an important part of the snack food market in many countries, and few studies have been published about the bioavailability of acrylamide after crisps have been through the digestion process [8,9]. Acrylamide intake in humans occurs mainly via food ingestion, where the total amount of this compound does not necessarily reflect the available amount to the body. There are chemical changes in the food when it enters the digestive tract, because of $\mathrm{pH}$ variations, and the action of several enzymes in every stage of the digestion process [10-12]. In this sense, bioaccessibility is used to evaluate the amount of a chemical compound available for absorption after it is released from the food matrix into the gastrointestinal tract. Several methodologies can be used to assess the bioaccessibility of contaminants or nutrients: 1) in vitro, 2) ex vivo, 3) in situ and 4) in vivo models $[13,14]$. Among the techniques mentioned before, in vitro models are more commonly used than in vivo models, because of their simplicity, lower cost, lack of ethical issues and good reproducibility under controlled conditions.

The present work evaluated some acrylamide mitigation strategies, employing a fractional factorial design experiment, and their influence on textural properties and bioaccesibility, by an in vitro simulated digestion assay.

\section{Results and Discussion}

\subsection{Acrylamide Content}

Potatoes of the Atlantic variety were selected for crisp production, because of their low levels of glucose and fructose compared to other varieties, such as the Ranger Russet [15]. According to the storage period of potato tubers, two sampling points were considered: freshly harvested potatoes (summer of 2018) and four-month stored potatoes. The main variables described for acrylamide reduction in potato crisps are [7]: temperature control and time of frying process, blanching, and the thickness of slices. These variables were selected because they are easily applicable in the industry and do not represent extra costs in production. A fractional factorial design $\left(2^{4-1}\right)$ was proposed, to evaluate the influence of frying process parameters in the total amount of acrylamide formed and its bioaccessibility. The levels selected for the variables were: temperature $(\mathrm{T})$ of 150 and $180{ }^{\circ} \mathrm{C}$; frying time (t) of 5 and $10 \mathrm{~min}$; blanching treatment (B) —no blanching treatment and $70{ }^{\circ} \mathrm{C}$ for $5 \mathrm{~min}$-and thickness of slice $(\mathrm{w})$, at 1.5 and $2.0 \mathrm{~mm}$. In this sense, eight experiments (in duplicate, a total of 16 experiments) were performed.

Table 1 shows the matrix used and the acrylamide content for the experimental design. According to the obtained results, the concentration of acrylamide was higher in stored potatoes. This can be explained by the difference between the content of reducing sugars between samples, since a concentration of $23 \mathrm{mg} \mathrm{kg}^{-1}$ of reducing sugars was found in freshly harvested potatoes, while, in samples stored for 4 months, a concentration of $34 \mathrm{mg} \mathrm{kg}^{-1}$ was found. During storage, a phenomenon called cold sweetening occurs, consisting of a degradation of the potato starch caused by the low temperatures [16]. Even if appropriate storage conditions of potato tubers are followed, a slight increase of reducing sugars is expected, and will affect the acrylamide concentration [17]. 
Table 1. Matrix of the experimental fractional factorial design and the average of obtained responses.

\begin{tabular}{ccccccc}
\hline \multirow{2}{*}{ Exp } & \multirow{T}{\mathbf{T}}{$\left({ }^{\circ} \mathbf{C}\right)$} & $\mathbf{t}(\mathbf{m i n})$ & $\mathbf{B}\left(\mathbf{7 0}{ }^{\circ} \mathbf{C}, \mathbf{m i n}\right)$ & $\mathbf{w}(\mathbf{m m})$ & \multicolumn{2}{c}{ Acrylamide Content $\left(\boldsymbol{\mu g} \mathbf{~ k g}^{-\mathbf{1}} \mathbf{\text { m }} \mathbf{\text { sd }}\right.$} \\
\cline { 6 - 7 } & & & & & Non-stored & 4-month stored \\
\hline 1 & $150(-1)$ & $5(-1)$ & $0(-1)$ & $1.5(-1)$ & $973 \pm 71$ & $1257 \pm 171$ \\
2 & $150(-1)$ & $10(+1)$ & $0(-1)$ & $2.0(+1)$ & $752 \pm 63$ & $890 \pm 52$ \\
3 & $150(-1)$ & $10(+1)$ & $5(+1)$ & $1.5(-1)$ & $825 \pm 67$ & $1483 \pm 58$ \\
4 & $150(-1)$ & $5(-1)$ & $5(+1)$ & $2.0(+1)$ & $885 \pm 62$ & $1097 \pm 205$ \\
5 & $180(+1)$ & $10(+1)$ & $0(-1)$ & $1.5(-1)$ & $2590 \pm 243$ & $4386 \pm 270$ \\
6 & $180(+1)$ & $5(-1)$ & $0(-1)$ & $2.0(+1)$ & $795 \pm 92$ & $1149 \pm 82$ \\
7 & $180(+1)$ & $5(-1)$ & $5(+1)$ & $1.5(-1)$ & $1138 \pm 220$ & $1812 \pm 70$ \\
8 & $180(+1)$ & $10(+1)$ & $5(+1)$ & $2.0(+1)$ & $2250 \pm 204$ & $3540 \pm 254$ \\
\hline
\end{tabular}

A comparison of each variance with respect to the variance of the residual allows the determination of the the experimental $F$ value $\left(F_{\text {exp }}\right)$, which is then compared with the $F_{\text {critical }}$ value $(5.32, p=0.05,1,8)$. The F-test indicated that, in both cases (non-stored and stored tubers), the critical factors for acrylamide formation were $(p=0.05)$ : temperature $(\mathrm{T})$ and frying time $(\mathrm{t})$. The contribution of potato thickness $(\mathrm{w})$ was also observed for stored samples (Table 2).

Table 2. Analysis of variance of the results obtained from the fractional factorial design, showing the factors significantly affecting acrylamide concentration.

\begin{tabular}{lllllll}
\hline \multirow{2}{*}{ Factor } & \multicolumn{2}{l}{ Non-Stored } & \multicolumn{4}{l}{ 4-month Stored } \\
\cline { 2 - 7 } & Effect & Variance & $\mathrm{F}_{\text {exp }}$ & Effect & Variance & F $_{\text {exp }}$ \\
\hline $\mathrm{T}$ & 834.5 & $2,785,561$ & $\mathbf{6 3 . 7 2}$ & 1540 & $9,486,400$ & $\mathbf{2 1 6 . 9 9}$ \\
$\mathrm{t}$ & 656.5 & $1,723,969$ & $\mathbf{3 9 . 4 3}$ & 1246 & $6,210,064$ & $\mathbf{1 4 2 . 0 5}$ \\
$\mathrm{B}$ & -3 & 36 & $8.2 \times 10^{-4}$ & 62.5 & 15,625 & 0.36 \\
$\mathrm{~W}$ & -211 & 178,084 & 4.07 & -565.5 & $1,279,161$ & $\mathbf{2 9 . 2 6}$ \\
Residual & & 43,718 & & & $56,593.5$ & \\
\hline
\end{tabular}

Figure 1 shows the mean effect graph for the effect of evaluated control factors on acrylamide concentration. Independently of storage time, the mean effect profile is similar in both cases, demonstrating that the increase in acrylamide concentration is mainly a consequence of the increment of reducing sugars concentration, rather than the processing variables. Bertuzzi et al. also reported a strong influence of reducing sugar concentration on acrylamide formation in processed potato products [18]. A percentage of reducing sugars between $0.15 \%-0.20 \%$ has been suggested as an indicator of the suitability of potatoes for processing [19]. Despite the lower reducing sugar content found in potatoes in this study, acrylamide formation reached values over the $750 \mu \mathrm{g} \mathrm{kg}^{-1}$ limit established by the European Commission [6].

The results obtained are congruent with others previously described, in which an increment in acrylamide content in potatoes, in relation to temperature and frying time, was observed $[18,20]$. In general, the increase in acrylamide content follows a linear function over time, while the relationship with frying temperature is not linear, although temperatures over $175{ }^{\circ} \mathrm{C}$ significantly increased acrylamide levels $[1,18,20-22]$. Any temperature-time combination proposed to mitigate acrylamide content should not affect the overall quality of the fried product, especially its texture.

Although the other processing parameters (blanching and thickness) had a smaller contribution, their interaction was also significant (Figure 2). As acrylamide is formed on the potato surface, the size:volume ratio of the potato slice influences the acrylamide content. In general, thinner and smaller cut sizes result in increased acrylamide formation [22]. Also, the blanching of potato slides prior to the frying process has been recommended to reduce the acrylamide content, since this helps remove reducing sugars on the surface $[8,23]$. In this study, a blanching process was required for thinner potatoes, to decrease acrylamide formation. However, a lower concentration of acrylamide 
was observed in thicker potatoes without the blanching treatment. It seems that, in thicker slices, heat diffusion is slower when the slice has not been blanched and, consequently, a decrement of acrylamide content can be observed. So, the blanching treatment should not be suitable for potato slices with a thickness over $2.00 \mathrm{~mm}$. This result is interesting for the industry because the application of blanching treatments at high temperatures and longer times represents an additional difficulty, since most industrial frying processes are continuous, and blanching could be unnecessary for certain types of crisps.

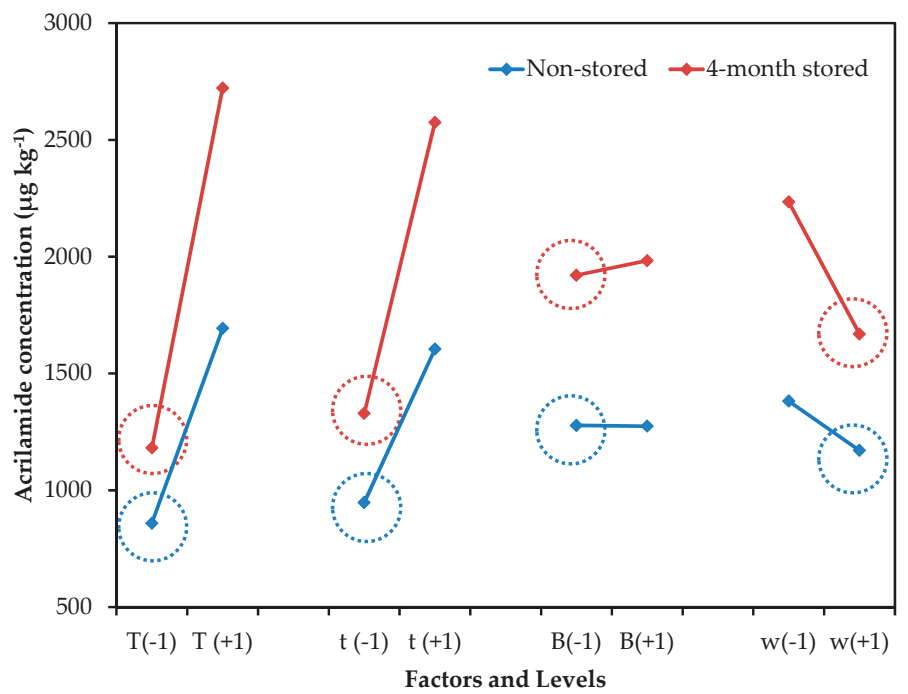

Figure 1. Mean effect graph vs. acrylamide concentration $\left(\mu \mathrm{g} \mathrm{kg}^{-1}\right)$ of the experimental design for non-stored and 4-month stored potato tubers storage.

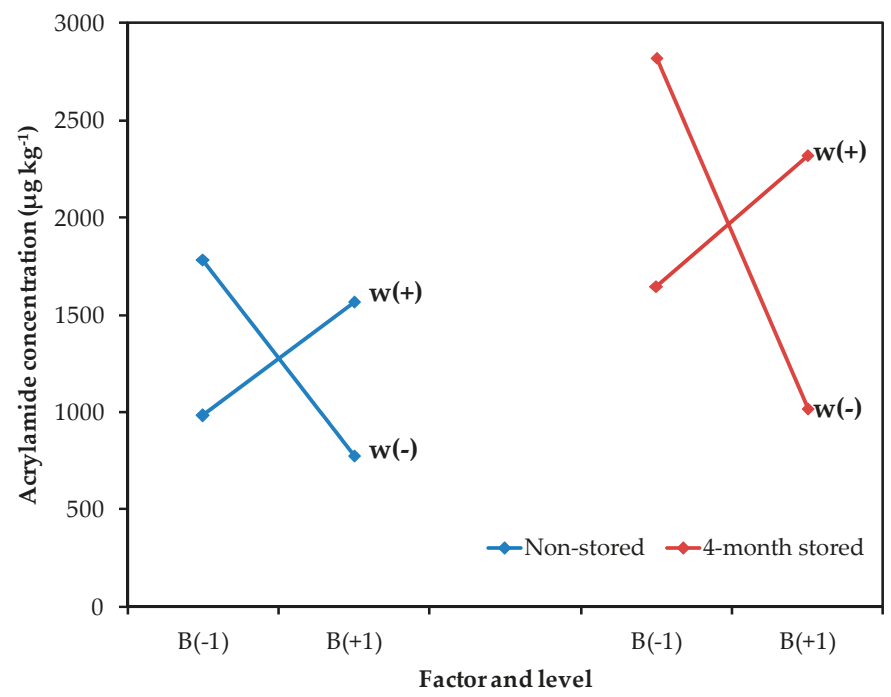

Figure 2. Mean effect graph vs. acrylamide concentration $\left(\mu \mathrm{g} \mathrm{kg}{ }^{-1}\right)$ for the interaction between blanching (B) and thickness (w) in non-stored and 4-month stored tubers. 
The combination of settings that generated the minimum acrylamide concentration was: temperature, $150{ }^{\circ} \mathrm{C}(-1)$; time, $5 \mathrm{~min}(-1)$; no blanching treatment $(-1)$; and a slice thickness of $2.0 \mathrm{~mm}(+1)$. Acrylamide content of 725 and $1030 \mathrm{mg} \mathrm{kg}^{-1}$ was determined at these conditions for non-stored and 4-month stored tubers, respectively.

\subsection{Texture Analysis and Bioaccesibility}

Potato chips are consumed as indulgent foods, with a characteristic flavor and crispiness, the latter evaluated through textural parameters. In order to evaluate it, crisps were prepared according to the processing parameters detailed above. Figure 3 shows a representative profile of the force $(N)$ vs. probe displacement $(\mathrm{mm})$. The force displacement curves have a jagged appearance, with several fracture events, which are typical of crispy food [24]. These graphics have two well-differentiated regions, the first one starting from the first contact between the potato crisp and the probe, until the major force is achieved (associated with major structural breakdown and hardness). The second region starts from the major structural breakdown and continues until the end, where smaller force events take place. The parameters evaluated were the maximum force applied $(\mathrm{N})$, related to hardness or firmness, and the gradient $\left(\mathrm{N} \mathrm{s}^{-1}\right)$, which is related to stiffness.

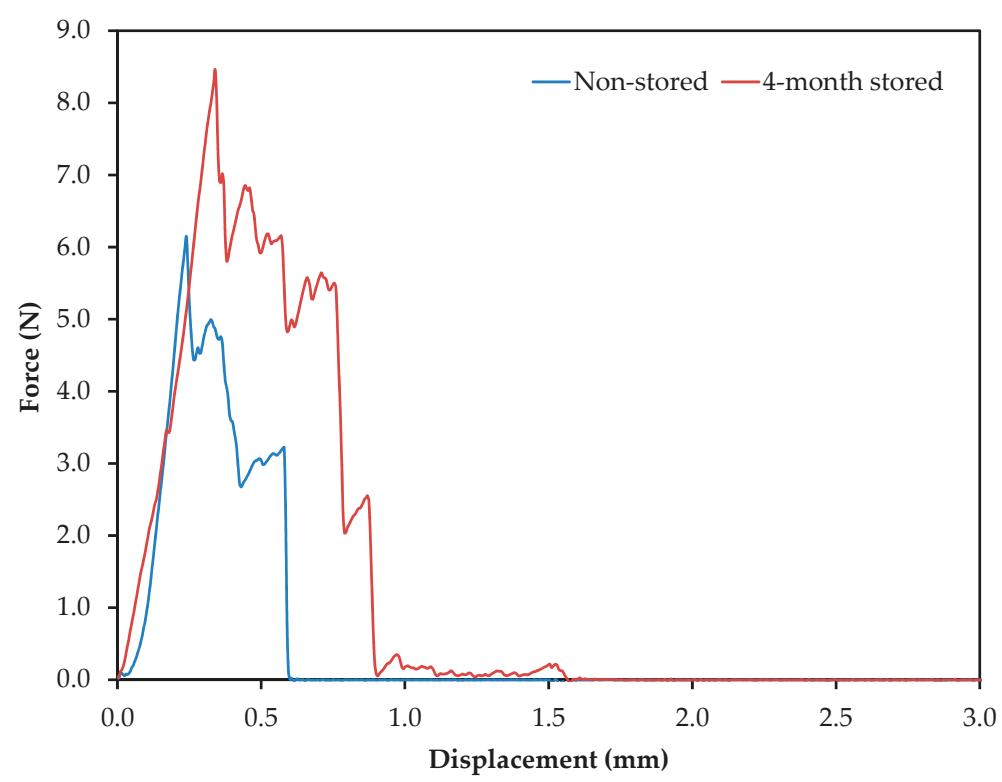

Figure 3. Force displacement curves generated from the analysis of potato crisps obtained from frying non-stored and 4-month stored tubers. Frying conditions: temperature, $150{ }^{\circ} \mathrm{C}$; time, $5 \mathrm{~min}$; no blanching treatment; and a slice thickness of $2.0 \mathrm{~mm}$.

The maximum force applied was 6.1 and $8.5 \mathrm{~N}$, for non-stored and 4-month stored samples, respectively. Genovese et al. have reported values below $6 \mathrm{~N}$ for firmness [25]. The storage of the tubers promoted an increase in firmness. On the other hand, samples obtained from frying the non-stored potato slices presented the highest gradient $\left(8.9 \mathrm{~N} \mathrm{~s}^{-1}\right)$ compared to 4 -month stored samples $\left(7.2 \mathrm{~N} \mathrm{~s}^{-1}\right)$, making them, therefore, the stiffest. Additionally, the number of total force peaks in each case can be evaluated: seven for non-stored tubers and 13 for 4-month stored tubers. Taking into account that values higher than six are considered high-sensory crispiness, both samples can be accepted as adequate snacks [26]. 
Once the effect of the control factors on acrylamide formation had been evaluated, it was important to know their effect on bioaccesibility. Values of $79.1 \% \pm 1.5 \%$ and $76.9 \% \pm 1.5 \%$ of bioaccesibility were obtained for the snacks using potatoes that were freshly harvested and stored for 4 months before frying, respectively. The results obtained in this study are in agreement with the predicted behavior of potato [10] and bakery products [12]. The main effect was observed at the end of the intestinal phase of the digestion process, and could be explained by the formation of Michael adducts, in which the acrylamide would be involved.

During the gastric phase of the digestion process, pepsin hydrolyzes the proteins present in the potato, generating small peptide chains and some amino acid residues, such as cysteine and lysine, that have a nucleophilic character (-SH and $-\mathrm{NH}_{2}$ ). These peptides are able to interact with acrylamide and form adducts, which consequently causes an apparent reduction in acrylamide during the intestinal phase [12]. Taking into account the mentioned results, this can be proposed as an alternative method of reducing acrylamide concentration in the digestion process, through the formation of adducts with thiol compounds (i.e., glutathione) contained in other foods, such as spinach, avocados or asparagus $[27,28]$

\section{Materials and Methods}

\subsection{Reagents}

Acrylamide, 2-naphthalenethiol, and the following enzymes: pepsin ( $\geq 250 \mathrm{U} \mathrm{mg}^{-1}$ solid), from porcine gastric mucosa, pancreatin $(4 \times \mathrm{USP})$, from porcine pancreas, $\alpha$-amylase, from human saliva (500 U) and porcine bile salts, were purchased from Sigma-Aldrich (St. Louis, MO, USA). Potassium chloride, sodium bicarbonate and sodium chloride were purchased from MEYER (Mexico City, Mexico). Acetonitrile (HPLC grade) and acetic acid were obtained from J.T. Baker (Philisburg, NJ, USA).

\subsection{Samples and Frying Conditions}

Potato (Atlantic variety) and vegetable oil (palm olein) were the raw materials used, provided by Fritos Totis (Tizayuca, Hidalgo, Mexico). Samples were collected in two periods, the first with potatos freshly harvested and the second after four months of storage, at $8{ }^{\circ} \mathrm{C}$ and $95 \%$ relative humidity. Slices (with a thickness of 1.5 and $2.0 \mathrm{~mm}$, and a diameter of around $35 \mathrm{~mm}$ ) were cut using a slicing machine. Slices were rinsed immediately after cutting for $1 \mathrm{~min}$ in deionized water (resistivity of $18.2 \mathrm{M} \Omega \mathrm{cm}$ ), to eliminate some starch material adhered onto the surface, before frying. Forty grams of slides were deep-fried in an electrical fryer Blazer FE-3 (Mexico city, Mexico) $1600 \mathrm{~W}, 127 \mathrm{~V}$ and equipped with a bowl with $3 \mathrm{~L}$ of capacity, a static basket and a regulating thermometer.

The main variables evaluated for acrylamide reduction in potato crisps were [6]: control of temperature and time of frying process, blanching, and slice thickness. These strategies were selected because they are easily applicable to the industry and do not represent extra costs in production. A fractional factorial design $\left(2^{4-1}\right)$ was proposed, to evaluate the influence of frying process parameters in the total amount of acrylamide formed and its bioaccessibility. The factors selected were temperature $(\mathrm{T})$, frying time $(\mathrm{t})$, blanching treatment $(\mathrm{B})$, and thickness of potato slices $(\mathrm{w})$. Results obtained from the fractional factorial design were subjected to an analysis of variance study. The mean effect of each factor on acrylamide content and the variance was estimated through the Yates algorithm [29]. Experimental results were analyzed using MINITAB ${ }^{\circledR}$ version 17 software (Minitab Inc., State College, PA, USA).

\subsection{Acrylamide Determination}

Acrylamide determination was carried out by chemical derivatization, using 2-naphthalenethiol as a derivatization reagent, followed by HPLC separation and quantification with fluorescence detection [30]. In brief, $3 \mathrm{~g}$ of potato crisps were homogenized with $30 \mathrm{~mL}$ of deionized water and then defatted with hexane. Then, the aqueous phase was centrifuged and filtered using a cellulose membrane (pore size, $0.45 \mu \mathrm{m}$ ). Afterwards, an aliquot of $7.5 \mathrm{~mL}$ was mixed with $1 \mathrm{~mL}$ of the solution 
2-naphthalenethiol $(62 \mathrm{mM})$, in a solution of sodium hydroxide $(0.1 \mathrm{M})$. The mixture was heated at $90{ }^{\circ} \mathrm{C}$ for $45 \mathrm{~min}$. The reaction was stopped with $1.5 \mathrm{~mL}$ of acetic acid (1\%) and the solution was centrifuged at $700 \mathrm{~g}$ for $15 \mathrm{~min}$. Acrylamide concentration of samples was calculated by standard additions, by spiking each sample with known concentrations of acrylamide.

Chromatography separation was performed using an Agilent Technologies 1260 Infinity chromatography system (Agilent Technologies, Waldbronn, Germany). Samples were manually injected using a $20-\mu \mathrm{L}$ loop, and a C-8 ZORBAX eclipse XDB column $(5 \mu \mathrm{m}$; $150 \times 4.6 \mathrm{~mm}$ internal diameter) from Agilent Technologies was used as the stationary phase. The mobile phase was acetic acid $(1.0 \% v / v)$ and acetonitrile in a 50:50 ratio $(v / v)$. The flow rate was $0.8 \mathrm{~mL} \mathrm{~min}^{-1}$.

\subsection{Texture Evaluation}

A TA.XTPlus Texture Analyser (Stable Micro Systems Ltd., Surrey, UK), equipped with a $5 \mathrm{~kg}$ load cell, was used for force/displacement measurements, with a stainless spherical probe (P/0.25S) of a 0.25 inch diameter. The samples were placed on a crisp fracture rig (HDP/CFS). The test settings were: test speed of $1 \mathrm{~mm} \mathrm{~s}^{-1}$, trigger force of $0.406 \mathrm{~N}$, travel distance of $3 \mathrm{~mm}$.

\subsection{In Vitro Digestion}

Bioaccessibility was estimated using an in vitro digestion model (oral, gastric and intestinal stages) and the simulated fluids-salivary (SFS), gastric (SFG) and intestinal (SFI)-were prepared according to an internationally agreed protocol (Table 3) [31]. Samples of potato crisps (5 g) were transferred to a conical tube and mixed with $5 \mathrm{~mL} \mathrm{SFS} \mathrm{(containing} 75 \mathrm{U} \alpha$-amylase $\mathrm{mL}^{-1}$ ) for $3 \mathrm{~min}$. After that, $5 \mathrm{~mL}$ of a pepsin solution $\left(12.5 \mathrm{mg} \mathrm{mL}^{-1}\right.$ in $\left.0.1 \mathrm{M} \mathrm{HCl}\right)$ and $10 \mathrm{~mL}$ of SFG were added. The mixture was adjusted to $\mathrm{pH} 2.0$ and incubated in a shaking water bath at $37^{\circ} \mathrm{C}$ for $2 \mathrm{~h}$, with an agitation speed of 60 strokes per min. After incubation, the $\mathrm{pH}$ was adjusted to 7.5 , and then bile salts $\left(10 \mathrm{mg} \mathrm{mL}^{-1}\right)$, dissolved in $20 \mathrm{~mL}$ of SFI together with a pancreatin solution $\left(5 \mathrm{~mL}, 10 \mathrm{mg} \mathrm{mL}^{-1}\right.$ in water), were added to the tube. The mixture was incubated at $37^{\circ} \mathrm{C}$ for $2 \mathrm{~h}$, with shaking at an agitation speed of 60 strokes per min, to simulate the duodenal phase. Digestion products were placed in a dialysis bag (6-8000 molecular weight cut off; Sigma Aldrich) and dialyzed in $250 \mathrm{~mL}$ of sodium bicarbonate solution $(\mathrm{pH}=7.5)$ for $12 \mathrm{~h}$. Dialysis aliquots were removed and acrylamide dialyzed was determined by the method described above. Bioaccesibility was reported as the percentage of acrylamide in the dialyzed sample compared to the value in the original sample.

Table 3. Composition of simulated salivary, gastric and intestinal electrolytes fluids.

\begin{tabular}{lccc}
\hline Compound & $\begin{array}{l}\text { Simulated Salivary } \\
\text { Fluid (SSF) } \mathbf{~ m m o l ~ L ~}^{-\mathbf{1}}\end{array}$ & $\begin{array}{l}\text { Simulated Gastric } \\
\text { Fluid (SGF) } \mathbf{~ m o l ~ L ~}^{-\mathbf{1}}\end{array}$ & $\begin{array}{l}\text { Simulated Intestinal } \\
\text { Fluid (SIF) } \mathbf{~ m m o l ~ L ~}^{-\mathbf{1}}\end{array}$ \\
\hline $\mathrm{KCl}$ & 15.10 & 6.90 & 6.80 \\
$\mathrm{KH}_{2} \mathrm{PO}_{4}$ & 3.70 & 0.90 & 0.80 \\
$\mathrm{NaHCO}$ & 13.60 & 25.00 & 85.00 \\
$\mathrm{NaCl}$ & - & 47.20 & 38.40 \\
$\mathrm{MgCl}_{2} \cdot 6 \mathrm{H}_{2} \mathrm{O}$ & 0.15 & 0.10 & 0.33 \\
$\left(\mathrm{NH}_{4}\right)_{2} \mathrm{CO}_{3}$ & 0.06 & 0.50 & - \\
$\mathrm{CaCl}_{2} \cdot 2 \mathrm{H}_{2} \mathrm{O}$ & 1.50 & 0.15 & 0.60 \\
\hline
\end{tabular}

\section{Conclusions}

The evaluation of potato crisps' processing parameters was performed by a chemometric approach, through fractional factorial design. The factors with a higher contribution were temperature and frying time, and an increment on the acrylamide, with respect to the store time of raw material, was also observed. Crisps obtained in the most suitable conditions have adequate texture parameters, while bioaccesibility takes place mainly at the intestinal phase, through reaction with $-\mathrm{NH}_{2}$ and 
-SH containing compounds. In order to reduce acrylamide concentration in the digestion process, the consumption of foods which contain compounds with these functional groups is proposed.

Author Contributions: E.M., J.A.R. and E.M.S. performed the experiments; E.M. and A.C.M. performed bioaccesibility experiments; J.M.L. analyzed the texture data. J.A.R. and E.M.S. are responsible for the writing of the work.

Funding: This research was funded by Fritos Totis SA de CV and CONACyT-Incentives for Research, Technological Development and Innovation Program (conv 2016-232271).

Acknowledgments: Programa para el Desarrollo Profesional Docente (PRODEP), Consejo Nacional de Ciencia y Tecnología (SNI membership), and Programa de Fortalecimiento de la Calidad Educativa (PFCE-2019).

Conflicts of Interest: The authors declare no conflict of interest.

\section{References}

1. Gökmen, V. Acrylamide in Food: Analysis, Content and Potential Health Effects; Academic Press: San Diego, CA, USA, 2016; pp. 1-9.

2. Oh, M.J.; Kim, Y.; Lee, S.H.; Lee, K.W.; Park, H.Y. Prediction of CML contents in the Maillard reaction products for casein-monosaccharides model. Food Chem. 2018, 267, 271-276. [CrossRef] [PubMed]

3. Blank, I. Current status of acrylamide research in food: Measurement, safety, assessment, and formation. Annals New York Academy Sci. 2015, 1043, 30-40. [CrossRef] [PubMed]

4. Bethke, P.C.; Bussan, A. Acrylamide in processed potato products. Am. J. Potato Res. 2013, 90, $403-424$. [CrossRef]

5. Agents Classified by the IARC Monographs, Volumes 1-123. Available online: https://monographs.iarc.fr/ agents-classified-by-the-iarc/ (accessed on 20 September 2019).

6. EC (European Commission). Commission Regulation EU of 20 November 2017 Establishing Mitigation Measures and Benchmark Levels for the Reduction of the Presence of Acrylamide in Food. Available online: https://publications.europa.eu/en/publication-detail/-/publication/1f3b45fb-ce6b-11e7a5d5-01aa75ed71a1/language-en (accessed on 20 September 2019).

7. Food Drink Europe. Acrylamide Toolbox. Available online: https://www.fooddrinkeurope.eu/publication/ fooddrinkeurope-updates-industry-wide-acrylamide-toolbox/ (accessed on 20 September 2019).

8. Pedreschi, F.; Mariotti, S.; Granby, K.; Risum, J.R. Acrylamide reduction in potato chips by using commercial asparaginase in combination with conventional blanching. LWT-Food Sci. Technol. 2011, 44, 1473-1476. [CrossRef]

9. Eriksson, S.; Karlsson, P. Alternative extraction techniques for analysis of acrylamide in food: Influence of pH and digestive enzymes. LWT-Food Sci. Technol. 2006, 39, 393-399. [CrossRef]

10. Sansano, M.; Heredia, A.; Peinado, I.; Andres, A. Dietary acrylamide: What happens during digestion. Food Chem. 2017, 237, 58-64. [CrossRef]

11. Moreda-Piñeiro, J.; Moreda-Piñeiro, A.; Romarís-Hortas, V.; Moscoso-Perez, C.; López-Mahía, P.; Muniategui-Lorenzo, S.; Bermejo-Barrera, P.; Prada-Rodríguez, D. In-vivo and in-vitro testing to assess the bioaccessibility and the bioavailability of arsenic, selenium and mercury species in food samples. Trends Anal. Chem. 2011, 30, 324-345. [CrossRef]

12. Hamzalioğlu, A.; Gökmen, V. Investigation of the reactions of acrylamide during in vitro multistep enzymatic digestion of thermally processed foods. Food Funct. 2014, 6, 109-114. [CrossRef]

13. Carbonell-Capella, J.M.; Buniowska, M.; Barba, F.J.; Esteve, M.J.; Frigola, A. Analytical methods for determining bioavailability and bioaccessibility of bioactive compounds from fruits and vegetables: A review. Comprehens. Rev. Food Sci. Food Safety 2014, 13, 155-171. [CrossRef]

14. Barba, J.F.; Mariutti, R.B.L.; Bragagnolo, N.; Mercadante, Z.A.; Barbosa-Canovas, G.V.; Orlien, V. Review: Bioaccessibility of bioactive compounds from fruits and vegetables after thermal and nonthermal processing. Trend. Food Sci. Technol. 2017, 67, 195-206. [CrossRef]

15. Rommens, C.M.; Yan, H.; Swords, K.; Richael, C.; Ye, J. Low-acrylamide French fries and potato chips. Plant Biotechnol. J. 2008, 6, 843-853. [CrossRef] [PubMed]

16. Sowokinos, J. The molecular and cellular biology of the potato. In Stress-induced Alterations in Carbohydrate Metabolism; Vayda, M.E., Park, W.D., Eds.; CAB international: Wallingford, UK, 1990; pp. 137-157. 
17. Medeiros, V.R.; Mestdagh, F.; Van Poucke, C.; Van Peteghem, C.; De Meulenaer, B. A two-year investigation towards and effective quality control of incoming potatoes as an acrylamide mitigation strategy in french fries. Food Add. Contaminants 2012, 29, 362-370.

18. Bertuzzi, T.; Mulazzi, A.; Rastelli, S.; Sala, L.; Pietri, A. Mitigation measures for acrylamide reduction in dough-based potato snacks during their expansion by frying. Food Add. Contaminants Part A 2018, 35, 1940-1947. [CrossRef] [PubMed]

19. Pedreschi, F.; Mariotti, M.S.; Granby, K. Current issues in dietary acrylamide: Formation, mitigation and risk assessment. J. Sci. Food Agricul. 2014, 94, 9-20. [CrossRef]

20. Pedreschi, F.; Moyano, P.; Kaack, K.; Granby, K. Color changes and acrylamide formation in fried potato slices. Food Res. Int. 2005, 38, 1-9. [CrossRef]

21. Yang, Y.; Achaerandio, I.; Pujola, M. Influence of the frying process and potato cultivar on acrylamide formation in French fries. Food control 2016, 62, 216-223. [CrossRef]

22. Vinci, R.M.; Mestdagh, F.; De Meulenaer, B. Acrylamide formation in fried potato products-Present and future, a critical review on mitigation strategies. Food Chem. 2012, 133, 1138-1154. [CrossRef]

23. Abboudi, M.; Al-Bachir, M.; Koudsi, Y.; Jouhara, H. Combined effects of gamma irradiation and blanching process on acrylamide content in fried potato strips. Int. J. Food Propert. 2016, 19, 1447-1454. [CrossRef]

24. Chen, J.; Karlsson, C.; Povey, M. Acoustic envelope detector for crispness assessment of biscuits. J. Texture Studies 2005, 36, 139-156. [CrossRef]

25. Genovese, J.; Tappi, S.; Luo, W.; Tylewicz, U.; Marzocchi, S.; Marziali, S.; Romani, S.; Ragni, L.; Rocculi, P. Important factors to consider for acrylamide mitigation in potato crisps using pulsed electric fields. Innovative Food Sci. Emerging Technol. 2019, 55, 18-26. [CrossRef]

26. Salvador, A.; Varela, P.; Sanz, T.; Fiszman, S.M. Understanding potato chips crispy texture by simultaneous fracture and acoustic measurements, and sensory analysis. LWT-Food Sci. Technol. 2009, 42, 763-767. [CrossRef]

27. Tong, G.C.; Cornwell, W.K.; Means, G.E. Reactions of acrylamide with glutathione and serum albumin. Toxicol. Lett. 2004, 147, 127-131. [CrossRef] [PubMed]

28. Ghareeb, D.A.; Khalil, A.A.; Elbassoumy, A.M.; Hussien, H.M.; Abo-Sraiaa, M.M. Ameliorated effects of garlic (Allium sativum) on biomarkers of subchronic acrylamide hepatotoxicity and brain toxicity in rats. Toxicol. Envir. Chem. 2010, 92, 1357-1372. [CrossRef]

29. Massart, D.L.; Vandeginste, B.G.M.; Buydens, L.M.C.; De Jong, S.; Lewi, P.J.; Smeyers-Verbeke, J. Chemometrics: A Textbook, 1st ed.; Elsevier: Amsterdam, The Netherlands, 1988; pp. 659-682.

30. Martinez, E.; Rodriguez, J.A.; Bautista, M.; Rangel-Vargas, E.; Santos, E.M. Use of 2-Naphthalenethiol for derivatization and determination of acrylamide in potato crisps by high-performance liquid chromatographic with fluorescence detection. Food Analy. Methods 2018, 11, 1636-1644. [CrossRef]

31. Minekus, M.; Alminger, M.; Alvito, P.; Balance, S.; Bohn, T.; Bourlieu, C.; Carriere, F.; Boutrou, R.; Corredig, M.; Dupont, D.; et al. A standardised static in-vitro digestion method suitable for food-An international consensus. Food Function 2014, 5, 1113-1124. [CrossRef]

Sample Availability: Samples of the compounds are not available from the authors.

(C) 2019 by the authors. Licensee MDPI, Basel, Switzerland. This article is an open access article distributed under the terms and conditions of the Creative Commons Attribution (CC BY) license (http://creativecommons.org/licenses/by/4.0/). 



\title{
Determination of $\mathrm{N}$-Carbamylglutamate in Feeds and Animal Products by High Performance Liquid Chromatography Tandem Mass Spectrometry
}

\author{
Yonghang Ma, Zhengcheng Zeng, Lingchang Kong, Yuanxin Chen and Pingli He * \\ State Key Laboratory of Animal Nutrition, College of Animal Science and Technology, \\ China Agricultural University, Beijing 100193, China \\ * Correspondence: hepingli@cau.edu.cn; Tel.: +86-10-62733688
}

Academic Editor: Jose M. Miranda

Received: 18 July 2019; Accepted: 30 August 2019; Published: 31 August 2019

\begin{abstract}
N$-carbamylglutamate (NCG), a synthetic analogue of $N$-acetylglutamate, is an activator of blood ammonia conversion and endogenous arginine synthesis. Here, we established an accurate quantitative determination of NCG in feeds, animal tissues, and body fluids using the high performance liquid chromatography tandem mass spectrometry (HPLC-MS/MS). The sample pretreatment procedures included extraction with $0.5 \%$ of formic acid in water/methanol $(80 / 20, v / v)$, and purification using an anionic solid phase extraction cartridge. Satisfactory separation of NCG was achieved in $20 \mathrm{~min}$ with the application of an Atlantis T3 column, and a confirmative detection of NCG was ensured by multiple reaction monitoring of positive ions. NCG spiked in feeds, tissues, and body fluids were evaluated in regard to linearity, sensitivity, recovery, and repeatability. Recoveries for different sample matrices were in the range of $88.12 \%$ to $110.21 \%$ with relative standard deviations (RSDs) less than $8.8 \%$. Limits of quantification were within the range of 0.012 to $0.073 \mathrm{mg} \mathrm{kg}^{-1}$ and 0.047 to $0.077 \mu \mathrm{g} \mathrm{mL}^{-1}$ for solid and liquid samples, respectively. This study will provide a solid foundation for the evaluation of availability and metabolic mechanism of NCG in animals.
\end{abstract}

Keywords: N-carbamylglutamate; feeds; animal products; milk; HPLC-MS/MS

\section{Introduction}

$\mathrm{N}$-carbamylglutamate (NCG) is a synthetic analogue of $\mathrm{N}$-acetylglutamate (NAG) (Figure 1), which is the allosteric stimulator of carbamyl phosphate synthase-1 (CPS1). CPS1 is a key enzyme functioning in the urea cycle and endogenous arginine synthesis pathway [1]. Like NAG, NCG can activate CPS1 and lead the conversion of blood ammonia into the mitochondrial carbamoyl-phosphate, further stimulating the endogenous synthesis of arginine. Due to its good stability and safety [2,3], NCG was initially used for the clinical treating of hyperammonemia caused by the NAG synthetase deficiency $[4,5]$, propionic aciduria and methylmalonic aciduria [6,7], and maple syrup urine disease [8]. NCG is also proven to be a novel, effective and low-cost substitute feed additive for arginine. In 2014, China's ministry of agriculture approved NCG as a new feed additive to use in the livestock (new feed additive certificate no. 2014-01). The maximum addition limit of NCG in the compound feed is $800 \mathrm{~g} \mathrm{t}^{-1}$ of sow, and $880 \mathrm{~g} \mathrm{t}^{-1}$ of dairy cow, respectively. Compared with the sole supplementation of NAG or arginine, NCG can avoid being catabolized by the deacylase or amino acid metabolism enzymes, and does not cause nutritional antagonism against other amino acids, especially lysine, tryptophan, and histidine [1,9]. Previous studies have indicated that oral administration of NCG $50 \mathrm{mg}$ per kg body weight two times a day, increases piglets' plasma arginine concentration by $68 \%$, and weight gain by $61 \%$ in 10 days [1]. More recently, several results have been reported that gilts with dietary supplementation of $0.05 \%$ and $0.1 \%$ of NCG had more pigs born alive, and significantly 
increased the live litter weight $[10,11]$. A similar effect of NCG on growth promotion and reproductive performance enhancement have also been found in other species of animals including the rat [12], cattle [13], sheep [14], goat [15], and yellow-feather broiler [16].

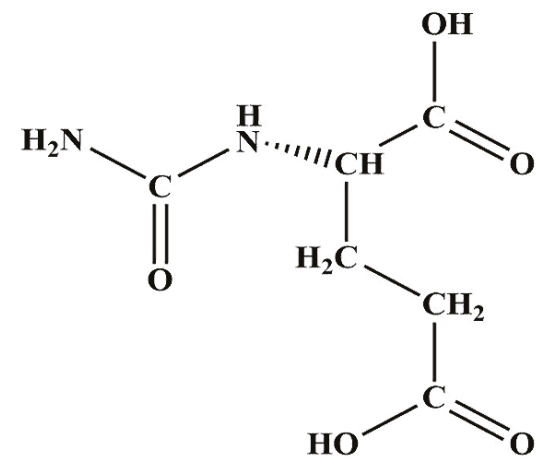

Figure 1. The chemical structure of $N$-carbamylglutamate.

Although the physiological functions of NCG have been well elucidated, and NCG has long been shown to be non-toxic and free of side effects [2], its metabolic process in animals remains unclear. With the promising use of NCG in the livestock, it is necessary to develop an accurate measurement method for NCG in the feed and animal products. Based on the chemical structure of NCG, the infrared spectroscopy (IR), nuclear magnetic resonance (NMR) spectroscopy, and high performance liquid chromatography (HPLC) have been adopted in the analysis of the structure and content of the NCG additive (purity $>97 \%$ ) [17]. However, due to the complexity of the feed and animal products matrices, few studies have been conducted to deal with the determination of NCG in the feeds [18], and to the best of our knowledge, there is no former report regarding the NCG residue detection in animal tissues or body fluids.

Since NCG has poor absorption of the UV-Vis spectrum, using the HPLC based on the UV detection will result in low responsivity and sensitivity. Our group tried to determine the NCG using the beforeor past-column derivation, but it showed a multiple matrix interference leading to unsatisfactory resolution results, and the procedures were relatively complex. In recent years, the high performance liquid chromatography-tandem mass spectrometry (HPLC-MS/MS), due to its high selectivity and sensitivity, has become the preferred method to analyze the trace small molecular compounds in the complex substrates $[19,20]$. This study developed a HPLC-MS/MS method to qualitatively and quantitatively determine NCG in the feed, animal tissues, and body fluids with excellent accuracy and sensitivity. The proposed method can achieve a fast separation of NCG within a 20 min gradient elution, and the method validation was achieved by evaluating the linearity, sensitivity, recovery, as well as the accuracy and repeatability for NCG in the feeds and animal products.

\section{Results and Discussion}

\subsection{Optimization of HPLC-MS/MS Conditions}

In order to improve the analytical sensitivity and selectivity, parameters of the mass spectrometry such as the ionization mode, source temperature, capillary voltage, nebulizer pressure, sheath gas flow, collision energy, and fragmentor voltage were optimized using the NCG standard solution. The result showed that the most abundant precursor ion of NCG was the pseudo-molecular ion $[\mathrm{M}+\mathrm{H}]^{+}$at $m / z$ 191.0 (Figure 2A and Figure S1). The MS/MS spectrum of this precursor ion is shown in Figure 2B. The most abundant product ion $(\mathrm{m} / \mathrm{z}$ 84.0) was used for quantitation while the two relatively abundant product ions ( $m / z$ 130.0, $m / z$ 148.0) were selected for qualification (Figure 2C-E). With the aim to increase 
the signal responses of characteristic product ions and their stability, the parameters (fragmentor, collision energy) in the second mass analyzer were optimized. The optimal fragmentor of the precursor ion $(\mathrm{m} / \mathrm{z} 191.0)$ is $50 \mathrm{~V}$. The optimal collision energy of $\mathrm{m} / \mathrm{z} 84.0, \mathrm{~m} / \mathrm{z} 130.0$, and $\mathrm{m} / \mathrm{z} 148.0$ are $15 \mathrm{~V}, 10 \mathrm{~V}$, and $5 \mathrm{~V}$, respectively.
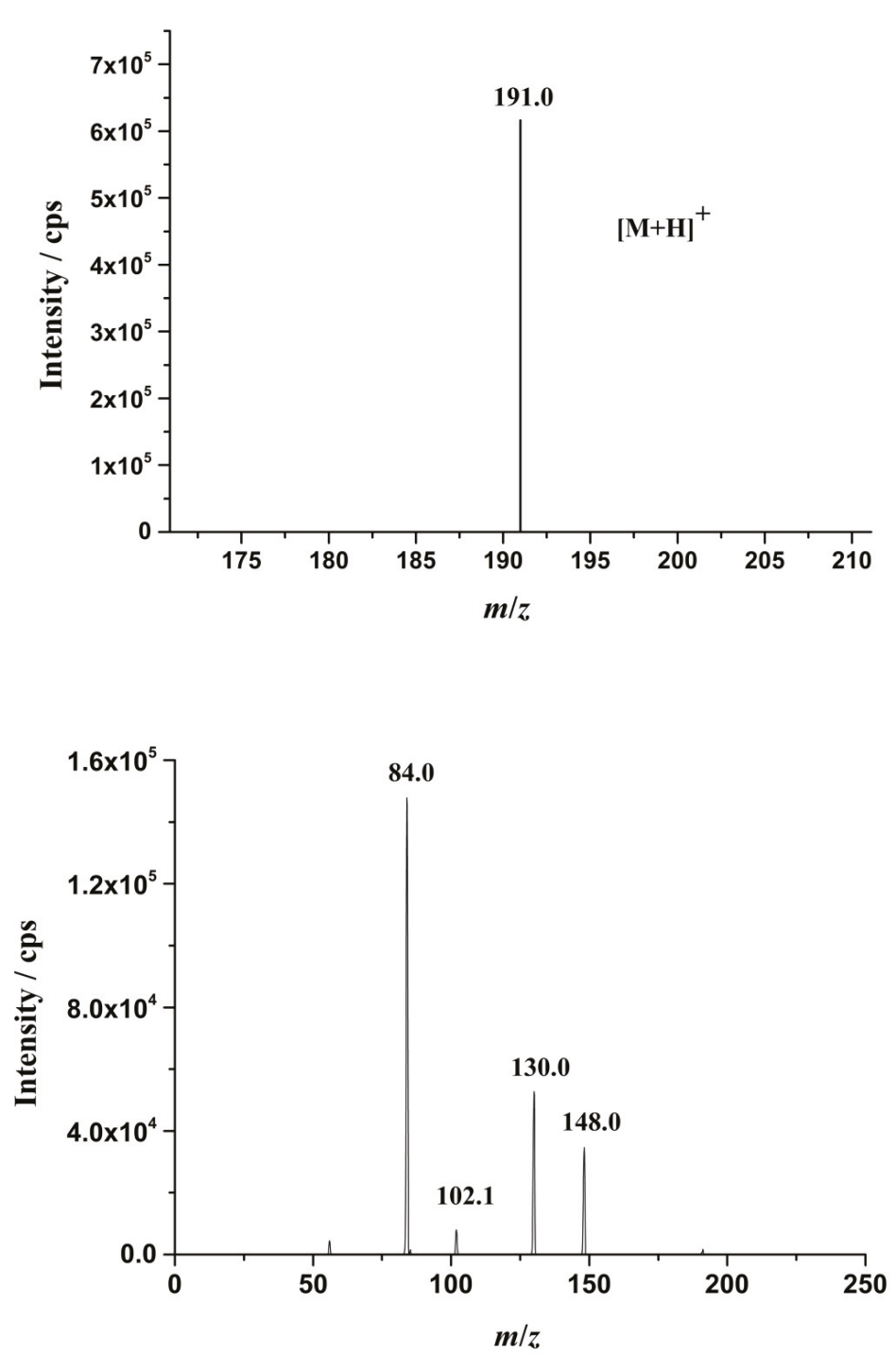

Figure 2. Cont. 

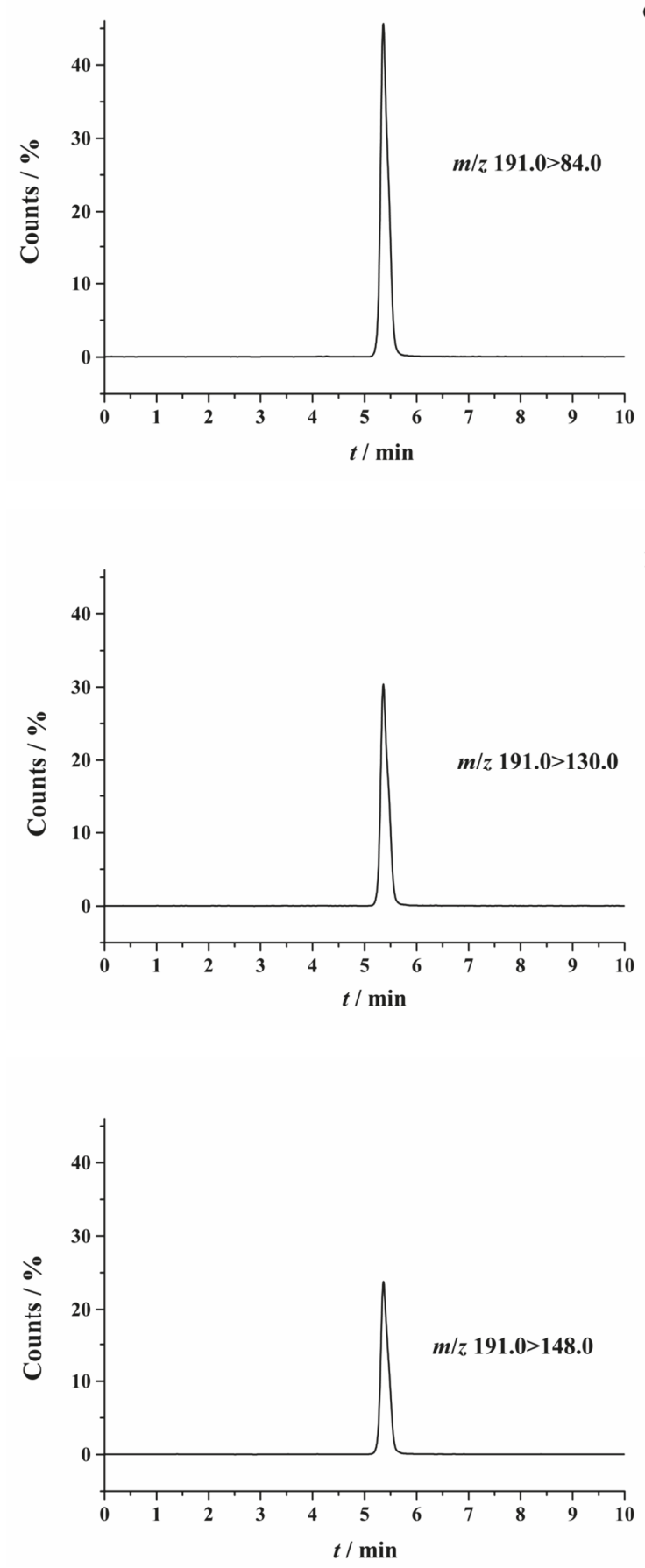

Figure 2. (A) Parent ion chromatogram of N-carbamylglutamate (NCG); (B) the tandem mass spectrometry (MS/MS) spectrum of the NCG precursor ion; (C-E) typical extracted mutiple reaction monitoring (MRM) ion chromatograms of the NCG standard conducted under optimal conditions. 
NCG is a compound with strong polarity. A Waters Atlantis $T_{3} C_{18}$ column $(4.6 \times 250 \mathrm{~mm}, 5 \mu \mathrm{m})$ was compared with a Waters BEH $\mathrm{C}_{18}$ column $(2.1 \times 100 \mathrm{~mm}, 1.7 \mu \mathrm{m})$. The $\mathrm{T}_{3}$ column showed a better retention for polar compounds with reduced peak tailing thus better peak shapes and improved analytical results than the $\mathrm{BEH}$ column. In addition, considering that there are many free amino acids, fatty acids, and other small molecular metabolites in animal samples, the long analytical column with strong polarity is more suitable for the separation of NCG without a precolumnar derivation. Thus, the Atlantis T3 C18 column was chosen as the analysis column. Moreover, the mobile phase of HPLC is a critical factor influencing the analytical results and sensitivity of the detection. Compared with acetonitrile, using methanol as the organic mobile solvent can achieve better chromatographic separation of NCG. Due to the weak acidity of NCG, the addition of a small amount of formic acid could improve the peak shape and improve the sensitivity. Therefore, $0.1 \%$ of the formic acid aqueous solution and methanol were selected to be the mobile phases for the binary gradient pump system. Figure 2C showed the typical extracted MRM ion chromatogram of NCG conducted under optimal conditions.

\subsection{Optimization of Extract Condition}

An effective pretreatment should serve the purpose that the impurity substance is excluded while the target analyte stays as much as possible. As NCG is soluble in both water and methanol, pilot experiments have been conducted to determine the optimal extraction solvent with the finest extraction result. For the feed samples, five extract solvents including water, water/methanol (80:20, $v / v)$, water/methanol $(50: 50, v / v)$, water/methanol $(20: 80, v / v)$ and methanol were compared. The results show that the recoveries were water $>$ water/methanol $(80: 20, v / v)>$ methanol $>$ water/methanol $(50: 50$, $v / v)>$ water/methanol $(20: 80, v / v)$. However, using water as the extraction solvent was subjected to a greater matrix effect presumably due to the complex water-soluble additive in the feed. Thus, water/methanol $(80: 20, v / v)$ was selected as the extraction solvent. To better improve the extraction efficiency of NCG in the water/methanol $(80 / 20, v / v)$ solvent, different concentration levels of formic acid in the water including $0,0.1 \%, 0.5 \%$, and $1 \%$ were compared. The results show that $0.5 \%$ of formic acid in water/methanol $(80 / 20, v / v)$ manifested the best extraction result with a recovery of $99.1 \%$. In addition, the high recovery $(>100 \%)$ were shown in Figure 3C and D. We speculated that the matrix effect in the $C$ and D extract may cause the enhancement of the NCG signal in MS, which leads to the recovery of NCG over $100 \%$. Therefore, $0.5 \%$ of formic acid in water/methanol $(80 / 20$, $v / v)$ was applied as the extraction solvent for NCG in the feeds (Figure 3). For the animal samples, the biggest interference came from the high lipid and protein content in the samples [21]. Similarly, different proportions of methanol and $0.5 \%$ of formic acid solution were also tested for the optimization of extraction agents. Moreover, the application of ice-cold methanol combined with the subsequent refrigerated centrifugation step can efficiently precipitate and remove most of the interference proteins present in milk, serum, and tissue samples [20,22]. Thus, ice-cold methanol $(100 \%)$ was finalized as the optimal extraction solvent for NCG in the animal body fluids and tissues due to its precipitation effect of proteins and relatively good recovery (Figure 3).

\subsection{Optimization of Purification Condition}

A subsequent purification experiment of the sample extracts was conducted using the solid-phase extraction (SPE) cartridges to further decrease the matrix interference and enhance sensitivity. NCG is a weak acid compound. A strong anion exchange SPE cartridge was used in virtue of its strong adsorption ability for the anionic compound. For the better retentivity of NCG, an appropriate amount of $5 \%$ ammonia solution was added to adjust the $\mathrm{pH}$ of the extract and make NCG anionic. The results show that the $\mathrm{pH}$ of the extract that ranged from 8 to 10 was optimal, the NCG retained above $95 \%$ on the SPE (Figure 4). Since the cartridge was a strong anion exchange column, considering the isoelectric point of the NCG ( $\mathrm{pI} 3.02$ ), a lower $\mathrm{pH}(<8)$ will not be able to sufficiently make the NCG anionic, resulting in lower retentivity. On the other hand, if the $\mathrm{pH}$ is too high $(>10)$, other interfering 
compounds may be turned anionic and compete with NCG for the limited retention capacity of the cartridge, this will also cause lower retentivity of NCG in the column. In addition, the NCG content in the feeds were very high, a direct application of the sample extracts may cause oversaturation and lead to unsatisfactory recoveries of NCG due to limited adsorption capacity of the cartridges. Our study has indicated that a reduction of the NCG concentration in the sample extracts could significantly increase the NCG recoveries. To avoid oversaturation and improve the peak shape, feed sample extracts were diluted 10 times with water before loaded onto the cartridges. On the contrary, if the content of the NCG in the sample is too low, such as the biological sample, the loading volume should be increased before passing through the column.

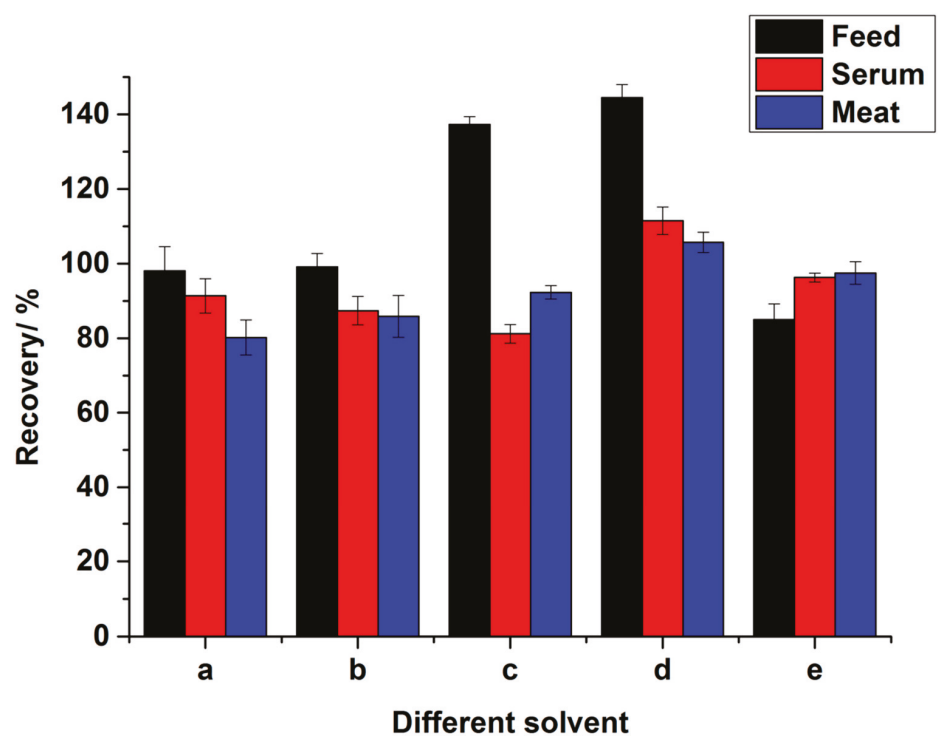

Figure 3. Recoveries of NCG from matrices using different solvents: (a) $0.5 \%$ of formic acid solution; (b) $0.5 \%$ of formic acid solution/methanol $(80: 20, v / v)$; (c) $0.5 \%$ of formic acid solution/methanol (50:50, $v / v)$; (d) $0.5 \%$ of formic acid solution/methanol $(20: 80, v / v)$; (e) methanol.

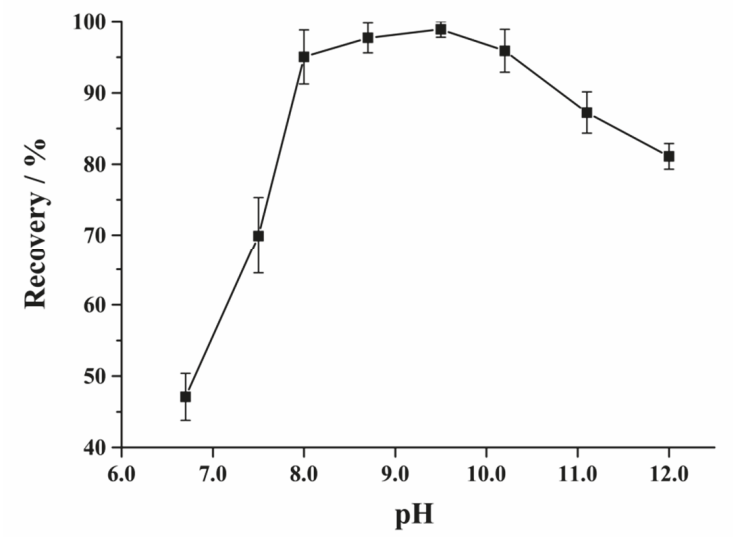

Figure 4. Dependence of the retention abilities of the NCG on the solid-phase extraction (SPE) cartridge with different $\mathrm{pH}$ of the loading solvent. 


\subsection{Method Validation}

\subsubsection{Stability and Matrix Effect}

For the stability test, the NCG stock solution was diluted into $0.005,0.1,2 \mu \mathrm{g} \mathrm{mL} \mathrm{m}^{-1}$ to have six aliquots with concentrations around the linearity range. These aliquots were stored at $-4{ }^{\circ} \mathrm{C}$ and $20{ }^{\circ} \mathrm{C}$, respectively. Normally, the criterion for the stability is that degradation is equal to or less than $5 \%$. The results show that the solution could be stored stably for at least three months and one week at the $-4{ }^{\circ} \mathrm{C}$ refrigerator and $20^{\circ} \mathrm{C}$, respectively.

Matrix effects come from various chemical and physical processes during ionization of the analytes in the ESI mode of mass spectrometry, which causes signal suppression or enhancement. The matrix effect was evaluated by comparing three NCG concentrations $\left(0.005,0.1,2 \mu \mathrm{g} \mathrm{mL}^{-1}\right)$ constructed in the solvent and fortified sample extract. The matrix effects were calculated by comparing the peak area of NCG in the solvent with the peak area of NCG in the fortified sample extract. The results show that the matrix effects ranged from 1.08 to 0.54 for the feed and biological samples. Especially for the biological samples, the matrix inhibition effects were obvious when a high concentration NCG was added. Therefore, the quantification of NCG must be performed using the matrix-matched calibrators.

\subsubsection{Linearity, Precision, Accuracy, LOQ and LOD}

A series of experiments were carried out with the aim to validate the linearity, sensitivity, precision, and accuracy of the established method. The NCG stock solution was diluted into 0.0016, 0.08, 0.2, 0.5, $1,2 \mu \mathrm{g} \mathrm{mL}{ }^{-1}$ working solutions. Excellent linearity was obtained at the NCG concentrations ranging from $0.0016-2 \mu \mathrm{g} \mathrm{mL}^{-1}$ with a correlation coefficient of $\left(\mathrm{R}^{2}\right) 0.999$. To evaluate the sensitivity of this method, the limits of detection (LOD) and the limits of quantitation (LOQ) were tested. The LOD, defined as the analyte concentration at three times the signal to noise ratio $(\mathrm{S} / \mathrm{N})$, was determined for NCG in the feed, milk, serum, meat, liver, and kidney samples. The results indicated that the LOD values were within the range of 0.0035 to $0.022 \mathrm{mg} \mathrm{kg}^{-1}$ and 0.014 to $0.023 \mu \mathrm{g} \mathrm{mL}^{-1}$ for the solid and liquid samples, respectively (Tables 1 and 2). The LOQ, defined as the analyte concentration at 10 times the $\mathrm{S} / \mathrm{N}$, were in the range of 0.012 to $0.073 \mathrm{mg} \mathrm{kg}^{-1}$ and 0.047 to $0.077 \mu \mathrm{g} \mathrm{mL}^{-1}$ for the solid and liquid samples, respectively (Tables 1 and 2). Here, the compound feed, concentrated feed, and premixed feed are all called the feed. Since the three matrices are similar, the LOD and LOQ values for the three feeds were just slightly different. For convenient use, we have integrated the three similar results into one LOD and one LOQ.

Table 1. Percentage recoveries and relative standard deviations (RSDs) of NCG in different feed matrices $(n=3)$.

\begin{tabular}{|c|c|c|c|c|}
\hline Matrices & $\begin{array}{c}\text { Added } \\
\text { Concentration (\%) }\end{array}$ & Recoveries (\%) & LOD (mg kg-1) & LOQ (mg kg-1) \\
\hline \multirow{4}{*}{ Compound feed } & 0.01 & $96.85(1.3)^{a}$ & \multirow{9}{*}{0.022} & \multirow{9}{*}{0.073} \\
\hline & 0.05 & $98.89(2.9)$ & & \\
\hline & 0.1 & $99.24(5.0)$ & & \\
\hline & 0.05 & $107.0(3.5)$ & & \\
\hline \multirow{3}{*}{ Concentrated feed } & 0.2 & $106.1(7.1)$ & & \\
\hline & 1.0 & $97.60(8.8)$ & & \\
\hline & 0.5 & $94.27(6.8)$ & & \\
\hline \multirow{2}{*}{ Premix } & 2.0 & $91.90(3.9)$ & & \\
\hline & 10 & $100.2(3.6)$ & & \\
\hline
\end{tabular}

${ }^{\mathrm{a}}$ Figures in bracket represented the relative standard deviation (\%). 
Table 2. Percentage recoveries and relative standard deviations (RSDs) of NCG in different animal samples $(n=3)$.

\begin{tabular}{|c|c|c|c|c|}
\hline Matrices & $\begin{array}{c}\text { Added } \\
\text { Concentration }\end{array}$ & Recoveries (\%) & $\operatorname{LOD}\left(\mu \mathrm{g} \mathrm{mL}^{-1}\right)$ & $\operatorname{LOQ}\left(\mu \mathrm{g} \mathrm{mL}^{-1}\right)$ \\
\hline \multirow{4}{*}{ Serum $\left(\mu \mathrm{g} \mathrm{mL}^{-1}\right)$} & 0.1 & $94.25(3.8)^{a}$ & \multirow{4}{*}{0.023} & \multirow{4}{*}{0.077} \\
\hline & 1.0 & $110.2(2.3)$ & & \\
\hline & 10 & $96.34(5.1)$ & & \\
\hline & 0.1 & $88.12(1.8)$ & & \\
\hline \multirow[t]{2}{*}{$\operatorname{Milk}\left(\mu \mathrm{g} \mathrm{mL} L^{-1}\right)$} & 1.0 & $102.5(3.2)$ & \multirow[t]{2}{*}{0.014} & \multirow[t]{2}{*}{0.047} \\
\hline & 10 & $89.58(4.7)$ & & \\
\hline \multirow{2}{*}{ Meat $\left(\mathrm{mg} \mathrm{kg}^{-1}\right)$} & 0.05 & $93.84(7.6)$ & \multirow{2}{*}{0.0038} & \multirow{2}{*}{0.013} \\
\hline & 0.1 & $101.6(3.4)$ & & \\
\hline \multirow{2}{*}{ Kidney (mg kg ${ }^{-1}$ ) } & 0.05 & $89.14(3.1)$ & \multirow{2}{*}{0.0069} & \multirow{2}{*}{0.023} \\
\hline & 0.1 & $93.65(5.6)$ & & \\
\hline \multirow{2}{*}{ Liver $\left(\mathrm{mg} \mathrm{kg}^{-1}\right)$} & 0.05 & $94.54(7.4)$ & \multirow{2}{*}{0.0035} & \multirow{2}{*}{0.012} \\
\hline & 0.1 & $97.36(2.9)$ & & \\
\hline
\end{tabular}

${ }^{a}$ Figures in bracket represented the relative standard deviation (\%).

The method precision and accuracy were evaluated by the recoveries of NCG in the spiked samples. Recoveries were determined for the feeds, milk, serum, meat, procine liver, and kidney, three replicates were used for each sample at different concentrations. The MRM ion chromatograms for a blank (free of NCG) feed sample and the compound feed sample spiked with NCG were demonstrated in Figure 5A,B and Figures S2-S19, respectively. The peak intensity ratio of the three product ions of NCG can be used to confirm the presence of NCG when compared with the peak intensity ratio obtained from the standard sample. The most abundant product ion of the mass spectrum was selected for the quantitative determination and evaluation of the recoveries for NCG. Calibration curves developed using an external standard were used to quantify NCG in the spiked samples. The spiked levels, spiked recoveries, and coefficients of variation were evaluated. According to the recommended dose of NCG in the feeds, NCG was spiked in the compound feed at $0.01 \%, 0.05 \%$, and $0.1 \%$, the premix feed at $0.05 \%, 0.2 \%$, and $1 \%$, and the concentrate feed at $0.5 \%, 2 \%$, and $10 \%$. Three replicates were analyzed for each concentration. A good consistency was found between the actual spiked amount of NCG and the estimated concentrations in three different feed matrices (Table 1). The recoveries were within the range of $91.90 \%$ to $107.0 \%$ with the coefficients of variation ranging from $1.3 \%$ to $8.8 \%$.

Similarly, the above established method was also applied to the detection of the NCG spiked animal products. The MRM ion chromatograms for the blank and spiked animal products samples were shown in Figure 5C-G and Figures S20-S49, respectively. NCG was spiked in meat, kidney, and liver at 0.05 , and $0.1 \mathrm{mg} \mathrm{kg}^{-1}$. For each sample concentration, three replicates were analyzed to evaluate the spiked levels, spike recoveries, and coefficients of variation. As presented in Table 2, reliable results were found for most test samples. The recoveries for NCG ranged from $89.14 \%$ to $101.56 \%$ and the coefficients of variation were less than $7.6 \%$. The NCG were spiked in milk and serum at $0.1,1$, and $10 \mu \mathrm{g} \mathrm{mL}^{-1}$. The recoveries ranged from $88.12 \%$ to $110.21 \%$ with the coefficients of variation ranging from $1.8 \%$ to $5.1 \%$ (Table 2 ).

Both the intra-assay and inter-assay reproducibility of this method were evaluated. For instance, five repeats at an intermediate concentration $(0.05 \%)$ were used to determine the recoveries of NCG spiked in the compound feed. According to the analytical results, the recoveries of NCG were within the range of $98.89 \%$ to $102.76 \%$ and the coefficients of variation were less than $2.9 \%$ and $3.8 \%$ for the intra-assay (within a day) and inter-assay (over a period of five consecutive days) measurements, respectively. For the animal samples, this method also showed satisfactory reproducibility. For $1 \mu \mathrm{g} \mathrm{mL} \mathrm{g}^{-1}$ of NCG spiked in the serum, the recoveries of NCG were within the range of $93.25 \%$ to $104.68 \%$ and the coefficients of variation were less than $4.7 \%$ and $5.4 \%$ for the intra-assay and inter-assay measurements, respectively. For $0.05 \mathrm{mg} \mathrm{kg}^{-1}$ of NCG spiked in the liver, 
the recoveries of NCG were within the range of $91.23 \%$ to $106.71 \%$ and the coefficients of variation were less than $3.9 \%$ and $6.7 \%$ for the intra-assay and inter-assay measurements, respectively.

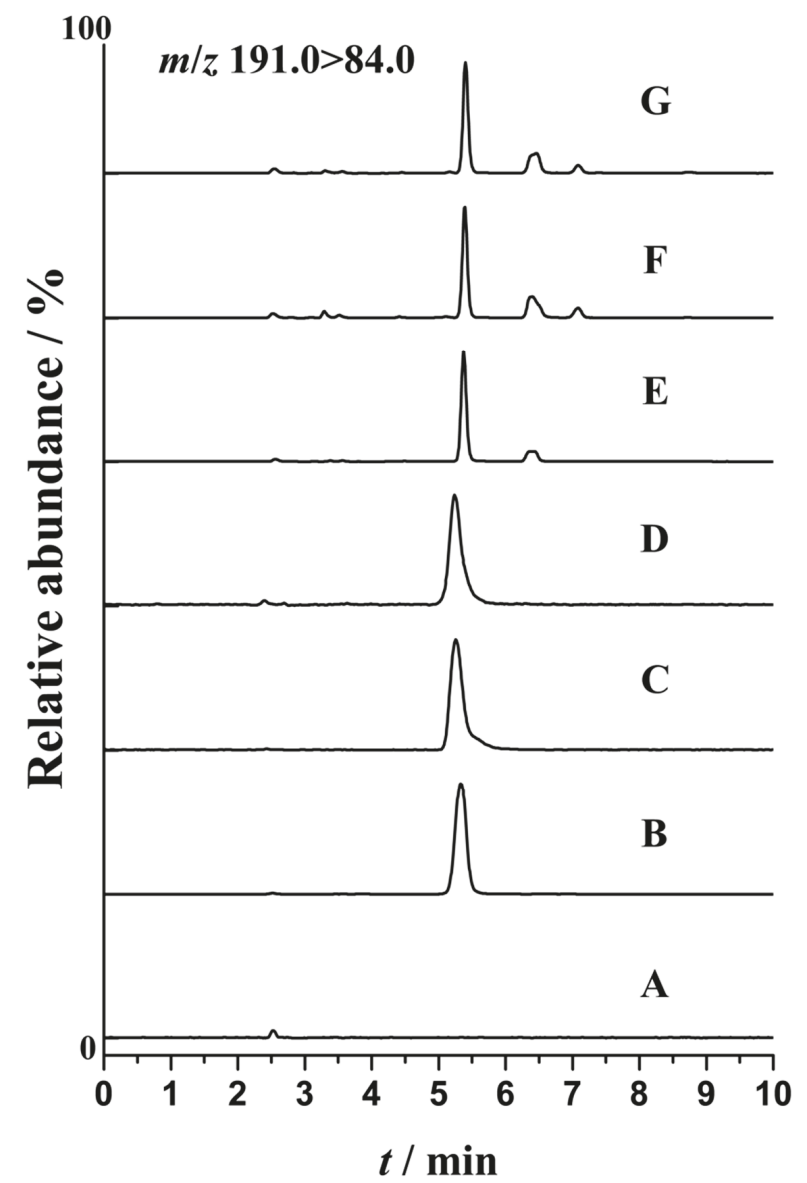

Figure 5. Quantitative product ion chromatograms of the NCG in different matrices: (A) Blank feed sample; (B) compound feed; (C) milk; (D) serum; (E) meat; (F) liver; (G) kidney.

\subsection{The Analysis of Authentic Samples}

The method established in this study was applied to determine the NCG content in the authentic feed samples added with NCG additive. The results showed that NCG was detected in the compound feed, concentrated feed, and premix feed samples with the average content of $0.098 \%, 0.95 \%$, and $9.53 \%$, respectively. The variation between the two parallel samples was less than $10 \%$, while NCG was not detected in the ordinary swine feed samples $\left(<0.022 \mathrm{mg} \mathrm{kg}^{-1}\right)$. According to the actual addition amount, the accuracy for the determination of the compound, concentrate, and premix feed was $98.0 \%, 95.0 \%$, and $95.3 \%$, respectively. The proposed method was also adopted for the determination of NCG in the authentic serum samples from pigs and milk sample from cows (each concentration has six replicates). The results showed that the concentration of NCG in the serum samples increased significantly with the increase of NCG in the diets (Table 3). Except for the control group, the NCG levels in the serum of four diets ranged from 0.11 to $1.31 \mu \mathrm{g} \mathrm{mL}^{-1}$. Moreover, the multiple relationship between the serum NCG and dietary NCG was basically consistent. The NCG concentration in milk was about 
$0.0647 \mu \mathrm{g} \mathrm{mL} \mathrm{m}^{-1}$ when the cow was fed $20 \mathrm{~g}$ of NCG per day. Therefore, the developed method proved both feasible and reliable for the quantitative determination of NCG in the routine analysis.

Table 3. The results of NCG in the authentic samples $(n=6)$.

\begin{tabular}{ccccc}
\hline Sample & Diets Added (\%) & $\begin{array}{c}\text { NCG Concentration } \\
\left(\mu \mathbf{g ~ m L}^{-1}\right)\end{array}$ & $\begin{array}{c}\text { Intra-Day } \\
\text { Precision CV (\%) }\end{array}$ & $\begin{array}{c}\text { Inter-Day } \\
\text { Precision CV (\%) }\end{array}$ \\
\hline \multirow{3}{*}{ Serum $^{\mathrm{b}}$} & 0 & $\mathrm{ND}^{\mathrm{a}}$ & - & - \\
& 0.025 & 0.112 & 6.8 & 8.7 \\
& 0.05 & 0.253 & 2.4 & 5.6 \\
Milk & 0.1 & 0.561 & 7.8 & 11 \\
& 0.2 & 1.31 & 12 & 5.1 \\
& 0 & $\mathrm{ND}$ & - & - \\
\hline
\end{tabular}

${ }^{\mathrm{a}}$ Not detected, ${ }^{\mathrm{b}}$ Serum from piglets.

\section{Materials and Methods}

\subsection{Materials and Reagents}

The NCG standard (purity $>99.5 \%$ ) was purchased from Sigma-Aldrich (St. Louis, MO, USA). The methanol and formic acid used were of a HPLC grade and were obtained from Fisher Scientific International (Hampton, NH, USA) and Dikma Technology (Richmond Hill, ON, Canada), respectively. Other chemicals used were all of the analytical grade. A Milli-Q system (Millipore Corporation, Bedford, MA, USA) was applied to provide ultrapure water for the preparation of all aqueous solutions.

The NCG stock solution $\left(1 \mathrm{mg} \mathrm{mL}^{-1}\right)$ was prepared by dissolving the NCG standard in ultrapure water, and preserved at $4{ }^{\circ} \mathrm{C}$. The preparation of the NCG working solutions was done daily by diluting the stock solution to appropriate concentrations with ultrapure water. The extraction solvent, $0.5 \%$ of formic acid in water/methanol $(80 / 20, v / v)$, was prepared by mixing $4 \mathrm{~mL}$ of formic acid with $796 \mathrm{~mL}$ of Milli-Q water, and then mixing with $200 \mathrm{~mL}$ of methanol.

\subsection{Instruments and Apparatus}

The HPLC-MS/MS was performed on an Agilent 1200 UHPLC system coupled with an Agilent 6460 Triple Quadrupole Mass Spectrometer (Agilent Technologies, Fermont, CA, USA). An Ultrasonic Cleaner (Kunshan, China) was used to promote the sample dissolution and extraction. A low temperature high speed centrifuge (Eppendorf, Hamburg, German) was used to centrifuge the samples.

\subsection{Sample Preparation}

Feed samples free of NCG were provided by the Ministry of Agricultural Feed Industry Centre (Beijing, China). The liver and kidney as blanks were from a porcine, and milk was from a cow. They were all purchased from local supermarkets. The serum of the pig as blanks were collected from the animal research station of China Agricultural University (Hebei, China). Prior to the extraction, the feed samples were crushed into about 60 mesh by a small mill. The meat, liver, and kidney tissues were homogenized in a homogenizer for five min. The milk and serum were pre-treated by centrifuging at $14,000 \mathrm{rpm}$ for $10 \mathrm{~min}$ at $4{ }^{\circ} \mathrm{C}$, then the supernatant was collected.

\subsection{Sample Extraction and Purification}

Extraction of the feed samples was carried out by adding $20 \mathrm{~mL}$ of the extraction solvent $(0.5 \%$ of formic acid in water/methanol, 80/20, $v / v$ ) into the feeds ( $2 \mathrm{~g}$ for the compound feed, $0.2 \mathrm{~g}$ for the concentrated feed and premix). Usually, the recommended amounts of NCG in the pig compound feed, premixed feed, and concentrated feed were about $0.05 \%, 1 \%$ and $10 \%$, respectively. Since the concentration of NCG in the premix or concentrated feed was too high, in order to avoid too much 
dilution before the HPLC-MS/MS analysis, the sample amount in the premix or concentrated feed was relatively reduced. After the vortex mixing and a $30 \mathrm{~min}$ ultrasonic bath, $10 \mathrm{~min}$ of centrifugation at $14,000 \mathrm{rpm}$ at $4{ }^{\circ} \mathrm{C}$ was completed and the supernatant was collected. For the fluid samples, $2 \mathrm{~mL}$ of pre-centrifuged milk or serum was pipetted into a Corning ${ }^{\circledR} 15 \mathrm{~mL}$ centrifuge tube, and $8 \mathrm{~mL}$ of an ice-cold extraction solvent was added. After the vortex mixing, the samples were centrifuged at $14,000 \mathrm{rpm}$ for $10 \mathrm{~min}$ at $4{ }^{\circ} \mathrm{C}$ and the supernatant collection was done. For the tissue analyses, $2 \mathrm{~g}$ of tissues samples (meat, kidney, or liver) were extracted by adding $20 \mathrm{~mL}$ of an ice-cold extraction solvent. After a thorough vortex mixing, the samples were placed on ice for $30 \mathrm{~min}$ and centrifuged for $10 \mathrm{~min}$ at $14,000 \mathrm{rpm}$ at $4{ }^{\circ} \mathrm{C}$, then the supernatant collection was done.

Before further purification, the above supernatant was diluted 10 times using water and adjusted by adding an appropriate amount of $5 \%$ of ammonia solution to $\mathrm{pH} 8-10$. The strong anion exchange cartridge (Agilent SampliQ SAX, 200 mg, 3 mL, Agilent Technologies, Fermont, CA, USA) was firstly preconditioned with $3 \mathrm{~mL}$ of methanol following by $3 \mathrm{~mL}$ of water. Then, $3 \mathrm{~mL}$ of the diluted supernatant was loaded and slowly passed through the cartridge with a flow rate of approximately $1 \mathrm{~mL} \mathrm{~min}{ }^{-1}$. After rinsing with $3 \mathrm{~mL} \mathrm{5 \%}$ of the ammonia solution and $3 \mathrm{~mL}$ of methanol, elution was carried out with $3 \mathrm{~mL} 2 \%$ of formic acid in methanol. The eluate was then collected and gently evaporated under a nitrogen stream in a $50{ }^{\circ} \mathrm{C}$ water bath. The residue was reconstituted with $1 \mathrm{~mL}$ $0.1 \%$ of an aqueous formic acid solution and filtered by a $0.1 \mu \mathrm{m}$ Syringe Filter (Tianjin Fuji Science and Technology, China). $10 \mu \mathrm{L}$ of the sample was injected by the autosampler for the HPLC-MS/MS analysis.

\subsection{HPLC-MS/MS Conditions}

A Waters Atlantis T3 column $(4.6 \times 250 \mathrm{~mm}, 5 \mu \mathrm{m})$ was applied in the chromatographic separation of NCG. The column temperature was maintained at $35^{\circ} \mathrm{C}$. The mobile phases consisted of solution A $(0.1 \%$ of an aqueous formic acid solution) and B (methanol), and were delivered at a flow rate of $0.8 \mathrm{~mL} \mathrm{~min}{ }^{-1}$. The total run time was set at $20 \mathrm{~min}$. A gradient elution program was developed as follows: $90 \%$ of solution A (initial), with $90-15 \%$ of solution A (from 6 to $6.1 \mathrm{~min}$ ), $15-90 \%$ of solution A (from 12 to $12.1 \mathrm{~min}$ ). Before the next injection, a 7.9 min equilibration was necessary. A calibration curve calculated from the NCG standard solution was used to quantify the NCG content in the spiked samples.

The electron spray ionization source was operated under an optimized condition: Capillary voltage $3500 \mathrm{~V}$, nebulizing gas temperature $350{ }^{\circ} \mathrm{C}$, nebulizing gas flow $5 \mathrm{~L} \mathrm{~min}^{-1}$, sheath gas temperature $350^{\circ} \mathrm{C}$, and sheath gas flow $7 \mathrm{~L} \mathrm{~min}^{-1}$. Positive ions were monitored. The multiple reaction monitor (MRM) mode was applied for the quantitation analysis. Data were collected and processed on the Agilent MassHunter Workstation software (Version B.04.00).

\subsection{The Method Validation}

The method validation was performed with the feeds, serum, meat, liver, and kidney samples. Extracts of the NCG-free samples were used for the preparation of matrix-matched calibration standards. The artificially prepared samples were spiked with the NCG standard solution of $0.01-10 \%$ in the feeds, $0.1-10 \mu \mathrm{g} \mathrm{mL} \mathrm{L}^{-1}$ in fluids, or $0.05-0.1 \mathrm{mg} \mathrm{kg}^{-1}$ in tissues. The validity of the method including the stability, matrix effect, linearity, sensitivity, as well as the precision and accuracy of the method were evaluated in three replicates.

\subsection{The Analysis of Authentic Samples}

One hundred $\mathrm{kg}$ of the commercially prepared compound feed, concentrated feed and premix were added with the NCG feed additive product (NCG content $\geq 97 \%$ ) obtained from Ya Tai XingMu company (Beijing, China) to the concentrations of $0.1 \%$ for the compound feed, $1 \%$ for the concentrated feed and $10 \%$ for the premix, respectively.

The animals breeding experiments were carried out at the animal research station of China Agricultural University (Hebei, China). All piglets used in this study were housed and handled 
according to the established guidelines of China Agricultural University, which were approved by the China Agricultural University Animal Care and Use Committee. Thirty weaned piglets (each 30-40 kg in weight) were randomly assigned to one of the five groups ( $\mathrm{n}=6$ piglets per group). Five pig diets were prepared with NCG added $0 \%, 0.025 \%, 0.05 \%, 0.1 \%$, and $0.2 \%$, respectively. After 26 fed days, blood samples from the precaval veins were collected after fasting $12 \mathrm{~h}$ and centrifuged ( $3000 \mathrm{rpm}$ ) for $10 \mathrm{~min}$. Then, the supernatant was transferred into new tubes and stored at $-20{ }^{\circ} \mathrm{C}$ until use. Milk samples were collected from the cow before and after feeding $20 \mathrm{~g}$ of NCG per day.

Thirty weaned piglets (each $30-40 \mathrm{~kg}$ in weight) were randomly assigned to one of the five groups ( $n=6$ piglets per group).

\section{Conclusions}

A fast, sensitive and reliable HPLC-MS/MS method was successfully developed and optimized for the qualitative and quantitative determination of NCG in the feeds, animal tissues, and body fluids. Based on the high selectivity and satisfactory separation result of the HPLC-MS/MS technique, this method can achieve confirmative identification and accurate determination of NCG in the complex matrices including feeds and animal products. Furthermore, the applicability of the established method has been validated using the real feed, serum and milk samples.

Supplementary Materials: The following are available online at http://www.mdpi.com/1420-3049/24/17/3172/s1.

Author Contributions: Y.M. and Z.Z. designed and performed the experiments; L.K. and Y.C. analyzed the data; P.H. and Y.M. wrote the paper.

Funding: The financial support from The National Key Research and Development Program of China (2018YFD0500402) is gratefully acknowledged.

Conflicts of Interest: The authors declare no conflict of interest.

\section{References}

1. Wu, G.; Knabe, D.A.; Kim, S.W. Arginine nutrition in neonatal pigs. J. Nutr. 2004, 134. [CrossRef] [PubMed]

2. Harper, M.S.; Shen, Z.A.; Barnett, J.F.; Krsmanovic, L.; Myhre, A.; Delaney, B. N-acetyl-glutamic acid: Evaluation of acute and 28-day repeated dose oral toxicity and genotoxicity. Food Chem. Toxicol. 2009, 47, 2723-2729. [CrossRef] [PubMed]

3. Wu, X.; Wan, D.; Xie, C.; Li, T.; Huang, R.; Shu, X.; Ruan, Z.; Deng, Z.; Yin, Y. Acute and sub-acute oral toxicological evaluations and mutagenicity of $\mathrm{N}$-carbamylglutamate (NCG). Regul. Toxicol. Pharmacol. 2015, 73, 296-302. [CrossRef] [PubMed]

4. Schubiger, G.; Bachmann, C.; Barben, P.; Colombo, J.P.; Tönz, O.; Schüpbach, D. N-Acetylglutamate synthetase deficiency: Diagnosis, management and follow-up of a rare disorder of ammonia detoxication. Eur. J. Pediatr. 1991, 150, 353-356. [CrossRef] [PubMed]

5. Burlina, A.B.; Bachmann, C.; Wermuth, B.; Bordugo, A.; Ferrari, V.; Colombo, J.P.; Zacchello, F. Partial N-acetylglutamate synthetase deficiency: A new case with uncontrollable movement disorders. J. Inherit. Metab. Dis. 1992, 15, 395-398. [CrossRef]

6. Gebhardt, B.; Vlaho, S.; Fischer, D.; Sewell, A.; Böhles, H. N-carbamylglutamate enhances ammonia detoxification in a patient with decompensated methylmalonic aciduria. Mol. Genet. Metab. 2003, 79, 303-304. [CrossRef]

7. Gebhardt, B.; Dittrich, S.; Parbel, S.; Vlaho, S.; Matsika, O.; Bohles, H. N-Carbamylglutamate protects patients with decompensated propionic aciduria from hyperammonaemia. J. Inherit. Metab. Dis. 2005, 28, 241-244. [CrossRef]

8. Kalkan, U.S.; Coker, M.; Habif, S.; Ulas, E.S.; Karapinar, B.; Ucar, H.; Kitis, O.; Duran, M. The first use of N-carbamylglutamate in a patient with decompensated maple syrup urine disease. Metab. Brain. Dis. 2009, 28, 241-244. [CrossRef]

9. Wu, G.; Bazer, F.W.; Davis, T.A.; Jaeger, L.A.; Johnson, G.A.; Kim, S.W.; Knabe, D.A.; Meininger, C.J.; Spencer, T.E.; Yin, Y.L. Important roles for the arginine family of amino acids in swine nutrition and production. Livest. Sci. 2007, 112, 8-22. [CrossRef] 
10. Liu, X.; Wu, X.; Yin, Y.; Liu, Y.; Geng, M.; Yang, H.; Blachier, F.; Wu, G. Effects of dietary l-arginine or $\mathrm{N}$-carbamylglutamate supplementation during late gestation of sows on the miR-15b/16, miR-221/222, VEGFA and eNOS expression in umbilical vein. Amino Acids. 2012, 42, 2111-2119. [CrossRef]

11. Zhang, B.; Che, L.; Lin, Y.; Zhuo, Y.; Fang, Z.; Xu, S.; Song, J.; Wang, Y.; Liu, Y.; Wang, P.; et al. Effect of dietary N-carbamylglutamate levels on reproductive performance of gilts. Reprod Domest. Anim. 2014, 49, 740-745. [CrossRef] [PubMed]

12. Liu, G.; Xiao, L.; Cao, W.; Fang, T.; Jia, G.; Chen, X.; Zhao, H.; Wu, C.; Wang, J. Changes in the metabolome of rats after exposure to arginine and N-carbamylglutamate in combination with diquat, a compound that causes oxidative stress, assessed by 1H NMR spectroscopy. Food Funct. 2016, 7, 964-974. [CrossRef] [PubMed]

13. Feng, T.; Schütz, L.; Morrell, B.; Perego, M.C.; Spicer, L. Effects of N-carbamylglutamate and L-arginine on steroidogenesis and gene expression in bovine granulosa cells. Anim. Reprod. Sci. 2018, 188, 85-92. [CrossRef] [PubMed]

14. Zhang, H.; Sun, L.; Wang, Z.; Deng, M.; Nie, H.; Zhang, G.; Ma, T.; Wang, F. N-carbamylglutamate and L-arginine improved maternal and placental development in underfed ewes. Reproduction 2016, 151, 623-635. [CrossRef] [PubMed]

15. Wang, Z.; Wang, R.; Meng, C.; Ji, Y.; Sun, L.; Nie, H.; Mao, D.; Wang, F. Effects of dietary supplementation of $\mathrm{N}$-Carbamylglutamate on lactation performance of lactating goats and growth performance of their suckling kidlets. Small Rumin. Res. 2019, 175, 142-148. [CrossRef]

16. Hu, Y.; Shao, D.; Wang, Q.; Xiao, Y.; Zhao, X.; Shen, Y.; Zhang, S.; Tong, H.; Shi, S. Effects of dietary $\mathrm{N}$-carbamylglutamate supplementation on growth performance, tissue development and blood parameters of yellow-feather broilers. Poult. Sci. 2019, 98, 2241-2249. [CrossRef] [PubMed]

17. Shu, X.; Wu, C.-L.; Wan, K.; Zhang, M.; Wu, X. Synthesis, Crystal Structure and Spectroscopic Properties of Zn(II) with N-carbamylglutamate Ligand. Chin. J. Struc. Chem. 2015, 34, 423-427.

18. Tang, S.; Wang, Y.; Wen, P.; Xin, Z. Determination of N-carbamyl-L-glutamic acid in feedstuff by high performance liquid chromatography coupled with electrospray ionization tandem mass spectrometry. Chinese J. Chromatogr. 2014, 32, 184-188. [CrossRef]

19. Liu, R.; Hei, W.; He, P.; Li, Z. Simultaneous determination of fifteen illegal dyes in animal feeds and poultry products by ultra-high performance liquid chromatography tandem mass spectrometry. J. Chromatogr. B 2011, 879, 2416-2422. [CrossRef]

20. Yin, B.; Li, T.; Zhang, S.; Li, Z.; He, P. Sensitive analysis of 33 free amino acids in serum, milk, and muscle by ultra-high performance liquid chromatography-quadrupole-qrbitrap high resolution mass spectrometry. Food Anal. Methods 2016, 9, 2814-2823. [CrossRef]

21. Dhondt, L.; Croubels, S.; De Cock, P.; De Paepe, P.; De Baere, S.; Devreese, M. Development and validation of an ultra-high performance liquid chromatography-tandem mass spectrometry method for the simultaneous determination of iohexol, p-aminohippuric acid and creatinine in porcine and broiler chicken plasma. J. Chromatogr. B 2019, 1117, 77-85. [CrossRef] [PubMed]

22. De Baere, S.; Devreese, M.; Watteyn, A.; Wyns, H.; Plessers, E.; De Backer, P.; Croubels, S. Development and validation of a liquid chromatography-tandem mass spectrometry method for the quantitative determination of gamithromycin in animal plasma, lung tissue and pulmonary epithelial lining fluid. J. Chromatogr. A. 2015, 1398, 73-82. [CrossRef] [PubMed]

Sample Availability: Samples of the compounds are not available from the authors.

(C) 2019 by the authors. Licensee MDPI, Basel, Switzerland. This article is an open access article distributed under the terms and conditions of the Creative Commons Attribution (CC BY) license (http://creativecommons.org/licenses/by/4.0/). 



\title{
Article \\ Sequence Identification of Bioactive Peptides from Amaranth Seed Proteins (Amaranthus hypochondriacus spp.)
}

\author{
Alexis Ayala-Niño ${ }^{1}$, Gabriela Mariana Rodríguez-Serrano ${ }^{2}$, \\ Luis Guillermo González-Olivares ${ }^{1}$, , Elizabeth Contreras-López ${ }^{1}$, Patricia Regal-López ${ }^{3}$ and \\ Alberto Cepeda-Saez ${ }^{3}$ \\ 1 Chemistry Investigation Center, Universidad Autónoma del Estado de Hidalgo, \\ Carretera Pachuca-Tulancingo km 4.5, Mineral de la Reforma Hidalgo C.P. 46067, Mexico \\ 2 Biotechnology Department, Universidad Autónoma Metropolitana, Unidad Iztapalapa, \\ Mexico City C.P. 55355, Mexico \\ 3 Universidad de Santiago de Compostela, Campus Lugo, 15705 Santiago de Compostela, \\ 27002 A Coruña, Spain \\ * Correspondence: lgonzalez@uaeh.edu.mx; Tel.: +52-771-717-2000
}

Received: 1 June 2019; Accepted: 3 August 2019; Published: 21 August 2019

\begin{abstract}
Amaranthus hypochondriacus spp. is a commonly grown cereal in Latin America, known for its high protein content. The objective of this study was to separate and identify bioactive peptides found in amaranth seeds through enzymatically-assisted hydrolysis using alcalase and flavourzyme. Hydrolysis was carried out for each enzyme separately and compared to two-step continuous process where both enzymes were combined. The biological activity of the resulting three hydrolysates was analyzed, finding, in general, higher bioactive potential of the hydrolysate obtained in a continuous process (combined enzymes). Its fractions were separated by RP-HPLC, and their bioactivity was analyzed. In particular, two fractions showed the highest biological activity as ACE inhibitors with IC50 at 0.158 and 0.134 , thrombin inhibitors with IC50 of 167 and 155, and antioxidants in ABTS assay with SC50 at 1.375 and $0.992 \mathrm{mg} / \mathrm{L}$, respectively. Further sequence analysis of the bioactive peptides was carried out using MALDI-TOF, which identified amino acid chains that have not been reported as bioactive so far. Bibliographic survey allowed identification of similarities between peptides reported in amaranth and other proteins. In conclusion, amaranth proteins are a potential source of peptides with multifunctional activity.
\end{abstract}

Keywords: amaranth protein; flavourzyme; alcalase; bioactive peptides; hydrolysates

\section{Introduction}

Many diseases that prevail nowadays could be tackled more efficiently, and even prevented, by combining a healthy diet with functional foods intake [1]. Among functional food components, we can find bioactive peptides, which are generally short sequences of amino acids encrypted in food proteins [2]. Bioactive peptides are released from proteins as a result of microorganisms' metabolic activity during fermentation, by proteolytic enzymes, or finally by the action of gastrointestinal enzymes once proteins are ingested. Application of commercially available enzymes has become a simple and inexpensive way to access free amino acids and peptides from proteins [3].

Consequently, a vast number of studies using various proteinases target the preparation of hydrolysates from different protein sources, such as cereals and pseudocereals, in an ongoing effort to obtain highly active biopeptides [4-7]. One of the most important highly-consumed Mesoamerican original seeds, with a high content of proteins and an excellent amino acid balance, is amaranth. 
In Mexico, amaranth is consumed in a fresh form, offered by traditional confectionary and in typical dishes of Mexican cuisine [8]. Bioactive peptides found in amaranth exhibit various biological activities—such as anticholesterolemic, antihypertensive, antioxidant, and antithrombotic - and they are released mainly by in vitro digestion [9-12]. However, multiple bioactivities shown by the same peptide fraction of amaranth have never been studied.

In order to find peptide sequences with different biological activities, our research work focused on the separation and identification of the peptide sequences from amaranth proteins released during hydrolysis with two commercial enzymes, alcalase and flavourzyme, in separate and continuous hydrolysis processes. The multiple biological activities exhibited by peptides released from amaranth proteins through enzymatically-assisted hydrolysis have not been reported until now.

\section{Results}

\subsection{Free Amine Groups Analysis during Enzymatic Hydrolysis}

Once the hydrolitic enzymes were added to the protein sample, the progress of the reaction was monitored every $20 \mathrm{~min}$ by the measurement of free amine groups concentration released during the reaction course (Figure 1). It was observed that after $120 \mathrm{~min}$ of hydrolysis with alcalase (H1), the concentration of free amine groups equaled to $6170.53 \pm 29.5 \mathrm{mg} / \mathrm{L} \mathrm{NH}:^{-}$, whereas flavourzyme hydrolysis $(\mathrm{H} 2)$ reached the highest concentration of free amine groups $(5551.11 \pm 33.83 \mathrm{mg} / \mathrm{L}$ $\left.\mathrm{NH}:^{-}\right)$after $90 \mathrm{~min}$ of reaction. It was concluded that, in terms of enzymatic efficiency, alcasase overdoes flavourzyme in the release of peptide fractions. Following the analysis of H1 and H2, the combined two-step hydrolysis (H3) was carried out, and a final free amine groups concentration of $7468.89 \pm 34.79 \mathrm{mg} / \mathrm{L} \mathrm{NH}:^{-}$was obtained after $40 \mathrm{~min}$ of reaction. This result proves that the continuous hydrolitic process (H3) was more efficient than using alcalase and flavourzyme separately.

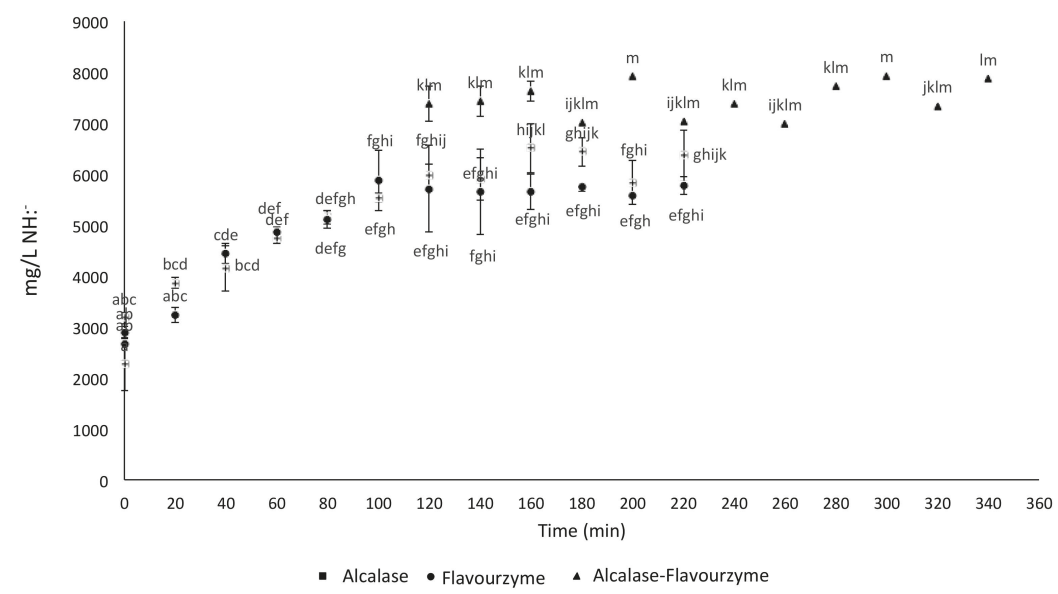

Figure 1. Free amine groups concentration during amaranth protein hydrolysis. ${ }^{*}$ Different letters indicate statistically significant differences between treatments.

\subsection{Hydrolysates Bioactivity Analysis}

Table 1 shows the assessment of the different biological activities exhibited by the hydrolysates $\mathrm{H} 1, \mathrm{H} 2$, and H3, determined during amaranth proteins hydrolysis. For thrombin inhibition essay, H1 hydrolysate showed the highest inhibitory potential (90\%), followed by $\mathrm{H} 2$ hydrolysate which inhibited thrombin activity by approximately $80 \%$. No significant difference was observed for $\mathrm{H} 3$ and $\mathrm{H} 1$ hydrolysates as thrombin inhibitors. When angiotensin-converting enzyme inhibition was evaluated, it was observed that $\mathrm{H} 3$ hydrolysate showed the highest inhibitory potential $(58 \%)$, in comparison 
to $\mathrm{H} 1$ and $\mathrm{H} 2$ hydrolysates (49\% and 39\%, respectively). Finally, antioxidant activity was measured by three different methods based on the free radical scavenging principle, such as ABTS, DPPH, and FRAP. The highest antioxidant activity was observed by the H3 sample in DPPH and FRAP assays (388.94 $\mu \mathrm{mol} \mathrm{TE} / 100 \mathrm{~g}$ and $592.54 \mu \mathrm{mol} \mathrm{Fe} 2 \mathrm{E} / 100 \mathrm{~g}$, respectively), while H1 hydrolysate exhibited the highest antioxidant activity measured by the ABTS method (425.86 $\pm 0.66 \mathrm{mg}$ TE/100 g). Noteworthy, the antioxidant potential of $\mathrm{H} 3$ hydrolysate increased fivefold in the DPPH assay and ninefold in the FRAP assay, compared to the control sample of unhydrolyzed amaranth proteins.

Table 1. Bioactivity potential of amaranth protein hydrolysates after treatment with alcalase (H1), flavourzyme (H2), and in two-step combined hydrolysis (H3).

\begin{tabular}{|c|c|c|c|c|c|}
\hline \multirow[b]{2}{*}{ Hydrolysis } & \multirow{2}{*}{$\begin{array}{c}\text { ACE } \\
\text { Inhibition (\%) }\end{array}$} & \multirow{2}{*}{$\begin{array}{c}\text { Thrombin } \\
\text { Inhibition (\%) }\end{array}$} & \multicolumn{3}{|c|}{ Antioxidant Activity } \\
\hline & & & $\begin{array}{c}\text { DPPH ( } \mu \mathrm{mol} \\
\text { Trolox E/100 g) }\end{array}$ & $\begin{array}{c}\text { ABTS (mg } \\
\text { Trolox E/100 g) }\end{array}$ & $\begin{array}{l}\text { FRAP ( } \mu \mathrm{mol} \\
\text { Fe2 E/100 g) }\end{array}$ \\
\hline nth $F$ & $10.58 \pm 1.19^{d}$ & $11.90 \pm 10.10^{c}$ & $76.66 \pm 1.60^{d}$ & $115.65 \pm 10.30^{d}$ & $63.37 \pm 5.72^{c}$ \\
\hline H1 & $49.49 \pm 1.47^{b}$ & $92.85 \pm 3.36^{\mathrm{a}}$ & $340.17 \pm 10.95^{b}$ & $425.86 \pm 0.66^{\mathrm{a}}$ & $241.70 \pm 9.38^{b}$ \\
\hline $\mathrm{H} 2$ & $39.77 \pm 2.15^{c}$ & $80.95 \pm 13.46^{b}$ & $274.03 \pm 10.84^{c}$ & $398.36 \pm 3.62^{c}$ & $226.29 \pm 11.20^{b}$ \\
\hline H3 & $58.53 \pm 2.58^{\mathrm{a}}$ & $92.85 \pm 3.36^{\mathrm{a}}$ & $388.94 \pm 2.73^{\mathrm{a}}$ & $404.90 \pm 1.52^{b}$ & $592.54 \pm 29.29^{a}$ \\
\hline
\end{tabular}

Values are shown as mean \pm standard deviation $(n=3)$; values in the same column with different superscript letters are significantly different $(p<0.05)$.

\subsection{RP-HPLC Separation and Fraction Bioactivity}

Since the H3 hydrolysate (obtained by application of continuous enzymatic hydrolysis) showed the highest bioactivity, it was chosen for further analysis in order to separate fractions and identify peptide sequences. In total, 56 fractions were obtained through RP-HPLC separation (see Appendix A), of which only 14 could be identified with known proteins. Moreover, protein content was determined in samples collected after $27 \mathrm{~min}$ (Table 2). In the case of the 14 fractions identified with protein, their bioactivity was evaluated by measurement of the IC50 in the ACE and thrombin inhibition assays, and SC50 in the ABTS assay. Results are gathered in Table 2.

Table 2. Bioactivities of amaranth protein fractions (Angiotensin I-Converting Enzyme and Thrombin inhibitory activity $\left(\mathrm{IC}_{50}, \mathrm{mg} / \mathrm{L}\right)$ ) and antioxidant activity (ABTS radical scavenging; $\mathrm{SC}_{50}, \mathrm{mg} / \mathrm{L}$ ).

\begin{tabular}{ccccc}
\hline Fraction & \left.${\text { ACE }\left(\mathrm{IC}_{50}\right)}\right)$ & Thrombin $\left(\mathrm{IC}_{\mathbf{5 0}}\right)$ & ABTS $\left(\mathrm{SC}_{\mathbf{5 0}}\right)$ & Peptide Concentration $(\mathrm{mg} / \mathrm{L})$ \\
\hline 2 & $0.332^{\mathrm{cd}}$ & $38.46^{\mathrm{i}}$ & $4.204^{\mathrm{e}}$ & 0.2125 \\
3 & $0.442^{\mathrm{e}}$ & $4.36^{\mathrm{h}}$ & $\mathrm{NI}$ & 0.8375 \\
9 & $\mathrm{NI}$ & $0.426^{\mathrm{f}}$ & $\mathrm{NI}$ & 0.9062 \\
18 & $0.614^{\mathrm{f}}$ & $2.65^{\mathrm{g}}$ & $2.538^{\mathrm{d}}$ & 0.7125 \\
19 & $0.173^{\mathrm{b}}$ & $0.183^{\mathrm{b}}$ & $\mathrm{NI}$ & 0.3750 \\
22 & $0.158^{\mathrm{ab}}$ & $0.167^{\mathrm{ab}}$ & $1.375^{\mathrm{b}}$ & 0.4687 \\
23 & $\mathrm{NI}$ & $0.349^{\mathrm{e}}$ & $2.809^{\mathrm{d}}$ & 0.5625 \\
27 & $0.808^{\mathrm{c}}$ & $0.402^{\mathrm{f}}$ & $1.616^{\mathrm{c}}$ & 0.3125 \\
28 & $0.346^{\mathrm{d}}$ & $0.135^{\mathrm{a}}$ & $1.728^{\mathrm{c}}$ & 0.0937 \\
32 & $0.192^{\mathrm{b}}$ & $0.298^{\mathrm{d}}$ & $6.931^{\mathrm{g}}$ & 0.4687 \\
34 & $0.317^{\mathrm{cd}}$ & $0.247^{\mathrm{c}}$ & $2.593^{\mathrm{d}}$ & 0.4937 \\
39 & $\mathrm{NI}^{\mathrm{c}}$ & $0.247^{\mathrm{c}}$ & $5.561^{\mathrm{f}}$ & 0.4375 \\
40 & $0.298^{\mathrm{c}}$ & $0.26^{\mathrm{cd}}$ & $4.547^{\mathrm{e}}$ & 0.8375 \\
45 & $0.134^{\mathrm{a}}$ & $0.155^{\mathrm{a}}$ & $0.992^{\mathrm{a}}$ & 0.8125 \\
\hline
\end{tabular}

Values for ACE, thrombin, and ABTS (mg peptide/mL) are mean \pm SD $(n=3)$; values in the same column with different superscript letters are significantly different $(p<0.05)$. NI: not identified.

For the antihypertensive potential, the IC50 calculated for the test fractions ranged from 0.134 to $0.808 \mathrm{mg} / \mathrm{mL}$ (Table 2). These values stay in agreement with the results reported elsewhere for amaranth protein hydrolysates $[10,13]$. On the other hand, values obtained in this work were lower than those 
found for other vegetable protein sources [14], or higher in comparison to buffalo milk [15]. Antioxidant potential based on the ABTS assay and expressed as SC50 varied from 0.992 to $6.931 \mathrm{mg} / \mathrm{mL}$, and was slightly higher than that obtained for amaranth hydrolysates by in vitro digestion [16]. This may be explained by the fact that the type of bioactive peptides released depends not only on the protein nature, but also on the enzymes used in the particular case of hydrolysis [17,18]. Concerning the thrombin IC50 values, the results obtained were in the range of 0.992 to $38.46 \mathrm{mg} / \mathrm{L}$, which stay in agreement with the values reported for amaranth hydrolyzed by alcalase and pepsin [12]. Finally, no statistically important differences were found for thrombin inhibition potential between $\mathrm{H} 3$ hydrolysate (alcalase and flavourzyme) investigated in this study, and amaranth hydrolyzed by alcalase and pepsin as reported in Sabbione et al. [12], which was also obtained via sequential two-enzyme process.

Based on the obtained results, fractions 22 and 45 were subjected to MALDI-TOF analysis (Figure 2), which allowed the identification of sequences with interesting multiple bioactivities.
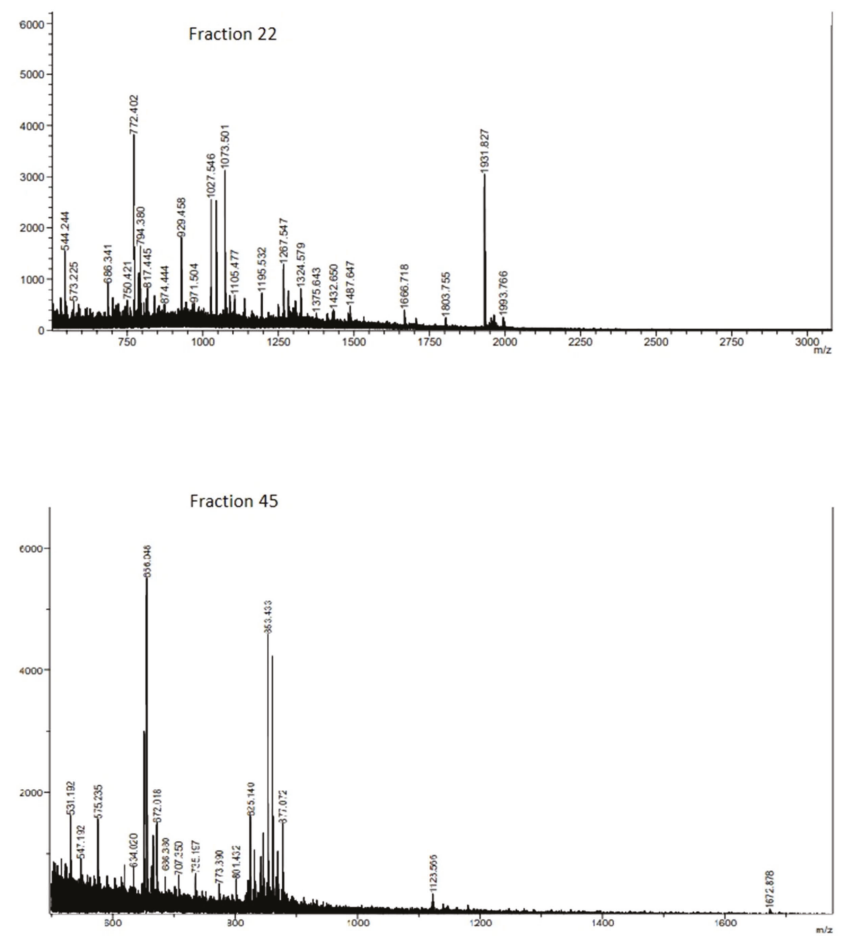

Figure 2. Fraction 22 and 45 MALDI-TOF mass Spectra.

The structure of the aminoacidic chains and the corresponding protein source are presented in Table 3.

Table 3. Peptides identified in the most active fractions from amaranth hydrolysate and their corresponding protein source.

\begin{tabular}{ccccc}
\hline Fraction & Mass $m / z$ & Calc $\mathbf{M H}^{+}$ & Sequence & Protein \\
\hline & & & Fraction 22 & \\
\hline $\mathbf{3 4}$ & 1375.6435 & 1375.6341 & ITASANEPDENKS & Agglutinin \\
$\mathbf{3}$ & 573.2252 & 573.3516 & LVRW & Agglutinin \\
$\mathbf{1 6}$ & 874.4448 & 874.4813 & NIDMLRL & Granule bound starch synthase I \\
\hline
\end{tabular}


Table 3. Cont.

\begin{tabular}{ccccl}
\hline Fraction & Mass $m / z$ & Calc MH $^{+}$ & Sequence & Protein \\
\hline $\mathbf{1 2}$ & 794.3805 & 794.4203 & Fraction 22 & \\
$\mathbf{5}$ & 686.3414 & 686.4081 & RPVFEF & Granule bound starch synthase I \\
$\mathbf{3}$ & 573.2251 & 573.3617 & IKEAL & Granule bound starch synthase I \\
$\mathbf{1 3}$ & 812.3607 & 812.4265 & NVEVhule bound starch synthase I & Cystatin \\
\hline & & & Fraction 45 & \\
\hline $\mathbf{2 7}$ & 853.4330 & 853.4329 & HVQLGHY & Agglutinin \\
$\mathbf{1 4}$ & 707.3505 & 707.3212 & SQIDTGS & Agglutinin \\
$\mathbf{1 4}$ & 707.3502 & 707.3185 & NWACTL & Agglutinin \\
$\mathbf{4}$ & 547.1921 & 547.2997 & VRWS & Agglutinin \\
$\mathbf{2 9}$ & 861.3847 & 861.4299 & CIHNIVY & Granule bound starch synthase I \\
$\mathbf{2 6}$ & 845.4098 & 845.4254 & EGTESIPL & Granule bound starch synthase I \\
$\mathbf{2 4}$ & 841.4242 & 841.3841 & PRYDQY & Granule bound starch synthase I \\
$\mathbf{1 9}$ & 823.4281 & 823.3696 & MSNIDML & Granule bound starch synthase I \\
$\mathbf{1 3}$ & 686.3805 & 686.4080 & DPKLTL & Granule bound starch synthase I \\
$\mathbf{6}$ & 619.2805 & 619.3566 & IPSRF & Granule bound starch synthase I \\
$\mathbf{3}$ & 531.1927 & 531.3042 & ARVW & Granule bound starch synthase I \\
$\mathbf{2}$ & 505.1907 & 505.2447 & CQAAL & Granule bound starch synthase I \\
$\mathbf{1}$ & 503.1730 & 503.2715 & EELL & Granule bound starch synthase I \\
$\mathbf{1}$ & 503.1731 & 503.2823 & LGVAGS & Granule bound starch synthase I \\
\hline
\end{tabular}

\section{Discussion}

Results obtained for the individual enzymatic hydrolysis were similar to those reported by Zhuang et al. [19] and Ma et al. [20], where it was observed that the enzymatic activity of alcalase and flavourzyme decreased after 90-120 min of the reaction course. The duration of enzymatic activity depends on the nature of the protein matrix and the amount of enzyme and substrate present in the medium. Additionally, other studies indicated a higher hydrolytic degree when only alcalase was used [21]. For H3 results, they are similar to those reported by Cumby et al. [22], who found that combined enzymatic hydrolysis increased peptide concentration when compared to hydrolysis performed solely with alcalase. It was also stated that hydrolysis with flavourzyme did not contribute to reach higher concentrations of free amine groups when alcalase was used in the first step of the combined enzymatic hydrolysis. On the other hand, the degree of hydrolysis depends on nature of protein and the specificity of the enzymes used [17,18].

Alcalase and flavourzyme have been used individually and in continuous hydrolytic processes applied to fragmentation of different food proteins in search of platelet inhibitory peptides [23,24]. In the case of amaranth proteins, the addition of a second enzyme different to flavourzyme, following hydrolysis with alcalase, has proven to enhance the inhibition potential of thrombin. This finding implies that the higher degree of hydrolysis, the greater bioactivity achieved [12,25]. In addition, Sabbione et al. [12] observed that the degree of hydrolysis of amaranth proteins, such as albumin and globulin, was an important factor in improved thrombin inhibition, reaching approximately $81 \%$, which matches with the results obtained in present study $(80 \%$ for $\mathrm{H} 2$, and $90 \%$ for $\mathrm{H} 1$ and $\mathrm{H} 3$ ).

The increase in thrombin inhibition activity may be due to the fact that amaranth protein has peptide sequences capable of inhibiting fibrinogen. These peptides are released by the action of proteolytic enzymes. Furthermore, it was observed that not only was the size of the peptide important for thrombin inhibition, but also the amino acid sequence, which might be homologous to the fibrinopeptides A and B from human fibrinogen (GGGVR-GP and PPSAR-GH, respectively) [26]. Therefore, antithrombotic activity is affected by the competition for platelet receptors between casoplatelin and the $\gamma$-chain of human fibrinogen (HHLGGAKQAGDV) [27,28], which is implicated in one of the three steps in thrombosis cascade reactions. Additionally, alcalase has been reported as an enzyme capable of 
releasing antithrombotic peptides form proteins like peanut [18], but no reports have been available so far on hydrolytic potential of flavourzyme to release bioactive peptides from amaranth.

In the case of antihypertensive activity, the results obtained in this study are similar to those reported by Ambigaipalan et al. [29]. They observed that the combination of two or more enzymes increased the inhibitory activity of angiotensin, converting the enzyme in date seed protein in a sequential enzymatic process. Many authors have reported that the variation in antihypertensive activity of the released peptides could be attributed to the differences in composition and hydrophobicity of the protein primary structure [30,31]. In this sense, hydrophobic residues of amino acids (leucine, valine, alanine, tryptophan, tyrosine, proline, and phenylalanine) bind at the ACE catalytic sites, acting as competitive inhibitors [32]. Nevertheless, milk proteins have been reported as a better source of bioactive peptides, especially those with antihypertensive activity reaching over $80 \%$ of ACE inhibition $[33,34]$. Furthermore, studies have been focused on peptides released from vegetable proteins, such as amaranth. In particular, 11S globulin was reported to show IC50 value in the ACE assay, ranging from $6.32 \mathrm{mM}$ to $175 \mu \mathrm{M}[9,35]$. It has been known that the low molecular weight of peptides is a prerequisite for their antihypertensive activity [36]. In this study, peptides with the latter feature were identified using SDS-PAGE (data not shown), revealing typical weights of these biopeptides.

In addition to antihypertensive activity, peptide size (peptide chain length less than 20 amino acids) has been related to antioxidant capacity, showing that smaller peptides have greater potential [37]. This observation could explain the higher antioxidant activity obtained for $\mathrm{H} 3$ hydrolysate, which contained a higher concentration of free amine groups. In conclusion, during the course of enzymatic hydrolysis H1, H2, and H3 carried out in this study, peptides with different biological properties were released-for example, those able to chelate reactive agents, or donate electrons or hydrogen [38]. Moreover, in several studies in which sequential hydrolysis of proteins with different enzymes was performed, it has been observed that the antioxidant activity remained the same or might be increased by the addition of a second enzyme [39,40]. Thus, the application of two hydrolytic enzymes allows the release of new bioactive peptides, which could affect the antioxidant capacity of the hydrolysates. Consequently, it has been observed that protein hydrolysates might present higher antioxidant properties as they increase their content of small peptides [41].

For RP-HPLC peptide separation, the results obtained in this work are similar to those reported by Moronta et al. [42], who hydrolyzed amaranth proteins with alcalase. It was found that peptides with a higher content of polar amino acids showed higher anti-inflammatory activity. Nonetheless, a fraction found in the non-polar region of the chromatographic analysis (45 min) exhibited higher potential in terms of antihypertensive, antithrombotic, and antioxidant activity than other polar fractions. In some studies, it has been demonstrated that peptides containing hydrophobic amino acids might enhance biological capacities, such as antihypertensive and antioxidant activities [43].

As observed in Table, fraction 22 contained the longest peptide sequence, identified as ITASANEPDENKS, with a molecular weight of approximately $1.44 \mathrm{kDa}$, being the highest molecular weight found in both fractions. In the case of the peptide NIDMLRL, the last part of its sequence (-LRL) has been identified in silico as an inhibitor of ACE in amaranth. This asseveration may be explained by the presence of leucine as hydrophobic amino acid interacting with the active site of ACE [44].

Additionally, the LVRW sequence was found in fraction 22. The three amino acid chain LVR was previously described as a bioactive peptide with antihypertensive activity in fig sap having an IC50 lower than $20 \mu \mathrm{M}$ [45]. Additionally, W might be also a bonding amino acid in the active site of ECA. On the other hand, the IC50 of ACE inhibitory potential found for fraction 45 was lower than for fraction 22. Fraction 45 contained VRWS, and the dipeptide VR was described as an antihypertensive agent by itself, with an IC50 of $52.80 \mu \mathrm{M}$ [46]. In addition, even though it was bound to other amino acids, such as Y or SP, it retained its bioactivity $[47,48]$. Similarly, the presence of Tyr in the C-terminal end should promote binding to ACE and thus enhance its inhibition [49]. It was proved for the tripeptide 
IVY [50], also present in the sequence CIHNIVY in fraction 45. Finally, in this fraction, various peptides containing Tyr residue were found.

In previous works on antioxidant peptides, it was stated that peptides with a length between 5 and 16 amino acids showed antiradical activity [51]. The results obtained in the present study support these findings, since the potential of antioxidant peptides had a molecular weight in the range of 500-1400 Da and contained 4-13 amino acid residues (Table 3).

One of the peptides described in fraction 22 was LVRW, which could play a role as an antioxidant agent. Haung et al. [52] determined that the presence of the RW amino acid sequence in the C-terminal end of the polypeptide chain might be accounted for by its high antiradical activity. A similar effect was observed for the peptide ARVW, were the antioxidant activity of Trp is mainly due to its indole group [53].

In fraction 45, the DPKLTL sequence was identified, which might have antioxidant capacity owning to the presence of the DPK fragment (previously described as an antioxidant peptide). Its bioactivity could be explained by the presence of aspartic acid, which has the ability to donate electrons and hydrogen. On the other hand, this fragment is bound to hydrophobic amino acids, namely Pro and Leu, which in turn could enhance the radical scavenging abilities of this peptide [54]. Additionally, the DPKLTL peptide might exhibit antithrombotic activity due to the presence of three amino DPK acid residues, previously known for inactivating thrombin in its active site [25].

According to the work of Wang et al. [55], peptides with antithrombotic bioactivity usually contain 3-20 amino acid residues. Table 3 shows that the longest peptide identified in fraction 22 had a 13 -amino acid chain. Moreover, it has been reported that sequences containing Val and Tyr might possess antithrombotic activity [23]. These amino acids were mainly found among peptide sequences present in fraction 45. On the other hand, Pro-Arg bonding N-terminal end of polypeptide chains has been reported as a thrombin inhibitor in its active site [26]. This bond is present in the structure of PRYDQY; however, more exhaustive studies are necessary on antithrombotic peptides as thrombin contain three main structural domains (a catalytic site and two exosites (I and II)), and enzyme inhibition can take place to different extents at any of these sites [26,56].

\section{Materials and Methods}

\subsection{Sample and Treatments}

Raw Amaranth hypochondriacus spp. seeds were obtained from Xochimilco, Mexico City, in July 2016. Seeds were ground in a Chopin mill, segregated according to their molecules size, and only a fraction with molecule size between 200 and $800 \mu \mathrm{m}$ was selected for the experiments. Protein extraction was performed following the methodology described by Martínez and Añón [57] with some modifications. First, flour was defatted with n-hexane $(10 \% w / v)$ for $24 \mathrm{~h}$. Then it was suspended in deionized water $10 \%(w / v)$, and $\mathrm{pH} 9$ was adjusted with $\mathrm{NaOH}$. The crude was incubated for $30 \mathrm{~min}$ at room temperature and centrifuged during $20 \mathrm{~min}$ at 10,000 rpm. The soluble protein fraction found in the supernatant was precipitated by $\mathrm{pH} 5$ adjustment, using $\mathrm{HCl}$. The sample was centrifuged $20 \mathrm{~min}$ at 10,000 rpm, and the pellet $\mathrm{pH}$ was adjusted to 7 . Following the lyophilization, the protein extract was stored at $4{ }^{\circ} \mathrm{C}$ until further use. This protein was called protein extract.

\subsection{Enzymatic Hydrolysis}

The enzymatic hydrolysis was performed according to the method described by Tironi and Añón [58]. Briefly, $5 \mathrm{~g}$ of the protein extract was diluted in $100 \mathrm{~mL}$ of deionized water (milli $\mathrm{Q}$ 18.2 $\mathrm{M}^{*} \mathrm{~cm}$, Manufacturer, Darmstadt, Germany). For alcalase hydrolysis (H1), prior to the reaction, the $\mathrm{pH}$ of the solution was adjusted to 10 , and alcalase ( $\geq 2.4 \mathrm{U} / \mathrm{g}$, Anson Units; Sigma-Aldrich (St. Loui, MO, USA) was added at concentration of $8 \mu \mathrm{L} / 100 \mathrm{mg}$ of the sample. For flavourzyme hydrolysis (H2), the $\mathrm{pH}$ of the reaction media was adjusted to 7 and flavourzyme ( $\geq 500 \mathrm{U} / \mathrm{g}$; Sigma Aldrich, St. Louis, MO, USA) was added at concentration of $5 \mu \mathrm{L} / 100 \mathrm{mg}$ of the sample. Finally, when both enzymes were 
used in a two-step continuous hydrolytic process (H3), after $2 \mathrm{~h}$ of hydrolysis with alcalase, the enzyme was inactivated by heating to $85{ }^{\circ} \mathrm{C}$ for $10 \mathrm{~min}$. The solution was adjusted to $\mathrm{pH} 7$ and hydrolysis with flavourzyme was carried out. For all three methods, hydrolysis was followed up during $4 \mathrm{~h}$ and progress of the reaction was monitored every $20 \mathrm{~min}$. The aliquots were heated to $85^{\circ} \mathrm{C}$ during $10 \mathrm{~min}$ and frozen until further use.

\subsection{Free Amine Groups Analysis by TNBS Test}

In order to determine free amine groups released during the enzymatic hydrolysis of the amaranth proteins, the 2,4,6-Trinitrobenzenesulfonic acid (TNBS) test was performed, with some modifications, according to the protocol described by Sashidhar et al. [59]. Briefly, 5\% TNBS solution (Sigma-Aldrich, (St. Loui, MO, USA) was diluted in $0.21 \mathrm{M}$ phosphate buffer ( $\mathrm{pH} 8.2$ ) to a final concentration of $1 \%$ $(v / v)$. Two milliliters of the prepared substrate was added to $2 \mathrm{~mL}$ of phosphate buffer $(0.21 \mathrm{M} ; \mathrm{pH} 8.2)$, and $0.25 \mathrm{~mL}$ of the test sample. The mixture was incubated during $1 \mathrm{~h}$ at $50{ }^{\circ} \mathrm{C}$ and the reaction was stopped by the addition of $2 \mathrm{~mL}$ of $0.1 \mathrm{~N} \mathrm{HCl}$. The absorbance was read at $340 \mathrm{~nm}$. Results were plotted against a calibration curve prepared by different glycine concentrations $(0,0.05 .0 .1,0.15,0.2$, and $0.25 \mathrm{mg} / \mathrm{mL})$ using the following equation $(\mathrm{R}=0.9972)$ :

$$
y=0.004 x+0.134
$$

Results are expressed as milligrams of free amines per liter (mg/L NH: ${ }^{-}$.

\subsection{Antihypertensive Activity}

Inhibitory effect on angiotensin converting enzyme (ACE) was evaluated spectrophotometrically according to the method of Cushman et al. [60] using Hippuril-Histidyl-Leucine (St. Loui, MO, USA) as substrate. Briefly, $5 \mathrm{mM}$ substrate solution was prepared in $0.1 \mathrm{M}$ sodium borate buffer $\mathrm{pH} 8.3$ containing $0.3 \mathrm{M}$ sodium chloride. A $5 \mathrm{mM} 100 \mu \mathrm{L}$ aliquot of substrate solution was mixed with $40 \mu \mathrm{L}$ of the test sample before adding $10 \mu \mathrm{L}$ of angiotensin converting enzyme (EC 3.4.15.1, 5.1 U/mg; Sigma-Aldrich). The reaction mixture was incubated during $1 \mathrm{~h} 15 \mathrm{~min}$ at $37^{\circ} \mathrm{C}$ and the enzyme was inactivated with $1 \mathrm{~mL}$ of $0.1 \mathrm{M} \mathrm{HCl}$. The hippuric acid formed in this reaction was extracted with ethyl acetate, concentrated under reduced pressure, and finally re-dissolved in distilled water. The absorbance was measured at $220 \mathrm{~nm}$ in a GENESYS spectrometer.

The inhibitory activity of ACE was calculated using the formula:

$$
\% \text { inhibitory activity }=(\mathrm{AbsC}-\mathrm{AbsM}) /(\mathrm{AbsC}-\mathrm{AbsB}) \times 100
$$

where:

AbsC: Hippuric acid formed during the reaction with ACE without inhibitor.

AbsB: Hippuril-Histidyl-Leucine that did not react and was extracted with ethyl acetate.

AbsM: Hippuric acid formed after the reaction with ACE in the presence of inhibitory substance.

\subsection{Antithrombotic Activity}

To evaluate antithrombotic activity, the methodology developed by Zhang et al. [61] was followed, including modifications of sodium chloride concentration proposed by Pérez-Escalante et al. [56]. Absorbance at $405 \mathrm{~nm}$ was measured before adding the enzyme to a microplate reader (Power Wave XS UV-Biotek, software KC Junior, USA) and after $10 \mathrm{~min}$ of incubation with the enzyme at $37^{\circ} \mathrm{C}$. The percentage of inhibition (\% inhibition) was calculated following the equation:

$$
\% \text { inhibitory activity }=[(C-C B)-(S-S B)] /(C-C B)^{*} 100
$$

where:

CB (control blank): The initial absorbance of the negative control of inhibition. 
C (control): The absorbance of the negative control after $10 \mathrm{~min}$ of incubation with thrombin. SB (sample blank): The initial absorbance of the sample.

$\mathrm{S}$ (sample): The absorbance of the sample after $10 \mathrm{~min}$ of incubation with thrombin.

\subsection{Antioxidant Activity}

Antioxidant activity was evaluated by three different methods.

\subsubsection{ABTS test}

Radical scavenging capacity was measured using the radical cation 2,2'-azino-bis 3-ethylbenzothiazoline-6-sulphonic acid (ABTS $\bullet+$ ), which was produced by mixing $7 \mathrm{mM}$ of ABTS $\bullet+$ stock solution with $2.45 \mathrm{mM}$ potassium persulfate in the dark at room temperature for $16 \mathrm{~h}$ prior to its usage. The ABTS + solution was diluted with deionized water, so that absorbance measured at 754 $\mathrm{nm}$ was of $0.70 \pm 0.02$. An aliquot of $20 \mu \mathrm{L}$ of test sample was added to $980 \mu \mathrm{L}$ of the diluted ABTS $\bullet+$ solution, and after $7 \mathrm{~min}$ of incubation at room temperature, the absorbance readings were taken at $754 \mathrm{~nm}$ in a microplate reader (Power Wave XS UV-Biotek, soft-ware KC Junior, USA). Antioxidant capacity was expressed as milligrams Trolox equivalents per liter (mg TE/100 g) [62].

\subsubsection{DPPH Test}

Radical scavenging activity was measured using 2,2-diphenyl-1-picrylhydrazyl (DPPH•) radical. An ethanolic solution $(7.4 \mathrm{mg} / 100 \mathrm{~mL})$ of the stable DPPH $\bullet$ radical was prepared. Then, $100 \mu \mathrm{L}$ of the test sample was added to $500 \mu \mathrm{L}$ of $\mathrm{DPPH} \bullet$ solution, and it was left to sit at room temperature for $1 \mathrm{~h}$. The solution was stirred and centrifuged at $3000 \mathrm{rpm}$ for $10 \mathrm{~min}$. Finally, absorbance of the supernatant was measured at $520 \mathrm{~nm}$ in a microplate reader. Antioxidant activity was expressed as micromole of Trolox equivalents per liter (TE $\mu \mathrm{mol} / 100 \mathrm{~g}$ ) [63].

\subsubsection{FRAP Test}

FRAP antioxidant activity was evaluated according to the Benzie and Strein method [64], in which $0.3 \mathrm{M}$ sodium acetate buffer $\mathrm{pH}$ 3.6, TPTZ, $20 \mathrm{mM} \mathrm{FeCl3}$, and 5M FeSO4 were elaborated. For the preparation of FRAP buffer, TPTZ and $\mathrm{FeCl}_{3}$ were mixed at 10:1 ratio (v:v). Briefly, $30 \mu \mathrm{L}$ of test sample was mixed with $900 \mu \mathrm{L}$ of FRAP solution and $90 \mu \mathrm{L}$ of distilled water, and agitated. The mixture was incubated during $10 \mathrm{~min}$ at $37^{\circ} \mathrm{C}$, after which the absorbance was measured at $593 \mathrm{~nm}$ in a microplate reader. Results were compared with a calibration curve constructed for $\mathrm{FeSO}_{4}$ standards at concentrations ranging from 0 to $1000 \mathrm{mM}$. Antioxidant activity was expressed as micromole equivalents of Fe (II) per $100 \mathrm{~g}$ ( $\mu \mathrm{molEFeII} / 100 \mathrm{~g}$ ).

\subsection{Identification of Bioactive Peptides by RP-HPLC}

\subsubsection{Sample Preparation}

For sample preparation, $10 \mathrm{mg} / \mathrm{mL}$ of freeze-dried amaranth protein hydrolysates were prepared with phosphate buffer ( $\mathrm{pH}$ 7.8). The crude mixture was stirred during $1 \mathrm{~h}$ at $37^{\circ} \mathrm{C}$ and followed by centrifugation at $10,000 \mathrm{rpm}$ for $10 \mathrm{~min}$ at room temperature. The resulting supernatant with corresponding soluble fractions was separated and stored.

\subsubsection{RP-HPLC Separation}

Peptides were separated by reversed-phase chromatography on a HPLC (Waters, USA) system equipped with a C8 column ( $250 \mathrm{~mm} \times 4.6 \mathrm{~mm} \times 5 \mathrm{~mm}$; Waters $)$ and photodiode array detector (Spectra System Thermo Scientific, USA) A gradient elution was applied from 100 to $0 \%$ A in 56 min at flow rate of $1 \mathrm{~mL} / \mathrm{min}$. A binary mobile phase consisted of solvent A: $0.065 \%$ trifluoroacetic acid [TFA] in water/acetonitrile [ACN] 98:2, and solvent B: 0.065\% TFA in water/ACN 35:65. Detection was performed at $280 \mathrm{~nm}$ and temperature was set at $40{ }^{\circ} \mathrm{C}$. The injection volume was $200 \mu \mathrm{L}$. Fractions 
were manually collected every $1 \mathrm{~min}$ in Eppendorf tubes and protein content was evaluated by the Bradford assay. Finally, samples were lyophilized (Labconco DrySystem/freezone 4.5) and bioactivity analysis was carried out only on the lyophilized samples containing protein.

\subsubsection{MALDI-TOF Spectrometry}

The collected fractions with the highest bioactivities were filtered through a Minisart RC4 filter $(0.45 \mu \mathrm{m})$ and analyzed by a matrix-assisted laser desorption ionization (MALDI) mass spectrometer, equipped with a delayed extraction source and a $355 \mathrm{~nm}$ pulsed nitrogen laser. A MALDI scoutMTPTM was run in the linear mode. A 100-times diluted sample was mixed with 1 volume of $20 \mathrm{mg} / \mathrm{mL}$ of sinapinic acid in acetonitrile/water 50:50 (v/v). Finally, $0.5 \mu \mathrm{L}$ of the mixture was deposited onto the MALDI target plate. All spectra were the result of signal averaging of 200 shots. The MALDI-TOF/TOF MS/MS was run in the positive refractor mode. The peptide sequencing was performed by processing the MS/MS spectra using Auto eXecute software. Mascot (Matrix Science Inc., Boston, MA, US) software was used to identify and characterize peptide structures.

\subsection{Statistical Analysis}

All data were obtained in triplicate and expressed as mean \pm standard deviation (SD). The data were analyzed by one-way analysis of variance (ANOVA) tests, and the differences among means were compared using the Tukey test with significance level set at $p<0.05$, using the SPSS ${ }^{\circledR}$ System for WINTM version 15.0 (IBM®Armonk, New York, NY, USA).

\section{Conclusions}

Amaranth protein hydrolysate, obtained through enzymatic reaction with alcalase and flavourzyme in a sequential two-step hydrolytic process, may be a source of bioactive peptides. Sequences were different from those obtained in more commonly performed enzymatic hydrolysis using pepsin and pancreatin for amaranth proteins digestion. The biological activities identified for some peptide sequences in this study have been proven in other food sources. Moreover, novel amino acid chains with possible multi-functional activities were identified. This is the first report of the multiple bioactivities of peptide fractions derived from hydrolyzed amaranth proteins. Additionally, this study shows that amaranth hydrolyzed with alcalase and flavourzyme could be used in the nutraceutical industry, as a value-added ingredient with multi-functional bioactive properties.

Author Contributions: Conceptualization, L.G.G.-O. and A.A.-N.; methodology, L.G.G.-O., A.A.-N. and G.M.R.-S.; software, E.C.-L., P.R.-L. and A.C.-S.; validation, P.R.-L., A.C.-S. and L.G.G.-O.; formal analysis, L.G.G.-O., A.A.-N. and P.R.-L.; investigation, A.A.-N.; resources, A.C.-S. and L.G.G.-O.; data curation, E.C.-L. and A.C.-S.; writing-original draft preparation, A.A.-N. and L.G.G.-O.; writing-review and editing, A.A.-N. and L.G.G.-O.; visualization, L.G.G.-O.; supervision, L.G.G.-O. and G.M.R.-S.; project administration, L.G.G.-O.; funding acquisition, L.G.G.-O., E.C.-L. and G.M.R.-S.

Funding: This research received no external funding.

Conflicts of Interest: The authors declare no conflict of interest. 


\section{Appendix A}

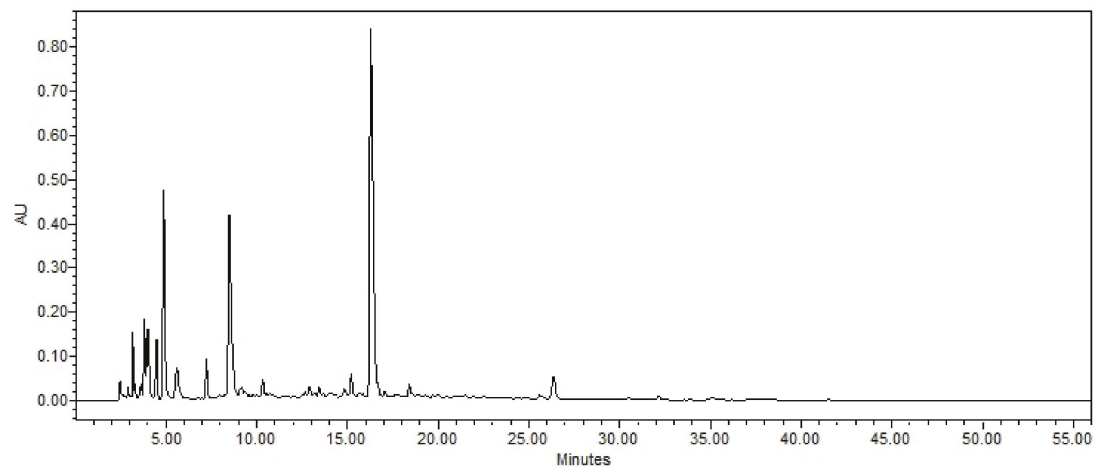

Figure A1. RP-HPLC separation of amaranth hidrolizated fractions.

\section{References}

1. Jew, S.; AbuMweis, S.S.; Jones, P.J.H. Evolution of the human diet: Linking our ancestral diet to modern functional foods as a means of chronic disease prevention. J. Med. Food 2009, 12, 925-934. [CrossRef] [PubMed]

2. Udenigwe, C.C.; Aluko, R.E. Food protein-derived bioactive peptides: Production, processing, and potential health benefits. J. Food Sci. 2012, 77, 11-24. [CrossRef] [PubMed]

3. Mazorra-Manzano, M.A.; Ramírez-Suarez, J.C.; Yada, R.Y. Plant proteases for bioactive peptides release: A review. Crit Rev. Food Sci. Nutr. 2018, 58, 2147-2163. [CrossRef] [PubMed]

4. Wattanasirithama, L.; Theerakulkaita, C.; Wickramasekara, S.; Maierb, C.S.; Stevensc, J.F. Isolation and identification of antioxidant peptides from enzymatically hydrolyzed rice bran protein. Food Chem. 2016, 192, 156-162. [CrossRef] [PubMed]

5. Najafian, L.; Babji, A.S. Production of bioactive peptides using enzymatic hydrolysis and identification antioxidative peptides from patin (Pangasius sutchi) sarcoplasmic protein hydrolysate. J. Funct. Foods 2014, 9, 280-289. [CrossRef]

6. Baltia, R.; Bougatef, A.; Silaa, A.; Guillochon, D.; Dhulster, P.; Nedjar-Arroume, N. Nine novel angiotensin I-converting enzyme (ACE) inhibitory peptides from cuttlefish (Sepia officinalis) muscle protein hydrolysates and antihypertensive effect of the potent active peptide in spontaneously hypertensive rats. Food Chem. 2015, 170, 519-525. [CrossRef] [PubMed]

7. Raikos, V.; Dassios, T. Health-promoting properties of bioactive peptides derived from milk proteins in infant food: A review. Dairy Sci. Technol. 2014, 94, 91-101. [CrossRef] [PubMed]

8. Tovar, L.R. Biotechnology for an Ancient Crop- Amaranth. In Amaranth Biology, Chemistry and Technology, 1st ed.; Paredes-López, O., Ed.; CRC Press: Boca Raton, FL, USA, 2018; Volume 1, pp. 14-36.

9. Mendonça, S.; Saldiva, P.H.; Cruz, R.J.; Areas, A.G. Amaranth protein presents cholesterol-lowering. Food Chem. 2009, 116, 738-742. [CrossRef]

10. Tovar-Pérez, E.G.; Guerrero-Legarreta, B.C.; Ferrés-González, A.; Soriano-Santos, J. Angiotensin I-converting enzyme-inhibitory peptide fractions from albumin 1 and globulin as obtained of amaranth grain. Food Chem. 2009, 116, 437-444. [CrossRef]

11. Orsini-Delgado, M.C.; Torini, V.A.; Añón, M.C. Antioxidant activity of amaranth protein or their hydrolysates under simulated gastrointestinal digestion. Food Sci. Technol. 2011, 44, 1752-1760. [CrossRef]

12. Sabbione, A.C.; Scilingo, A.; Añón, M.A. Potential antithrombotic activity detected in amaranth proteins and its hydrolysates. Food Sci. Technol. 2015, 60, 171-177. [CrossRef]

13. Tiengo, A.; Faria, M.; Neitto, E.M. Characterization and ACE-Inhibitory activity of Amaranth proteins. J. Food Sci. 2009, 74, H121-H126. [CrossRef] [PubMed]

14. Rudolph, S.; Lunow, D.; Kaiser, S.; Henle, T. Identification and quantification of ACE-inhibiting peptides in enzymatic hydrolysates of plant proteins. Food Chem. 2017, 224, 19-25. [CrossRef] [PubMed] 
15. Abdel-Hamid, M.; Otte, J.; De Gobba, C.; Osman, A.; Hamad, E. Angiotensin I-converting enzyme inhibitory activity and antioxidant capacity of bioactive peptides derived from enzymatic hydrolysis of buffalo milk proteins. Int. Dairy J. 2017, 66, 91-98. [CrossRef]

16. Orsini-Delgado, A.; Galleano, M.; Añón, M.C.; Tironi, V.A. Amaranth peptides from simulated gastrointestinal digestión: Antioxidant Activity against Reactive species. Plants Foods Human Nutr. 2015, 70, 27-34. [CrossRef]

17. Zhang, J.; Zhang, H.; Wang, L.; Guo, X.; Wang, G.; Wang, X.; Yao, H. Isolation and identification of antioxidative peptides from rice endosperm protein enzymatic hydrolysates by consecutive chromatography and MALDI-TOF/TOF MS/MS. Food Chem. 2010, 119, 226-234. [CrossRef]

18. Zhang, B.S. In vitro antithrombotic activities of peanut protein hydrolysates. Food Chem. 2016, 202, 1-8. [CrossRef]

19. Zhuang, H.; Tang, N.; Yuan, Y. Purification and identification of antioxidant peptides from corn gluten meal. J. Funct. Foods 2013, 5, 1810-1821. [CrossRef]

20. Ma, Y.; Wang, L.; Sun, X.; Zhang, J.; Wang, J.; Li, Y. Study on Hydrolysis Conditions of Flavourzyme in Soybean Polypeptide Alcalase Hydrolysate and Soybean Polypeptide Refining Process. Adv. J. Food Sci. Technol. 2014, 6, 1027-1032. [CrossRef]

21. Foh, M.B.; Amadou, I.; Foh, B.M.; Kamara, M.T.; Xia, W. Functionality and antioxidant properties of Tilipa (Oreochromis niloticus) as influences by degree of hydrolysis. Int. J. Mol. Sci. 2010, 11, 1851-1869. [CrossRef]

22. Cumby, N.; Zhong, Y.; Naczk, M.; Shahidi, F. Antioxidant activity and water-holding capacity of canola protein hydrolysates. Food Chem. 2008, 109, 144-148. [CrossRef]

23. Cian, R.E.; Garzón, A.G.; Martínez-Augustin, O.; Botto, C.C.; Drago, S.R. Antithrombotic activity of Brewer's spent grain peptides and their effects on blood coagulation pathways. Plant. Foods Hum. Nutr. 2018, 73, 241-246. [CrossRef]

24. Kasiwut, J.; Sirinupong, N.; Wirote, Y. The anticoagulant and angiotensin I-Converting Enzyme (ACE) Inhibitory peptides from tuna cooking juice produced by alcalase. Curr. Nutr. Food Sci. 2018, 14, 225-234. [CrossRef]

25. Sabbione, A.C.; Nardo, E.A.; Añón, M.C.; Scilingo, A. Amaranth peptides with antithrombotic activity released by sumulated gastrointestinal digestion. J. Funct. Foods 2016, 20, 204-214. [CrossRef]

26. Cheng, S.; Tu, M.; Liu, H.; Zhao, G.; Du, M. Food-derived antithrombotic peptides: Preparation, identification and interactions with thrombin. Crit. Rev. Food Sci. Nutr. 2019, 2019. [CrossRef] [PubMed]

27. Laudano, A.P.; Doolittle, R.F. Synthetic peptides derivatives that bind to fibrinogen and prevent the polymerization of fibrin monomers. PNAS USA 1978, 75, 3085-3089. [CrossRef] [PubMed]

28. Fiat, A.M.; Levy-Toledano, S.; Caen, J.P.; Jolles, P. Biologically active peptides of casein and lactoferrin implicated in platelet function. J. Dairy Res. 1989, 56, 351-355. [CrossRef] [PubMed]

29. Ambigaipalan, P.; Al-Khalifa, A.S.; Shahidi, F. Antioxidant and angiotensin I converting enzyme (ACE) inhibitory activities of date seed protein hydrolysate prepared using Alcalase, Flavourzyme and Thermolysin. J. Funct. Foods 2015, 18, 1125-1137. [CrossRef]

30. Jung, W.K.; Mendis, E.; Je, J.; Park, P.J.; Son, B.; Kim, H.C.; Choi, Y.K.; Kim, S.K. Angiotensin I-converting enzyme inhibitory peptide from yellowfin sole (Limanda aspera) frame protein and its antihypertensive effect in spontaneously hypertensive rats. Food Chem. 2006, 94, 26-32. [CrossRef]

31. Wijesekara, I.; Kim, S.K. Angiotensin-I-converting enzyme (ACE) inhibitors from marine resources: Prospects in the pharmaceutical industry. Mar. Drugs 2010, 8, 1080-1093. [CrossRef] [PubMed]

32. Hanafi, M.A.; Hashim, S.N.; Yea, C.S.; Ebrahimpour, A.; Zarei, M.; Muhammad, K.; Abdul-Hamid, A.; Saari, N. High angiotensin-I converting enzyme (ACE) inhibitory activity of Alcalase-digested green soybean (Glycine max) hydrolysates. Food Res. Int. 2018, 106, 589-597. [CrossRef] [PubMed]

33. González-González, C.R.; Tuohy, K.M.; Jauregi, P. Production of angiotensin-I-converting enzyme (ACE) inhibitory activity in milk fermented with probiotic strains: Effects of calcium, $\mathrm{pH}$ and peptides on the ACE-inhibitory activity. Int. Dairy J. 2011, 21, 615-622. [CrossRef]

34. Ayyash, M.; Al-Dhaheri, A.S.; Mahadin, S.A.; Kizhakkayil, J.; Abushelaibi, A. In vitro investigation of anticancer, antihypertensive, antidiabetic and antioxidant activities of camel milk fermented with camel milk probiotic: A comparative study with fermented bovine milk. J. Dairy Sci. 2018, 101, 1-12. [CrossRef] [PubMed]

35. Vecchi, B.; Añón, M.C. ACE inhibitory tetrapeptides from Amaranthus hypochondriacus 11S globulin. Phytochemistry 2009, 70, 864-870. [CrossRef] [PubMed] 
36. Miralles, B.; Amigo, L.; Recio, I. Critical Review and Perspective on Food-Derived Antihypertensive Peptides. J. Agric. Food Chem. 2018, 66, 9384-9390. [CrossRef] [PubMed]

37. Zou, T.B.; He, T.P.; Li, H.B.; Tang, H.W.; Xia, W.Q. The structure-activity relationship of the antioxidant peptides from natural proteins. Molecules 2016, 12, 72. [CrossRef]

38. Virtanen, T.; Pihlanto, A.; Akkanen, S.; Korhonen, H. Development of antioxidant activity in milk whey during fermentation with lactic acid bacteria. J. Appl. Microbiol. 2007, 102, 106-115. [CrossRef] [PubMed]

39. Je, J.Y.; Lee, K.H.; Lee, M.H.; Ahn, C.B. Antioxidant and antihypertensive protein hydrolysates produces from tuna liver by enzymatic hydrolysis. Food Res. Int. 2009, 42, 1266-1272. [CrossRef]

40. Chirinos, R.; Ochoa, K.; Aguilar-Galvez, A.; Carpentier, S.; Pedreschi, R.; Campos, D. Obtaining of peptides with in vitro antioxidant and angiotensin I converting enzyme inhibitory activities from cañihua protein (Chenopodium pallidicaule Aellen). J. Cereal. Sci. 2018, 83, 139-146. [CrossRef]

41. Choi, Y.; Lim, T.; He, Y.; Hwang, T. Chemical characteristics and antioxidant properties of wheat gluten hydrolysates produced by single and sequential enzymatic hydrolyses using commercial proteases and their application in beverage systems. J. Food Meas. Charact. 2019, 13, 745-754. [CrossRef]

42. Moronta, J.; Smaldini, P.L.; Docena, G.H.; Añón, M.C. Peptides of amaranth were targeted as containing sequences with potential anti-inflammatory properties. J. Funct. Foods 2018, 21, 463-473. [CrossRef]

43. Ijaritomi, O.S.; Malomo, S.A.; Alashi, A.M.; Nwachukwu, I.D.; Fagbemi, T.N.; Osundahunsi, O.F.; Aluko, R.E. Antioxidant and antihypertensive activities of wonderful cola (Buchholzia coriacea) seed protein and enzymatic protein hydrolysates. J. Food Bioact. 2018, 3, 133-143. [CrossRef]

44. Montoya-Rodríguez, A.; Gómez-Fávela, M.A.; Reyes-Moreno, C.; Milán-Carrillo, J.; González de Mejía, E. Identification of Bioactive Peptides Sequences from Amaranth (Amaranthus hypochodriacus) Seeds Proteins and Their Potential Role in the Prevention of Chronic Diseases. Compr. Rev. Food Sci. Food Saf. 2015, 14, 139-159. [CrossRef]

45. Balgir, P.P.; Sharma, M. Biopharmaceutical potential of ACE-Inhibitory peptides. J. Proteomics Bioinform. 2017, 10, 171-177. [CrossRef]

46. Gómez-Ruiz, J.A.; Ramos, M.; Recio, I. Identification of a novel angiotensin-converting enzyme-inhibitory peptides ovine milk proteins by CE-MS and chromatographic techniques. Electrophoresis 2007, 28, 4202-4211. [CrossRef] [PubMed]

47. Wang, X.; Wu, S.; Xu, D.; Xie, D.; Guo, H. Inhibitor and substrate binding by angiotensin-converting enzyme: Quantum Mechanical/Molecular Mechanical Molecular Dynamics Studies. J. Chem. Inf. Model. 2011, 51, 1074-1082. [CrossRef] [PubMed]

48. De Gobba, C.; Tompa, G.; Otte, J. Bioctive peptides from caseins released by cold active proteolytic enzymes from Arsukibacterium ikkense. Food Chem. 2014, 15, 205-215. [CrossRef]

49. Wu, J.; Aluko, R.E.; Nakai, S. Structural Requirements of Angiotensin I-Converting Enzyme Inhibitory peptides: Quantitative Structure-Activity Reletionship Study of di and tripeptides. J. Agric. Food Chem. 2006, 54, 732-738. [CrossRef]

50. Ueno, T.; Tanaka, M.; Matsiu, T.; Matsumoto, K. Determination of antihypertensive small peptides, Val-Tyr and Ile-Val-Tyr, by fluorometric high-performance liquid chromatography combined with a double heart-cut column-switching technique. Anal. Sci. 2005, 21, 997-1000. [CrossRef]

51. Umayaparvathi, S.; Meenakshi, S.; Vimalraj, V.; Arumugam, M.; Sivagami, G.; Balasubramanian, T. Antioxidant activity and anticancer effect of bioactive peptide from enzymatic hydrolysate of oyster (Saccostrea cucullata). Biomed. Prev. Nutr. 2014, 4, 343-353. [CrossRef]

52. Haung, W.Y.; Majumder, K.; Wu, J. Oxygen radical absorbance capacity of peptuides from egg white protein ovotransferrin and their interaction with phytochemicals. Food Chem. 2010, 123, 635-641. [CrossRef]

53. Nimalaratne, C.; Lopes-Lutz, D.; Scheiber, A.; Wu, J. Free aromatic amino acids in egg yolk show antioxidant properties. Food Chem. 2011, 129, 151-161. [CrossRef]

54. Liu, C.; Ren, D.; Li, J.; Fang, L.; Wang, J.; Liu, J.; Min, W. Cytoprotective effect and purification of novel antioxidant peptides from hazelnut (C. heterophylla Fish) protein hydrolysates. J. Funct. Foods 2018, 42, 203-215. [CrossRef]

55. Wang, X.Q.; Yu, H.H.; Xing, R.; Li, P.C. Characterization, preparation, and purification of marine bioactive peptides. Bio Med. Res. Int. 2017, 2017, 1-16. [CrossRef] [PubMed] 
56. Pérez-Escalante, E.; González-Olivares, L.G.; Cruz-Guerrero, A.E.; Galán-Vidal, C.A.; Páez-Hernández, M.E.; Álvarez-Romero, G.A. Size exclusion chromatography (SEC-HPLC) as an alternative to study thrombin inhibition. J. Chromatogr. B 2018, 1074, 34-38. [CrossRef] [PubMed]

57. Martínez, N.E.; Añón, C.M. Composition and structural characterization of amaranth protein isolates: An electrophoretic and calorimetric study. J. Agric. Food Chem. 1996, 44, 2523-2530. [CrossRef]

58. Tironi, V.A.; Añón, M.C. Amaranth proteins as a source of antioxidant peptides: Effect of proteolysis. Food Res. Int. 2010, 43, 315-322. [CrossRef]

59. Sashidhar, R.B.; Capoor, A.K.; Ramana, D. Quantification of amino group using amino acids as reference standards by trinitrobenzene sulfonic acid: A simple spectrophotometric method for the estimation of hapten to carrier protein ratio. J. Inmunol. Methods 1995, 167, 121-127. [CrossRef]

60. Cushman, D.W.; Cheung, H.B.; Sabo, E.F.; Ondetti, M.A. Design of potent competitive inhibitors of angiotensin converting enzyme. Carboxylalkanoyl and mercaptoalkanoyl aminoacids. Biochemistry 1977, 16, 5484-5491. [CrossRef] [PubMed]

61. Zhang, B.S.; Zhang, W.; Xu, S.Y. Antioxidant and antithrombotic activity of raoeseed peptides. J. Am. Oil Chem. Soc. 2008, 85, 521-527. [CrossRef]

62. Kuskoski, E.; Asuero, A.; Troncoso, A.; Mancini-Filho, J.; Fett, R. Aplicación de diversos métodos químicos para determinar actividad antioxidante en pulpa de fruto. Ciênc Tecnol. Aliment. 2005, 25, 726-732. [CrossRef]

63. Delgado-Andrade, C.; Rufian-Henares, J.A.; Morales, F.J. Assessing the antioxidant activity of melanoidins from coffee brews by different antioxidant methods. J. Agric. Food Chem. 2005, 53, 7832-7836. [CrossRef] [PubMed]

64. Benzie, I.; Strain, J. The Ferric Reducing Ability of Plasma (FRAP) as a measure if "Antioxidant power". The FRAP assay. Anal. Biochem. 1996, 239, 70-76. [CrossRef] [PubMed]

Sample Availability: Samples of the compounds are not available from the authors.

(C) 2019 by the authors. Licensee MDPI, Basel, Switzerland. This article is an open access article distributed under the terms and conditions of the Creative Commons Attribution (CC BY) license (http://creativecommons.org/licenses/by/4.0/). 
Article

\title{
Green Extraction of Phenolic Acids from Artemisia argyi Leaves by Tailor-Made Ternary Deep Eutectic Solvents
}

\author{
Li Duan ${ }^{1, \dagger}$, Chenmeng Zhang ${ }^{1, \dagger}$, Chenjing Zhang ${ }^{1}$, Zijing Xue ${ }^{2}$, Yuguang Zheng ${ }^{2, *}$ and \\ Long Guo 2,* \\ 1 College of Chemistry and Material Science, Hebei Normal University, Shijiazhuang 050024, China \\ 2 School of Pharmacy, Hebei University of Chinese Medicine, Shijiazhuang 050200, China \\ * Correspondence: zyg314@163.com (Y.Z.); guo_long11@163.com (L.G.); Tel.: +86-0311-89926316 (Y.Z.); \\ +86-0311-89926017 (L.G.) \\ $\dagger$ These authors contributed equally to this work. \\ Academic Editor: Jose M. Miranda \\ Received: 25 June 2019; Accepted: 3 August 2019; Published: 5 August 2019
}

\begin{abstract}
The Artemisia argyi leaf (AL) has been used as a traditional medicine and food supplement in China and other Asian countries for hundreds of years. Phytochemical studies disclosed that AL contains various bioactive constituents. Among bioactive constituents, phenolic acids have been recognized as the main active compounds in AL. To the best of our knowledge, no research has been focused on extraction method for the bioactive phenolic acids from AL. Nowadays, deep eutectic solvents (DESs) are emerging as a new type of green and sustainable solvent for efficient extraction of bioactive compounds from natural products. In the present study, an environmentally friendly extraction method based on DESs was established to extract bioactive phenolic acids from ALs. Diverse tailor-made solvents, including binary and ternary DESs, were explored for simultaneous extraction of four phenolic acids (3-caffeoylquinic acid, 3,4-di-O-caffeoylquinic acid, 3,5-di-O-caffeoylquinic acid, and 4,5-di-O-caffeoylquinic acid) from AL. The results indicated that the ternary DES composed of a 2:1:2 molar ratio of choline chloride, malic acid, and urea showed enhanced extraction yields for phenolic acids compared with conventional organic solvents and other DESs. Subsequently, the extraction parameters for the four phenolic acids by selected tailor-made DESs, including liquid-solid ratios, water content (\%) in the DESs, and extraction time, were optimized using response surface methodology and the optimal extraction conditions were: extraction time, $23.5 \mathrm{~min}$; liquid-solid ratio, $57.5 \mathrm{~mL} / \mathrm{g}$ (mL of DES/g dry weight of plant material); water content, $54 \%$. The research indicated that DESs were efficient and sustainable green extraction solvents for extraction of bioactive phenolic acids from natural products. Compared to the conventional organic solvents, the DESs have a great potential as possible alternatives to those organic solvents in health-related areas such as food and pharmaceuticals.
\end{abstract}

Keywords: deep eutectic solvents; Artemisia argyi leaves; phenolic acids; extraction; response surface methodology

\section{Introduction}

The Artemisia argyi leaf (AL), which is widely distributed in China and other Asian countries, has been used as a traditional medicine or food supplement for hundreds of years [1]. As a traditional Chinese medicine, AL is reported to possess antioxidant, antibacterial, anti-inflammatory, anticancer, hemostatic, and analgesic activities and is commonly used for treatment of hemorrhage, pain, eczema, and menstruation-related symptoms [2-4]. AL is also consumed as a food ingredient because of its 
delicious flavor and distinctive smell. In China, $\mathrm{AL}$ is used as a common condiment and colorant for the traditional Chinese food "Qingtuan". In Japan, AL is added into food as an additive to enhance the flavor and nutrition [5].

Although the AL has been used as an herbal medicine and food ingredient for a long time, studies on its bioactive compositions are still limited. Phytochemical studies disclosed that AL contains various bioactive constituents, mainly including volatile oils, phenolic acids, flavonoids, and terpenoids [6,7]. Among bioactive constituents, phenolic acids have been recognized as the main active compounds in AL $[8,9]$. Therefore, the content of the phenolic acids is an important index for quality analysis and normal applications of AL. To date, several bioactive phenolic acids, such as 3-caffeoylquinic acid, 3,4-di-O-caffeoylquinic acid, 3,5-di-O-caffeoylquinic acid, and 4,5-di-O-caffeoylquinic acid, have been isolated from AL. A number of analytical methods, including high-performance liquid chromatography (HPLC) and high-performance liquid chromatography coupled with mass spectrometry (HPLC-MS), have been used for qualitative and quantitative analysis of the main phenolic acids in AL [5,7]. However, the research focused on extraction methods for bioactive phenolic acids from AL is still limited.

Nowadays, conventional organic solvents, such as alcohols, ethyl acetate, acetone, and chloroform, are widely used in the extraction of bioactive components from natural sources [10]. However, the consumption of large amounts of these volatile and hazardous organic solvents may contribute to environmental pollution and leave unacceptable solvent residues in extracts. Therefore, in analytical chemistry, green extraction methods which are environmentally friendly and sustainable for sample preparation have received more and more attention [11]. Since being introduced as a new type of green solvent, deep eutectic solvents (DESs) have rapidly gained great interest as sustainable alternatives to conventional organic solvents. DESs are prepared by simply mixing two or more naturally occurring, inexpensive, and biodegradable components together to obtain a eutectic mixture [12]. The availability, low cost, biodegradability, and environmental friendliness of the components make the DESs versatile alternatives to conventional organic solvents [13]. Due to their excellent properties, including biodegradability, low toxicity, solute stabilization, and low cost, DESs have been widely used in organic synthesis, separation processes, and biomedical applications $[14,15]$.

Generally, DESs are prepared by simply mixing two or more naturally occurring, inexpensive, and biodegradable components together to obtain eutectic mixtures. As tunable solvents, diverse possible combinations of starting components have different targeted functionality, which means that we can increase the solubility and extraction efficiency of DESs for target compounds by selecting appropriate combinations of starting components. The tailor-made DESs have tremendous potential for efficient and simultaneous extraction and separation of compounds which have obvious differences in nature [16]. Recently, many reports have shown that tailor-made DESs were successfully employed in the extraction and separation of different kinds of bioactive compounds, such as phenolic acids, flavonoids, alkaloids, and saponins, from various plant materials [17-22]. Nonetheless, most of the research used tailor-made binary DESs as extraction solvents for bioactive compound extractions, the number of reports on the application of tailor-made ternary DESs for extraction is still limited, and the efficiency of DESs for extraction of bioactive phenolic acids from AL still remains unknown.

In the present study, in order to evaluate DESs for the extraction of phenolic acids, several tailor-made binary and ternary DESs were used for simultaneous extraction of four bioactive phenolic acids (3-caffeoylquinic acid, 3,4-di-O-caffeoylquinic acid, 3,5-di-O-caffeoylquinic acid, and 4,5-di-O-caffeoylquinic acid) from $\mathrm{AL}$, and the extraction efficiency of tailor-made DESs was compared with that of conventional organic solvents. Moreover, the extraction parameters for phenolic acids by tailor-made DESs were systematically optimized using response surface methodology (RSM). 


\section{Results and Discussion}

\subsection{Chromatographic Conditions and Method Validation}

In order to achieve a rapid and efficient analysis of the four phenolic acids (3-caffeoylquinic acid, 3,4-di-O-caffeoylquinic acid, 3,5-di-O-caffeoylquinic acid, and 4,5-di-O-caffeoylquinic acid) in AL, different mobile phases (including water-methanol, water-acetonitrile, formic acid water-methanol, and formic acid water-acetonitrile), flow rates $(0.7 \mathrm{~mL} / \mathrm{min}, 0.8 \mathrm{~mL} / \mathrm{min}$, and $1.0 \mathrm{~mL} / \mathrm{min})$, as well as column temperatures $\left(15^{\circ} \mathrm{C}, 20^{\circ} \mathrm{C}, 25^{\circ} \mathrm{C}\right.$, and $30^{\circ} \mathrm{C}$, Supplementary Materials Figure S1) were examined and compared. As a result, the formic acid water-acetonitrile system at $15{ }^{\circ} \mathrm{C}$ with a flow rate of $0.7 \mathrm{~mL} / \mathrm{min}$ was finally selected for the suitable analysis duration, greater separation ability, and better peak shapes. The gradient elution was as follows: $0-5 \mathrm{~min}, 12 \% \mathrm{~B} ; 5-15 \mathrm{~min}, 12-22 \% \mathrm{~B}$; 15-25 min, 22\% B; 25-35 min, 22-25\% B; 35-40 min, 25-40\% B. The typical HPLC chromatograms of the AL sample and four phenolic acids reference standards are shown in Figure 1.
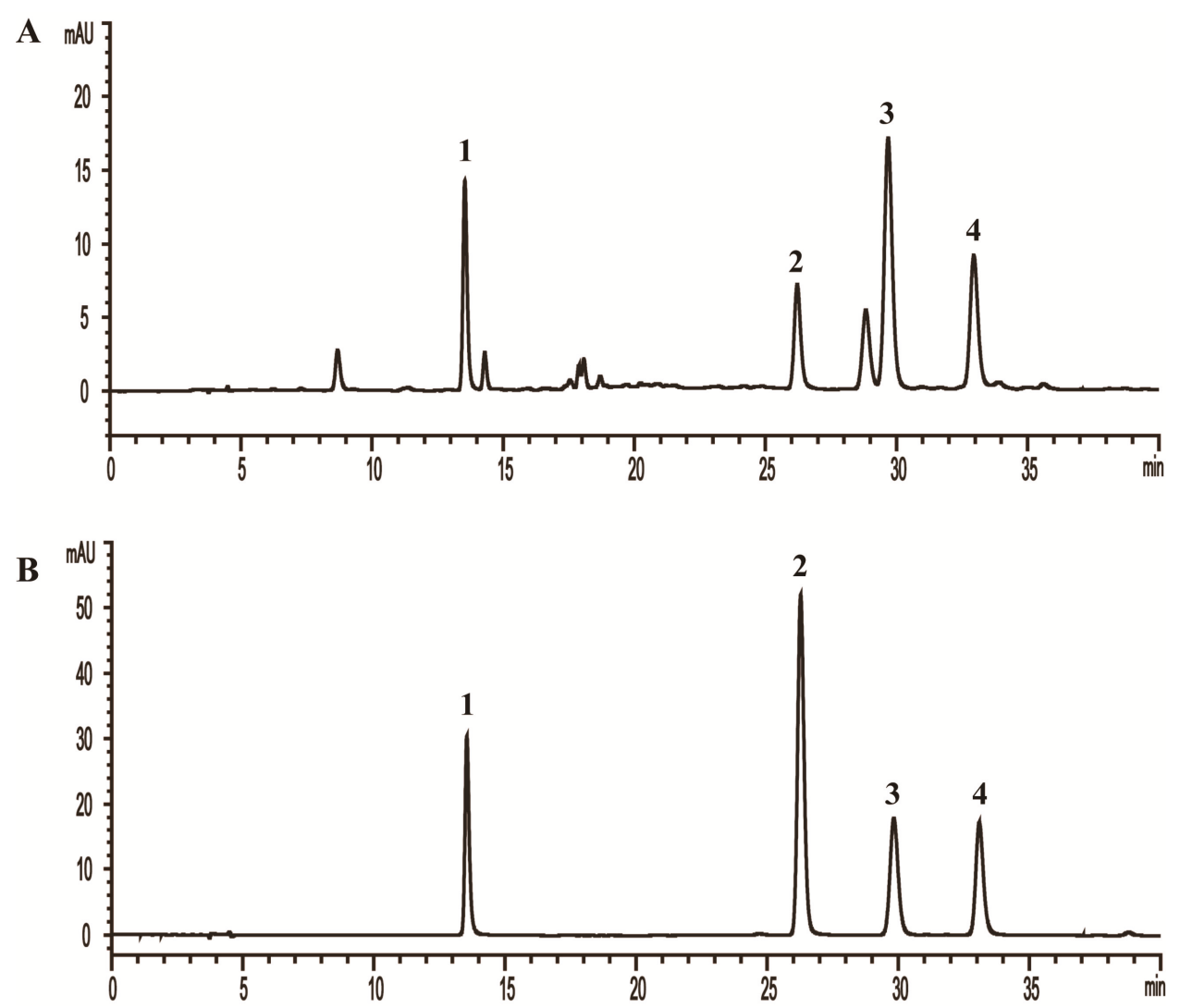

Figure 1. The typical HPLC chromatograms of (A) Artemisia argyi leaves sample $(20 \mathrm{mg} / \mathrm{mL})$ and (B) four phenolic acids reference standards. (1. 3-caffeoylquinic acid, $4.96 \mu \mathrm{g} / \mathrm{mL} ; 2$. 3,4-di-O-caffeoylquinic acid, $4.24 \mu \mathrm{g} / \mathrm{mL}$; 3. 3,5-di-O-caffeoylquinic acid, $5.36 \mu \mathrm{g} / \mathrm{mL} ; 4$. 4,5-di-O-caffeoylquinic acid, $4.16 \mu \mathrm{g} / \mathrm{mL}$ ).

Method validation of quantitative analysis was performed. The linearity, limit of detections (LODs), limit of quantifications (LOQs), precision, repeatability, stability, and accuracy for the four phenolic acids were validated. Each calibration curve was performed with six different concentrations in triplicate. All calibration curves were of good linearity with high correlation coefficient $\left(R^{2}>0.9997\right)$ 
over the tested range. The LODs and LOQs of the four analytes were defined by the concentration that generated peaks with signal-to-noise values of 3 and 10 using standard solutions. The precision of the developed method was determined by the intra- and interday variations. For the intraday test, the sample was analyzed six times within the same day, while for the interday test, the sample was examined in duplicates for three consecutive days. The relative standard deviations (RSDs) of intraday and interday precisions were less than $1.61 \%$ and $2.14 \%$, respectively. For the repeatability test, six replicates of the same sample were prepared and analyzed, and for the stability test, the same sample was stored at room temperature and analyzed by replicate injection analysis at $0,2,4,8,12$, and $24 \mathrm{~h}$. The repeatability presented as RSDs was less than $2.71 \%$, and the stability was less than $2.06 \%$. The recovery was used to evaluate the accuracy of the method. Known amounts of the four phenolic acids standard solutions were added into the same samples in sextuplicate, and then extracted and analyzed with the same procedures. The recovery of each analyte was calculated by the equation: Recovery $(\%)=($ Detected amount - Original amount $) /$ Spiked amount $\times 100 \%$. The overall recoveries of the four analytes were in the range of $101.15-102.86 \%$ with RSDs less than $1.67 \%$. The data of method validation are shown in Supplementary Materials Table S1.

\subsection{Screening of DESs for the Extraction of Phenolic Acids from $A L$}

\subsubsection{Extraction of Phenolic Acids by Binary DESs}

DESs are composed of a mixture consisting of hydrogen bond acceptors (HBAs) with hydrogen bond donors (HBDs). The composition of DESs determines their physicochemical properties and consequently greatly influences extraction efficiency of natural compounds [23]. In the present study, six choline-chloride-based binary DESs, ChCl-Ma, ChCl-Ur, ChCl-Ga, ChCl-Pa, $\mathrm{ChCl}-\mathrm{Eg}$, and $\mathrm{ChCl}-\mathrm{Gl}$, were successfully synthesized (Table 1) and selected to test their extraction efficiency for phenolic acids. The high viscosity of most DESs at room temperature restricted their application due to a slow mass transfer. To overcome this problem, extraction conditions were adjusted to reduce the viscosity by increasing extraction temperature and adding a certain amount of water [24]. In the initial screening experiments, $75 \%$ DES solution in water $(v / v)$ was employed, and the extraction conditions were as follows: extraction time, $30 \mathrm{~min}$; extraction temperature, $50{ }^{\circ} \mathrm{C}$; liquid-solid ratio, $50 \mathrm{~mL} / \mathrm{g} \mathrm{(mL} \mathrm{of}$ DES/g dry weight of plant material).

Table 1. The binary DESs synthesized in this study.

\begin{tabular}{ccccc}
\hline NO. & Abbreviation & Component 1 & Component 2 & Molar Ratio \\
\hline BD-1 & ChCl-Ma & choline chloride & DL-malic acid & $1: 1$ \\
BD-2 & ChCl-Ur & choline chloride & urea & $1: 2$ \\
BD-3 & ChCl-Ga & choline chloride & glutaric acid & $1: 1$ \\
BD-4 & ChCl-Pa & choline chloride & propanedioic acid & $1: 1$ \\
BD-5 & ChCl-Eg & choline chloride & ethylene glycol & $1: 3$ \\
BD-6 & ChCl-Gl & choline chloride & glycerol & $1: 2$ \\
\hline
\end{tabular}

Extraction yields of the four phenolic acids (3-caffeoylquinic acid, 3,4-di-O-caffeoylquinic acid, 3,5-di-O-caffeoylquinic acid, and 4,5-di-O-caffeoylquinic acid) with different binary DESs are shown in Figure 2. The initial screening results indicated that the extraction efficiency for phenolic acids was influenced by the types of DES solvents, and different types of DESs resulted in different extraction yields. In general, extraction yields of the four phenolic acids followed the order 3,5-di-O-caffeoylquinic acid $>3$-caffeoylquinic acid > 4,5-di-O-caffeoylquinic acid > 3,4-di-O-caffeoylquinic acid. The phenolic acid, 3,5-di-O-caffeoylquinic acid, showed high extraction efficiency in $\mathrm{ChCl}$-Eg with the concentration $9.35 \pm 0.03 \mathrm{mg} / \mathrm{g}(\mathrm{mg} / \mathrm{g}$ dry weight of plant material), followed by ChCl-Ma $(9.05 \pm 0.05 \mathrm{mg} / \mathrm{g})$ and $\mathrm{ChCl}-\mathrm{Pa}(8.71 \pm 0.03 \mathrm{mg} / \mathrm{g})$. For 3-caffeoylquinic acid, ChCl-Ma $(4.45 \pm 0.03 \mathrm{mg} / \mathrm{g})$ and $\mathrm{ChCl}-\mathrm{Ur}(4.47 \pm$ $0.03 \mathrm{mg} / \mathrm{g}$ ) led to higher extraction yields. For 4,5-di-O-caffeoylquinic acid, ChCl-Ma (4.10 $\pm 0.02 \mathrm{mg} / \mathrm{g})$, $\mathrm{ChCl}-\mathrm{Pa}(3.90 \pm 0.03 \mathrm{mg} / \mathrm{g})$, and $\mathrm{ChCl}-\mathrm{Eg}(3.72 \pm 0.02 \mathrm{mg} / \mathrm{g})$ exhibited higher extraction efficiency. For 
3,4-di-O-caffeoylquinic acid, $\mathrm{ChCl}$-Ur $(3.32 \pm 0.03 \mathrm{mg} / \mathrm{g})$ showed higher extraction efficiency, followed by ChCl-Ma $(3.03 \pm 0.02 \mathrm{mg} / \mathrm{g})$ and $\mathrm{ChCl}-\mathrm{Pa}(2.97 \pm 0.03 \mathrm{mg} / \mathrm{g})$. In conclusion, the extraction yields of the total phenolic acids were calculated, and it was clearly shown that $\mathrm{ChCl}-\mathrm{Ma}$ (BD-1) was the best binary DES for extraction of four phenolic acids from AL with the extraction yields $20.64 \pm 0.08 \mathrm{mg} / \mathrm{g}$.
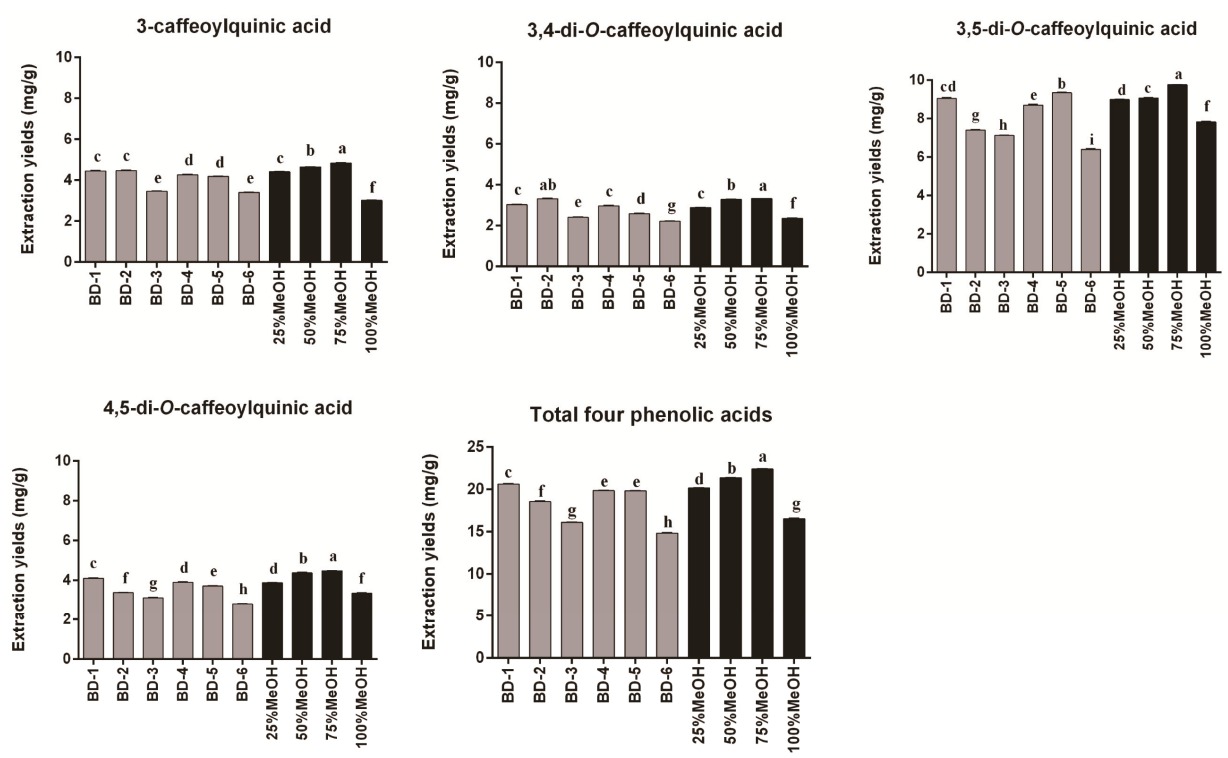

Figure 2. Extraction yields of different binary DESs and different ratios of methanol for 3-caffeoylquinic acid, 3,4-di-O-caffeoylquinic acid, 3,5-di-O-caffeoylquinic acid, 4,5-di-O-caffeoylquinic acid, and total four phenolic acids from Artemisia argyi leaves $(n=3)$. Numbers on horizontal axis are in accordance with the numbers in Table 1 . Error bars indicate the SD $(n=3)$. Extraction yields which do not share the same letter are significantly different $(p<0.05)$.

In order to comprehensively compare the extraction efficiency of DESs and conventional solvents for extraction of phenolic acids from AL, different ratios of methanol $(25 \% \mathrm{MeOH}, 50 \% \mathrm{MeOH}, 75 \%$ $\mathrm{MeOH}$, and $100 \% \mathrm{MeOH}$ ), efficient solvents commonly used in the extraction of bioactive compounds from natural products, were selected as reference solvents [7]. As shown in Figure 2, among the different ratios of $\mathrm{MeOH}, 75 \% \mathrm{MeOH}$ displayed the highest extraction efficiency for the four phenolic acids. It was clear that all the six tailor-made binary DESs exhibited higher extraction efficiency for the four phenolic acids compared with $100 \% \mathrm{MeOH}$ (16.56 $\pm 0.06 \mathrm{mg} / \mathrm{g}$ ). However, compared to $75 \%$ $\mathrm{MeOH}(22.41 \pm 0.03 \mathrm{mg} / \mathrm{g})$, none of the six binary DESs exhibited a higher extraction yield. Based on the results above, ChCl-Ma (BD-1) was selected as the best binary DES for extraction of phenolic acids from $\mathrm{AL}$, and we attempted to synthesize a series of ternary DESs based on ChCl-Ma to enhance extraction efficiency of phenolic acids in further tests.

\subsubsection{Extraction of Phenolic Acids by Ternary DESs}

DESs can be synthesized from two or more components. According to the previous report, the ternary DESs forming with addition of glycerol to the binary DESs show lower melting points and viscosities [25]. Adding the third component to binary DESs may change the properties of ternary DESs and thus influence the extraction yields. In this study, based on the best binary DES (ChCl-Ma) selected above, several tailor-made ternary DESs were designed in order to further enhance the extraction yields of phenolic acids from AL. Five ternary DESs, including ChCl-Ma-Ur, ChCl-Ma-Ga, ChCl-Ma-Pa, $\mathrm{ChCl}-\mathrm{Ma}-\mathrm{Eg}$, and $\mathrm{ChCl}-\mathrm{Ma}-\mathrm{Gl}$, were successfully synthesized (Table 2) and further used to test their 
extraction efficiency for phenolic acids. The extraction yields of the four phenolic acids employing the tailor-made ternary DESs are listed in Figure 3. The results indicated that compared to the binary DESs, some tailor-made ternary DESs could change the extraction efficiency. Almost all of the tailor-made ternary DESs exhibited higher extraction efficiency for the four phenolic acids compared with the best binary DES (ChCl-Ma), except ChCl-Ma-Gl (TD-12 and TD-13). It could be speculated that the addition of the third component might reduce the viscosity of DESs, enhancing the hydrogen bond interactions between DESs and the target components, thus improving the extraction yields [26].

Table 2. The ternary DESs synthesized in this study.

\begin{tabular}{|c|c|c|c|c|c|c|}
\hline NO. & Abbreviation & Component 1 & Component 2 & Component 3 & Molar Ratio & $\begin{array}{c}\text { Extraction Yield of } \\
\text { Four Phenolic Acids } \\
(\mathrm{mg} / \mathrm{g})\end{array}$ \\
\hline TD-1 & ChCl-Ma-Ur & choline chloride & DL-malic acid & urea & $2: 1: 1$ & $21.92 \pm 0.04$ \\
\hline TD-2 & ChCl-Ma-Ur & choline chloride & DL-malic acid & urea & $2: 2: 1$ & $22.26 \pm 0.04$ \\
\hline TD-3 & ChCl-Ma-Ur & choline chloride & DL-malic acid & urea & $2: 1: 2$ & $22.43 \pm 0.02$ \\
\hline TD-4 & ChCl-Ma-Ga & choline chloride & DL-malic acid & glutaric acid & $2: 1: 1$ & $21.41 \pm 0.04$ \\
\hline TD-5 & ChCl-Ma-Ga & choline chloride & DL-malic acid & glutaric acid & $2: 2: 1$ & $21.89 \pm 0.02$ \\
\hline TD-6 & ChCl-Ma-Pa & choline chloride & DL-malic acid & propanedioic acid & $2: 2: 1$ & $20.81 \pm 0.06$ \\
\hline TD-7 & ChCl-Ma-Pa & choline chloride & DL-malic acid & propanedioic acid & $2: 1: 1$ & $21.30 \pm 0.05$ \\
\hline TD-8 & ChCl-Ma-Pa & choline chloride & DL-malic acid & propanedioic acid & $1: 1: 1$ & $21.55 \pm 0.04$ \\
\hline TD-9 & ChCl-Ma-Pa & choline chloride & DL-malic acid & propanedioic acid & $2: 1: 2$ & $22.08 \pm 0.03$ \\
\hline TD-10 & ChCl-Ma-Eg & choline chloride & DL-malic acid & ethylene glycol & $1: 2: 0.5$ & $21.67 \pm 0.04$ \\
\hline TD-11 & ChCl-Ma-Eg & choline chloride & DL-malic acid & ethylene glycol & $2: 2: 1$ & $22.12 \pm 0.05$ \\
\hline TD-12 & ChCl-Ma-Gl & choline chloride & DL-malic acid & glycerol & $1: 2: 0.5$ & $20.02 \pm 0.02$ \\
\hline TD-13 & ChCl-Ma-Gl & choline chloride & DL-malic acid & glycerol & $2: 2: 1$ & $20.09 \pm 0.04$ \\
\hline
\end{tabular}
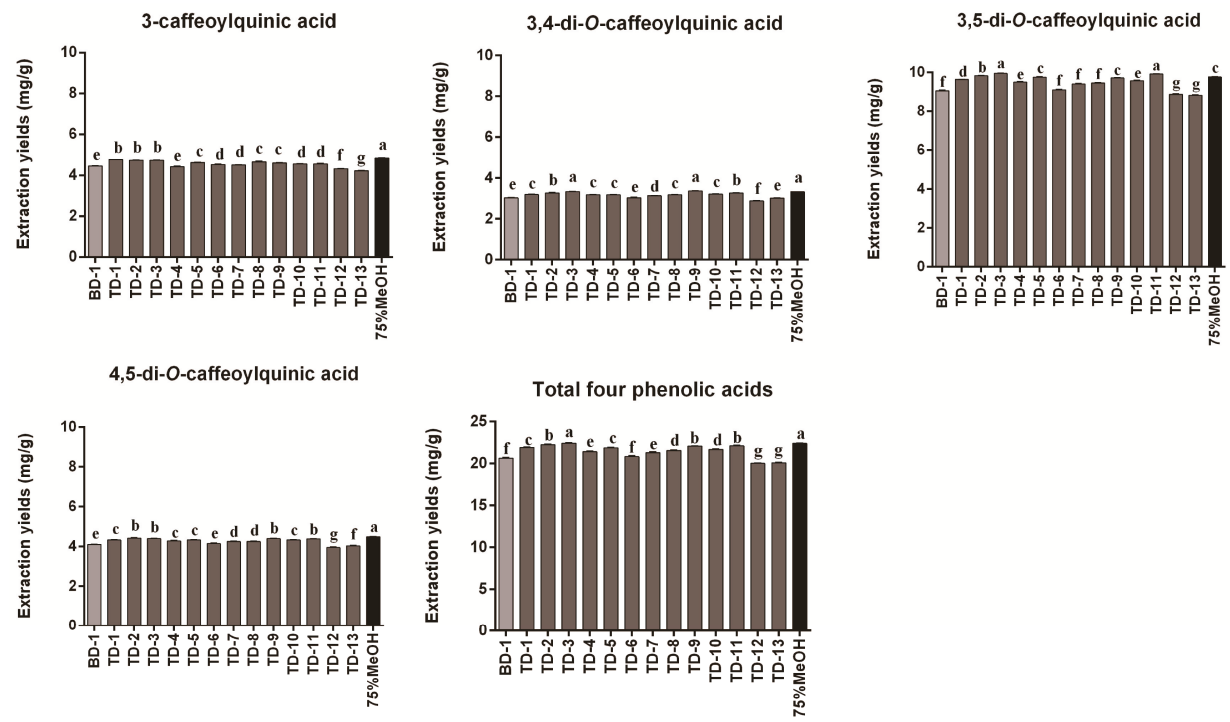

Figure 3. Extraction yields of different ternary DESs for 3-caffeoylquinic acid, 3,4-di-O-caffeoylquinic acid, 3,5-di-O-caffeoylquinic acid, 4,5-di-O-caffeoylquinic acid, and total four phenolic acids from Artemisia argyi leaves $(n=3)$. Numbers on horizontal axis are in accordance with the numbers in Tables 1 and 2. Error bars indicate the SD $(n=3)$. Extraction yields which do not share the same letter are significantly different $(p<0.05)$.

Several studies have revealed that different molar ratios of DES components result in different viscosities and surface tensions, thereby affecting the extraction efficiency of target components from natural biomass [27]. Thus, in the study, the effects of molar ratios of tailor-made ternary DESs were also investigated. As shown in Figure 3, the optimal molar ratio of ChCl-Ma-Ur was 2:1:2 (TD-3) 
and the extraction yields of the four phenolic acids were $22.43 \pm 0.02 \mathrm{mg} / \mathrm{g}$. The optimal molar ratio of ChCl-Ma-Ga was 2:2:1 (TD-5) and the extraction yields of the four phenolic acids were $21.89 \pm$ $0.02 \mathrm{mg} / \mathrm{g}$. The optimal molar ratio of ChCl-Ma-Pa was 2:1:2 (TD-9) and the extraction yields of the four phenolic acids were $22.08 \pm 0.03 \mathrm{mg} / \mathrm{g}$. The optimal molar ratio of ChCl-Ma-Eg was 2:2:1 (TD-11) and the extraction yields of the four phenolic acids were $22.12 \pm 0.05 \mathrm{mg} / \mathrm{g}$. The optimal molar ratio of ChCl-Ma-Gl was 2:2:1 (TD-13) and the extraction yields of the four phenolic acids were $20.09 \pm$ $0.04 \mathrm{mg} / \mathrm{g}$. None of the tailor-made ternary DESs with different molar ratios exhibited an extraction yield higher than $75 \% \mathrm{MeOH}$, the best conventional solvent. However, the tailor-made ternary DES, ChCl-Ma-Ur (2:1:2), produced similar extraction efficiency for the four phenolic acids compared to $75 \%$ $\mathrm{MeOH}(p>0.05)$. Based on the results, the ChCl-Ma-Ur with a molar ratio of 2:1:2 (TD-3) was selected as the best ternary DES for extraction of phenolic acids from AL.

\subsection{Optimization of the Extraction Parameters for Phenolic Acids}

The above extraction investigations showcased that the tailor-made ternary DES, ChCl-Ma-Ur (2:1:2), was selected as the best ternary DES for extraction of phenolic acids from AL. In order to obtain the optimal extraction efficiency for phenolic acids from AL, several numerical variables that could affect the extraction efficiencies were optimized by RSM, a valuable statistical technique to determine the optimal values of the independent variables and to enable the user to effectively investigate the effects of multiple factors [28,29]. Similar to previous studies [30], three variables of extraction time, liquid-solid ratios, and water content in DESs were evaluated using Box-Behnken design (BBD). After determining the range of extraction factors on the basis of preliminary single-factor test, the extraction time (A), liquid-solid ratios (B), and water content $(\mathrm{C})$ were varied at three levels $(-1,0,+1)$ as follows: A, 8.0-40.0 min; B, 17.5-57.5 mL/g; C 20-70\%. The total extraction amounts of the four phenolic acids were taken as the responses of the design experiments. The experimental orders, levels of variables, and response values are summarized in Table 3.

Table 3. The experimental orders, levels of variables, and response values in Box-Behnken design.

\begin{tabular}{ccccc}
\hline Run & \multicolumn{3}{c}{ Factors } & Responses \\
\cline { 2 - 5 } & $\begin{array}{c}\text { Extraction Time } \\
\text { (A, min) }\end{array}$ & $\begin{array}{c}\text { Liquid-Solid } \\
\text { Ratios (B, mL/g) }\end{array}$ & $\begin{array}{c}\text { Water Content (C) } \\
\text { \%) }\end{array}$ & $\begin{array}{c}\text { Total Extraction Amounts } \\
\text { of Four Phenolic Acids } \\
\text { (mg/g) }\end{array}$ \\
\hline 1 & 24.0 & 37.5 & 45 & 22.60 \\
2 & 40.0 & 57.5 & 45 & 22.61 \\
3 & 24.0 & 17.5 & 20 & 18.47 \\
4 & 8.0 & 37.5 & 20 & 16.13 \\
5 & 24.0 & 37.5 & 45 & 22.10 \\
6 & 40.0 & 17.5 & 45 & 21.96 \\
7 & 24.0 & 57.5 & 70 & 20.85 \\
8 & 24.0 & 37.5 & 45 & 21.40 \\
9 & 8.0 & 57.5 & 45 & 22.34 \\
10 & 24.0 & 17.5 & 70 & 18.86 \\
11 & 24.0 & 57.5 & 20 & 22.65 \\
12 & 24.0 & 37.5 & 45 & 21.27 \\
13 & 8.0 & 17.5 & 45 & 19.84 \\
14 & 40.0 & 37.5 & 70 & 22.02 \\
15 & 24.0 & 37.5 & 45 & 20.06 \\
16 & 8.0 & 37.5 & 70 & 17.00 \\
17 & 40.0 & 37.5 & 20 & \\
\hline
\end{tabular}

Experiments conducted according to the design resulted in a second-order polynomial equation for total extraction amounts $(\mathrm{Y})$ expressed using coded variables (A, B, and C) as follows:

$$
\mathrm{Y}=22.16-0.20 \mathrm{~A}+0.095 \mathrm{~B}+1.56 \mathrm{C}-0.11 \mathrm{AB}-0.27 \mathrm{AC}+1.24 \mathrm{BC}-0.14 \mathrm{~A}^{2}+0.027 \mathrm{~B}^{2}-3.76 \mathrm{C}^{2}
$$


The model was evaluated in terms of the square of correlation coefficient $\left(R^{2}\right)$ and the lack of fit by the analysis of variance (ANOVA) at the $95 \%$ confidence level (Table 4 ). The resulting $\mathrm{R}^{2}$ value was 0.9765 , indicating that the experimental data were in relatively good agreement with predicted extraction yields. The lack-of-fit value, which evaluates the failure of the model to represent the data in the experimental domain points, was insignificant for the response with $p$-value of $0.3789(p>0.05)$.

Table 4. The ANOVA results of the quadratic multiple regression model for phenolic acids.

\begin{tabular}{ccccccc}
\hline Source & Sum of Squares & df & Mean Square & F Value & $p$-Value Prob $>$ F & Significance \\
\hline Model & 86.54 & 9 & 9.62 & 32.38 & $<0.0001$ & significant \\
A & 0.32 & 1 & 0.32 & 1.08 & 0.3323 \\
B & 0.073 & 1 & 0.073 & 0.24 & 0.6359 \\
C & 19.53 & 1 & 19.53 & 65.78 & 0.0001 \\
AB & 0.045 & 1 & 0.045 & 0.15 & 0.7085 \\
AC & 0.3 & 1 & 0.3 & 1.02 & 0.3468 \\
BC & 6.13 & 1 & 6.13 & 20.64 & 0.0027 \\
A $^{2}$ & 0.08 & 1 & 0.08 & 0.27 & 0.9215 \\
$B^{2}$ & $3.10 \times 10^{-3}$ & 1 & $3.10 \times 10^{-3}$ & 0.01 & $<0.0001$ \\
C $^{2}$ & 59.51 & 1 & 59.51 & 200.42 & 0.3789 \\
Residual & 2.08 & 7 & 0.3 & & not significant \\
Lack of Fit & 1.04 & 3 & 0.35 & 1.34 & \\
Pure Error & 1.04 & 4 & 0.26 & & \\
R $^{2}$ & 0.9765 & & & & \\
\hline
\end{tabular}

Statistical analysis and 3D response plots (Figure 4) illustrated the significant variables affecting extraction yields of phenolic acids and the interaction effects between the variables. In the model, the water content $(C)$ showed significant effects on the extraction efficiency of phenolic acids $(p<0.0001)$. Based on the adequate model, the calculated optimum conditions for the extraction of phenolic acids from AL were as follows: extraction time, $23.5 \mathrm{~min}$; liquid-solid ratio, $57.5 \mathrm{~mL} / \mathrm{g}$; water content, 54\%. Triplicate experiments were carried out under the optimal extraction conditions and mean values of experimental results were compared with the predicted values. Under the optimum conditions, the total extraction amounts of the four phenolic acids were $22.80 \mathrm{mg} / \mathrm{g}$, which were closed to the predicted values of $22.79 \mathrm{mg} / \mathrm{g}$. The results obtained through confirmation experiments indicated the model is adequate for predicting the expected optimization.
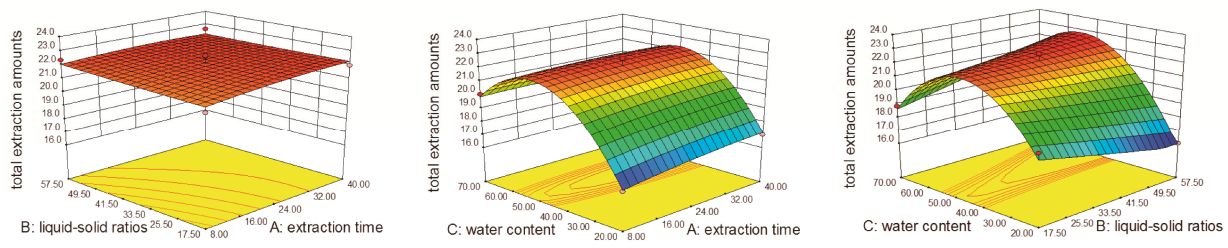

Figure 4. Response surface plots of the model for extraction of phenolic acids from Artemisia argyi leaves. (A. extraction time, min; B. liquid-solid ratios, $\mathrm{mL} / \mathrm{g}$; C. water content, \%).

\section{Materials and Methods}

\subsection{Materials and Reagents}

AL samples were purchased from a Chinese herbal medicine market (Anguo, China). The samples were dried in the shade and stored in the desiccator. The AL samples were authenticated by Prof. Yuguang Zheng from Department of Pharmacognosy, Hebei University of Chinese Medicine and the voucher specimens were deposited in Hebei University of Chinese Medicine, Shijiazhuang, China.

Four phenolic acids reference compounds, 3-caffeoylquinic acid, 3,4-di-O-caffeoylquinic acid, 3,5-di-O-caffeoylquinic acid, and 4,5-di-O-caffeoylquinic acid, were purchased from Chengdu Must Bio-technology Co., Ltd. (Chengdu, China). The purities of the four reference compounds were 
determined to be higher than $98 \%$ by high-performance liquid chromatography diode array detection analysis. The structures of the four phenolic acids are shown in Figure 5.<smiles>O=C(/C=C/c1ccc(O)c(O)c1)O[C@H]1C[C@@](O)(C(=O)O)C[C@H](O)[C@H]1O</smiles>

3-caffeoylquinic acid<smiles>O=C(/C=C/c1ccc(O)c(O)c1)OC1CC(O)(C(=O)O)C[C@H](OC(=O)/C=C/c2ccc(O)c(O)c2)C1O</smiles>

3,5-di- $O$-caffeoylquinic acid<smiles>O=C(/C=C/c1ccc(O)c(O)c1)O[C@H]1C[C@@](O)(C(=O)O)CC(O)[C@H]1OC(=O)/C=C/c1ccc(O)c(O)c1</smiles>

3,4-di-O-caffeoylquinic acid<smiles>O=C(/C=C/c1ccc(O)c(O)c1)O[C@H]1[C@@H](O)C[C@@](O)(C(=O)O)C[C@H]1OC(=O)/C=C/c1ccc(O)c(O)c1</smiles>

4,5-di- $O$-caffeoylquinic acid

Figure 5. Chemical structures of 3-caffeoylquinic acid, 3,4-di-O-caffeoylquinic acid, 3,5-di-O-caffeoylquinic acid, and 4,5-di-O-caffeoylquinic acid.

Chemical compounds for DES preparation including choline chloride (ChCl), DL-malic acid $(\mathrm{Ma})$, urea (Ur), glutaric acid (Ga), propanedioic acid (Pa), ethylene glycol (Eg), glycerol (Gl) were obtained from Aladdin Reagent Company (Shanghai, China). Acetonitrile, methanol, and formic acid (chromatographic grade) were purchased from Merck (Darmstadt, Germany). Deionized water was prepared by a Milli-Q water purification system (Millipore, Billerica, MA, USA). Other reagents and chemicals used in this work were of analytical grade.

\subsection{HPLC Analysis}

HPLC analysis was performed on an Agilent 1260 HPLC system equipped with a quaternary pump, a degasser, an autosampler, a thermostated column compartment, and a diode array detector (Agilent Technologies, Palo Alto, CA, USA). Chromatographic separation was achieved on an Agilent SB C18 column $(4.6 \times 250 \mathrm{~mm}, 5 \mu \mathrm{m})$. The mobile phase was composed of $0.1 \%$ formic acid water (A) and acetonitrile (B) with a gradient elution as follows: 0-5 min, $12 \%$ B; 5-15 min, $12-22 \%$ B; $15-25 \mathrm{~min}$, $22 \% \mathrm{~B} ; 25-35 \mathrm{~min}, 22-25 \% \mathrm{~B} ; 35-40 \mathrm{~min}, 25-40 \% \mathrm{~B}$. The detection wavelength was $330 \mathrm{~nm}$. The flow rate was set at $0.7 \mathrm{~mL} / \mathrm{min}$ and the column temperature was set at $15^{\circ} \mathrm{C}$.

\subsection{Preparation of DESs}

The DESs were synthesized according to the previous studies [31]. Briefly, different DESs were obtained by simply mixing hydrogen bond acceptors (HBAs) and hydrogen bond donors (HBDs) together in a proper molar ratio with constant stirring at $80{ }^{\circ} \mathrm{C}$ until a clear and homogeneous liquid formed.

\subsection{Extraction of Phenolic Acids From AL}

The AL samples were powdered and screened through 40 mesh sieves. An accurately weighed powder $(20 \mathrm{mg}$ ) was extracted with $1 \mathrm{~mL}$ of different solvents (different DESs, $25 \% \mathrm{MeOH}, 50 \% \mathrm{MeOH}$, $75 \% \mathrm{MeOH}$, and $100 \% \mathrm{MeOH}$ ) in a $2 \mathrm{~mL}$ centrifuge tube by ultrasonic cleaner (KQ5200B, 200W, $40 \mathrm{kHz}$, Kunshan, China) for $30 \mathrm{~min}$. After extraction, the extracted solution was centrifuged at 13,000 rpm/min 
for $10 \mathrm{~min}$. Then, $0.1 \mathrm{~mL}$ of supernatant was sampled and diluted 10-fold with methanol. The diluted solution $(2 \mu \mathrm{L})$ was injected into the HPLC instrument for analysis. Three replicates of each sample were prepared and analyzed $(n=3)$.

\subsection{DESs Tailoring}

In order to determine the effect of the DES compositions on the extraction of the four phenolic acids from $\mathrm{AL}$, six ChCl-based binary DESs, including ChCl-Ma, ChCl-Ur, ChCl-Ga, ChCl-Pa, ChCl-Eg, and $\mathrm{ChCl}-\mathrm{Gl}$, were successfully synthesized in initial screening. Then, the extraction efficiency of the different binary DESs for the four phenolic acids was investigated and the optimal binary DES was selected. Next, different efficient components were added into the optimal binary DES obtained in initial screening to design different ternary DESs. Five tailored ternary DESs with different molar ratios, including ChCl-Ma-Ur, ChCl-Ma-Ga, ChCl-Ma-Pa, ChCl-Ma-Eg, and ChCl-Ma-Gl, were synthesized and the extraction efficiencies for the four phenolic acid compounds were tested.

\subsection{Optimization of the DES Extraction Parameters for Phenolic Acids}

The optimal extraction parameters for the phenolic acids from AL were obtained using RSM. RSM was performed using the Design-Expert Ver. 8.0.6 (Stat-Ease Inc., Minneapolis, MN, USA). After determining the range of extraction variables on the basis of preliminary single-factor test, Box-Behnken design (BBD) was used to find the optimal values for three independent variables: extraction time (A), liquid-solid ratios (B), and water content (\%) in DESs (C). The total extraction amounts of the four phenolic acids were taken as the response of the design experiments. Regression analysis was performed according to the experimental data. Subsequently, additional confirmation experiments were conducted to confirm the validity of the statistical experimental strategies.

\section{Conclusions}

In this work, a green and efficient extraction method using tailor-made DESs as extraction solvents was established for extraction of bioactive phenolic acids from AL. Six binary DESs and five ternary DESs were successfully synthesized and used to extract four phenolic acids from AL. The results indicated that the tailor-made DESs were efficient solvents for the extraction of phenolic acids. The ternary DES, ChCl-Ma-Ur with a molar ratio of 2:1:2, proved to be the most efficient solvent for phenolic acid extraction from AL. Moreover, the optimal extraction conditions for phenolic acids by ChCl-Ma-Ur (2:1:2) were determined using RSM and the optimal extraction conditions are extraction time, $23.5 \mathrm{~min}$; liquid-solid ratio, $57.5 \mathrm{~mL} / \mathrm{g}$; and water content, $54 \%$. The present study suggests that the DES-based extraction method is efficient and sustainable for extraction of bioactive phenolic acids from AL. The DESs are truly designed and efficient solvents which could be used as green solvents for the extraction of bioactive compounds from natural products and have a great potential as possible alternatives to those organic solvents in health-related areas such as food and pharmaceuticals.

Supplementary Materials: The Supplementary Materials are available online.

Author Contributions: Conceptualization, L.D. and L.G.; Data curation, C.Z. (Chenmeng Zhang); Investigation, L.D. and C.Z. (Chenmeng Zhang); Methodology, C.Z. (Chenjing Zhang); Project administration, Y.Z.; Resources, Z.X.; Writing—original draft, L.D. and L.G.; Writing—review \& editing, Y.Z. and L.G.

Funding: This research was funded by National Natural Science Foundation of China $(81803697,81803685)$, Natural Science Foundation of Hebei Province (H2018205185, H2018423032), Research Foundation of Hebei Province Education Department (BJ2019006, QN2017093), Research Foundation of Hebei Provincial Administration of Traditional Chinese Medicine (2018108), and Innovation Team of Hebei Province Modern Agricultural Industry Technology System (HBCT2018060205).

Conflicts of Interest: The authors declare no conflict of interest. 


\section{References}

1. Abad, M.J.; Bedoya, L.M.; Apaza, L.; Bermejo, P. The artemisia, Genus: A review of bioactive essential oils. Molecules 2012, 17, 2542-2566. [CrossRef] [PubMed]

2. Bora, K.S.; Sharma, A. The genus Artemisia: A comprehensive review. Pharm. Biol. 2011, 49, 101-109. [CrossRef] [PubMed]

3. Guan, X.; Ge, D.; Li, S.; Huang, K.; Liu, J.; Li, F. Chemical composition and antimicrobial activities of Artemisia argyi Lévl. et Vant essential oils extracted by simultaneous distillation-extraction, subcritical extraction and hydrodistillation. Molecules 2019, 24, 483. [CrossRef] [PubMed]

4. Li, S.; Zhou, S.; Yang, W.; Meng, D. Gastro-protective effect of edible plant Artemisia argyi in ethanol-induced rats via normalizing inflammatory responses and oxidative stress. J. Ethnopharmacol. 2018, 214, 207-217. [CrossRef] [PubMed]

5. Han, B.; Xin, Z.; Ma, S.; Liu, W.; Zhang, B.; Ran, L.; Yi, L.; Ren, D. Comprehensive characterization and identification of antioxidants in Folium Artemisiae Argyi using high-resolution tandem mass spectrometry. J. Chromatogr. B 2017, 1063, 84-92. [CrossRef] [PubMed]

6. Li, N.; Mao, Y.; Deng, C.; Zhang, X. Separation and identification of volatile constituents in Artemisia argyi flowers by GC-MS with SPME and steam distillation. J. Chromatogr. Sci. 2008, 46, 401-405. [CrossRef] [PubMed]

7. Guo, L.; Zhang, D.; Xue, Z.J.; Jiao, Q.; Liu, A.P.; Zheng, Y.G.; Liu, E.H.; Duan, L. Comparison of Artemisiae argyi Folium and Artemisiae lavandulaefoliae Folium by simultaneous determination of multi-components with single reference standard method and chemometric analysis. Phytochem. Anal. 2019, 30, 14-25. [CrossRef] [PubMed]

8. Kim, K.O.; Lee, D.; Hiep, N.T.; Song, J.H.; Lee, H.J.; Lee, D.; Kang, K.S. Protective effect of phenolic compounds isolated from Mugwort (Artemisia argyi) against contrast-induced apoptosis in kidney epithelium cell line LLC-PK1. Molecules 2019, 24, 195. [CrossRef]

9. Lee, D.; Kim, C.E.; Park, S.Y.; Kim, K.O.; Hiep, N.T.; Lee, D.; Jang, H.J.; Lee, J.W.; Kang, K.S. Protective effect of Artemisia argyi and its flavonoid constituents against contrast-induced cytotoxicity by iodixanol in LLC-PK1 cells. Int. J. Mol. Sci. 2018, 19, 1387. [CrossRef]

10. Belwal, T.; Ezzat, S.M.; Rastrelli, L.; Bhatt, I.D.; Daglia, M.; Baldi, A.; Devkota, H.P.; Orhan, I.E.; Patra, J.K.; Das, G.; et al. A critical analysis of extraction techniques used for botanicals: Trends, priorities, industrial uses and optimization strategies. Trends Analyt. Chem. 2018, 100, 82-102. [CrossRef]

11. Chemat, F.; Vian, M.A.; Cravotto, G. Green extraction of natural products: Concept and principles. Int. J. Mol. Sci. 2012, 13, 8615-8627. [CrossRef] [PubMed]

12. Abbott, A.P.; Capper, G.; Davies, D.L.; Rasheed, R.K.; Tambyrajah, V. Novel solvent properties of choline chloride/urea mixtures. Chem. Commun. 2003, 1, 70-71. [CrossRef]

13. Zhang, Q.; De Oliveira, K.; Royer, S.; Jérôme, F. Deep eutectic solvents: Syntheses, properties and applications. Chem. Soc. Rev. 2012, 41, 7108-7146. [CrossRef] [PubMed]

14. Huang, J.; Guo, X.; Xu, T.; Fan, L.; Zhou, X.; Wu, S. Ionic deep eutectic solvents for the extraction and separation of natural products. J. Chromatogr. A 2019. [CrossRef] [PubMed]

15. Zhao, H. DNA stability in ionic liquids and deep eutectic solvents. J. Chem. Technol. Biotechnol. 2015, 90, 19-25. [CrossRef]

16. Fernández, M.L.Á.; Boiteux, J.; Espino, M.; Gomez, F.J.V.; Silva, M.F. Natural deep eutectic solvents-mediated extractions: The way forward for sustainable analytical developments. Anal. Chim. Acta 2018, 1038, 1-10.

17. Cunha, S.C.; Fernandes, J.O. Extraction techniques with deep eutectic solvents. TrAC Trend Anal. Chem. 2018, 105, 225-239. [CrossRef]

18. Zainal-Abidin, M.H.; Hayyan, M.; Hayyan, A.; Jayakumar, N.S. New horizons in the extraction of bioactive compounds using deep eutectic solvents: A review. Anal. Chim. Acta 2017, 979, 1-23. [CrossRef]

19. Ruesgas-Ramón, M.; Figueroa-Espinoza, M.C.; Durand, E. Application of deep eutectic solvents (DES) for phenolic compounds extraction: Overview, challenges, and opportunities. J. Agric. Food. Chem. 2017, 65, 3591-3601. [CrossRef]

20. Jablonský, M.; Škulcová, A.; Malvis, A.; Šima, J. Environmentally-friendly extraction of flavonoids from Cyclocarya paliurus (Batal.) Iljinskaja leaves with deep eutectic solvents and evaluation of their antioxidant activities. Molecules 2018, 23, E2110. 
21. Duan, L.; Dou, L.L.; Guo, L.; Li, P.; Liu, E. Comprehensive evaluation of deep eutectic solvents in extraction of bioactive natural products. ACS Sustainable Chem. Eng. 2016, 4, 2405-2411. [CrossRef]

22. Jeong, K.M.; Lee, M.S.; Nam, M.W.; Zhao, J.; Jin, Y.; Lee, D.K.; Kwon, S.W.; Jeong, J.H.; Lee, J. Tailoring and recycling of deep eutectic solvents as sustainable and efficient extraction media. J. Chromatogr. A 2015, 1424, 10-17. [CrossRef] [PubMed]

23. Li, X.; Row, K.H. Development of deep eutectic solvents applied in extraction and separation. J. Sep. Sci. 2016, 39, 3505-3520. [CrossRef] [PubMed]

24. Dai, Y.; Row, K.H. Application of natural deep eutectic solvents in the extraction of quercetin from vegetables. Molecules 2019, 24, 2300. [CrossRef] [PubMed]

25. Maugeri, Z.; de Maria, P.D. Novel choline-chloride-based deep-eutectic-solvents with renewable hydrogen bond donors: Levulinic acid and sugar-based polyols. RSC Adv. 2012, 2, 421-425. [CrossRef]

26. Xu, M.; Ran, L.; Chen, N.; Fan, X.; Ren, D.; Yi, L. Polarity-dependent extraction of flavonoids from citrus peel waste using a tailor-made deep eutectic solvent. Food Chem. 2019, 297, 124907. [CrossRef] [PubMed]

27. Cao, J.; Wang, H.; Zhang, W.; Cao, F.; Ma, G.; Su, E. Tailor-made deep eutectic solvents for simultaneous extraction of five aromatic acids from Ginkgo biloba leaves. Molecules 2018, 23, 3214. [CrossRef] [PubMed]

28. Guo, N.; Ping, K.; Jiang, Y.W.; Wang, L.T.; Niu, L.J.; Liu, Z.M.; Fu, Y.J. Natural deep eutectic solvents couple with integrative extraction technique as an effective approach for mulberry anthocyanin extraction. Food Chem. 2019, 296, 78-85. [CrossRef] [PubMed]

29. Ma, Y.; Liu, M.; Tan, T.; Yan, A.; Guo, L.; Jiang, K.; Tan, C.; Wan, Y. Deep eutectic solvents used as extraction solvent for the determination of flavonoids from Camellia oleifera flowers by high-performance liquid chromatography. Phytochem. Anal. 2018, 29, 639-648. [CrossRef]

30. Wang, H.; Ma, X.; Cheng, Q.; Wang, L.; Zhang, L. Deep eutectic solvent-based ultrahigh pressure extraction of baicalin from Scutellaria baicalensis Georgi. Molecules 2018, 23, 3233. [CrossRef]

31. Duan, L.; Zhang, W.H.; Zhang, Z.H.; Liu, E.H.; Guo, L. Evaluation of natural deep eutectic solvents for the extraction of bioactive flavone C-glycosides from flos trollii. Microchem. J. 2018, 145, 180-186. [CrossRef]

Sample Availability: Samples of Artemisia argyi leavesare available from the authors.

(C) 2019 by the authors. Licensee MDPI, Basel, Switzerland. This article is an open access article distributed under the terms and conditions of the Creative Commons Attribution (CC BY) license (http://creativecommons.org/licenses/by/4.0/). 
Article

\title{
Biochemical, Micronutrient and Physicochemical Properties of the Dried Red Seaweeds Gracilaria edulis and Gracilaria corticata
}

\author{
Thomas Rosemary ${ }^{1}$, Abimannan Arulkumar ${ }^{1,2}$, Sadayan Paramasivam ${ }^{1, *}$, \\ Alicia Mondragon-Portocarrero ${ }^{3}$ and Jose Manuel Miranda ${ }^{3}$ \\ 1 Department of Oceanography and Coastal Area Studies, School of Marine Sciences, Alagappa University, \\ Thondi Campus, Thondi-623 409, India; rosemarythomas@gmail.com (T.R.); aruul3@gmail.com (A.A.) \\ 2 Department of Biotechnology, Achariya Arts and Science College, Villianur, Puducherry-60 110, India \\ 3 Departamento de Química Analítica, Nutrición y Bromatología, Facultade de Veterinaria, Universidade de \\ Santiago de Compostela, Pabellón 4, Planta Baja, 27002 Lugo, Spain; aliciamondragon@yahoo.com (A.M.-P.); \\ josemanuel.miranda@usc.es (J.M.M.) \\ * Correspondence: drparamsan@gmail.com; Tel.: +91-9047733300; Fax: +91-4565-225525
}

Academic Editor: Gavino Sanna

Received: 25 April 2019; Accepted: 11 June 2019; Published: 14 June 2019

\begin{abstract}
The present study sought to evaluate the nutritional composition and physicochemical properties of two dried commercially interesting edible red seaweeds, Gracilaria corticata and G. edulis. Proximate composition of the dried seaweeds revealed a higher content in carbohydrates $(8.30 \mathrm{~g} / 100 \mathrm{~g})$, total crude protein $(22.84 \mathrm{~g} / 100 \mathrm{~g})$ and lipid content $(7.07 \mathrm{~g} / 100 \mathrm{~g})$ in G. corticata than in G. edulis. Fatty acids profile showed that G. corticata samples contain higher concentrations of saturated fatty acids, such as palmitic and stearic acids, and polyunsaturated ones such as $\alpha$-linolenic and docosahexaenoic acids. Contrariwise, G. edulis contained higher amounts of monounsaturated oleic acid. Total amino acid content was $76.60 \mathrm{mg} / \mathrm{g}$ in G. corticata and $65.42 \mathrm{mg} / \mathrm{g}$ in G. edulis, being the essential amino acid content higher in G. edulis (35.55 mg/g) than in G. corticata $(22.76 \mathrm{mg} / \mathrm{g})$. Chlorophyll $a$ was found in significantly higher amounts in G. edulis $(17.14 \mu \mathrm{g} / \mathrm{g})$ than G. corticata, whereas carotenoid content was significantly higher in G. corticata $(12.98 \mu \mathrm{g} / \mathrm{g})$ than in G. edulis. With respect to physical properties, both water- and oil-holding capacities were similar in both seaweeds, whereas swelling capacity was higher in G. edulis. In view of the results, the present study suggests that G. corticata and G. edulis contains important nutrients for human health and are possible natural functional foods.
\end{abstract}

Keywords: water holding capacity; seaweeds; Gracilaria; carbohydrates; fatty acids; vitamins

\section{Introduction}

Seaweeds are very important natural resources from the oceans that are employed as human foods and animal feeds in their whole form, and as sources of polysaccharides (mainly alginates, carrageenans and agar), carotenoids, lipids, vitamins, minerals, dietary fiber, proline and amino acids for use in food and pharmaceutical industry [1]. Seaweeds have been included for a long time in the traditional diet of East Asian countries such as Japan, Korea and China; more recently, their presence in all forms in the diet of Western countries has been progressively increasing [2].

Seaweeds are considered healthy foods because, despite their low caloric content, they are rich in important nutrients such as protein, essential amino acids, vitamins, minerals and some bioactive compounds [1]. Seaweeds are also an excellent source of both soluble and insoluble dietary fiber. Among red algae, the genus Gracilaria contains a broad diversity of valuable contents for human 
nutrition and are one of the world's most cultivated and valuable marine seaweed [3]. Its lipid content is low (1-5\% dry weight, DW) [1], but it contains docosahexaenoic acid (DHA) which is recognized as the most important $n-3$ polyunsaturated fatty acid (PUFA) to reduce the risk of cardiovascular diseases $[4,5]$. In particular, $n-3$ PUFAs act as excellent antioxidants, strengthening the cell membrane, repairing damaged cells and tissues, improving heart function and fighting against cancer [6]. n-3 PUFAs were also found to prevent the growth of atherosclerotic plaque that affects blood clotting and blood pressure and improve the immune function, while $n-6$ PUFAs decrease low-density lipoprotein cholesterol and may also decrease high-density lipoprotein, cholesterol which reduces heart disease risk [7].

With respect to their protein content, the most abundant amino acids in Gracilaria species are aspartic acid, alanine, glutamic acid and glutamine. These amino acids provide the typical flavor of algae and accumulate in response to stress conditions [8]. Gracilaria is also a good source of both soluble and insoluble dietary fiber, so it can be employed as a potential alternative to cereal-based fiber in Western countries [1]. Soluble dietary fiber helps to increase viscosity and reduce glycemic response and plasma cholesterol in humans [1]. Insoluble dietary fiber improves the bulking effect caused by water absorption in feces and thus contributes to weight management, improvement of cardiovascular and gastrointestinal functions and cancer prevention [1]. Polysaccharides isolated from red seaweeds show potent antibacterial, antiviral, antioxidant, anticoagulant and anti-inflammatory activity [9].

Seaweeds such as Gracilaria can concentrate minerals from seawater and reach a mineral content 10-20 times higher than that of terrestrial plants [10]. Consequently, they are a valuable source of minerals, with important human nutrition functions [11,12]. Chlorophyll, an important pigment constituent present in algae, has positive effects on inflammation, oxidation and wound healing [13]. Chlorophyll acts directly as a reducer of free radicals and has the potential to protect lymphocytes against oxidative DNA damage by free radicals [14]. Moreover, a large number of potentially bioactive compounds such as phenols, polyphenols, terpenes, steroids, halogenated ketones and alkanes, fucoxanthin, polyphloroglucinol and bromophenols have been isolated [15-17].

However, the nutrient profile of seaweeds such as Gracilaria is influenced by different factors such as seaweed species, habitat, maturity stage, season, water temperature and the sampling conditions and method employed in the determinations [1,2]. Gracilaria edulis and G. corticata is abundantly available in almost all seasons in Palk Bay, on the southeast coast of India, rather than other Gracilaria sp. Both G. edulis and G. corticata are commercially important and commonly edible seaweeds in India. These two algae exhibited in a previous work high biological activities (proximate composition, antioxidant, antibacterial, and biopreservative effects in seafoods during preservation and extended shelf life than other Gracilaria species in a previous work [18]. Thus, the present study sought to evaluate and compare the chemical composition (proximate composition, lipid profile, amino acids, vitamins and pigments such as chlorophyll and carotenoids) and physicochemical properties of both, Gracilaria corticata and Gracilaria edulis from the Thondi coast of Palk Bay, southeast India.

\section{Results}

Proximate, polysaccharide content and fatty acids profile of both G. corticata and G. edulis in a DW basis are shown in Table 1. 
Table 1. Proximate composition (g/100 g dry weight seaweed) G. corticata and G. edulis.

\begin{tabular}{ccc}
\hline Parameter & G. corticata & G. edulis \\
\hline Moisture & $8.40 \pm 0.65^{\mathrm{b}}$ & $10.40 \pm 0.69^{\mathrm{a}}$ \\
Protein & $22.84 \pm 0.87^{\mathrm{b}}$ & $25.29 \pm 0.67^{\mathrm{a}}$ \\
Fat & $7.07 \pm 0.33^{\mathrm{a}}$ & $4.76 \pm 0.73^{\mathrm{b}}$ \\
Carbohydrates & $8.30 \pm 1.89^{\mathrm{a}}$ & $4.71 \pm 0.60^{\mathrm{b}}$ \\
Ash & $8.10 \pm 0.49$ & $7.36 \pm 0.39$ \\
Polysaccharides & $49.64 \pm 3.89^{\mathrm{a}}$ & $38.02 \pm 4.32^{\mathrm{b}}$
\end{tabular}

Values are mean \pm standard deviation, $n=3$. ${ }^{\mathrm{a}-\mathrm{b}}$ values with different superscripts within the same line were significantly different.

The crude polysaccharide content found for G. corticata and G. edulis was $49.64 \mathrm{~g} / 100 \mathrm{~g}$ and $38.02 \mathrm{~g} / 100 \mathrm{~g}$, respectively. The moisture content (in dried seaweeds) of G. corticata and G. edulis was $8.40 \mathrm{~g} / 100 \mathrm{~g}$ and $10.40 \mathrm{~g} / 100 \mathrm{~g}$, respectively. With respect to proximate composition, important differences were obtained for the two seaweeds investigated. Carbohydrates and fat content were significantly higher in G. corticata, whereas protein content was significantly higher in the case of G. edulis.

With respect to fatty acids profile, total fatty acid content, expressed as $\mathrm{g}$ fatty acids methyl esters (FAME)/100 g total fat, of G. corticata and G. edulis was $5.49 \pm 0.30 \mathrm{~g} / 100 \mathrm{~g}$ and $3.92 \pm 0.13 \mathrm{~g} / 100 \mathrm{~g}$, respectively (Table 2). The main saturated fatty acids (SFAs) found in both G. corticata and G. edulis were palmitic acid (C16:0), margaric acid (C17:0) and stearic acid (C18:0). With respect to PUFAs, linoleic acid (C18:2n-6), $\alpha$-linolenic acid (C18:3n-3), stearidonic acid (C18:4n-3) and DHA (C22:6n-3) were found in both seaweeds. In the case of monounsaturated fatty acids (MUFAs), only oleic acid (C18:1) was detected in relevant amounts in both G. corticata and G. edulis. Margaric, linoleic and stearidonic acids were found in similar amounts in G. corticata and G. edulis. Palmitic, stearic, $\alpha$-linolenic acid were found in higher amounts in G. corticata than in G. edulis. Overall, in G. corticata, SFAs accounted $49.4 \%$ of total fatty acids, MUFAs accounted a $3.3 \%$ and PUFAs accounted a $47.3 \%$, whereas in the case of G. edulis, SFAs accounted $43.9 \%$ of total fatty acids, MUFAs accounted a $27 \%$ of total fatty acids, and PUFAs accounted a $29 \%$.

Table 2. Fatty acids profile ( $\mathrm{g}$ fatty acid methyl esters/100 $\mathrm{g}$ total fat) of G. corticata and G. edulis.

\begin{tabular}{|c|c|c|}
\hline Parameter & G. corticata & G. edulis \\
\hline Palmitic acid & $1.22 \pm 0.04^{\mathrm{a}}$ & $0.63 \pm 0.09^{b}$ \\
\hline Margaric acid & $0.16 \pm 0.25$ & $0.15 \pm 0.10$ \\
\hline Stearic acid & $1.31 \pm 0.03^{\mathrm{a}}$ & $0.93 \pm 0.05^{b}$ \\
\hline Oleic acid & $0.18 \pm 0.12^{b}$ & $1.05 \pm 0.05^{\mathrm{a}}$ \\
\hline Linoleic acid & $0.63 \pm 0.04$ & $0.65 \pm 0.18$ \\
\hline$\alpha$-Linolenic acid & $1.26 \pm 0.04^{\mathrm{a}}$ & $0.14 \pm 0.04^{b}$ \\
\hline Stearidonic acid & $0.21 \pm 0.01$ & $0.22 \pm 0.05$ \\
\hline Docosohexaenoic acid & $0.48 \pm 0.14^{a}$ & $0.12 \pm 0.18^{b}$ \\
\hline$\sum$ FA & $5.49 \pm 0.30^{\mathrm{a}}$ & $3.92 \pm 0.13^{b}$ \\
\hline
\end{tabular}

$\sum F A=$ Total fatty acids. Values are mean \pm standard deviation, $n=3 .{ }^{\mathrm{a}-\mathrm{b}}$ values with different superscripts within the same line were significantly different.

The protein of G. corticata and G. edulis is shown in Table 3. The total amino acid content was higher in G. corticata $(76.60 \pm 5.14 \mathrm{mg} / \mathrm{g})$, than in G. edulis $(65.42 \pm 3.58 \mathrm{mg} / \mathrm{g})$. These values are comparable to their corresponding crude protein content of $22.84 \pm 0.87$ and $25.29 \pm 0.67 \mathrm{~g} / 100 \mathrm{~g}$, respectively, indicating that the amount of non-protein nitrogenous materials in these red seaweeds is low.

Nine essential amino acids (EAAs), and 11 non-essential amino acids (NEAAs), were found in both G. corticata and G. edulis. Total EAAs where significantly higher in G. edulis $(35.55 \pm 1.75 \mathrm{mg} / \mathrm{g})$ than in G. corticata $(22.76 \pm 1.81 \mathrm{mg} / \mathrm{g})$, whereas total NEAAs where higher in G. corticata $(36.14 \pm 3.33 \mathrm{mg} / \mathrm{g})$ than in G. edulis $(29.86 \pm 1.83 \mathrm{mg} / \mathrm{g})$. The EAAs/total amino acid ratio suggests that more than $50 \%$ of the amino acids found in G. edulis are EAAs. The results also indicate a good ratio of 
essential amino acids to non-essential amino acids in G. corticata $(0.62 \pm 0.54 \mathrm{mg} / \mathrm{g})$ and G. edulis $(1.19 \pm 0.95 \mathrm{mg} / \mathrm{g})$. It was noted that a much higher concentration of the essential amino acid threonine $(20.57 \pm 0.62 \mathrm{mg} / \mathrm{g})$ was found in G. edulis than in G. corticata. Contrariwise, alanine content was much higher in G. corticata $(21.11 \pm 0.54 \mathrm{mg} / \mathrm{g})$ than in G. edulis $(1.46 \pm 0.18 \mathrm{mg} / \mathrm{g})$. Aspartic acid content was similar in both seaweeds.

The mineral content of G. corticata and G. edulis is shown in Table 4. G. corticata showed a higher content of $\mathrm{Mg}(463.23 \pm 8.87 \mathrm{mg} / \mathrm{kg})$ and Fe $(1072.48 \pm 20.97 \mathrm{mg} / \mathrm{kg})$ than G. edulis. Moreover, G. edulis was found to possess more of trace elements like $\mathrm{Zn}(42.73 \pm 2.12 \mathrm{mg} / \mathrm{kg})$ and Cu $(14.61 \pm 0.46 \mathrm{mg} / \mathrm{kg})$ than $G$. corticata. In view of the present results, both $G$. corticata and G. edulis contain an adequate amount of minerals, which suggests that these seaweeds could act as important sources of mineral supplements which are essential for human nutrition.

Table 3. Protein composition of G. corticata and G. edulis.

\begin{tabular}{|c|c|c|}
\hline Amino Acid & G. corticata & G. edulis \\
\hline Aspartic acid & $14.37 \pm 0.78$ & $12.67 \pm 0.64$ \\
\hline Glutamic acid & $2.54 \pm 0.06$ & $2.77 \pm 0.15$ \\
\hline Asparagine & $1.45 \pm 0.05^{b}$ & $1.89 \pm 0.15^{\mathrm{a}}$ \\
\hline Serine & $2.23 \pm 0.18^{b}$ & $2.73 \pm 0.13^{\mathrm{a}}$ \\
\hline Glutamine & $2.01 \pm 0.7^{\mathrm{b}}$ & $2.42 \pm 0.29^{a}$ \\
\hline Glycine & $4.71 \pm 0.18^{a}$ & $3.42 \pm 0.27^{b}$ \\
\hline Theronine * & $1.32 \pm 0.09^{b}$ & $20.57 \pm 0.62^{a}$ \\
\hline Arginine * & $3.41 \pm 0.30$ & $3.33 \pm 0.17$ \\
\hline Alanine & $21.11 \pm 0.54^{\mathrm{a}}$ & $1.46 \pm 0.18^{b}$ \\
\hline Cysteine & $1.49 \pm 0.30$ & $1.27 \pm 0.06$ \\
\hline Tyrosine * & $1.25 \pm 0.15^{b}$ & $2.50 \pm 0.24^{b}$ \\
\hline Histidine & $2.46 \pm 0.27^{a}$ & $0.18 \pm 0.02^{a}$ \\
\hline Valine * & $0.16 \pm 0.01$ & $0.15 \pm 0.02$ \\
\hline Methionine * & $8.73 \pm 0.31^{a}$ & $4.98 \pm 0.48^{b}$ \\
\hline Isoleucine * & $2.53 \pm 0.16^{\mathrm{a}}$ & $1.22 \pm 0.07^{b}$ \\
\hline Phenylalanine * & $1.42 \pm 0.17^{\mathrm{b}}$ & $2.20 \pm 0.10^{\mathrm{a}}$ \\
\hline Leucine * & $1.58 \pm 0.35^{\mathrm{a}}$ & $0.38 \pm 0.02^{b}$ \\
\hline Lysine * & $2.37 \pm 0.27^{\mathrm{a}}$ & $0.22 \pm 0.03^{b}$ \\
\hline Proline & $0.47 \pm 0.20$ & $0.46 \pm 0.18$ \\
\hline Tryptophan & $1.00 \pm 0.07^{\mathrm{a}}$ & $0.59 \pm 0.16^{b}$ \\
\hline Total amino acids & $76.60 \pm 5.14^{\mathrm{a}}$ & $65.42 \pm 3.58^{b}$ \\
\hline Total EAAs & $22.76 \pm 1.81^{b}$ & $35.55 \pm 1.75^{\mathrm{a}}$ \\
\hline Total NEAAs & $36.14 \pm 3.33^{a}$ & $29.86 \pm 1.83^{b}$ \\
\hline EAAs/Total AAs & $0.29 \pm 0.35^{b}$ & $0.54 \pm 0.48^{\mathrm{a}}$ \\
\hline EAAs/NEAAs & $0.62 \pm 0.54^{b}$ & $1.19 \pm 0.95^{\mathrm{a}}$ \\
\hline
\end{tabular}

Values are mean \pm standard deviation, $n=3$ expressed as $\mathrm{mg} / \mathrm{g}$ seaweed in a dry weight basis. ${ }^{*}$ EAAs: Essential amino acids; NEAAs: Non-essential amino acids. ${ }^{a-b}$ values with different superscripts within the same line are significantly different.

Table 4. Mineral content ( $\mathrm{mg} / \mathrm{kg})$ in G. corticata and G. edulis.

\begin{tabular}{ccc}
\hline Minerals & G. corticata & G. edulis \\
\hline $\mathbf{Z n}$ & $31.52 \pm 0.69^{\mathrm{b}}$ & $42.73 \pm 2.12^{\mathrm{a}}$ \\
$\mathbf{C u}$ & $11.42 \pm 0.72^{\mathrm{b}}$ & $14.61 \pm 0.46^{\mathrm{a}}$ \\
$\mathbf{M g}$ & $463.23 \pm 8.87^{\mathrm{a}}$ & $89.56 \pm 0.77^{\mathrm{b}}$ \\
$\mathbf{F e}$ & $1072.48 \pm 20.97^{\mathrm{a}}$ & $557.36 \pm 0.57^{\mathrm{b}}$ \\
\hline
\end{tabular}

Values are mean \pm standard deviation, $n=3$ on dry weight basis. Macro minerals: Zinc (Zn), copper (Cu), magnesium $(\mathrm{Mg})$ and iron $(\mathrm{Fe}) .{ }^{\mathrm{a}-\mathrm{b}}$ values with different superscripts within the same line are significantly different.

For both G. corticata and G. edulis, the presence of water-soluble vitamins (vitamin $B_{1}$, vitamin $B_{2}$, vitamin $B_{3}$, vitamin $B_{6}$, vitamin $B_{9}$ and vitamin $C$ ) and fat-soluble vitamins (vitamin $A$ and vitamin $E$ ) 
was found, as shown in Table 5. G. corticata had a higher vitamin A $(2.67 \pm 0.31 \mathrm{mg} / \mathrm{g}$ vs. $2.14 \pm 0.17 \mathrm{mg} / \mathrm{g})$ and vitamin $B_{9}$ contents $(1.00 \pm 0.07 \mathrm{mg} / \mathrm{g}$ vs. $0.45 \pm 0.06 \mathrm{mg} / \mathrm{g})$ than G. edulis, whereas G. edulis showed a significantly higher content of vitamin $B_{2}(1.54 \pm 0.39 \mathrm{mg} / \mathrm{g}$ vs. $0.05 \pm 0.01 \mathrm{mg} / \mathrm{g})$ and vitamin $\mathrm{B}_{6}$ $(4.77 \pm 0.23 \mathrm{mg} / \mathrm{g}$ vs. $3.79 \pm 0.30 \mathrm{mg} / \mathrm{g})$ than G. corticata .

Table 5. Vitamin composition (mg/g), chlorophyll and carotenoid content ( $\mu \mathrm{g} / \mathrm{g})$ of $\mathrm{G}$. corticata and G. edulis.

\begin{tabular}{ccc}
\hline Name of Vitamins/Pigments & G. corticata & G.edulis \\
\hline Vitamin $\mathbf{B}_{1}$ & $0.38 \pm 0.02$ & $0.36 \pm 0.02$ \\
Vitamin $\mathbf{B}_{2}$ & $0.05 \pm 0.01^{\mathrm{b}}$ & $1.54 \pm 0.07^{\mathrm{a}}$ \\
${\text { Vitamin } \mathbf{B}_{3}}_{\text {Vitamin } \mathbf{B}_{\mathbf{6}}}$ & $1.54 \pm 0.39$ & $1.10 \pm 0.29$ \\
Vitamin $\mathbf{B}_{9}$ & $3.79 \pm 0.30^{\mathrm{b}}$ & $4.77 \pm 0.23^{\mathrm{a}}$ \\
Vitamin C & $1.00 \pm 0.07^{\mathrm{a}}$ & $0.45 \pm 0.06^{\mathrm{b}}$ \\
Vitamin A & $14.66 \pm 0.23$ & $13.41 \pm 0.57$ \\
Vitamin E & $2.67 \pm 0.30^{\mathrm{a}}$ & $2.07 \pm 0.06^{\mathrm{b}}$ \\
chlorophyll $\boldsymbol{a}$ & $1.40 \pm 0.10$ & $1.49 \pm 0.10$ \\
chlorophyll $\boldsymbol{b}$ & $8.96 \pm 0.39^{\mathrm{b}}$ & $17.14 \pm 0.55^{\mathrm{a}}$ \\
carotenoid & $7.74 \pm 0.33$ & $8.44 \pm 0.63$ \\
\end{tabular}

Values are mean \pm standard deviation, $n=3$ on dry weight basis. ${ }^{\mathrm{a}-\mathrm{b}}$ values with different superscripts within the same line are significantly different.

The methanolic extracts of G. corticata and G. edulis at $1 \mathrm{mg} / \mathrm{mL}$ concentration indicate the presence of three major compounds, chlorophyll $a$, chlorophyll $b$ and carotenoids, in G. corticata (Retention factor (Rf) value $=0.97,0.92$ and 0.95 , respectively) and G. edulis ( $\mathrm{Rf}=0.96,0.960 .84$, respectively). G. corticata and G. edulis contained $8.96 \pm 0.39 \mu \mathrm{g} / \mathrm{g}$ and $17.14 \pm 0.55 \mu \mathrm{g} / \mathrm{g}$ of chlorophyll $a$ and $7.74 \pm 0.33 \mu \mathrm{g} / \mathrm{g}$ and $8.44 \pm 0.63 \mu \mathrm{g} / \mathrm{g}$ of chlorophyll $b$, respectively. With respect to the carotenoid content, it was higher for G. corticata $(12.82 \pm 0.50 \mu \mathrm{g} / \mathrm{g})$ than for G. edulis $(2.99 \pm 0.56 \mu \mathrm{g} / \mathrm{g})$.

Table 6 shows the swelling capacity (SWC), water-holding capacity (WHC) and oil-holding capacity (OHC) of G. corticata and G. edulis. In general, as temperature varied, the SWC and WHC of G. corticata and G. edulis powder varied, due to an increase in the solubility of the dietary fiber and the presence of protein in G. corticata and G. edulis. However, it also reaches significant differences for the case of SWC, whereas no statistical differences were obtained for WHC or OHC. The SWC of G. edulis were higher than G. corticata at both $25^{\circ} \mathrm{C}$ and $37^{\circ} \mathrm{C}(8.66 \pm 0.53 \mathrm{~mL} / \mathrm{g} \mathrm{vs} .7 .90 \pm 0.32 \mathrm{~mL} / \mathrm{g}$, and $7.70 \pm 0.60 \mathrm{~mL} / \mathrm{g}$ vs. $5.70 \pm 0.65 \mathrm{~mL} / \mathrm{g}$, respectively).

Table 6. Swelling capacity (SWC), water holding capacity (WHC) and oil holding capacity (OHC) of G. corticata and G. edulis.

\begin{tabular}{ccccccc}
\hline \multirow{2}{*}{ Seaweeds } & \multicolumn{2}{c}{ SWC $(\mathbf{m L} / \mathbf{g})$} & \multicolumn{2}{c}{ WHC $(\mathrm{g} / \mathrm{g})$} & \multicolumn{2}{c}{ OHC $(\mathrm{g} / \mathrm{g})$} \\
\cline { 2 - 6 } & $\mathbf{2 5}{ }^{\circ} \mathbf{C}$ & $\mathbf{3 7}{ }^{\circ} \mathbf{C}$ & $\mathbf{2 5}{ }^{\circ} \mathbf{C}$ & $37^{\circ} \mathbf{C}$ & $\mathbf{2 5}{ }^{\circ} \mathbf{C}$ & $37^{\circ} \mathbf{C}$ \\
\hline G. corticata & $7.90 \pm 0.32^{\mathrm{bA}}$ & $5.70 \pm 0.65^{\mathrm{bB}}$ & $4.03 \pm 0.39$ & $3.96 \pm 0.58$ & $2.06 \pm 0.24$ & $1.84 \pm 0.40$ \\
G. edulis & $8.66 \pm 0.53^{\mathrm{aA}}$ & $7.70 \pm 0.6^{\mathrm{aB}}$ & $4.09 \pm 0.32$ & $3.64 \pm 0.40$ & $1.87 \pm 0.28$ & $1.91 \pm 0.18$ \\
\hline
\end{tabular}

Values are mean \pm standard deviation, $n=3$ on dry weight basis. ${ }^{\mathrm{a}-\mathrm{b}}$ values with different superscripts within the same column are significantly different between seaweeds. ${ }^{\mathrm{A}-\mathrm{B}}$ values with different superscripts within the same line shows significant differences between temperatures.

With respect to the WHC of G. corticata and G. edulis, values of $4.03 \pm 0.39$ and $4.09 \pm 0.28 \mathrm{~g} / \mathrm{g}$, respectively, were obtained at $25^{\circ} \mathrm{C}$, reduced to $3.96 \pm 0.58 \mathrm{~g} / \mathrm{g}$ in G. corticata and $3.64 \pm 0.18 \mathrm{~g} / \mathrm{g}$ in G. edulis at $37^{\circ} \mathrm{C}$. In this study, both G. corticata and G. edulis exhibited similar OHC values (about $2 \mathrm{~g} / \mathrm{g}$ ) at both $25^{\circ} \mathrm{C}$ and $37^{\circ} \mathrm{C}$. 


\section{Discussion}

With respect to proximate content, the moisture of G. corticata and G. edulis was lower than most results obtained for Gracilaria sp. in general, such as the $12.15 \mathrm{~g} / 100 \mathrm{~g}$ obtained for G. acerosa [6] the $19.2 \mathrm{~g} / 100 \mathrm{~g}$ for G. edulis [8], and the $12.86 \mathrm{~g} / 100 \mathrm{~g}$ for G. edulis [1], but higher than the $5.32 \mathrm{~g} / 100 \mathrm{~g}$ obtained for G. changii [19]. In this work, G. edulis showed a higher ash content in a DW basis than G. corticata. Similarly, it was reported an ash content of $8.70 \mathrm{~g} / 100 \mathrm{~g}$ in G. edulis [8], whereas other authors reported a higher ash content $(40.30 \mathrm{~g} / 100 \mathrm{~g})$ in G. changii [19] than those found in the present work. A high ash content shows the presence of appreciable amounts of diverse minerals found in both seaweeds. A similar observation was for G. changii [19] in which were found an ash content of $6.40 \mathrm{~g} / 100 \mathrm{~g}$. Interestingly, total dietary fiber is known to have physiological properties for the prevention and treatment of cancer, obesity and diabetes [20,21]. Therefore, G. corticata and G. edulis may have the potential to be used as a source of dietary fiber in the nutraceutical industries.

Other authors found much lower crude protein contents in Gracilaria spp. than those found in the present work. Thus, it was reported a crude protein content of $6.68 \mathrm{~g} / 100 \mathrm{~g}$ for G. edulis [8], $0.61 \mathrm{~g} / 100 \mathrm{~g}$ for G. acerosa [6], 12.57 g/100 g in G. changii [19] or $19.70 \mathrm{~g} / 100 \mathrm{~g}$ for G. cervicornis [22]. Moreover, the high protein content of G. corticata and G. edulis indicates that these seaweeds may be considered as potential marine plant sources of protein [22]. Proteins from seaweeds can have antibacterial, antioxidant, immunostimulating, antithrombotic and anti-inflammatory activities. Consequently, they can be used for prevention and treatment of hypertension, diabetes and hepatitis among other positive effects in the organism [20].

The total carbohydrate content of both G. corticata and G. edulis was markedly lower than that reported [8] for G. edulis (10.2 g/100 g) or the $29.44 \mathrm{~g} / 100 \mathrm{~g}$ reported for G. changii [19]. However, other authors found lower carbohydrate content in Gracilaria species, such as G. acerosa, for which was reported a carbohydrate content of $1.05 \mathrm{~g} / 100 \mathrm{~g}$ [6]. The wide variation in the carbohydrate content observed in red and brown seaweed species might be due to the influence of different factors like salinity, temperature and sunlight intensity [2]. Moreover, carbohydrate content is also influenced by biomass, which reveals the link between growth and carbohydrate content [23].

In general, seaweeds have a low fat content [23]; that makes seaweeds low-calorie foods and in the present work both seaweeds contained fat amounts of $7.07 \mathrm{~g} / 100 \mathrm{~g}$ DW seaweed (G. corticata) and $4.71 \mathrm{~g} / 100 \mathrm{~g}$ DW seaweed (G. edulis). These results are lower than those obtained by other authors [8], whose reported a crude lipid content for G. edulis of $8.30 \mathrm{~g} / 100 \mathrm{~g}$ but significantly that the $0.3 \%$ reported for G. changi [19], or the 1.7-3.6\% reported for G. fisheri and G. tenuistipitata [5]. Thus, Gracilaria content in fat can widely vary depending on the species and source.

Polysaccharides are polymers composed of at least 10 monosaccharides linked by glycosidic bonds [9]. Recently, seaweed polysaccharides have been given large attention by the scientific community due to their outstanding bioactivities and correspondingly low toxicity [9]. They have been shown to have other beneficial health effects, including their prebiotic effect and antioxidant or anti-inflammatory activity [20]. The polysaccharide content obtained in the present work was higher than the polysaccharide extracted from Gracilaria species in previous works, such as $29.08 \mathrm{~g} / 100 \mathrm{~g}$ [24], $27.20 \mathrm{~g} / 100 \mathrm{~g}$ [25], $21.40 \mathrm{~g} / 100 \mathrm{~g}$ [26], and $32.80 \mathrm{~g} / 100 \mathrm{~g}$ [27]. Contrariwise, it was also reported a higher polysaccharide content in G. debilis [28], in the range 52-67 g/100 g. A previous work [29] reported that the polysaccharide yield from Gracilaria species varies due to seasonal variations, physiochemical factors, environmental conditions and extraction methods. Additionally, the variations in the polysaccharide content of Gracilaria can vary depending on atmospheric temperature at the time of extraction [26]. Hence the present study significantly indicates that the crude polysaccharides present in G. corticata and G. edulis may exert varied biological activity [25].

With respect to the fatty acids composition, those of seaweeds often differ from those of terrestrial plants whereby seaweeds have a higher proportion of PUFAs than terrestrial vegetables. Red seaweeds are particularly rich in SFAs and PUFAs which have nutritional applications that lead to their extensive use in food, feed, cosmetic, biotechnological and pharmaceutical applications [30,31]. Variation in 
fatty acid content may also be due to the season of collection as well as other abiotic factors such as nutrition, salinity, light and temperature $[8,20]$. In the present work, total fatty acids were significantly lower than those obtained by other authors [8], who found $11.41 \mathrm{~g} / 100 \mathrm{~g}$ in G. edulis. According to this work [8], the most abundant fatty acids in both seaweeds were palmitic, stearic and $\alpha$-linoleic acid acids. The same fatty acids were also found abundant in G. changii [20]. However, our results were significantly lower than those obtained in G. changii for DHA content, in which DHA were found as the most abundant fatty acids, with a $48.36 \%$ of total fatty acids. The results of the present study revealed that both seaweeds are rich in SFAs and especially in PUFAs, which provide important health benefits. With respect to most commonly found n-3 PUFA, eicosapentaenoic acid (EPA) and DHA, it is common that their contents vary dramatically from Gracilaria spp. and even into the same species [32]. No EPA presence were found for the seaweeds tested in the present work. The presence of this $n-3$ fatty acid in Gracilaria spp. is inconstant, because it was found in G. gracilis [20], but it was not detected in G. changii [19] or G. edulis [8]. Fatty acids overall profile obtained in this work were significantly different than $57.5 \%$ SFAs, $18.3 \%$ MUFAs and $18.4 \%$ PUFAs reported for Gracilaria sp. [3] or the $7.5 \%$ SFAs, 38.3\% MUFAs and 51.2\% PUFAs 18.4\% reported for Gracilaria changii [19].

The protein composition found in this work for G. corticata and G. edulis was lower than those found in a previous work [20], which reported an amino acid content of $91.90 \mathrm{mg} / \mathrm{g}$ in G. changii. The EAAs/total amino acid ratio was higher than those previously reported $[6,19,26]$. Aspartic acid content, that is important for the organoleptic point of view because it was reported that it is responsible for the special flavor and taste of seaweeds [33], was in similar contents in both seaweeds.

Seaweeds are one of the richest sources of minerals and trace elements, because the cell-wall polysaccharides and proteins of seaweed contain sulfate, anionic carboxyl and phosphate groups which act as binding sites for metal retention [34]. With respect to the mineral content, G. corticata showed a higher content of $\mathrm{Mg}(463.23 \mathrm{mg} / \mathrm{kg})$ and Fe $(1072.48 \mathrm{mg} / \mathrm{kg})$ than G. edulis. Moreover, G. edulis was found to possess more of trace elements like $\mathrm{Zn}(42.73 \mathrm{mg} / \mathrm{kg})$ and $\mathrm{Cu}(14.61 \mathrm{mg} / \mathrm{kg})$ than $\mathrm{G}$. corticata. Both seaweeds had a higher or similar content of minerals like $\mathrm{Zn}, \mathrm{Cu}, \mathrm{Mg}$ and $\mathrm{Fe}$ when compared with the content of G. acerosa [6], G. edulis [8], G. fisheri and G. tenuistipidatata [5] or G. changii [19], with the exception of Mg in G. edulis which were lower than those found for other previous works as $G$. changii [19]. The ability of seaweeds to accumulate metals will depend on a variety of factors such as location, exposure, salinity, temperature, $\mathrm{pH}$, light, nitrogen content, season, plant age, metabolic processes or the affinity of the plant for each element among others [35]. In view of the present results, both G. corticata and G. edulis contain an adequate amount of minerals, which suggests that these seaweeds could act as important sources of mineral supplements which are essential for human nutrition.

For both G. corticata and G. edulis, the presence of water-soluble vitamins (vitamin $\mathrm{B}_{1}$, vitamin $\mathrm{B}_{2}$, vitamin $B_{3}$, vitamin $B_{6}$, vitamin $B_{9}$ and vitamin $C$ ) and fat-soluble vitamins (vitamin $A$ and vitamin $E$ ) was found. G. corticata had a higher vitamin A $(2.67 \mathrm{mg} / \mathrm{g} \mathrm{vs.} 2.14 \mathrm{mg} / \mathrm{g})$ and vitamin B $\mathrm{B}_{9}$ contents $(1.00 \mathrm{mg} / \mathrm{g}$ vs. $0.45 \mathrm{mg} / \mathrm{g})$ than G. edulis, whereas G. edulis showed a significantly higher content of vitamin $B_{2}(1.54 \mathrm{mg} / \mathrm{g}$ vs. $0.05 \mathrm{mg} / \mathrm{g})$ and vitamin $B_{6}(4.77 \mathrm{mg} / \mathrm{g}$ vs. $3.79 \mathrm{mg} / \mathrm{g})$ than G. corticata. With respect to previously published works, the vitamin content reported for Gracilaria species is widely different between the different authors $[1,6,8]$. Perhaps the more remarkable difference in vitamin content is that in the present work both G. corticata and G. edulis showed a significantly higher vitamin A content (2.67 and 2.07, respectively) than those previously reported for G. acerosa [6] or for G. edulis [1].

Another important difference was found for the case of vitamin $C$ that showed a higher content than those previously reported $[6,8]$ for G. edulis or G. acerosa, respectively. The variation in vitamin content may be due to some environmental factors such as salinity, atmospheric temperature, seasonality and methods of preservation and processing [6].

G. corticata and G. edulis contained $8.96 \mu \mathrm{g} / \mathrm{g}$ and $17.14 \mu \mathrm{g} / \mathrm{g}$ of chlorophyll $a$ and $7.74 \mu \mathrm{g} / \mathrm{g}$ and $8.44 \mu \mathrm{g} / \mathrm{g}$ of chlorophyll $b$, respectively. In a previous work describing the composition of several 
seaweeds [36] it was reported that chlorophyll $a$ and $b$ in red seaweeds ranged from 68 to $162 \mu \mathrm{g} / \mathrm{g}$ and from 25 to $46 \mu \mathrm{g} / \mathrm{g}$, respectively. Specifically, for Gracilaria spp., it was reported high chlorophyll $a$ of $577.89 \mu \mathrm{g} / \mathrm{g}$ and low chlorophyll $b$ of $1.11 \mu \mathrm{g} / \mathrm{g}$ in G. changii [19].

With respect to carotenoid content, a higher total carotenoid content was reported for G. changii than in the present study $(74.22 \mu \mathrm{g} / \mathrm{g})$ [19]. Carotenoids such as $\beta$-carotene, lutein, zeaxanthin and antheraxanthin have been identified in red seaweed, including Gracilaria species. Further, seaweed carotenoids, especially $\beta$-carotene, are preferred by the market of natural products, because they are a mixture of cis and trans isomers, which may possess anticancer activity [37].

The SWC, WHC and OHC properties of seaweeds are generally related to their content and type of polysaccharides as well as protein which links to the cell wall of polysaccharide [5]. Previous works described that variations in temperature can widely vary physicochemical properties of seaweeds, due to increase in the solubility of the dietary fiber and the presence of protein $[5,8]$. However, in our work, only were found significant variations in the case of SWC. Previous works [8] reported a SWC of $20 \mathrm{~mL} / \mathrm{g}$ in G. edulis, higher than those found in the present study. Similarly, a SWC at $37^{\circ} \mathrm{C}$ of $7.68 \mathrm{~mL} / \mathrm{g}$ in G. changii was reported [19], whereas for G. acerosa [6] an SWC at $37^{\circ} \mathrm{C}$ of $5 \mathrm{~mL} / \mathrm{g}$ was reported.

With respect to the WHC of G. corticata and G. edulis, a similar observation was also made in a previous work [8], that reported a WHC for G. edulis of $3.08 \mathrm{~g} / \mathrm{g}$. Other authors found better WHC than in the present work for other Gracilaria spp., such as G. fisheri, for which a WHC of $5.53 \mathrm{~g} / \mathrm{g}$ was reported [5], and G. changii [26], for which WHC values of $6.15 \mathrm{~g} / \mathrm{g}$ at $24^{\circ} \mathrm{C}$ and $9.93 \mathrm{~g} / \mathrm{g}$ at $37^{\circ} \mathrm{C}$ were reported. Both SWC and WHC of seaweeds might be attributed due to different protein content and increases in the number and nature of the water binding sites on the protein molecules [38].

$\mathrm{OHC}$ is another functional property of food ingredients used in formulated foods for consumption. Ingredients with high $\mathrm{OHC}$ values allow the stabilization of food emulsions and high-fat food products [19]. For other Gracilaria spp., it was reported [8] that G. edulis showed an OHC of $1.64 \mathrm{~g} / \mathrm{g}$, which is very similar to the OHC values of the present study. Moreover, for G. changii [19] OHCs of $3.11 \mathrm{~g} / \mathrm{g}$ at $24^{\circ} \mathrm{C}$ and $1.17 \mathrm{~g} / \mathrm{g}$ at $37^{\circ} \mathrm{C}$ were reported. The low oil absorption capacity of red seaweeds is generally related to the hydrophilic nature of the changed polysaccharides (agar, carrageenan, fucans and alginates) of soluble dietary fiber [39]. The results of the present study for physicochemical properties confirmed that G. corticata and G. edulis could be considered as a source of food ingredients including proteins, dietary and soluble fiber [39].

\section{Materials and Methods}

\subsection{Sample Collection}

Samples of the commercially important and commonly edible red seaweeds G. edulis and G. corticata were collected by hand from the Thondi Coast (Latitude: $9^{\circ} 44^{\prime} \mathrm{N}$ and Longitude: $79^{\circ} 00^{\prime} \mathrm{E}$ ), Palk Bay, on the southeast coast of India. Freshly collected seaweeds were washed thoroughly in seawater and transported to the laboratory immediately. Epiphytes, sediment particles and other debris were removed by washing thoroughly using potable water and thoroughly washed with distilled water immediately after washing with potable water. Seaweeds were identified using a standard manual [40]. The voucher specimen was deposited in museum at Department of Oceanography and Coastal Area Studies, School of Marine Sciences, Alagappa University. Seaweeds were shade dried for 5 days at constant temperature of $25^{\circ} \mathrm{C} \pm 2{ }^{\circ} \mathrm{C}$. Dried seaweed samples were powdered using a mechanical blender and stored at room temperature in an airtight container (Tarsons, Kolkatta, India) for further analysis within a maximum period of one week. Further the remaining powder sample stored at frozen condition $\left(-20^{\circ} \mathrm{C}\right)$ for future use.

\subsection{Proximate Composition}

The proximate composition of each Gracilaria species was determined in all cases following Association of Official Analytical Chemists (AOAC) methods [41]. AOAC methods were employed 
to determine in G. corticata and G. edulis the ash content by heating at $550{ }^{\circ} \mathrm{C}$ for $24 \mathrm{~h}$ in a muffle furnace (AOAC, 930.05), moisture content by heating at $105^{\circ} \mathrm{C}$ for $24 \mathrm{~h}$ (AOAC, 934.01), total fat by Soxhlet extraction with petroleum ether (AOAC 991.36) and protein by the Kjeldahl method $(\mathrm{N} \times 6.25)$ (AOAC 981.10) [41]. The total carbohydrate content of G. corticata and G. edulis was determined by the phenol-sulfuric acid method [38]. All measurements were performed in triplicate for each seaweed and expressed as $\mathrm{g} / 100 \mathrm{~g}$ seaweeds in a dry weight matter.

\subsection{Isolation of Polysaccharides}

Polysaccharides were separated from G. corticata and G. edulis using $2 \mathrm{~g}$ samples of each seaweed according as previously described [42]. Powdered G. corticata and G. edulis were dissolved and homogenized with distilled water under constant stirring for $2 \mathrm{~h}$ at $100{ }^{\circ} \mathrm{C}$. The residues obtained were then removed by centrifuging the sample at $6300 \mathrm{~g}$ for $10 \mathrm{~min}$ using a CPR 30 plus centrifuge (Remi Lab World, Mumbai, India). The obtained supernatant was then precipitated by addition of an ethanol-in-water solution (1:3 v/v), followed by subsequent washing with $30 \mathrm{~mL}$ of acetone. The precipitated polysaccharides were then collected and subsequently air-dried, re-dissolved in distilled water and washed with acetone. Afterwards, the collected polysaccharides were stored at $-20{ }^{\circ} \mathrm{C}$ in a deep freezer (Blue Star, Mumbai, India) for further use. Isolation were performed in triplicate for each seaweed and results are expressed as $\mathrm{g} / 100 \mathrm{~g}$ seaweeds in a dry weight basis.

\subsection{Extraction of Crude Lipid and Determination of Fatty Acids Content}

Portions of $500 \mathrm{mg}$ each of powdered G. corticata and G. edulis were mixed with $5 \mathrm{~mL}$ of a chloroform:methanol solution $(2: 1 \mathrm{v} / \mathrm{v})$, tightly covered with aluminum foil and kept at room temperature for $24 \mathrm{~h}$. After this period, solutions were filtered through $11 \mu \mathrm{m}$ Whatman No. 1 filter paper, and the filtered extract was placed in a pre-weighed and oven-dried beaker. The beaker was weighed with lipids, and the difference in weight was taken as total lipid content and expressed as a percentage [43]. Afterwards, an aliquot of the total lipids of each sample was used to determine the fatty acids content, based on a method published [6]. For this purpose, $0.45 \mathrm{~g}$ was introduced into a $10 \mathrm{~mL}$ volumetric flask, dissolved in hexane containing $50 \mathrm{mg}$ of butylated hydroxytoluene per $\mathrm{L}$ and diluted to $10 \mathrm{~mL}$ with the same solvent. Afterwards, $2 \mathrm{~mL}$ of the solution was transferred into a quartz tube and evaporated by means of a nitrogen flow. Further, $1.5 \mathrm{~mL}$ of a $20 \mathrm{~g} / \mathrm{L}$ solution of sodium hydroxide in methanol, covered with nitrogen, was added, capped tightly with a polytetrafluoroethylene-lined cap, mixed and heated in a water bath for $7 \mathrm{~min}$. After the water bath, samples were cooled at room temperature, and $2 \mathrm{~mL}$ of boron trichloride-methanol solution was added; then, they were blanketed with nitrogen, capped tightly, mixed and heated in a water bath for $30 \mathrm{~min}$. After this period, samples were cooled to $40-50{ }^{\circ} \mathrm{C}$, and $1 \mathrm{~mL}$ of trimethylpentane was added; then, they were capped and shaken vigorously for at least $30 \mathrm{~s}$. Immediately, $5 \mathrm{~mL}$ of saturated sodium chloride solution was added, then the samples were covered with nitrogen, capped and vortexed or shaken thoroughly for at least $15 \mathrm{~s}$. The upper layer was allowed to become clear and then transferred to a separate tube. In the separate tube, the methanol layer was shaken once more with $1 \mathrm{~mL}$ of trimethylpentane and combined with trimethylpentane extracts. The organic solvent was then removed, and FAME were subjected to gas chromatography (GC), performed on a Perkin Elmer Clarus 580 gas chromatograph (Perkin Elmer, Gaithersburg, MD, USA) equipped with a flame ionization detector and an HP-5 capillary column $(30 \mathrm{~m} \times 0.25 \mathrm{~mm})$. Initial temperature was maintained at $70{ }^{\circ} \mathrm{C}$, then increased to $250^{\circ} \mathrm{C}\left(10^{\circ} \mathrm{C} / \mathrm{min}\right)$; the injection temperature employed was $225^{\circ} \mathrm{C}$. Helium was used as carrier gas, with a flow rate of $1 \mu \mathrm{L} / \mathrm{min}$. FAME peaks were identified by comparison of their retention times and quantified by comparison with individual calibration curves performed with a standard FAME mix (Supelco, Sigma-Aldrich, St Louis, MO, USA). Tricosanoic acid (C23; Sigma-Aldrich) was used as internal standard. Fatty acid composition was determined in triplicate for each seaweed and was expressed as g FAME/100 $\mathrm{g}$ total fat. 


\subsection{Protein Composition}

Protein composition of G. corticata and G. edulis was determined based on a reversed-phase high performance liquid chromatography (HPLC) analysis method [6]. Two grams each of powdered seaweeds was mixed with phosphate buffer (pH 7.0) and centrifuged at $1200 \mathrm{~g}$ (Remi Lab World) for $20 \mathrm{~min}$ at $4{ }^{\circ} \mathrm{C}$. The supernatant was collected, and protein content was precipitated by adding $10 \% \mathrm{v} / \mathrm{v}$ trichloroacetic acid (TCA). The protein pellet was resuspended in $1 \mathrm{~N} \mathrm{NaOH}$ and hydrolyzed by heating the solution with $6 \mathrm{~N} \mathrm{HCl}$ in a boiling water bath for $24 \mathrm{~h}$. After incubation, the supernatant was collected by centrifuging the sample at $3500 \mathrm{~g}$ for $15 \mathrm{~min}$. The supernatant was then filtered and neutralized by the addition of $1 \mathrm{~N} \mathrm{NaOH}$. The filtered supernatant was diluted to 1:100 $(\mathrm{v} / \mathrm{v})$ with deionized water. The sample was subjected to reversed-phase HPLC analysis (Lachrome Hitachi, Tokyo, Japan) with UV and fluorescence detectors. One $\mu \mathrm{l}$ of sample was injected into a Denali C18 5 -mm column $(4.6 \mathrm{~mm} \times 150 \mathrm{~mm})$ at $23{ }^{\circ} \mathrm{C}$ with detection at $254 \mathrm{~nm}$. The mobile phase used was $20 \mathrm{mM}$ sodium acetate/triethylamine $(0.018 \% \mathrm{v} / \mathrm{v})$ in phase A. The $\mathrm{pH}$ was adjusted to 7.2 using $1-2 \%$ acetic acid. In phase $\mathrm{B}, 20 \%$ of $100 \mathrm{mM}$ sodium acetate ( $\mathrm{pH} 7.2$ ) with $1-2 \%$ acetic acid was used; $40 \%$ acetonitrile was used as the mobile phase. The protein composition was determined in triplicate for each seaweed and expressed as mg of amino acid/g of seaweed in a DW basis.

\subsection{Determination of Mineral Content}

$\mathrm{Zn}, \mathrm{Cu}, \mathrm{Mg}$ and $\mathrm{Fe}$ analysis of G. corticata and G. edulis was performed according to the European Standards, with minor modifications according to the method previously described [17]. One gram of homogenized seaweed sample was added to mixed reagent at a ratio of 5:2:1 (nitric acid:perchloric acid:sulfuric acid). Mineralization was performed on a hot plate at $50{ }^{\circ} \mathrm{C}$ for $30 \mathrm{~min}$. After the end of digestion, $10 \mathrm{~mL}$ of $2 \mathrm{~N} \mathrm{HCL}$ was added; digested solvents were filtered and made up to $25 \mathrm{~mL}$ with distilled water and stored at room temperature for further analysis [44]. $\mathrm{Zn}, \mathrm{Cu}, \mathrm{Mg}$ and Fe were determined by atomic absorption spectroscopy (AAS; Anton Paar-AAS, Graz, Austria). The metal standards were prepared and run to check the precision of the instrument throughout the analysis. Quality assurance and quality control protocols set by the US Environmental Protection Agency [45] for metal analysis were used. Quality assurance testing relied on the control of blanks and yield for the chemical procedure. Mineral content was determined in triplicate for each seaweed and expressed as $\mathrm{mg} / \mathrm{kg}$ of DW seaweed.

\subsection{Determination of Vitamin Content}

The vitamin content of G. corticata and G. edulis was determined by the method previously described [20]; vitamin A or retinol (328 nm), vitamin B1 or thiamine monohydrate $(420 \mathrm{~nm})$, vitamin B2 or riboflavin $(254 \mathrm{~nm})$, vitamin B6 or pyridoxine $\mathrm{HCl}(254 \mathrm{~nm})$, vitamin C or ascorbic acid, vitamin E or tocopheryl acetate $(520 \mathrm{~nm})$ and folic acid $(550 \mathrm{~nm})$ were determined by HPLC methods, and the results were compared with the respective standards retinyl acetate, thiamine monohydrate, riboflavin, pyridoxine $\mathrm{HCl}$, ascorbic acid, tocopheryl, and folic acid (Sigma Aldrich). Vitamin content was determined in triplicate for each seaweed and was expressed as $\mathrm{mg} / \mathrm{g}$ of DW seaweed.

\subsection{Determination of Chlorophyll $a, b$ and Carotenoids}

Thin-layer chromatography (TLC) was used to screen chlorophyll $a$ and $b$ and carotenoid content in the G. corticata and G. edulis extracts [8]. The mobile phase contained methanol and chloroform (1:9). The sample (approximately $1 \mathrm{mg} / \mathrm{mL}$ ) was spotted onto the TLC plates and air-dried. The spots were identified under long-wave and short-wave UV light, and also in an iodine chamber. The Rf value, which is the distance moved by the solute relative to the distance moved by the solvent, was calculated to find chlorophyll $a$ and $b$ and carotenoid content.

Afterwards, for chlorophyll $a$ and $b$ determination, $1 \mathrm{~g}$ each of G. corticata and G. edulis powder was extracted with $96 \% \mathrm{CH}_{3} \mathrm{OH}$, and the supernatant was collected by centrifugation at $1000 \mathrm{~g}$ for $1 \mathrm{~min}$. 
After filtration, the supernatant was again filtered with Whatman No. 1 filter paper, centrifuged at $2300 \mathrm{~g}$ (Remi Lab World) for $10 \mathrm{~min}$, and the absorbance of the collected supernatant was measured using a UV-Vis spectrophotometer [8]. The chlorophyll $a$ and $b$ contents were calculated using the following formulas in triplicate for each seaweed and expressed as $\mu \mathrm{g} / \mathrm{g}$ of DW:

$$
\begin{aligned}
& \text { Chlorophyll } a=15.65\left(\mathrm{~A}_{666}\right)-7.340\left(\mathrm{~A}_{653}\right) \\
& \text { Chlorophyll } b=27.05\left(\mathrm{~A}_{653}\right)-11.21\left(\mathrm{~A}_{666}\right)
\end{aligned}
$$

where $\mathrm{A}_{666}=$ absorbance at $666 \mathrm{~nm} ; \mathrm{A}_{653}=$ absorbance at $653 \mathrm{~nm}$. Carotenoid content was determined according to [46]. One gram each of G. corticata and G. edulis powder was extracted with $5 \mathrm{~mL}$ of acetone and incubated in the dark for $45 \mathrm{~min}$, and the supernatant was collected by centrifugation at $10,000 \mathrm{~g}$ for $5 \mathrm{~min}$. The supernatant was then stored in a refrigerator, and the extraction repeated with acetone until it became colourless. The supernatant was pooled and made up to $10 \mathrm{~mL}$ with acetone, and the absorbance of the collected supernatant was measured at $450 \mathrm{~nm}$ using a UV-Vis spectrophotometer (Shimadzu, Kyoto, Japan). Carotenoid content was calculated using the following formula in triplicate for each seaweed and expressed as $\mu \mathrm{g} / \mathrm{g}$ of DW:

$$
\text { Carotenoid content }=\mathrm{A} 450 / 2500
$$

where 2500 is the extinction coefficient.

\subsection{Physicochemical Properties}

In order to determine the physicochemical properties of the G. corticata and G. edulis powder, the SWC, WHC and OHC were determined for each powder. The SWC of G. corticata and G. edulis was assessed based on a method previously described [38]. Briefly, $500 \mathrm{mg}$ of G. corticata and G. edulis were taken and mixed with $20 \mathrm{~mL}$ of distilled water and stirred vigorously. The influence of temperature on SWC was determined by maintaining the tubes at $25^{\circ} \mathrm{C}$ and $37^{\circ} \mathrm{C}$ overnight. The SWC of G. corticata and G. edulis was calculated using the following formula and expressed as $\mathrm{ml}$ of swollen sample per $\mathrm{g}$ of DW:

$$
\text { SWC }=\text { Initial volume of water }(\mathrm{mL})-\text { Volume of water after incubation }(\mathrm{mL})
$$

The WHC of G. corticata and G. edulis was assessed by a modified method [38]. Briefly, $500 \mathrm{mg}$ each of G. corticata and G. edulis was put into two sets of centrifuge tubes, and $20 \mathrm{~mL}$ of deionized water was added. The tubes were kept separately in an incubator shaker for $24 \mathrm{~h}$ at 25 and $37{ }^{\circ} \mathrm{C}$. The supernatant was discarded after centrifuging the tubes at 12,000 $\mathrm{g}$ for $30 \mathrm{~min}$ (Remi Lab World). The wet weight of G. corticata and G. edulis was noted. The samples were dehydrated by keeping them in an oven at $160^{\circ} \mathrm{C}$ for $2 \mathrm{~h}$, and the dry weight of the sample was noted. The WHC was determined in triplicate for each seaweed and calculated using the following formula and expressed as the weight in $\mathrm{g}$ of water held by $1 \mathrm{~g}$ of DW sample:

$$
\text { WHC }=\text { Wet weight of the sample }(\mathrm{g}) \text { - Dry weight of the sample }(\mathrm{g})
$$

The OHC of G. corticata and G. edulis was assessed according to previous methods [20,38]. About $3 \mathrm{~g}$ of dried G. corticata and G. edulis was taken in a tube and mixed with $10.5 \mathrm{~g}$ of corn oil. The tubes were placed in a shaker at room temperature for $30 \mathrm{~min}$. The oil supernatant was collected by centrifugation at $3000 \mathrm{~g}$ for $30 \mathrm{~min}$ (Remi Lab World). The OHC was determined in triplicate for each seaweed and was determined using the following formula and expressed as the number of $\mathrm{g}$ of oil held by $1 \mathrm{~g}$ of DW sample:

$$
\mathrm{OHC}=\text { Initial volume of oil }(\mathrm{g})-\text { Volume of oil after incubation }(\mathrm{g})
$$




\subsection{Statistical Analysis}

All results were expressed as mean \pm SD. Paired sample $t$-test was used to compare composition values between G. edulis and G. corticata. One-way analysis of variance (ANOVA) and Duncan's test were used to compare the effects of temperature on the physicochemical properties. All determinations were performed using SPPS version 14 (SPSS Science, Chicago, IL, USA). A positive significant variation was defined at the significance level of $p<0.05$.

\section{Conclusions}

The polysaccharide content of the investigated dried red seaweeds (G. corticata and G. edulis) were found to be rich sources of polysaccharides. Because of the potential as prebiotics, antioxidant and anti-inflammatory compounds, carbohydrates from seaweeds has are compounds in high demand by consumers today. The physicochemical properties and proximate composition revealed that both G. corticata and G. edulis have appreciable levels of ash, protein, carbohydrate, fatty acid, essential and non-essential amino acid and vitamin content. It is suggested that both the seaweeds tested have great potential as potential food supplements and may be used in the food industry as a source of ingredients with an appreciable amount of nutritional value. Since both red seaweeds were found to be a good source of essential nutrients, their commercial value can be enhanced by marketing them as value-added products. However, depending on their composition, G. edulis and G. corticata have important differences that make it more adequate for certain cases. G. edulis showed higher concentration of essential amino acids, chlorophyll, vitamin $\mathrm{B}_{2}$ and $\mathrm{Zn}$. Thus, it could be a good nutrient for low-protein diets or people whose need to reduce their oxidative status, because of its content in chlorophyll and Zn. Contrariwise, G. corticata showed higher PUFA content, carotenoids and minerals as Fe and Mg. Thus G. corticata is more adequate than G. edulis for people who need to reinforce their intake of such nutrients.

Author Contributions: Conceptualization, S.P. and A.A.; methodology, T.R. and A.A.; software, A.A. and A.M.-P.; validation, A.A.; formal analysis, T.R. and A.A.; investigation, A.A. and S.P.; resources, S.P.; data curation, J.M.M.; writing—original draft preparation, J.M.M.; writing—review and editing, A.M.-P.; visualization, S.P. and J.M.M.; supervision, S.P.; project administration, S.P.; funding acquisition, S.P.

Funding: This research received external funding by RUSA-2. 0 grant sanctioned vide Letter No. F. 24-51/2014-U, Policy (TNMulti-Gen), Department of Education, Government of India and by FEADER (The European Agricultural Fund for Rural Development (EAFRD)), grant number 2018/001B and ED431C 2018/05.

Acknowledgments: The authors thank the authorities of Alagappa University for providing necessary facilities.

Conflicts of Interest: The authors declare no conflict of interest.

\section{References}

1. Debbarama, J.; Rao, B.M.; Murthy, L.N.; Mathew, S.; Venkateshwarlu, G.; Ravishankar, C. Nutritional profiling of the edible seaweeds Gracilaria edulis, Ulva lactuca and Sargassum sp. Indian J. Fish. 2016, 63, 81-87. [CrossRef]

2. Torres, P.; Santos, J.P.; Chow, F.; dos Santos, D.Y. A comprehensive review of traditional uses, bioactivity potential, and chemical diversity of the genus Gracilaria (Gracilariales, Rhodophyta). Algal Res. 2019, 37, 288-306. [CrossRef]

3. Da Costa, E.; Melo, T.; Moreira, A.S.P.; Bernardo, C.; Helguero, L.; Ferreira, I.; Cruz, M.T.; Rego, A.M.; Domingues, P.; Calado, R.; et al. Valorization of lipids from Gracilaria sp. Through lipidomics and decoding of antiproliferative and anti-inflammatory activity. Mar. Drugs 2017, 15, 62. [CrossRef] [PubMed]

4. Meyer, B.J.; de Groot, R.H.M. Effects of omega-3 long chain polyunsaturated fatty acid supplementation on cardiovascular mortality: The importance of the dose of DHA. Nutrients 2017, 9, 1305. [CrossRef] [PubMed]

5. Benjama, O.; Masniyom, P. Biochemical composition and physicochemical properties of two red seaweeds (Gracilaria fisheri and G. tenuistipitata) from the Pattani Bay in Southern Thailand. Songklanakarin J. Sci. Technol. 2012, 34, 223-230. 
6. Syad, A.N.; Shunmugiah, K.P.; Kasi, P.D. Seaweeds as nutritional supplements: Analysis of nutritional profile, physicochemical properties and proximate composition of G. acerosa and S. wightii. Biomed. Prev. Nut. 2013, 3, 139-144. [CrossRef]

7. Chan, P.T.; Matanjum, P.; Yasir, S.M.; Tan, T.S. Antioxidant and hypolipidaemic properties of red seaweed, Gracilaria changii. J. Appl. Phycol. 2014, 26, 302-310. [CrossRef]

8. Sakthivel, R.; Devi, K.P. Evaluation of physicochemical properties, proximate and nutritional composition of Gracilaria edulis collected from Palk Bay. Food Chem. 2015, 174, 68-74. [CrossRef]

9. Ju, T.; Deng, Y.; Xi, J. Optimization of circulating extraction of polysaccharides from Gracilaria lemaneiformis using pulsed electrical discharge. ACS Sustain. Chem. Eng. 2019, 7, 3593-3601. [CrossRef]

10. Moreda-Piñeiro, A.; Peña-Vázquez, E.; Bermejo-Barrera, P. Significance of the presence of trace and ultratrace elements in seaweeds. In Handbook of Marine Macroalgae: Biotechnology and Applied Phycology; Kim, S.K., Ed.; John Wiley \& Sons: Chichester, UK, 2012; pp. 116-170.

11. Mišurcová, L. Chemical Composition of Seaweeds. In Handbook of Marine Macroalgae: Biotechnology and Applied Phycology; Kim, S.K., Ed.; John Wiley \& Sons: Chichester, UK, 2012; pp. 173-192.

12. Jeon, T. Biological Effects of Proteins Extracted from Marine Algae. In Handbook of Marine Macroalgae: Biotechnology and Applied Phycology; Kim, S.K., Ed.; John Wiley \& Sons: Chichester, UK, 2012; pp. 387-397.

13. Inanc, A.L. Chlorophyll: Structural properties, health benefits and its occurrence in virgin olive oils. Akademik Gida. 2011, 9, 26-32.

14. Hsu, C.Y.; Chao, P.Y.; Hu, S.P.; Yang, C.M. The antioxidant and free radical scavenging activities of chlorophylls and pheophytins. Food Nutr. Sci. 2013, 4, 1-8. [CrossRef]

15. Fleurence, J.; Morançais, M.; Dumay, J.; Decottignies, P.; Turpin, V.; Munier, M.; Garcia-Bueno, N.; Jaouen, P. What are the prospects for using seaweed in human nutrition and for marine animals raised through aquaculture? Trends Food Sci. Technol. 2012, 27, 57-61. [CrossRef]

16. Peinado, I.; Girón, J.; Koutsidis, G.; Ames, J. Chemical composition, antioxidant activity and sensory evaluation of five different species of brown edible seaweeds. Food Res. Int. 2014, 66, 36-44. [CrossRef]

17. Arulkumar, A.; Paramasivam, S.; Miranda, J.M. Combined effect of icing medium and red alga Gracilaria verrucosa on shelf life extension of Indian Mackerel (Rastrelliger kanagurta). Food Bioprocess Tech. 2018, 11, 1911-1922. [CrossRef]

18. Arulkumar, A.; Rosemary, T.; Paramasivam, S.; Babu Rajendran, R. Phytochemical composition, in vitro antioxidant, antibacterial potential and GC-MS analysis of red seaweeds (Gracilaria corticata and Gracilaria edulis) from Palk Bay, India. Biocatal. Agric. Biotechnol. 2018, 15, 63-71. [CrossRef]

19. Chan, P.T.; Matanjun, P. Chemical composition and physicochemical properties of tropical red seaweed, Gracilaria changii. Food Chem. 2017, 221, 302-310. [CrossRef] [PubMed]

20. Francavilla, M.; Franchi, M.; Monteone, M.; Caroppo, C. The red seaweed Gracilaria gracilis as a multi products source. Mar. Drugs 2013, 11, 3754-3776. [CrossRef]

21. Kendall, C.W.C.; Esfahani, A.; Jenkins, D.J.A. The link between dietary fibre and human health. Food Hydrocoll. 2010, 24, 42-48. [CrossRef]

22. Marinho-Soriano, E.; Fonseca, P.; Carneiro, M.; Moreira, W. Seasonal variation in the chemical composition of two tropical seaweeds. Bioresour. Technol. 2006, 97, 2402-2406. [CrossRef]

23. Mabeau, S.; Fleurence, J. Seaweed in food products: Biochemical and nutritional aspects. Trends Food Sci Technol. 1993, 4, 103-107. [CrossRef]

24. Seedevi, P.; Moovendhan, M.; Viramani, S.; Shanmugam, A. Bioactive potential and structural characterization of sulfated polysaccharide from seaweed (Gracilaria corticata). Carbohydr. Polym. 2017, 155, 516-524. [CrossRef]

25. Souza, B.W.; Cerqueira, M.A.; Bourbon, A.I.; Pinheiro, A.C.; Martins, J.T.; Teixeira, J.A.; Coimbra, M.A.; Vicente, A.A. Chemical characterization and antioxidant activity of sulfated polysaccharide from the red seaweed Gracilaria birdiae. Food Hydrocoll. 2012, 27, 287-292. [CrossRef]

26. Melo, M.; Feitosa, J.; Freitas, A.; De Paula, R. Isolation and characterization of soluble sulfated polysaccharide from the red seaweed Gracilaria cornea. Carbohydr. Polym. 2002, 49, 491-498. [CrossRef]

27. Barros, F.C.; da Silva, D.C.; Sombra, V.G.; Maciel, J.S.; Feitosa, J.P.; Freitas, A.L.; de Paula, R.C. Structural characterization of polysaccharide obtained from red seaweed Gracilaria caudata (J Agardh). Carbohydr. Polym. 2013, 92, 598-603. [CrossRef] [PubMed] 
28. Sudharsan, S.; Subhapradha, N.; Seedevi, P.; Shanmugam, V.; Madeswaran, P.; Shanmugam, A.; Srinivasan, A. Antioxidant and anticoagulant activity of sulfated polysaccharide from Gracilaria debilis (Forsskal). Int. J. Biol. Macromol. 2015, 81, 1031-1038. [CrossRef] [PubMed]

29. Armisen, R. World-wide use and importance of Gracilaria. J. Appl. Phycol. 1995, 7, 231. [CrossRef]

30. Bocanegra, A.; Bastida, S.; Benedí, J.; Ródenas, S.; Sánchez-Muniz, F.J. Characteristics and nutritional and cardiovascular-health properties of seaweeds. J. Med. Food 2009, 12, 236-258. [CrossRef]

31. Kumari, P.; Kumar, M.; Gupta, V.; Reddy, C.R.K.; Jha, B. Tropical marine macroalgae as potential sources of nutritionally important PUFAs. Food Chem. 2010, 120, 749-757. [CrossRef]

32. Khotimchenko, S.V.; Vaskovsky, V.E.; Przhemenetskaya, V.F. Distribution of eicosapentaenoic and arachidonic acids in different species of Gracilaria. Phytochemistry 1991, 30, 207-209. [CrossRef]

33. Matanjun, P.; Mohamed, S.; Mustapha, N.M.; Muhammad, K. Nutrient content of tropical edible seaweeds, Eucheuma cottonii, Caulerpa lentillifera and Sargassum polycystum. J. Appl. Phycol. 2009, 21, 75-80. [CrossRef]

34. Ródenas de la Rocha, S.; Sánchez-Muniz, F.J.; Gómez-Juaristi, M.; Marín, M.T.L. Trace elements determination in edible seaweeds by an optimized and validated ICP-MS method. J. Food Compos. Anal. 2009, 22, 330-336. [CrossRef]

35. Sánchez-Rodríguez, I.; Huerta-Diaz, M.A.; Choumiline, E.; Holguín-Quiones, O.; Zertuche-González, J.A. Elemental concentrations in different species of seaweeds from Loreto Bay, Baja California Sur, Mexico: Implications for the geochemical control of metals in algal tissue. Environ. Pollut. 2001, 114, 145-160. [CrossRef]

36. Hong, D.D.; Hien, H.M.; Son, P.N. Seaweeds from Vietnam used for functional food, medicine and biofertilizer. J. Appl. Phycol. 2007, 19, 817-826. [CrossRef]

37. Christaki, E.; Bonos, E.; Giannenasa, I.; Florou-Paneria, P. Functional properties of carotenoids originating from algae. J. Sci. Food Agric. 2013, 93, 5-11. [CrossRef]

38. Wong, K.H.; Cheung, P.C.K. Nutritional evaluation of some subtropical red and green seaweeds Part II. In vitro protein digestibility and amino acid profiles of protein concentrates. Food Chem. 2001, 72, 11-17. [CrossRef]

39. Rupérez, P.; Saura-Calixto, F. Dietary fibre and physicochemical properties of edible Spanish seaweeds. Eur. Food Res. Technol. 2001, 212, 349-354. [CrossRef]

40. Jha, B.; Reddy, C.R.K.; Thakur, M.C.; Rao, M.U. The diversity and distribution of seaweeds of Gujarat Coast. In Developments in Applied Phycology; Springer: New York, NY, USA, 2009; pp. 1-213.

41. Association of Official Analytical Chemists (AOAC). Official Methods of Analysis, 17th ed.; AOAC: Gaithersburg, MD, USA, 2002.

42. Dubois, M.; Gilles, K.A.; Hamilton, J.K.; Rebers, P.A.; Smith, F. Colorimetric method for determination of sugars and related substances. Anal. Chem. 1956, 28, 350-356. [CrossRef]

43. Folch, J.; Lees, M.; Sloane Stanley, G.H. A simple method for the isolation and purification of total lipids from animal tissues. J. Biol. Chem. 1957, 226, 497-509.

44. Manual of Methods in Aquatic Environment Research (pat 9). Analyses of Metals and Organochlorines in Fish; FAO Fisheries Technical Paper; Food and Agriculture Organization of the United Nations: Rome, Italy, 1984; p. 212.

45. Fish and Fishery Products Hazards and Controls Guidance, Center for Food Safety and Applied Nutrition's, 3rd ed.; Food and Drug Administration (FDA): Gainesville, FL, USA, 2001.

46. Jansen, A. Chlorophylls and Carotenoids. In Handbook of Phycological Methods; Cambridge University Press: Cambridge, UK, 1978; pp. 60-70.

Sample Availability: Samples of the Gracilaria edulis and Gracilaria corticata are available from the authors.

(C) 2019 by the authors. Licensee MDPI, Basel, Switzerland. This article is an open access article distributed under the terms and conditions of the Creative Commons Attribution (CC BY) license (http://creativecommons.org/licenses/by/4.0/). 


\title{
Concentration of EPA and DHA from Refined Salmon Oil by Optimizing the Urea-Fatty Acid Adduction Reaction Conditions Using Response Surface Methodology
}

\author{
Gretel Dovale-Rosabal ${ }^{1}$, Alicia Rodríguez ${ }^{1, *}$, Elyzabeth Contreras ${ }^{1}$, Jaime Ortiz-Viedma ${ }^{1, *}$, \\ Marlys Muñoz ${ }^{1}$, Marcos Trigo ${ }^{2}$, Santiago P. Aubourg ${ }^{2, *}$ and Alejandra Espinosa ${ }^{3}$ \\ 1 Department of Food Science and Chemical Technology, Faculty of Chemical and Pharmaceutical Sciences, \\ Santos Dumont 964, University of Chile, Santiago 8380000, Chile; gretel.dovale@ug.uchile.cl (G.D.-R); \\ ely_tcn@hotmail.com (E.C.); marlys_dayane@hotmail.com (M.M.) \\ 2 Department of Food Technology, Marine Research Institute (CSIC), Eduardo Cabello, 6, 36208 Vigo, Spain; \\ mtrigo@iim.csic.es \\ 3 Department of Medical Technology, School of Medicine, University of Chile, Santiago 8380000, Chile; \\ bespinosa@med.uchile.cl \\ * Correspondence: arodrigm@uchile.cl (A.R.); jaortiz@uchile.cl (J.O.-V.); saubourg@iim.csic.es (S.P.A.)
}

Academic Editor: Jose M. Miranda

Received: 19 March 2019; Accepted: 20 April 2019; Published: 26 April 2019

\begin{abstract}
This research focused on obtaining eicosapentaenoic acid (EPA, 20:5n-3) and docosahexaenoic acid (DHA, 22:6n-3) (EPA+DHA) concentrates from refined commercial salmon oil (RCSO). Independent variables of the complexation process were optimized by means of the application of response surface methodology (RSM) in order to obtain the maximum content of such fatty acids (FAs). As a result of employing the optimized conditions for all the variables (6.0, urea:FA content ratio; $-18.0^{\circ} \mathrm{C}$, crystallization temperature; $14.80 \mathrm{~h}$, crystallization time; $500 \mathrm{rpm}$, stirring speed), high contents of EPA and DHA could be obtained from RCSO, achieving increases of 4.1 and 7.9 times in the concentrate, with values of 31.20 and $49.31 \mathrm{~g} / 100 \mathrm{~g}$ total FA, respectively. Furthermore, a 5.8-time increase was observed for the EPA + DHA content, which increased from 13.78 to $80.51 \mathrm{~g} / 100 \mathrm{~g}$ total FA. It is concluded that RCSO can be transformed into a profitable source of EPA and DHA (EPA+DHA), thus leading to a product with higher commercial value.
\end{abstract}

Keywords: refined commercial salmon oil; $n$-3 long-chain polyunsaturated fatty acids ( $n-3$ LCPUFAs) concentration; EPA; DHA; EPA+DHA; total FA yield; process variable maximization; response surface methodology (RSM); multiple response optimization; desirability function

\section{Introduction}

In recent years, it has been recognized that the consumption of eicosapentaenoic acid (EPA) is associated with a low prevalence of coronary, circulatory, and inflammatory diseases [1-4]. Furthermore, docosahexaenoic acid (DHA) has been associated with fetal development, the prevention of neurodegenerative diseases, and the correct functioning of the nervous system and visual organs in the fetus [5-10]. According to the Food and Agriculture Organization/World Health Organization (FAO/WHO) [1], the recommended intake of EPA+DHA is at least $250 \mathrm{mg} /$ day for adult males and non-pregnant/non-lactating adult females. Interestingly, the optimal brain development of children would need a $150 \mathrm{mg} /$ day diet of such fatty acids. EPA+DHA concentrates may be produced by various methods, such as supercritical fluid chromatography, supercritical fluid fractionation, molecular distillation, silver complexation, enzymatic methods, and urea 
complexation [11,12]. Among them, complexation with the urea can be considered as the most efficient method, since polyunsaturated fatty acids (PUFAs) may be separated from saturated and monounsaturated ones by means of an economic process at low temperature [13-18]. The present research was focused on the employment of refined commercial salmon oil (RCSO) as a profitable source of EPA+DHA concentrates, which in time could lead to a product of higher commercial value. For it, independent variables of the urea adduction reaction conditions (urea:FA content ratio, crystallization time and temperature, and crystallization stirring speed) were optimized by response surface methodology (RSM) in order to achieve the maximum content of EPA, DHA and EPA+DHA. Additionally, the quality of the starting salmon oil was determined and evaluated.

\section{Results}

\subsection{Characterization of the Initial Refined Commercial Salmon Oil}

Results for the composition of RCSO reported that the most abundant fatty acids were 18:1 9c (29.61\%), 18:2 9c, 12c (16.69\%), and 16:0 (13.74 \%) followed by EPA $(7.53 \%)$ and DHA (6.25\%) $(\mathrm{g} / 100 \mathrm{~g}$ total FA). The total value of saturated fatty acids (SFAs) was $21.28 \%$, which was composed mainly of palmitic, stearic, and myristic acids (Table 1). Special interest is the confirmation of the absence of phytanic acid within the lipid composition of RCSO. This fatty acid has been linked to neurological disorders in some people, but it is also associated with the prevention of metabolic syndrome or type 2 diabetes [19].

Table 1. Composition of fatty acids in (RCSO) and the optimized concentrate from RCSO ( $/ 100 \mathrm{~g}$ total FA)*.

\begin{tabular}{|c|c|c|}
\hline FA or FA Groups & RCSO & RCSO Optimum \\
\hline $12: 0$ & 0.07 & $\mathrm{Nd}$ \\
\hline $14: 0$ & 3.19 & 0.12 \\
\hline $15: 0$ & 0.20 & 0.09 \\
\hline $16: 0$ & 13.74 & $\mathrm{Nd}$ \\
\hline $16: 19 \mathrm{t}$ & 0.15 & $\mathrm{Nd}$ \\
\hline $16: 17 \mathrm{c}$ & $\mathrm{Nd}$ & $\mathrm{Nd}$ \\
\hline $16: 19 \mathrm{c}$ & 4.66 & 0.51 \\
\hline $16: 111 \mathrm{c}$ & $\mathrm{Nd}$ & $\mathrm{Nd}$ \\
\hline $16: 113 c$ & $\mathrm{Nd}$ & $\mathrm{Nd}$ \\
\hline $17: 0$ & 0.13 & 0.10 \\
\hline $17: 110 \mathrm{c}$ & 0.56 & 1.28 \\
\hline $18: 0$ & 3.69 & 0.28 \\
\hline $18: 19 \mathrm{c}$ & 29.61 & 0.59 \\
\hline $18: 111 \mathrm{c}$ & 3.69 & 0.04 \\
\hline $18: 29 t, 12 t$ & $\mathrm{Nd}$ & $\mathrm{Nd}$ \\
\hline $18: 29 c, 12 c$ & 16.69 & 7.48 \\
\hline $18: 29 c, 15 c$ & $\mathrm{Nd}$ & $\mathrm{Nd}$ \\
\hline $18: 36 c, 9 c, 12 c$ & 0.22 & 1.09 \\
\hline 20:0 & 0.26 & $\mathrm{Nd}$ \\
\hline $18: 39 c, 12 c, 15 c$ & 3.25 & 2.60 \\
\hline $20: 15 c$ & $\mathrm{Nd}$ & $\mathrm{Nd}$ \\
\hline $20: 18 c$ & $\mathrm{Nd}$ & $\mathrm{Nd}$ \\
\hline $20: 111 \mathrm{c}$ & 1.60 & $\mathrm{Nd}$ \\
\hline $18: 46 c, 9 c, 12 c, 15 c$ & $\mathrm{Nd}$ & $\mathrm{Nd}$ \\
\hline $20: 211 c, 14 c$ & 0.79 & 0.05 \\
\hline $20: 38 c, 11 c, 14 c$ & 0.30 & 1.16 \\
\hline $20: 311 c, 14 c, 17 \mathrm{c}$ & 0.12 & 0.03 \\
\hline $20: 48 c, 11 c, 14 c, 17 c$ & 0.40 & 1.37 \\
\hline $22: 113 c$ & 0.21 & $\mathrm{Nd}$ \\
\hline $20: 55 c, 8 c, 11 c, 14 c, 17 c$ & 7.53 & 31.20 \\
\hline $24: 115 c$ & $\mathrm{Nd}$ & $\mathrm{Nd}$ \\
\hline
\end{tabular}


Table 1. Cont.

\begin{tabular}{ccc}
\hline $22: 57 \mathrm{c}, 10 \mathrm{c}, 13 \mathrm{c}, 16 \mathrm{c}, 19 \mathrm{c}$ & 2.69 & 2.70 \\
$22: 64 \mathrm{c}, 7 \mathrm{c}, 10 \mathrm{c}, 13 \mathrm{c}, 16 \mathrm{c}, 19 \mathrm{c}$ & 6.25 & 49.31 \\
Total SFAs & 21.28 & 0.59 \\
Total MUFAs & 40.48 & 2.42 \\
Total PUFAs & 38.24 & 96.99 \\
Total $n$-3PUFAs & 20.45 & 87.21 \\
Total $n$-3LCPUFAs & 18.08 & 85.82 \\
EPA+DHA & 13.78 & 80.51
\end{tabular}

* Abbreviations employed: DHA (docosahexaenoic acid), EPA (eicosapentaenoic acid), FA (fatty acid), SFAs (saturated fatty acids), MUFAs (monounsaturated fatty acids), RCSO (refined commercial salmon oil), n-3LCPUFAs (n-3 long chain polyunsaturated fatty acids), Nd (not detected).

Values obtained for the oxidative stability of RCSO were: peroxide value $(P V)=5.23 \pm 0.05$ meq. active oxygen $\mathrm{kg}^{-1}$ oil; $\mathrm{p}$-anisidine value $(\mathrm{pAV})=6.84 \pm 0.46$; and total oxidation value $($ TOTOX $)=17.30 \pm 0.40$ and free fatty acids $($ FFA $)=0.30 \pm 0.01 \mathrm{~g}$ oleic acid $/ 100 \mathrm{~g}$ oil. Previous studies performed on refined salmon oil samples [18] indicated average values of $P V=3.54 \pm 0.16$ meq active oxygen $\mathrm{kg}^{-1}$ oil; $\mathrm{p}$-anisidine value $(\mathrm{pAV})=5.14 \pm 1.02$ and $\mathrm{FFA}=0.23 \pm 0.00 \mathrm{~g}$ oleic acid $/ 100 \mathrm{~g}$ oil. and at and $12.22 \pm 1.34$, respectively.

\subsection{Effect of Process Variables on Total FA Yield, EPA Contents, and DHA Contents of RCSO Concentrate}

\subsubsection{Refined Commercial Salmon Oil Concentrate}

According to the experimental design, showed in Table 2, 28 assays were performed to obtain different refined commercial salmon oil concentrates. This table reports the experimental values obtained for the different response variables: $\mathrm{R}_{1}$ (total FA yield; $g$ FA in the non-urea complexing fraction/100 g initial saponified oil FA), $R_{2}$ (EPA content; $g / 100 \mathrm{~g}$ total FA), and $\mathrm{R}_{3}$ (DHA content; $\mathrm{g} / 100 \mathrm{~g}$ total FA) of RCSO concentrate. Table 2 also includes the predicted values for the described corresponding variables, whereas the experimental values were replaced by the application of the model (R1', R2', and R3' values, respectively). As a result, all the independent variables (A: urea/FA content ratio, $w / w$; B: crystallization temperature, ${ }^{\circ} \mathrm{C}$; $\mathrm{C}$ : crystallization time, $\mathrm{h}$; D: stirring speed, rpm) significantly affected $(p<0.05)$ the response variables during the urea complexation process. On the other hand, the enrichment of EPA and DHA in concentrates varied inversely according to total FA yield, obtaining correlation coefficient values (r) of -0.7756 and -0.7185 , respectively.

Table 2. Values obtained for the experimental and predicted response variables of RCSO concentrate by central composite rotatable design $2^{4}+$ star based on the response surface methodology ${ }^{1}$.

\begin{tabular}{|c|c|c|c|c|c|c|c|c|c|c|}
\hline \multirow{3}{*}{ Run } & \multirow{2}{*}{\multicolumn{4}{|c|}{ Process Variables * }} & \multicolumn{6}{|c|}{ Response Variables ${ }^{* *}$} \\
\hline & & & & & \multicolumn{3}{|c|}{ Experimental Values } & \multicolumn{3}{|c|}{ Predicted Values } \\
\hline & A & B & $\mathrm{C}$ & D & $\mathbf{R}_{1}$ & $\mathbf{R}_{2}$ & $\mathbf{R}_{3}$ & $\mathbf{R}_{1}^{\prime}$ & $\mathbf{R}_{2}^{\prime}$ & $\mathbf{R}_{3}^{\prime}$ \\
\hline 1 & 1.5 & -15 & 14.3 & 200 & 40.44 & 10.47 & 11.04 & 33.77 & 13.77 & 14.00 \\
\hline 2 & 4.5 & -15 & 14.3 & 200 & 12.64 & 28.41 & 44.38 & 12.23 & 28.09 & 45.89 \\
\hline 3 & 1.5 & 15 & 14.3 & 200 & 48.71 & 9.22 & 9.52 & 40.35 & 9.52 & 10.23 \\
\hline 4 & 4.5 & 15 & 14.3 & 200 & 17.45 & 25.09 & 32.69 & 18.82 & 23.85 & 26.94 \\
\hline 5 & 1.5 & -15 & 36.8 & 200 & 36.25 & 10.46 & 11.13 & 29.02 & 13.22 & 15.24 \\
\hline 6 & 4.5 & -15 & 36.8 & 200 & 10.44 & 24.42 & 55.91 & 21.55 & 27.55 & 47.14 \\
\hline 7 & 1.5 & 15 & 36.8 & 200 & 4.22 & 7.96 & 8.18 & 20.22 & 8.98 & 11.47 \\
\hline 8 & 4.5 & 15 & 36.8 & 200 & 18.12 & 24.87 & 30.47 & 12.76 & 23.30 & 28.18 \\
\hline 9 & 1.5 & -15 & 14.3 & 600 & 41.74 & 10.23 & 10.89 & 44.89 & 14.52 & 14.71 \\
\hline 10 & 4.5 & -15 & 14.3 & 600 & 12.77 & 30.20 & 46.43 & 12.14 & 28.84 & 46.61 \\
\hline 11 & 1.5 & 15 & 14.3 & 600 & 78.45 & 9.02 & 9.41 & 68.43 & 10.27 & 10.94 \\
\hline 12 & 4.5 & 15 & 14.3 & 600 & 16.11 & 25.16 & 34.34 & 21.40 & 24.60 & 27.65 \\
\hline
\end{tabular}


Table 2. Cont.

\begin{tabular}{|c|c|c|c|c|c|c|c|c|c|c|}
\hline 13 & 1.5 & -15 & 36.8 & 600 & 45.49 & 9.91 & 10.06 & 40.14 & 13.97 & 15.96 \\
\hline 14 & 4.5 & -15 & 36.8 & 600 & 9.86 & 27.56 & 48.55 & 7.17 & 28.30 & 47.85 \\
\hline 15 & 1.5 & 15 & 36.8 & 600 & 58.94 & 7.84 & 7.91 & 48.30 & 9.73 & 12.18 \\
\hline 16 & 4.5 & 15 & 36.8 & 600 & 12.64 & 23.05 & 28.93 & 15.33 & 24.05 & 28.89 \\
\hline 17 & 0 & 0 & 25.5 & 400 & 57.38 & 6.33 & 6.39 & 67.84 & -0.77 & 0.94 \\
\hline 18 & 6 & 0 & 25.5 & 400 & 15.86 & 25.45 & 30.43 & 13.34 & 27.88 & 49.55 \\
\hline 19 & 3 & -30 & 25.5 & 400 & 12.21 & 29.26 & 44.37 & 19.61 & 24.94 & 36.61 \\
\hline 20 & 3 & 30 & 25.5 & 400 & 33.82 & 13.52 & 14.65 & 34.36 & 16.45 & 13.88 \\
\hline 21 & 3 & 0 & 3.05 & 400 & 12.71 & 20.41 & 22.67 & 25.65 & 21.24 & 24.00 \\
\hline 22 & 3 & 0 & 48.0 & 400 & 16.31 & 23.01 & 28.93 & 14.83 & 20.15 & 26.49 \\
\hline 23 & 3 & 0 & 25.5 & 0 & 19.11 & 22.62 & 25.72 & 13.39 & 19.95 & 24.53 \\
\hline 24 & 3 & 0 & 25.5 & 800 & 16.47 & 26.07 & 33.39 & 27.09 & 21.44 & 25.95 \\
\hline 25 & 3 & 0 & 25.5 & 400 & 20.77 & 22.43 & 25.82 & 20.24 & 20.69 & 25.24 \\
\hline 26 & 3 & 0 & 25.5 & 400 & 20.74 & 21.40 & 25.20 & 20.24 & 20.69 & 25.24 \\
\hline 27 & 3 & 0 & 25.5 & 400 & 17.20 & 24.00 & 29.15 & 20.24 & 20.69 & 25.24 \\
\hline 28 & 3 & 0 & 25.5 & 400 & 22.74 & 18.23 & 20.23 & 20.24 & 20.69 & 25.24 \\
\hline \multicolumn{9}{|c|}{ Equations } & \multicolumn{2}{|c|}{$\mathrm{R}^{2}$ Adjusted } \\
\hline \multirow{4}{*}{\multicolumn{9}{|c|}{$\begin{array}{l}\text { Total FA yield = 57.60- 19.47A }+0.26 \mathrm{~B}-0.87 \mathrm{C}+0.08 \mathrm{D}+2.26 \mathrm{AA}+0.01 \mathrm{BB}+0.21 \mathrm{AC} \\
-0.02 \mathrm{AD}-0.02 \mathrm{BC}+0.001 \mathrm{BD} \\
\qquad \begin{array}{c}\text { EPA }=-0.90+9.53 \mathrm{~A}-0.14 \mathrm{~B}-0.79 \mathrm{AA} \\
\text { DHA }=-1.19+8.10 \mathrm{~A}+0.17 \mathrm{~B}-0.19 \mathrm{AB} \\
\text { EPA }+\mathrm{DHA}=3.52+12.88 \mathrm{~A}-0.52 \mathrm{~B}\end{array}\end{array}$}} & \multicolumn{2}{|c|}{$0.72(1)$} \\
\hline & & & & & & & & & \multicolumn{2}{|c|}{$0.84(2)$} \\
\hline & & & & & & & & & \multicolumn{2}{|c|}{$0.81(3)$} \\
\hline & & & & & & & & & \multicolumn{2}{|c|}{$0.80(4)$} \\
\hline
\end{tabular}

\footnotetext{
${ }^{1}$ Central composite design: $2^{4}+$ star, which studies the effects of 4 factors in 28 runs based on the RSM. ${ }^{*}$ Independent variables: A (urea/FA content ratio, $w / w), \mathrm{B}$ (crystallization temperature, ${ }^{\circ} \mathrm{C}$ ), $\mathrm{C}$ (crystallization time, $\mathrm{h}$ ), and $\mathrm{D}$ (stirring speed, rpm). ${ }^{* *}$ Response variables: $R_{1}$ (total FA yield, $g$ FA in the non-urea complexing fraction/100 $\mathrm{g}$ initial saponified oil FA), $R_{2}$ (EPA content, $g / 100 \mathrm{~g}$ total FA), and $R_{3}$ (DHA content, $\mathrm{g} / 100 \mathrm{~g}$ total FA). Predicted response variables: $R_{1}{ }^{\prime}, R_{2}{ }^{\prime}$, and $R_{3}{ }^{\prime}$.
}

\subsubsection{Effect of Process Variables on EPA, DHA, and EPA+DHA Content and Total FA Yield:}

Pareto Charts and RSM Analysis

Pareto charts (Figure 1) were obtained for the different dependent variables as a function of the concentrate processing variables from RCSO; furthermore, the linear, quadratic, and interaction terms in the second-order polynomial were used to generate a three-dimensional response surface graph. Panel (A) indicates that the total FA yield (R1) of concentrates was dependent $(p<0.05)$ on the linear terms of the urea:FA content ratio (A), crystallization temperature (B), crystallization time $(C)$, stirring speed $(D)$, the quadratic terms $A A$ and $B B$, and the interactions terms $A D, B D, B C$, and AC. Figure 1 (Panel B) shows the response surface of the urea complexation process for the total FA yield. The total FA yield decreased when the urea:FA content ratio increased and the crystallization temperature decreased. A similar result was found for the total FA yield effect in concentrate obtained from a by-product of rainbow trout processing where the total FA yield presented a minimum value in the response surface analysis when considering high urea:FA content ratios, at low crystallization temperature levels and stirring speeds, and at intermediate levels of crystallization time [17]. In the case of the EPA content (Figure 1, Panel C), the Pareto charts showed that certain linear terms-the urea:FA content ratio (A), crystallization temperature (B), and the quadratic urea:FA content ratio (AA) - provided a significant effect $(p<0.05)$. However, linear terms such as the crystallization time (C) and stirring speed (D) did not produce significant changes $(p>0.05)$. Figure 1 (Panel D) exhibits the response surface of the urea complexation process for EPA content. It was found that the EPA content increased with the urea:FA content ratio while it decreased as the crystallization temperature increased. For the DHA content (Figure 1, Panel E), the Pareto charts reported that the linear terms of the urea:FA content ratio (A), crystallization temperature (B), and the interaction between the urea:FA content ratio and the crystallization temperature $(\mathrm{AB})$ revealed a significant effect $(p<0.05)$. The DHA content increased when the urea:FA content ratio increased, while it decreased as the crystallization temperature increased (Figure 1, Panel F). Finally, concerning the EPA+DHA 
content, the urea:FA content ratio showed a positive effect, whereas the crystallization temperature had a negative effect $(p<0.05)$ (Figure 1, Panel G). These results agree with those obtained by authors concerning the employment of the Asian catfish (Pangasius bocourti) and by-product of rainbow trout oil, which reported an inverse relationship between the urea:FA content ratio and the crystallization temperature on the urea concentrate process [16,17]. When the urea:FA content ratio increased and the crystallization temperature decreased as result, high values were obtained for DHA in the non-urea complexing fraction, as well as a great retention of saturated and monounsaturated FA in the urea crystal adducts. In this case, similar results for the EPA content were found. In all the cases, the EPA, DHA, and EPA+DHA contents did not significantly varied depending on the stirring speed $(p>0.05)$.

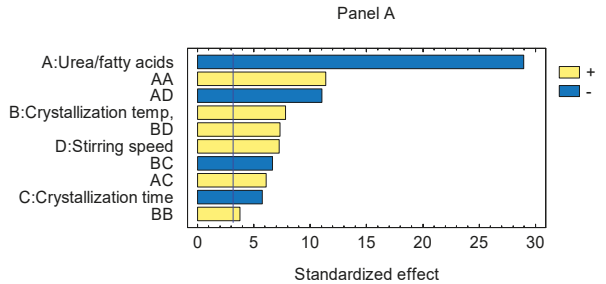

(A)

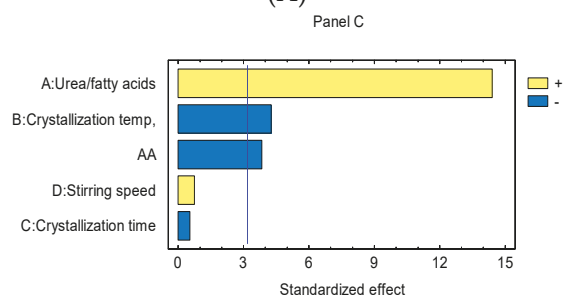

(C)

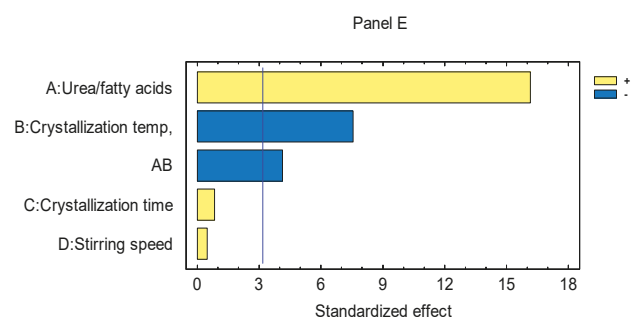

(E)

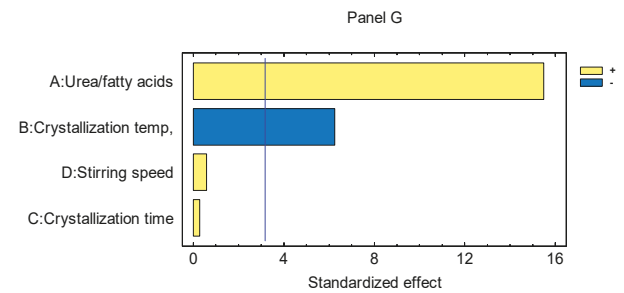

(G)

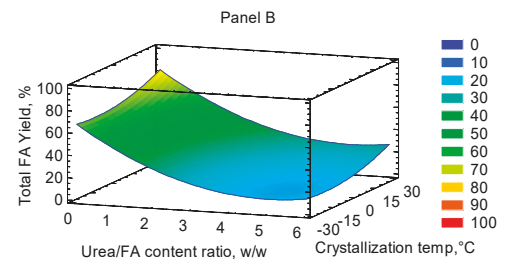

(B)

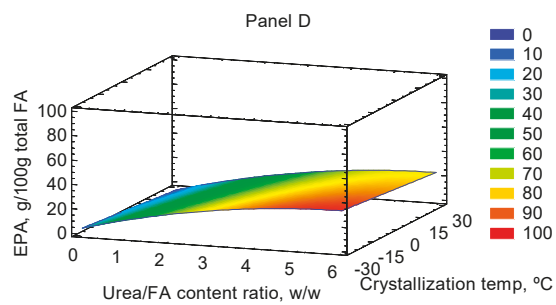

(D)

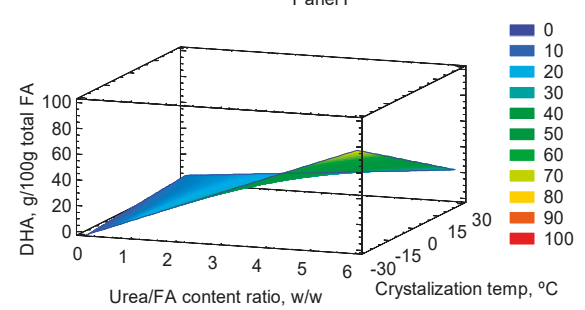

(F)

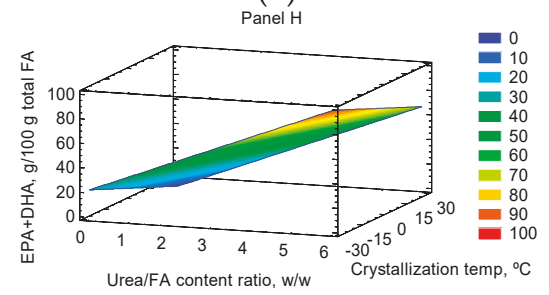

(H)

Figure 1. Pareto charts and response surfaces for the effects of different process variables: Panels in total FA yield (\%, panels A,B), EPA content ( $\mathrm{g} / 100 \mathrm{~g}$ total FA, panels C,D), DHA content ( $\mathrm{g} / 100 \mathrm{~g}$ total FA, panels E,F), EPA+DHA content (g/100 g total FA, panels $\mathbf{G}, \mathbf{H})$. A: urea/FA contents ratio, $w / w$; B: crystallization temperature, ${ }^{\circ} \mathrm{C}$; C: crystallization time, $\mathrm{h}$; and $\mathrm{D}$ : stirring speed, rpm). 


\subsubsection{Models Obtained for the Concentration of EPA, DHA, and EPA+DHA}

Equations obtained for the experimental process variables of the response surface model calculated by multiple regression are shown in Table 2. According to the equations obtained, all the response variables were found to be dependent on the same process variables expressed in the Pareto analysis (Figure 1). The four RCSO concentrated models had an adjusted $\mathrm{R}^{2}$ by degrees of freedom of $72.0 \%$ for total FA yield (Equation (1)), 84.0\% for EPA (Equation (2)), 81.0\% for DHA (Equation (3)), and 80.0\% for EPA+DHA (Equation (4)). Such values reported that the models adequately represented the variability of the results. Since the $p$-values obtained for lack-of-fit in the ANOVA study $(0.014,0.35$, 0.19, 0.28; Equation (1) to Equation (4), respectively) was greater or equal to 0.05, except for Equation (1), the model appears to be adequate for the observed data at the $95.0 \%$ confidence level.

\subsubsection{Independent Variables and Multiple Response Optimization}

Table 3 (part a) shows the optimization of the independent variables for the response variables (EPA, DHA, and EPA+DHA) of the urea complexation process. The optimum values of dependent variables for EPA, DHA, and EPA+DHA content were 33.01, 76.81, and 98.85 (g/100 g total FA), respectively. In all the cases, a tendency toward the same values for the urea:FA content ratio and crystallization temperature was observed, so that the optimum EPA, DHA, and EPA+DHA contents were obtained.

Table 3. Process variables * optimization and multiple response optimization of the response variables.

\begin{tabular}{|c|c|c|c|c|c|c|}
\hline \multicolumn{7}{|c|}{ Part a) Optimization of the Process Variables } \\
\hline Dependent Variables & \multicolumn{4}{|c|}{ Process Variables } & \multirow{2}{*}{$\begin{array}{l}\text { Stationary } \\
\text { Point }\end{array}$} & \multirow{2}{*}{$\begin{array}{l}\text { Optimum } \\
\text { Value }\end{array}$} \\
\hline & $\mathrm{A}$ & B & $\mathrm{C}$ & $\mathrm{D}$ & & \\
\hline EPA & 5.99 & -29.79 & 3.05 & 599.00 & Maximum & 33.01 \\
\hline DHA & 6.00 & -29.98 & 48.05 & 108.30 & Maximum & 76.81 \\
\hline $\mathrm{EPA}+\mathrm{DHA}$ & 6.00 & -29.95 & 47.79 & 271.36 & Maximum & 98.85 \\
\hline \multicolumn{7}{|c|}{ Part b) Multiple Response Optimization of the Response Variables } \\
\hline Dependent Variables & \multicolumn{4}{|c|}{ Process Variables } & $\begin{array}{c}\text { Stationary } \\
\text { Point }\end{array}$ & $\begin{array}{l}\text { Predicted } \\
\text { Value }\end{array}$ \\
\hline & A & B & C & $\mathrm{D}$ & & \\
\hline EPA & & & & & & $30.71-$ \\
\hline DHA & 5.84 & -17.69 & 14.83 & 453.36 & Maximum & 62.94 \\
\hline $\mathrm{EPA}+\mathrm{DHA}$ & & & & & & 90.07 \\
\hline Maximum desirability & & & & & & 1.0 \\
\hline \multicolumn{7}{|c|}{ Part c) Experimental Validation of the Multiple Response Optimization of the Dependent Variables } \\
\hline Dependent Variables & \multicolumn{4}{|c|}{ Process Variables } & $\begin{array}{c}\text { Stationary } \\
\text { Point }\end{array}$ & $\begin{array}{l}\text { Experimental } \\
\text { Value }\end{array}$ \\
\hline & A & B & C & $\mathrm{D}$ & & \\
\hline EPA & & & & & & 31.20 \\
\hline DHA & 6.00 & -18 & 14.80 & 500 & Maximum & 49.31 \\
\hline $\mathrm{EPA}+\mathrm{DHA}$ & & & & & & 80.51 \\
\hline
\end{tabular}

* Process variables (A, B, C, and D) as expressed in Table 2. ** Values expressed as $\mathrm{g} / 100 \mathrm{~g}$ total FA.

Table $3 b$ shows the levels of factors that maximized the EPA, DHA, and EPA+DHA contents ( $\mathrm{g} / 100 \mathrm{~g}$ total FA) by means of multiple response optimization and the stationary point that predicted a maximum of 30.71, 62.94, and 90.07 (g/100 g total FA) in EPA, DHA, and EPA+DHA, respectively. Maximum desirability score of 1 (range, $0-1$ ) was attained. A maximum predicted value could be obtained, provided that the following process conditions were applied: 5.84 (urea: FA content ratio), $-17.69^{\circ} \mathrm{C}$ (crystallization temperature), $14.83 \mathrm{~h}$ (crystallization time), and $453.00 \mathrm{rpm}$ (stirring speed). 
Figure 2 (panels A, B) shows the contours and estimated response surface of the urea:FA content ratio and crystallization temperature of the combination of factors levels to maximize the desirability function for RCSO concentrate. It is observed that the highest desirability values were reached by taking into account the high values of the urea:FA content ratio and the low crystallization temperature values. These results were similar to those previously reported for rainbow trout belly oil [17], where a maximum desirability score of 0.91 was obtained in the multiple response optimization of EPA, DHA and EPA+DHA contents. Furthermore, the predictive values of 32.50, 37.00, and 67.70 (g/100 g total FA) in the by-product concentrate of rainbow trout oil, respectively, were obtained. As a result, the following process conditions were applied in such study: 4.21 (urea:FA contents ratio), $-15.00{ }^{\circ} \mathrm{C}$ (crystallization temperature), $24.0 \mathrm{~h}$ (crystallization time), and $1000 \mathrm{rpm}$ (stirring speed).

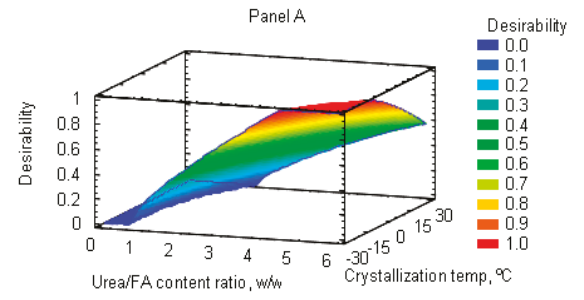

(A)

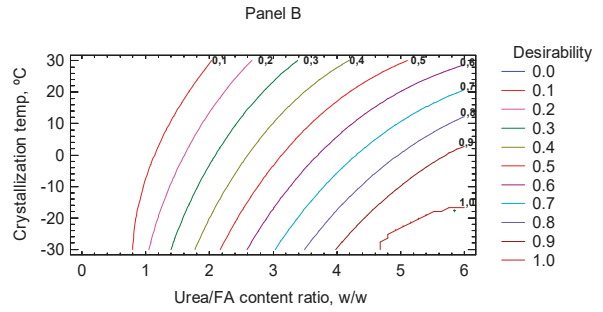

(B)

Figure 2. Combination of factors to maximize the desirability function for RCSO concentrate: response surface $(\mathbf{A})$ and contour surface $(\mathbf{B})$.

2.2.5. Validation of the Optimized Process and Characterization of the EPA+DHA Content Obtained

Table $3 \mathrm{c}$ shows the validation of multiple response optimization after experimentally performing the process conditions. For EPA content, comparison of the predicted value and the value obtained experimentally showed that both values were similar (i.e., 30.71 and $31.20 \mathrm{~g} / 100 \mathrm{~g}$ total FA, respectively); however, the experimental value of DHA content was substantially different from the predictive value (49.31 and $62.94 \mathrm{~g} / 100 \mathrm{~g}$ total FA, respectively). Experimental values performed on rainbow trout belly oil [17] were shown to be similar to the predicted values obtained in the current study for EPA and DHA (36.10 and $47.70 \mathrm{~g} / 100 \mathrm{~g}$ of total FA, respectively). In the experimental validation, an $80.51 \mathrm{~g} / 100 \mathrm{~g}$ total FA value was obtained for the EPA+DHA content, which agrees with the value revealed by other authors who obtained a stationary point of $89.38 \%$ for the EPA+DHA content [14].

\subsection{Composition of FA in the RCSO Optimized Concentrate after Validation}

Table 1 shows the FA composition of the RCSO compared to the composition of FA from the validated optimum concentrate. Optimization process validation was performed experimentally by combining the factors levels in which the optimal EPA+DHA content was attained (Table 3b,c). In these experiments, the effect of the urea complexation process on the composition of FA and FA groups in the optimized concentrate ( $\mathrm{g} / 100 \mathrm{~g}$ FA) after validation can be observed. When compared to the initial RCSO, there was a marked increase in the concentration of total PUFAs (96.99\%) and a substantial decrease in the concentration of SFAs (0.59\%) and MUFAs (2.42\%). Furthermore, the predominant FAs in the optimum concentrate oil were EPA, DHA, and EPA+DHA $(31.20,49.31$, and 80.51 g/100 g total FA, respectively). The urea complexation under the optimization process conditions has revealed a high efficiency, since a marked increase of total PUFAs from 38.24 to $96.99 \mathrm{~g} / 100 \mathrm{~g}$ total FA could be observed; this increase was 1.21 times higher than that reported by Pando et al. [18]. Additionally, the total $\mathrm{EPA}+\mathrm{DHA}$ final content was 2.5 times higher than that reported for refined salmon oil concentrate without the optimization process [18]. 


\section{Discussion}

In the present research, the distribution of SFAs in RSCO showed that this FA group was mainly composed of palmitic, stearic, and myristic acids. Similar values have been established for the SFAs group from crude commercial salmon oil [18]; interestingly, refined commercial salmon oil and Asian catfish oil also showed these three FA as the major ones, but a higher presence of stearic acid compared with myristic acid was detected in our study $[16,18]$. Among the MUFAs, the most abundant in the present study were 18:19c, 16:1 9c, 18:1 11c, and 20:111c. The total n-3 long chain polyunsaturated fatty acids ( $n-3$ PUFAs) content was 1.14 times higher than the content of total $n-6$ PUFAs, showing values higher than those previously reported in different kinds of oils obtained crude commercial salmon, and rainbow trout (Oncorhynchus mykiss) [18,20]. The analysis of process variables shows a high recovery performance of RCSO concentrate when the urea:FA content ratio has the lowest value, and the value considered for the crystallization temperature is the highest. The results show a higher content of EPA and DHA when the total FA yield is lower, indicating that this experiment eliminated most of the SFAs and MUFAs from the starting oil, only leaving a small fraction of such acids in the urea non-complexed fraction. Similar values have been observed by other authors [17,21], who reported major yields with higher stirring speed, corroborating a significant effect of the stirring speed on the total FA yield in the urea complexation process $(p<0.05)$. Current results show an inverse relationship between the urea:FA content ratio and the crystallization temperature on the DHA content, which is a conclusion that has already been than those reported by several authors, whose employed different oils from marine origin such as seal blubber oil, tuna oil, Asian catfish oil, and a by-product of rainbow trout $[13,14,16,17]$. In this case, results similar for EPA content were found. As an explanation for this, it could be argued that the urea:FA content ratio has a significant positive effect $(p<0.05)$ on the concentration of EPA and DHA, probably as a result of increasing the concentration of urea with respect to that of FFA; consequently, this would lead to an increase of the number of adducts formed between the flat structures of SFA and urea molecules, this favoring the formation of hexagonal complexes and crystals [13], and leading to an increased concentration of EPA and DHA in the non-urea complexing solution. Previous studies on tuna oil concentrates have revealed that the regression models for total FA yield and total EPA+DHA content were highly significant with satisfactory $\mathrm{R}^{2}$ coefficients $[14,22]$. The present data proved that the urea complexation under the optimization process conditions has shown to be highly efficient, since an increase in the total PUFAs content from 38.24 to $96.99 \mathrm{~g} / 100 \mathrm{~g}$ total FA could be reached, which was 1.2 times higher than that reported by Pando et al. [18]. Additionally, the total EPA+DHA final content was 2.5 times higher than that reported for refined salmon oil concentrate without applying an optimization process [18]. On the other hand, the oxidative and hydrolytic stability parameters (PV, pAV, TOTOX, and FFA) indicate that the quality of the oil used in this study was included within the acceptable quality limits for edible fats and oils of marine origin according to the Chilean Food Sanitary Regulations. Government institutions and trade associations, such as the Council for Responsible Nutrition (CRN) and the Global Organization for EPA and DHA Omega-3s (GOED), have set strict guidelines for marine oil quality and safety parameters. According to the previously described recommended values $[23,24]$, the starting RCSO can be considered included in the $98 \%$ of fish oil products compliant with the PV limit of 10 meq. active oxygen $\mathrm{kg}^{-1}$ oil set by British Pharmacopeia Fish Oil Type I, European Union (EU) Pharmacopeia Fish Oil Type I, and Australian government guidelines. Furthermore, salmon oil samples were compliant with the pAV limit of 15 set by British and EU Pharmacopeia Fish Oil Type II, as well as the pAV limit of 20 set by the GOED, Canada Natural Health Product Directorate (NHP), United States Pharmacopeia, and Codex Alimentarius Commission, Food and Agriculture Organization of the United Nations (CODEX/FAO). Thus, the primary and secondary lipid oxidation levels of RCSO are not exceeding the regulatory thresholds in the testing peroxide values and p-anisidine values. Interestingly, such lipid oxidation scores can be considered similar to those previously obtained for refined salmon oil samples [18] and salmon oil [24]. On the other hand, the FA composition of the RCSO showed that most abundant FAs were C18:1 9c, 18:2 9c, 12c, and C16:0, followed by EPA and DHA. The value of the total SFAs was 
found to be $21.28 \%$ in RCSO. Concerning PUFAs, the most abundant in RCSO concentrates were DHA, EPA, and 18:2 9c, 12c.

\section{Materials and Methods}

\subsection{Materials and Chemicals}

Refined commercial salmon oil was provided by Fiordo Austral S.A. (Puerto Montt, Chile). Fatty acid methyl ester (FAME) standards, fatty acid (FA) standards, and C23:0-methyl ester (2COT N-23M-A29-4 NU-CHECK-PREP-INC) were obtained from NU-CHECK-PREP, INC (Elysian, MN, USA). All the solvents and chemicals used (including urea, ethanol, $\alpha$-tocopherol, and $n$-hexane) were of analytical grade (Merck, Santiago, Chile).

\subsection{Characterization of Refined Commercial Salmon Oil}

Initial RCSO characterization was carried out by chemical analyses. For it, the following standard Association of Official Analytical Chemists (AOAC) and official methods [25] were carried out: peroxide value (PV; method Cd 8b-90:1-2), p-anisidine value (pAV; method Cd 18-19:1-2), and total oxidation value (TOTOX; method Cg 3-91) and free fatty acids (FFA) contents (method Ca 5a-40:1).

\subsection{FA Composition of the RCSO and n-3 LCPUFA Concentrates}

For analyzing the FA composition of the RCSO and the different LCPUFA concentrates, a methylation process was performed to obtain FAMEs. For it, a two-step process was performed, according to previous research $[18,26]$. FAME analysis was carried out on an HP 5890 series II GLC with a flame ionization detector (FID) with the injection system split. A fused silica capillary column (100 m length $\times 0.25 \mathrm{~mm} \times 0.2 \mu \mathrm{m}$ film thickness) coated with SPTM-2560 (Supelco, Bellefonte, PA, USA) was used [18,26-29]. DataApex ClarityTM software (DataApex Ltd., Prague, Czech Republic) for chromatogram analysis was applied. The reference standard NU-CHEK GLC463 was used to identify the FA profiles. The concentration of the different FAME was determined from the calibration curves by assessment of the peak/area ratio. The quantification of all the individual FAs ( $\mathrm{g} / 100 \mathrm{~g}$ total FA) was achieved by employing C23:0 methyl ester as the internal standard according to the (AOCS Official Method (Ce 1j-7, 2009) [26].

\section{4. n-3 LCPUFA Concentrates from RCSO}

The procedure included salmon oil saponification, which was in agreement with other authors $[17,18,30]$. Concentrate from RCSO was prepared by FFA collection, the formation of urea FFA inclusion complexes, and the extraction of free n-3 LCPUFA. For it, the urea complexation method was carried out by 28 experimental runs with different urea:FA content ratios (0 to $6 w / w)$, crystallization temperatures $\left(-30\right.$ to $\left.30^{\circ} \mathrm{C}\right)$, crystallization times $(0$ to $48 \mathrm{~h})$, and stirring speeds $(0$ to $800 \mathrm{rpm})$. The FFAs were mixed with urea and $95 \%$ ethanol, and the mixture was subsequently stirred and heated at $60{ }^{\circ} \mathrm{C}$ with magnetic stirring. Then, it was cooled with constant stirring to different conditions of temperature and time as described in the experimental design. The crystals formed were separated from the liquid phase by filtration with a Whatman No.1 paper. The non-urea complexing fraction was diluted with $100 \mathrm{~mL}$ of distilled water by each $10 \mathrm{~g}$, acidified to $\mathrm{pH} 4.5$ with $6 \mathrm{~N} \mathrm{HCl}$, and washed in a separating funnel with hexane $(400 \mathrm{~mL})$. The hexane phase was filtered with anhydrous sodium sulfate in a Whatman No.1 paper, and the solvent was partially removed using a rotatory evaporator at $40^{\circ} \mathrm{C}$ under vacuum $[16,17]$. The resulting $\mathrm{n}-3 \mathrm{LCPUFA}$ concentrates were stored at $-80{ }^{\circ} \mathrm{C}$ with $0.5 \%$ of $\alpha$-tocopherol under nitrogen atmosphere until use for further analysis.

\subsection{Experimental Design and Optimization Procedure}

A rotational central composite design $2^{4}+$ star, with 4 factors and 5 levels, was carried out, with 28 experimental runs that included 4 repetitions of the central point based on the RSM. The following 
conditions for the independent variables were considered (Table 1): urea:FA content ratio (variable A: 0 to $6 w / w)$, crystallization temperature (variable B: -30 to $30^{\circ} \mathrm{C}$ ), crystallization time (variable C: 3.05 to $48.0 \mathrm{~h}$ ), and stirring speed (variable D: 0 to $800 \mathrm{rpm}$ ). On the basis of the non-urea complexing fraction, the following response variables ( $\mathrm{R}$ variables) of the experiment design were chosen: total FA yield (variable R1: $g$ FA in the non-urea complexing fraction/100 $g$ initial RCSO), EPA content (variable R2: $\mathrm{g} / 100 \mathrm{~g}$ total FA in concentrate), and DHA content (variable R3: $\mathrm{g} / 100 \mathrm{~g}$ total FA in concentrate). Four replicates were carried out at the central point of the experimental design in order to evaluate the experimental error. All experiments were performed randomly to minimize the effect of unexplained variability in responses resulting from extraneous factors [31]. In order to obtain response surfaces, multiple regression equations were fitted to the responses obtained by discarding non-significant terms $(p>0.05)$ to obtain response surfaces. To maximize the desirability function a multiple response optimization was performed to optimize several responses simultaneously, which maximized the desirability function scores that ranged between 0 and 1 [32]. The RSM was used to optimize and maximize the response variables, and a quadratic polynomial regression model was assumed for predicting individual $\mathrm{Y}$ variables. The model proposed for each $\mathrm{Y}$ value was as according to Equation (5):

$$
Y_{i}=\beta_{0}+\sum_{i=1}^{4} \beta_{i} X_{i}+\sum_{i=1}^{4} \beta_{i i} X_{i}^{2}+\sum_{i=1}^{3} \sum_{j=i+1}^{4} \beta_{i j} X_{i} X_{j}+\varepsilon,
$$

where $\beta_{0}, \beta_{i}$, and $\beta_{i i}$ represent the intercept, linear, and quadratic coefficients, respectively; $\beta_{\mathrm{ij}}$ corresponds to the interaction coefficient terms for the interaction of variables $i$ and $j ; X_{i}$ represents the independent variables; and $\varepsilon$ denotes to the random error $[31,32]$.

\subsection{Statistical Analysis}

Multiple regression analysis, ANOVA. canonical, and ridge maximum of data in the response surface regression (RSREG) procedure was used. The estimated response surface and contours of the estimated response surface were developed using the fitted quadratic polynomial equations obtained from the response surface regression (RSREG) analysis, holding the independent variables with the least effect on the response at a constant value and changing the levels of the other two variables [31,32]. A multiple-response optimization was performed to assess the combination of experimental factors that simultaneously optimize several responses; as a result, maximization of the desirability function was obtained, this function ranging from 0 to 1 [32]. Analyses were performed in triplicate considering the standard deviation of each sample. The lack-of-fit test was carried out by comparison of the variability of the current model residuals with the variability between observations at replicate settings of the factors [31,32]. Statgraphics Centurion XV.II (Manugistics Inc., Rockville, USA) was used.

\section{Conclusions}

The physical-chemical analyses of refined commercial salmon oil indicate that it is a good quality raw material that complies with the characteristics that are typical of oils of marine origin. A high concentration of EPA and DHA was obtained from RCSO, achieving an increase of up to 4.1 and 7.9 times in the concentrate, with values of 31.20 and $49.31 \mathrm{~g} / 100 \mathrm{~g}$ total FA, respectively. Interestingly a 5.8-time increase was observed for the EPA+DHA content, from 13.78 to $80.51 \mathrm{~g} / 100 \mathrm{~g}$ total FA. Therefore, it has been proved that it is possible to maximize the EPA and/or DHA content by the optimization of the variables in the urea inclusion process. The results of this study could serve as a basis for the food and nutraceutical industry, whose processes with clean technologies can develop new functional foods enriched with EPA and DHA. Furthermore, the consumption of such new functional foods would be likely to produce a positive and profitable impact on the health of a wide range of consumers such as pregnant women, infants, and older adults in general. 
Author Contributions: Conceptualization, A.R., J.O.-V., S.P.A., and M.T.; methodology, E.C., A.R., M.M., and A.E.; data curation, M.M. and A.R.; writing —original draft preparation, A.R., G.D.-R., and J.O.-V.; writing-review and editing, A.R., J.O.-V., A.E., and G.D.-R.

Funding: This research was funded by the FONDECYT program (Government of Chile) throughout, grant number 1181774 .

Conflicts of Interest: The authors declare no conflict of interest.

\section{References}

1. Food and Agriculture Organization/World Health Organization (FAO/WHO). Fats and Fatty Acids in Human Nutrition; Report of an Expert Consultation; FAO/WHO: Rome, Italy, 2010; 166p, ISBN 978-92-5-106733-8.

2. Schuncka, W.; Konkelb, A.; Fischerb, R.; Weylandtc, K. Therapeutic potential of omega-3 fatty acid-derived epoxyeicosanoids in cardiovascular and inflammatory diseases. Pharm. Therap. 2018, 183, 177-204. [CrossRef] [PubMed]

3. Siscovick, D.S.; Barringer, T.A.; Fretts, A.M.; Wu, J.H.Y.; Lichtenstein, A.H.; Costello, R.B.; Kris-Etherton, P.M.; Jacobson, T.A.; Engler, M.B.; Alger, H.M.; et al. Omega-3 polyunsaturated fatty acid (fish oil) supplementation and the prevention of clinical cardiovascular disease: A science advisory from the American Heart Association. American Heart Association Nutrition Committee of the Council on Lifestyle and Cardiometabolic Health; Council on Epidemiology and Prevention; Council on Cardiovascular Disease in the Young; Council on Cardiovascular and Stroke Nursing and Council on Clinical Cardiology. Circulation 2017, 135, e867-e884.

4. Weylandt, K.; Schmöcker, C.; Ostermann, A.; Kutzner, L.; Willenberg, I.; Kiesler, S.; Steinhagen-Thiessen, E.; Schebb, N.; Kassner, U. Activation of lipid mediator formation due to lipoprotein apheresis. Nutrients 2019, 11, 363. [CrossRef]

5. Swanson, S.; Block, R.; Mousa, S.A. Omega-3 fatty acids EPA and DHA: Health benefits throughout life. Adv. Nutr. 2012, 3, 1-7. [CrossRef]

6. Haast, R.; Kiliaan, A. Impact of fatty acids on brain circulation, structure and function. Prost. Leuk. Ess. Fatty Ac. J. 2015, 92, 3-14. [CrossRef] [PubMed]

7. Minihane, A.; Armah, C.; Miles, E.; Madden, J.; Clark, A.; Caslake, M.; Calder, P. Consumption of fish oil providing amounts of eicosapentaenoic acid and docosahexaenoic acid that can be obtained from the diet reduces blood pressure in adults with systolic hypertension: A retrospective analysis. J. Nut. 2016, 146, 516-523. [CrossRef]

8. WHO. World Health Statistics: Monitoring health for the SDGs, Sustainable Development Goals; WHO: Geneva, Switzerland, 2016.

9. Ofosu, F.K.; Daliri, E.B.M.; Lee, B.H.; Yu, X. Current trends and future perspectives on omega-3 fatty acids. Res. J. Biol. 2017, 5, 11-20.

10. Zanoaga, O.; Jurj, A.; Raduly, L.; Cojocneanu-Petric, R.; Fuentes-Mattei, E.; Wu, O.; Braicu, C.; Gherman, C.D.; Berindan-Neagoe, I. Implications of dietary $\omega-3$ and $\omega-6$ polyunsaturated fatty acids in breast cancer (Review). Experim. Therap. Med. 2018, 15, 1167-1176. [CrossRef]

11. Rubio-Rodríguez, N.; Beltrán, S.; Jaime, I.; De Diego, S.M.; Sanz, M.T.; Rovira, J. Production of omega-3 polyunsaturated fatty acid concentrates: A review. Innov. Food Sci. Em. Technol. 2010, 11, 1-12. [CrossRef]

12. Haq, M.; Getachew, A.T.; Saravana, P.S.; Cho, Y.J.; Park, S.K.; Kim, M.J.; Chun, B.-S. Effects of process parameters on EPA and DHA concentrate production from Atlantic salmon by-product oil: Optimization and characterization. Kor. J. Chem. Eng. 2016, 34, 2255-2264. [CrossRef]

13. Wanasundara, U.; Shahidi, F. Concentration of omega 3- polyunsaturated fatty acids of seal blubber oil by urea complexation: Optimization of reaction conditions. Food Chem. 1999, 65, 41-49. [CrossRef]

14. Liu, S.; Zhang, C.; Hong, P.; Ji, H. Concentration of docosahexaenoic acid (DHA) and eicosapentaenoic acid (EPA) of tuna oil by urea complexation: Optimization of process parameters. J. Food Eng. 2006, 73, 203-209. [CrossRef]

15. Patil, D. Recent trends in production of polyunsaturated fatty acids (PUFA) Concentrates. J. Food Res Technol. 2014, 2, 15-23.

16. Thammapat, P.; Siriamornpun, S.; Raviyan, P. Concentration of eicosapentaenoic acid (EPA) and docosahexaenoic acid (DHA) of Asian catfish oil by urea complexation: Optimization of reaction conditions. J. Sci. Technol. 2016, 38, 163-170. 
17. Pando, M.; Rodríguez, A.; Galdames, A.; Berríos, M.M.; Rivera, M.; Romero, N.; Valenzuela, M.A.; Ortiz, J.; Aubourg, S.P. Maximization of the docosahexaenoic and eicosapentaenoic acids content in concentrates obtained from a by-product of rainbow trout (Oncorhynchus mykiss) processing. Eur. Food Res. Technol. 2018, 244, 937-948. [CrossRef]

18. Pando, M.; Bravo, B.; Berríos, M.M.; Galdames, A.; Rojas, C.; Romero, N.; Camilo, C.; Rodriguez, A.; Aubourg, S.P. Concentrating $n-3$ fatty acids from crude and refined commercial salmon oil. Czech J. Food Sci. 2014, 32, 169-176. [CrossRef]

19. Roca-Saavedra, P.; Mariño-Lorenzo, P.; Miranda, J.M.; Porto-Arias, J.J.; Lamas, A.; Vazquez, B.I.; Franco, C.M.; Cepeda, A. Phytanic acid consumption and human health, risks, benefits and future trends: A review. Food Chem. 2017, 15, 237-247. [CrossRef]

20. Haliloğlu, H.I.; Bayır, A.; Sirkecioğlu, A.N.; Aras, N.M.; Atamanalp, P. Comparison of fatty acid composition in some tissues of rainbow trout (Oncorhynchus mykiss) living in seawater and freshwater. Food Chem. 2004, 86, 55-59. [CrossRef]

21. Guil-Guerrero, J.L.; Belarbi, H. Purification process for cod liver oil polyunsatured fatty acids. J. Am. Oil Chem. Soc. 2001, 78, 477-484. [CrossRef]

22. Fei, Ch.; Salimon, J.; Said, M. Optimization of Urea Complexation by Box-Behnken Design. Sains Malaysiana. 2010, 39, 795-803.

23. De Boer, A.; Ismail, A.; Marshall, K.; Bannenberg, G.; Yan, K.L.; Rowe, W.J. Examination of marine and vegetable oil oxidation data from a multi-year, third-party database. Food Chem. 2018, 254, 249-255. [CrossRef]

24. Méndez, C.; Masson, L.; Jiménez, P. Estabilización de aceite de pescado por medio de antioxidantes naturales. Aceites y Grasas 2010, 80, 492-500.

25. AOAC. Official Methods and Recommended Practices of the American Oil Chemists Society (edited by AOCS); AOAC: Champaign, IL, USA, 1993.

26. AOCS. Determination of Cis-, Trans-, Saturated, Monounsaturated, and Polyunsaturated Fatty Acids by Capillary Gas Liquid Chromatography (GLC). Official Method Ce 1j-7. Official Methods and Recommended Practices of the American Oil Chemists Society (edited by AOCS); AOCS: Champaign, IL, USA, 2009.

27. Tran, Q.T.; Le, T.T.T.; Pham, M.Q.; Do, T.L.; Vu, M.H.; Nguyen, D.C.; Bach, L.G.; Bui, L.M.; Pham, Q.L. Fatty acid, lipid classes and phospholipid molecular species composition of the marine Clam Meretrix lyrata (Sowerby) from Cua Lo Beach, Nghe An Province, Vietnam. Molecules 2019, 24, 895. [CrossRef]

28. Kieliszek, M.; Błażejak, S.; Bzducha-Wróbel, A.; Kot, A.M. Effect of selenium on lipid and amino acid metabolism in yeast cells. Biol. Trace Elem. Res. 2019, 187, 316-327. [CrossRef]

29. Berríos, M.; Rodríguez, A.; Rivera, M.; Pando, M.; Valenzuela, M.A.; Aubourg, S.P. Optimization of rancidity stability in long-chain PUFA concentrates obtained from a rainbow trout (Oncorhynchus mykiss) by-product. Int. J. Food Sci. Technol. 2017, 52, 1463-1472. [CrossRef]

30. Zuta, C.P.; Simpson, B.K.; Chan, H.M.; Phillips, L. Concentrating PUFA from Mackerel Processing Waste. J. AOCS. 2003, 80, 933-936. [CrossRef]

31. Myers, R.H.; Montgomery, D.C. Response Surface Methodology: Process and Product Optimization Using Design Experiments; John Wiley \& Sons, Inc.: New York, NY, USA, 1995.

32. Derringer, G.; Suich, R. Simultaneous Optimization of Several Response Variables. J. Qual. Technol. 1980, 12, 214-219. [CrossRef]

Sample Availability: Samples of the compounds are not available from the authors.

(C) 2019 by the authors. Licensee MDPI, Basel, Switzerland. This article is an open access article distributed under the terms and conditions of the Creative Commons Attribution (CC BY) license (http://creativecommons.org/licenses/by/4.0/). 


\title{
Potential Use of Marine Seaweeds as Prebiotics: A Review
}

\author{
Aroa Lopez-Santamarina, Jose Manuel Miranda *, Alicia del Carmen Mondragon, \\ Alexandre Lamas, Alejandra Cardelle-Cobas, Carlos Manuel Franco and Alberto Cepeda \\ Laboratorio de Higiene Inspección y Control de Alimentos, Departamento de Química Analítica, Nutrición y \\ Bromatología, Universidade de Santiago de Compostela, 27002 Lugo, Spain; a_lo_san@hotmail.com (A.L.-S.); \\ aliciamondragon@yahoo.com (A.d.C.M.); alexandre.lamas@usc.es (A.L.); alejandra.cardelle@usc.es (A.C.-C.); \\ carlos.franco@usc.es (C.M.F.); alberto.cepeda@usc.es (A.C.) \\ * Correspondence: josemanuel.miranda@usc.es; Tel.: +34-982-252-231 (ext. 22407); Fax: +34-982-254-592
}

Academic Editors: Sylvia Colliec-Jouault and Jesus Simal-Gandara

Received: 16 December 2019; Accepted: 21 February 2020; Published: 24 February 2020

\begin{abstract}
Human gut microbiota plays an important role in several metabolic processes and human diseases. Various dietary factors, including complex carbohydrates, such as polysaccharides, provide abundant nutrients and substrates for microbial metabolism in the gut, affecting the members and their functionality. Nowadays, the main sources of complex carbohydrates destined for human consumption are terrestrial plants. However, fresh water is an increasingly scarce commodity and world agricultural productivity is in a persistent decline, thus demanding the exploration of other sources of complex carbohydrates. As an interesting option, marine seaweeds show rapid growth and do not require arable land, fresh water or fertilizers. The present review offers an objective perspective of the current knowledge surrounding the impacts of seaweeds and their derived polysaccharides on the human microbiome and the profound need for more in-depth investigations into this topic. Animal experiments and in vitro colonic-simulating trials investigating the effects of seaweed ingestion on human gut microbiota are discussed.
\end{abstract}

Keywords: prebiotic; polysaccharides; seaweed; Rhodophyceae; Phaeophyceae; Chlorophyceae

\section{Introduction}

Marine seaweeds have been consumed whole by East Asian populations for centuries, if not millennia, appearing in traditional recipe books in many countries [1]. Additionally, their human consumption in Western countries has been increasing in the latest decades because of their association with improved human health. Some benefits of their consumption include a lower incidence of cancers, decreased blood pressure and blood sugar, and antiviral, anti-inflammatory, immunomodulatory or neuroprotective activities [1,2]. A mechanistic link proposed to explain the prevention of such diseases by seaweed consumption implicates the presence of diverse health-promoting bioactive compounds in seaweeds, including sulphated polysaccharides, polyphenols, pigments (chlorophylls, fucoxanthins, phycobilins), carotenoids, omega-3 fatty acids or mycosporine-like amino acids $[1,3,4]$. In some cases, these compounds are not produced by terrestrial plants or are not consumed in adequate quantities as part of a typical Western diet.

Nowadays, with a continuously expanding world population, fresh water is an increasingly scarce commodity, and the world's desertification processes continue. About $45 \%$ of the world's land surface is considered drylands, while 12 million hectares of land are degraded yearly through lack of water and related processes [5]. According to the Food and Agriculture Organization of the United Nations [6], agricultural productivity is persistently declining at over $1 \%$ per year. It is thus reasonable to expect that in the next decades there will be a need for increasing algae production to replace or supplement 
the intake of plant foods of terrestrial origin. Seaweeds have numerous advantages over terrestrial plants, such as rapid growth rates, and they do not require arable land, fresh water or contaminating fertilizers [7]. Additionally, an increase in seaweed cultivation would provide environmental services as an added benefit [5].

Marine seaweeds constitute approximately 25,000-30,000 different species, with a great diversity of forms and sizes [8]. The taxonomic groups, which reflect their pigmentation, include red algae (Rhodophyceae), brown algae (Phaeophyceae) and green algae [8]. Although they are still produced on a very modest scale relative to global food production, their worldwide cultivation has increased rapidly in the last decades, reaching a current yearly production of about 29 million tonnes [8]. Asian countries dominate world production, with $99 \%$ of the total, while most other maritime countries produce little or none [5]. Polysaccharides account for the majority of seaweed biomass (up to $76 \%$ of dry weight in some species; [8] and together with oligosaccharides have been the key focus of many studies of seaweed-derived compounds. Phenolic compounds and proteins from seaweeds have also attracted interest as potential functional ingredients [8]. Besides their consumption as an entire food, seaweeds or their polysaccharides are considered valuable additives in the food industry because of their rheological properties as gelling and thickening agents [2]. Additionally, seaweeds were largely employed in the formulation of animal feed [9], as well as in the formulation of cosmetics, drugs and fertilizers [10].

Regarding specific benefits on human health, seaweeds have demonstrated to exert preventive effects against several non-transmissible diseases such as cardiovascular diseases [11,12], antihypertensive [13], anti-obesity effects [14] and anti-diabetic effects [15,16], anti-cancer [17,18] or antioxidant activities [19].

Regarding cardiovascular diseases, there are large contributing risk factors that overlap and intertwine, contributing overall to the onset and growth of the disease [11]. Between them, it can be cited a cascade of mechanisms including vascular inflammation, oxidative stress, hypercoagulability and activation of the sympathetic and renin-angiotensin systems. Although in some cases the exact mechanisms through seaweeds can prevent cardiovascular diseases are not always fully understood, it was demonstrated that seaweed consumption can prevent cardiovascular diseases [11,12]. Functional oligosaccharides from seaweeds are associated with a variety of biological processes linked to hypoglycaemic and hypolipidaemic activities, although the concrete mechanisms have not been well studied [15]. With respect to hypertension, various compounds from seaweeds, such as protein-derived bioactive peptides and phlorotannins, can prevent hypertension by inhibition of angiotensin-I converting enzyme activity [13].

The potential anti-obesity activity derived from seaweeds consumption may involve a large variety of mechanisms and alterations in lipid metabolism, suppression of inflammation, suppression of adipocyte differentiation and delay in gastric emptying [14]. Between then, an important anti-obesity activity of seaweeds is the inhibition of peroxisome proliferator-activated receptor $\gamma(\operatorname{PPAR} \gamma)$ expression and activation of the adenosine monophosphate-activated protein kinase (AMPK) phosphorylation [13]. Other important anti-obesity mechanism of seaweeds is related with inhibition of lipases, especially pancreatic lipase, that is one of the main therapeutic targets of anti-obesity drugs [14] and was recently demonstrated for various seaweeds species [20]. Additionally, anti-obesity mechanisms related with concrete seaweed components, such as phlorotannins, that target the inhibition of adipocyte differentiation or fucosterol, that decreases the expression of the adipocyte marker proteins PPAR $\gamma$ and CCAAT/enhancer-binding protein alpha were reported. Seaweeds can also prevent obesity by means of the modification of the relative quantities of phyla in the gut microbiota (GM), and polysaccharides from seaweeds can reduce obesity also by repairing the intestinal barrier and reducing inflammation [21].

Although abundant signaling pathways have been found to be involved in the process of glucose metabolism and anti-diabetic effects $[15,16]$, among them, the IRS1/PI3K/JNK/AKT/GLUT4 pathways are important mechanisms in insulin signal transduction. Some seaweed components were shown in animal models to ameliorate the hepatic insulin resistance by regulating the cited signaling pathways $[15,16,22]$. In addition, seaweeds significantly increased the abundance and diversity of gut 
microbiota in animal models and showed the ability to increase the population of beneficial microbiota and maintain the homeostasis of the GM $[15,22]$.

With respect to the antioxidant activity of seaweeds, this protective affects depends mainly on phlorotannins, secondary metabolites that exert their great antioxidant activity via the scavenging of reactive oxygen species [19]. Secondary metabolites of seaweeds are also responsible for the anti-cancer activity, whose includes different mechanisms such as repairing the intestinal barrier by intensifying the expression of the tight junction proteins via increasing the phosphorylation of MAPK and ERKT/2 genes [18], and activating the caspase cascades. Other potential mechanisms are reducing the expression of cyclin-dependent kinases and matrix metalloprotease family [17] and inducing decreased levels of pro-apoptotic metabolic signals [19].

\section{Polysaccharides from Marine Seaweeds}

Indigestible dietary polysaccharides attract attention as functional food ingredients with health benefits [7]. Most carbohydrates entering the colon are fermented in the proximal colon, which is considered a saccharolytic environment. As digesta moves through the distal colon, carbohydrate availability decreases, and proteins and amino acids become the main metabolic energy sources for bacteria in this region. The main end-products of saccharolytic fermentation are short chain fatty acids (SCFA), which contribute towards the host's daily energy requirements. On the contrary, the end-products of proteolytic fermentation include metabolites such as phenolic compounds, and nitrogenous ones like amines and ammonia, some of which are carcinogens. This means that the GM exerts a key contribution to the human energy balance and nutrition, by extending the host metabolic capacity to indigestible polysaccharides. In addition, intestinal microorganisms contribute to develop and maintain the host immune system, defending the host from colonization by opportunistic pathogens [2]. The effects of polysaccharides on the GM are generally evaluated by the contents of SCFAs, the composition and the abundance of beneficial intestinal bacteria [20].

Polysaccharides in today's human diet originate primarily from terrestrial plant cell walls, while other sources, such as seaweeds, are less represented [8]. Studies indicate that polysaccharides and oligosaccharides derived from seaweeds can modulate intestinal metabolism, including fermentation, inhibit pathogen adhesion and evasion, and potentially treat inflammatory bowel disease $[8,23]$. Some seaweed polysaccharides also demonstrate anticoagulant [24], antitumor [25], anti-inflammatory [26], antiviral, antihyperlipidemic [27] or antioxidant activity [28]. Other research has focused on their use as prebiotics to aid in limiting the occurrence of non-transmissible chronic diseases common in Western countries, such as obesity, diabetes, cardiovascular diseases or some types of cancer [2]. Nevertheless, many seaweed fibres are high-molecular-weight polymers that need to be transformed into oligosaccharides to increase their fermentability by the GM [2].

Depending on the taxonomic classification of algae, polysaccharides can vary greatly in their composition [8]. Seaweeds feature an integrated network of biopolymers in their cell walls, mainly formed by polysaccharides associated with other compounds, such as proteins, proteoglycans, polyphenols and some mineral elements, like calcium and potassium [8]. It is because of this complexity that for most seaweed polysaccharides, the exact structures, constituents and chemistry are not fully known [29]. Depending on the algal taxa, both structural and storage polysaccharides may vary. Structural polysaccharides are the most abundant, and their composition can be influenced by the seaweed species [29], as well as environmental factors, such as salinity, water temperature and sunlight intensity [30]. Some of the structural polysaccharides are carboxylated or sulphated, which can affect their fermentability [2].

Green seaweeds contain mostly sulphated structural polysaccharides, like ulvans (the most abundant, representing $8-29 \%$ of dry weight) and sulphated galactans, xylans and mannans. These polymers are composed mainly of rhamnose, xylose, glucose, glucuronic acid and sulphates, with smaller amounts of mannose, arabinose and galactose [31,32]. These polysaccharides are not fully fermented by the human GM [33,34]. Conversely, the main carbohydrate in storage is starch. 
Contrariwise, brown seaweeds contain mainly cellulose, alginic acids, fucoidans and sargassans as structural polysaccharides, while the storage polysaccharides are alginates [35] (the most abundant at $17-45 \%$ of dry weight), fucoidans and laminarins $[2,8,36]$. Finally, red seaweeds contain agars, carrageenans, xylans, sulphated galactans and porphyrins as main structural polysaccharides, while the main storage polysaccharide is starch [21,37].

Through a long time of co-evolution between GM and host, the intestinal microbes have evolved diverse strategies for degrading polysaccharides from terrestrial plants [38]. However, because the consumption of seaweeds polysaccharides was not common over human evolution, the human GM did not acquire the same efficacy to degrade seaweed polysaccharides. Thus, although humans possess the enzymes necessaries to degrade some algal polysaccharides, such as starches, they are unable to digest the most complex polysaccharides [2,38]. An elegant work carried out by Hehemann et al. [39], showed that specific genes coding for enzymes with potential capacity to degrade seaweed polysaccharides, as porphyranases or agarases, can be transferred from a member of marine Bacteroidetes, Zobellia galactanivorans to the GM bacterium Bacteroides plebeius in Japanese individuals. As a consequence, GM of those subjects acquires the ability to degrade porphyran and agarose, as compared to the GM from North American individuals, who are incapable of degrading it [39].

De Jesus Raposo et al. [40] suggested that most seaweed polysaccharides can be regarded as dietary fibre, as they are resistant to digestion by enzymes present in the human gastrointestinal tract, reaching the distal gut. In this allocation, polysaccharides are fermented and become food for the commensal bacteria, stimulating their growth. For this reason, great efforts have been placed on developing efficient methods for seaweed polysaccharides extraction, purification and structural characteristics elucidation in order to improve their bioavailability, especially for insoluble fibre [2].

It was previously shown that variations in the chemical structure of a prebiotic can impact its selective fermentation by bacteria [41]. For this reason, there were published large works regarding the investigation of the potential prebiotic effect of single polysaccharides, often contained in seaweeds, but employing pure standards [42-44]. However, it should be considered that seaweeds contain other components than also can affect GM. Consequently, trials employing whole seaweeds are required to investigate their real effect in human GM. Furthermore, although several works investigated the effects of seaweeds in livestock gut microbiota, they are more oriented to study the effects of seaweeds in animal production and welfare. An elegant review was recently published where they can be checked [32].

\section{Other Bioactive Compounds from Marine Seaweeds}

In addition to polysaccharides, seaweeds also contain other bioactive compounds, called secondary metabolites much of them with antioxidant activity [45]. Among these, polyoletides (such as phlorotannins), isoprenoids (such as terpenes, carotenoids and steroids), alkaloids and shkimates (such as flavonoids) are the main groups of secondary metabolites found in algae [46]. Compared with other macroalgae, red seaweeds are richer sources of these secondary metabolites [47]. The human health benefits afforded by these bioactive compounds include anti-inflammatory, antioxidant, anticoagulant, antiviral, antimicrobial, antidiabetic, antitumor, antihypertensive, antiallergic and immunomodulatory activities [45-48].

Exceptionally, phlorotannins or polyphenols are recognized as structural classes of polyketides, found primarily in brown algae. These compounds can also reach the large intestine where GM can convert them into beneficial bioactive metabolites. Phlorotannins are highly hydrophilic components formed by polymerization of monomeric units of phloroglucinol (1,3,5-trihydroxybenzene). There are six main groups: fucols, floretoles, fucofloretols, fuhalols, isofuhalols and eckols, and all display strong antioxidant properties and act against oxidative stress [46]. Certain polyphenols are used as prophylactics against problems such as cardiovascular diseases, cancers, arthritis and autoimmune disorders [47]. In addition, some phlorotannins have been shown to decrease blood glucose levels after carbohydrate-rich meals. This action is achieved by interfering with the enzymes amylase and sucrase that intervene in the digestion and assimilation of these carbohydrates. In addition to their 
effects on the metabolic functions of the host, phlorotannins also appear to have some antibacterial activities [47], which may explain the low production of AGCC derived from seaweeds in which they are an important part [7]. However, like other phenolic compounds, bacterial growth inhibition occurs selectively in microbial populations, including some pathogens, and its antibacterial effect is minor in commensal bacteria [7]. Because of this selective inhibition of bacterial pathogens, large whole seaweeds and seaweeds ethanolic extracts has been used to extend the shelf life of fresh fishery foods, such as Fucus spiralis [48,49], Bifurcaria bifurcata [50], Cytoseira compressa [51] or Gracilaria verrucosa [52] Another of its potentially therapeutic functions is that extracts with high phlorotannins content have demonstrated a potent inhibitory action on the growth of cancerous cell lines [53,54].

Bromophenols present in marine algae have attracted much attention in the field of antimicrobial agents [55]. Previous studies indicate that marine bromophenols possess promising antibacterial $[56,57]$ and antiviral activities [58]. In addition, symphyocladin $G$, a new bromophenol adduct derived from the red seaweed Symphyocladia latiuscula, is found to have antifungal activity against Candida albicans [59]. Several bromophenols isolated from the red alga Odonthalia corymbifera, are promising candidates for antifungal agents in crop protection [56]. These properties are not exclusive to red algae because compounds, such as bis(2,3-dibromo-4,5-dihydroxybenzyl) ether, isolated from brown algae Leathesia nana, showed cytotoxic activity against some cancer cells [54], and exhibited antibacterial activity against several strains of Gram-positive and Gram-negative bacteria [56].

With respect to terpenes, there are about 200 different diterpenoids, of which some have important cytotoxic and antiviral, antimicrobial and antiparasitic activities (such as against Leishmania) [60,61]. These compounds are found in red and brown algae.

Flavonoids and their glycosides are present in green, brown and red algae. These compounds possess antioxidant properties and have demonstrated action against arteriosclerosis and cancer [45]. Within this group, fucoxanthin, $\beta$-carotene and violaxanthin stand out. Besides its strong anticancer activity, fucoxanthin has promise in preventing obesity [62]. The correlation between a carotenoid-rich diet and a low risk of cardiovascular and ophthalmological diseases has been supported by recent research with different types of carotenoids in cellular systems and human intervention studies [63]. Specifically, flavonoids from Enteromorpha prolifera influenced the GM balance in diabetic mice, increasing the presence of Alistipes, Lachnospiraceae and Odoribacter genera [63]. Alistipes spp. is one of the most abundant bacterial genera in the mouse intestine and is capable of fermenting glucose and lactic acid to produce propionic, acetic and succinic acid, which modulate the release of intestinal hormones, thereby influencing the release of insulin and appetite. It is perhaps for this reason that $E$. prolifera is traditionally used in China as a natural herb to treat diseases associated with inflammation [63]. It has recently been observed that a polysaccharide of E. prolifera could be used as a novel agent to treat obesity and hyperlipidaemia [62].

Other important secondary metabolites contained in seaweeds and responsible of important beneficial effect in human health are peptides, such as lectins [48]. Lectins primarily show antiviral, antibacterial, and antifungal activities. Specially one type of lectin, griffithsin, showed important antiviral activity and is nowadays considered a promise antiviral agent, with great potential concerning the prevention of sexually transmitted infections [48], including HIV [64]. Other important peptides are renin inhibitor tridecapeptide [65] and dipeptide [66], which demonstrated hypotensive effect dipeptide. Phycoerythrin [43] and kahalalide F [67] are other important peptidic compounds isolated from seaweeds than showed antitumor effect.

Besides the so-called secondary metabolites, seaweeds contain other minor nutrients of immense importance for human health. Phycobiliproteins, responsible for the characteristic bright pink appearance of red algae, are classified into phycoerythrin (red) and phycocyanin (blue). These pigments are used commercially in food, nutraceuticals, and for their therapeutic properties, mainly antimicrobial, antioxidant, anti-inflammatory, neuroprotective, hepatoprotective, immuno-modulatory and anticancer effects [67-72]. Such compounds may improve the efficacy of standard anticancer drugs, decrease their side effects, and act as photosensitisers for the treatment of tumour cells [30]. 


\section{Effects of Seaweed Polysaccharides on Human Health}

Compounds with prebiotic activity, such as oligosaccharides, lactulose, fructo-oligosaccharides (FOS), inulin, galacto-oligosaccharides and arabinoxylano-saccharides are used as functional ingredients in the food industry [10]. While most of the above compounds are now derived from terrestrial plants, some studies have shown that polysaccharides and oligosaccharides derived from marine algae can also modulate intestinal metabolism, including fermentation, inhibit adhesion and invasion of pathogens, and treat inflammatory bowel disease [23,73]. Furthermore, these compounds have demonstrated anticoagulant, antioxidant, immunomodulatory, antitumor and antiviral activities [10].

Being much less degradable by enzymes from the human upper gastrointestinal tract than their terrestrial plant counterparts, polysaccharides from marine algae reach a greater proportion in the descending colon. For this reason, some authors [42,74] have found that polysaccharides from marine algae, such as alginate, agarose oligosaccharides and $k$-carrageenan oligosaccharides, have a higher prebiotic activity than FOS in vitro. Specifically, sulphated polysaccharides from marine algae show anticoagulant, antiviral, antitumor, anti-inflammatory, antibacterial, immunological, antioxidant and many other biological and physiological activities $[8,75]$. Sulphated polysaccharides include fucoidans (L-fucose and sulphated ester groups) from brown seaweeds, agars and carrageenans (sulphated galactans) from red seaweeds, and ulvans (sulphated glucuronoxylorhamnan) and other sulphated glycans from green seaweeds [8].

The consumption of these sulphated polysaccharides can block the adhesion of leukocytes to the epithelium of blood vessels, preventing the migration of these cells to the site of inflammation [76]. These polysaccharides often stimulate the growth and activity of beneficial bacteria by acting as substrates for fermentation in the large intestine, leading to the production of SCFA, with multiple functions that help maintain health [8]. As previously mentioned, seaweed polysaccharides differ in their properties and compositions from one type of algae to another [46], so their effects on the human GM will also differ.

The GM, especially in its most distal parts, harbors many bacteria, archaea, protozoa and viruses, which along with their genetic material, is collectively referred to as the gut microbiome (GMB) [77]. This GM is composed of up to 12 different bacterial phyla of which more than $90 \%$ belong to the Proteobacteria, Firmicutes, Actinobacteria and Bacteroidetes [78], while the remaining phyla are much less constant and numerous [79]. The most frequent bacterial species in the colon, which is where the highest bacterial concentration exists [78], belong mainly to the families Bacteroidaceae, Prevotellaceae, Rikenellaceae, Lachnospiraceae and Ruminococcaceae [77]. The GM presents a diverse set of functions important to human health, such as the extraction of energy from a broad spectrum of nutrients, the production of vitamins, the promotion of immune homeostasis and the prevention of colonization of the intestine by pathogens [80]. One of the most important functions of the GM is in the prevention of chronic low-grade inflammation [81]. Host genetics define the chemistry and physics of the GM, including the availability of nutrients and the threshold of activity required to induce an immune response. Consequently, intestinal microbial communities are composed of species that have evolved to occupy specific ecological niches in the gut, including the ability to metabolize specific molecules available from the host or to evade host defenses [77].

Nutrients can interact directly with the GM to promote or inhibit its growth. In this sense, the ability of the GM to extract energy from specific components of the diet offers a direct competitive advantage to specific members of the GM, allowing them to proliferate at the expense of other members [81]. Thus, diet affects not only the composition and absolute abundance of intestinal bacteria but also their growth kinetics [82]. In this context, the most influential nutrients are indigestible carbohydrates, which can be of both terrestrial and marine algae origin [81].

The human genome encodes a limited number of hydrolases capable of hydrolyzing the glycosidic bonds of polysaccharides in dietary fibre (collectively referred to as CAZymes). Consequently, many polysaccharides, such as resistant starch, inulin, lignin, pectin, cellulose and FOS, reach the large intestine undigested. In contrast, the GMB codes tens of thousands of CAZymes. In the 
presence of bacteria harboring key enzymes involved in carbohydrate metabolism, these complex polysaccharides can thus be degraded and metabolized in vivo [83]. The bacteria able to degrade these complex polysaccharides are called primary degraders and include members of the genera Bacteroides, Bifidobacterium and Ruminococcus, Roseburia, Facealibacterium, Anaerostides or Coprococcus. A relative abundance of these genera in our GM infers that during a food shortage, these bacteria can alternate between energy sources by using sensors and regulatory mechanisms that control gene expression [21, 81]. Hydrolases act on polysaccharides to generate oligosaccharides and monosaccharides. Secondary fermentation of these compounds by the GM produces SCFA, specifically acetic, propionic, butyric, lactic and succinic acids, which initiate a complex metabolic network [81].

The GM of hunter-gatherer, rural and agricultural populations are usually more bacterially diverse than in modernized urban societies [84] and so require a greater functional repertoire to maximize their energy intake from dietary fibres. Conversely, the consumption of a diet composed mainly of products of animal origin causes an enrichment in the GM of genera of bile-tolerant bacteria, such as Alistipes, Bilophila and Bacteroides, and the almost total exhaustion of bacteria that metabolize polysaccharides, such as Roseburia, Eubacterium rectale subgroup and Ruminococcus bromii [81].

Clinical studies investigating prebiotic effects have some disadvantages with respect to ethical constraints, as well as limited sampling possibilities from the colon and limited measurements of in situ SCFA production. These concerns are commonly avoided by applying an in vivo approach [41], that are the most common in the investigation of seaweed effects on human GM, as is described below. Contrariwise, in vitro studies show important limitations because only represent the first step of a long process, and the results observed in vitro can be magnified, diminished, or totally different in a more complex and integrated system [48]. An additional limitation is that, due to the short fermentation time in in vitro studies, they fails to capture the complete picture of cross-feeding interactions between gut microbes, and which may not fully correlate with the long-term effects of seaweed compounds on GM [41].

\subsection{Polysaccharides from Brown Seaweeds}

Although the prebiotic and immuno-modulation properties of brown algae have been studied both in animal models and in vitro, humans intervention studies are also needed to assess whether there is a direct association between these uses of algae and the human GM, but are currently restricted due to ethical concerns [78]. The most relevant results obtained from examining the impacts of brown seaweeds on the GM can be found in Table 1. In this table it were included results about the prebiotic effect of brown seaweed species from genus Ecklonia [7,85], Sargassum [86-88], Laminaria [82,89-92], Ascophyllum [93-95], Fucus [23,63], Undaria [90], Saccorhiza [96] or Porphyra [97]. As can be seem in Table 1, in most cases, the administration of whole brown seaweed or brown seaweed-extracted polysaccharides resulted in an increase of SCFA production, stimulating of beneficial bacteria grown such as Lactobacillus $[7,82,85,86,95]$, Bifidobacterium $[7,82,85,87,92]$ or Faecalibacterium $[7,58,87]$. In some cases, the brown seaweed or brown seaweed-extracted polysaccharides also inhibited the growth of potentially pathogen bacteria $[73,86]$. In some cases, it were reported other beneficial effects not strictly related with action on GM, such as reducing serum inflammatory markers [23], reducing serum levels of lipopolysaccharide-binding protein [44], increasing CAZymes [44], reducing activity of fecal bile salt hydrolase activity [96], or reduced the expression or diabetes-related genes [15].

Laminar storage polysaccharides, typical of brown seaweeds, are low-molecular-weight, linear polysaccharides composed of glucose units with a low degree of branching [79]. Besides affecting mucin composition and SCFA concentration, laminins can affect the adherence, translocation and proliferation of bacteria in the gut $[98,99]$. At the same time, laminins stimulate the proportion of Bifidobacterium, which generates a prebiotic potential. In other research, laminarin has been shown to promote an immune response [98], and could be useful for inhibiting the production of putrefactive substances from undigested proteins [100]. In vitro batch fermentation of laminarin for $24 \mathrm{~h}$ promoted an increase in Bifidobacterium and Bacteroides, and propionate and butyrate production [42]. Contradicting results by other researchers indicated that laminarin was not selectively fermented by Lactobacillus and 
Bifidobacterium, but could modify the composition, secretion and metabolism of the jejunal, ileal, caecal and colonic mucosa to protect against bacterial translocation [32]. In addition, laminarin increased the presence of Clostridium spp. and Parabacteroides distasonis in rats [101].

An in vitro study conducted with the species Sargassum thunbergii revealed a dramatic increase in the population of beneficial bacteria (from $17 \%$ to $28 \%$ ), while a group of harmful Firmicutes decreased from $75 \%$ to $64 \%$ after $48 \mathrm{~h}$ of fermentation [87]. No noticeable changes were found in Proteobacteria or Actinobacteria. At the genus level, an increase in Lactobacillus, Bifidobacterium, Roseburia, Parasutterella and Fusicatenibacter appeared after incubation for $24 \mathrm{~h}$, followed by an increase in Faecalibacterium and Coprococcus at $48 \mathrm{~h}$ of incubation [87]. Bifidobacterium, Coprococcus and Parasutterella have been negatively correlated with non-alcoholic steatohepatitis, hepatocellular carcinoma and diabetes [102], while Ruminococcus, Roseburia and Faecalibacterium are producers of butyric acid and are facilitate the degradation of polysaccharides and fibres [103]. Fusicatenibacter was positively associated with increased serum leptin in obese rats [104], which reduces their appetite. All these findings highlight the prebiotic potential of $S$. thunbergii by its modulation of the composition and abundance of beneficial GM.

An in vitro study using $S$. wightii in MRS broth evaluated their antioxidant activity and prebiotic score comparing L. plantarum and Salmonella Typhimurium relative growths. The study showed that the prebiotic activity score was positive, promoting selectively the growth of L. plantarum with respect to the pathogen S. Typhimurium. Specifically, a prebiotic effect by 1.42 -fold more growth stimulation of L. plantarum than $S$. Typhymurium [86].

In other work Chen et al. [58] showed an increase in fucoidan from A. nodosum in an in vitro assay simulating the human digestive tract was due to an increase in Bacteroidetes, Firmicutes and SCFA. At the genus level, the genera Bacteroides, Phascolarctobacterium, Oscillospira and Faecalibacterium increased, while the levels of Fusobacterium, Megamonas, Parabacteroides, Clostridium and Dorea decreased relative to the samples to which the algae $A$. nodosum had not been added [46]. demonstrated the in vitro prebiotic activity of a mixture of fucoidans and alginates obtained from A. nodosum, leading to an increase in the growth rate of $L$. delbrueckii and $L$. casei to levels similar to those observed after administration of inulin, a standard commercial prebiotic [46]. Other authors [93] conducted a study in rats, which were administered polysaccharides extracted from A. nodosum, and they were seen an increase in both acetate, propionate and butyrate SCFAs.

According to Zaporozhets et al. [76], fucoidans obtained from $F$. evanescens stimulate the colonic growth of beneficial Bifidobacterium species, such as B. longum B379M and B. bifidum 791B. Lean et al. [23] administered F. vesiculosus-derived fucoidan extracts to mice and, interestingly, found a reduction in markers associated with inflammatory bowel diseases.

When Wister rats were fed with feed enriched with alginates or laminarins, An et al. [101] found a notable decrease in the number of metabolites resulting from putrefaction, such as indole, $\mathrm{H}_{2} \mathrm{~S}$ and phenol. This result was subsequently confirmed in both in vitro and rat models by Nakata et al. [100], who also found a decrease in ammonium levels with alginate. At the phyla level, alginate increased the levels of Actinobacteria, while laminarins increased the levels of Proteobacteria. At the genus level, Bacteroides was markedly more abundant in the group fed with alginate, and B. capillosus was the most frequent species. In rats fed with laminarin-enriched feed, Parabacteroides, Lachnospiraceae and Parasutterella bacterium were detected in greater abundance than in control rats. Nguyen et al. [44] studied laminarin supplementation in a mice high-fat diet. They could see a decrease in Firmicutes and an increase in the Bacteroidetes phylum, especially the genus Bacteroides.

Ramnani et al. [94] performed in vitro fermentation with A. nodosum-derived alginates, which increased Bifidobacterium and SCFAs. An increase in the proportion of Bacteroidetes to Firmicutes was observed as well in fermentations added with sulphated polysaccharides extracted from A. nodosum versus controls. Increased levels of Bacteroidetes and decreased levels of Firmicutes have been associated with a reduced risk of obesity in humans [79]. 


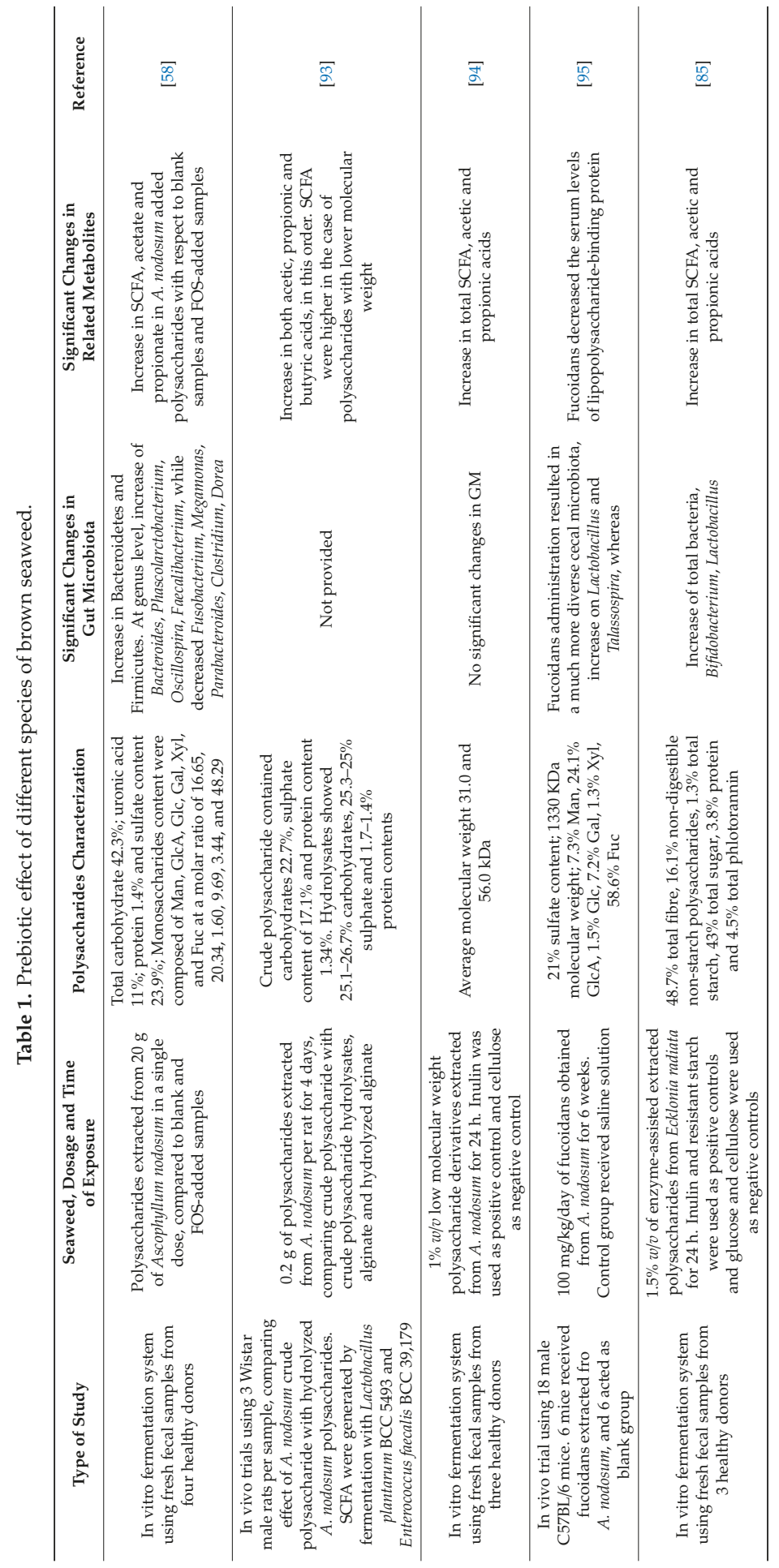




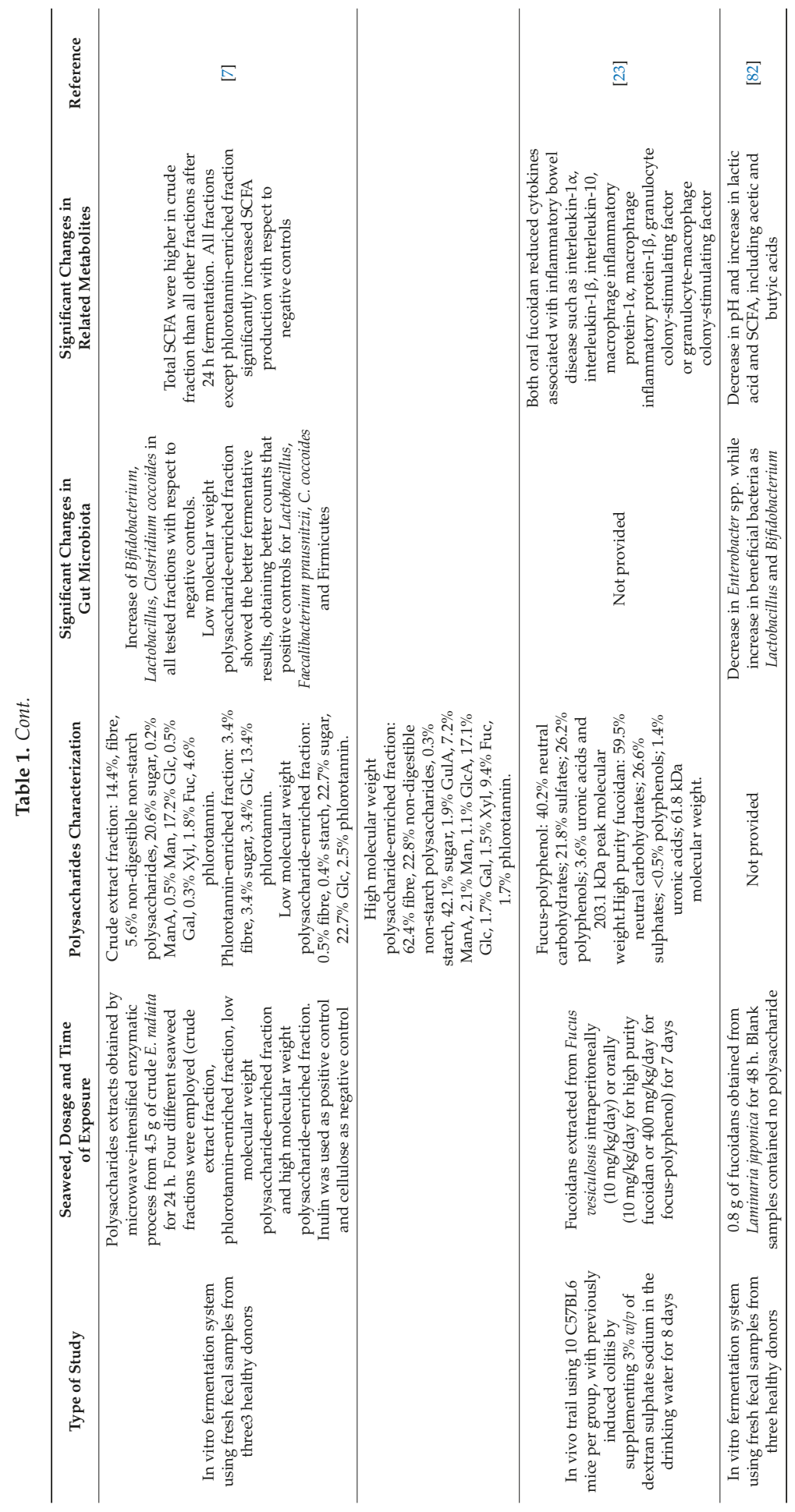




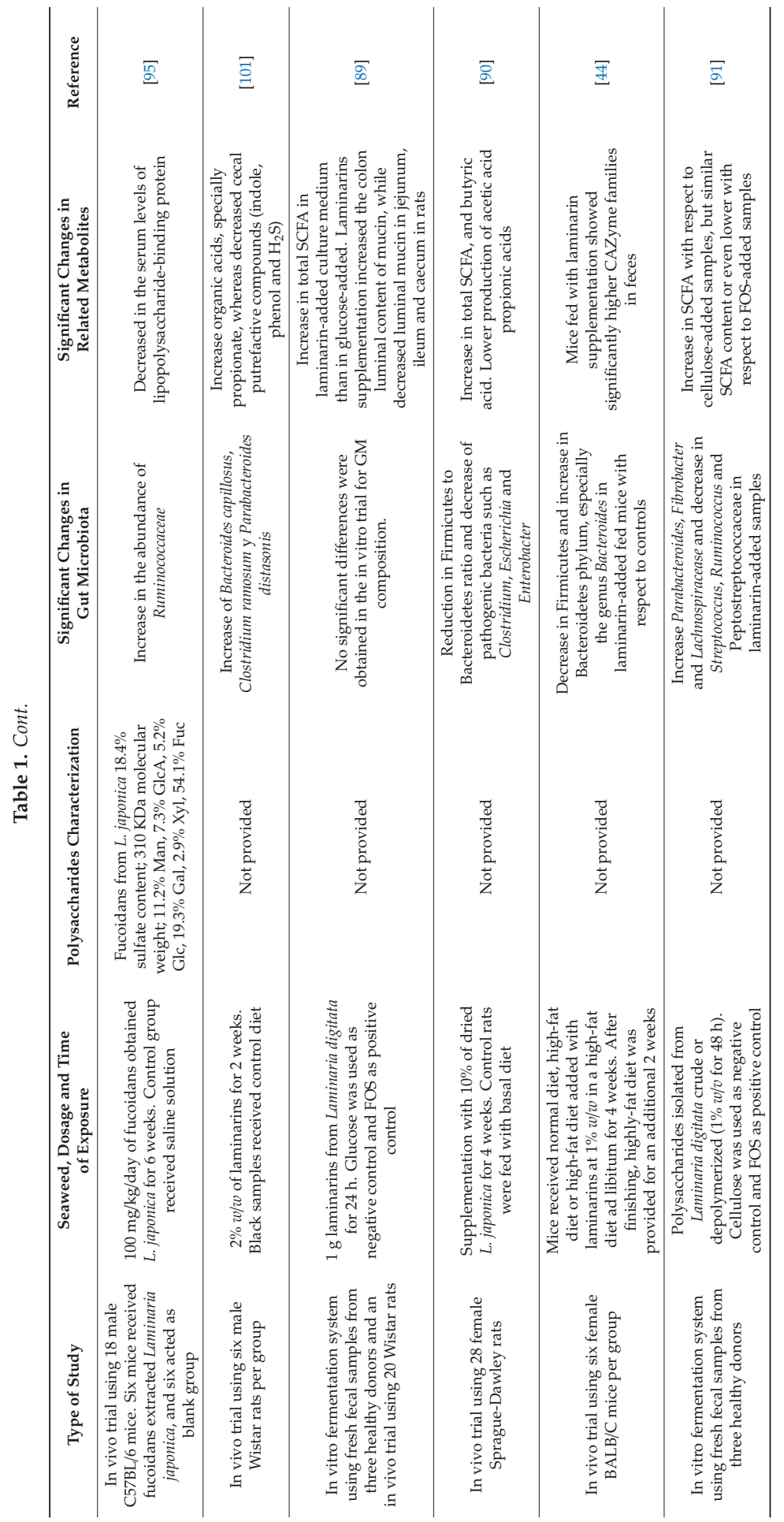




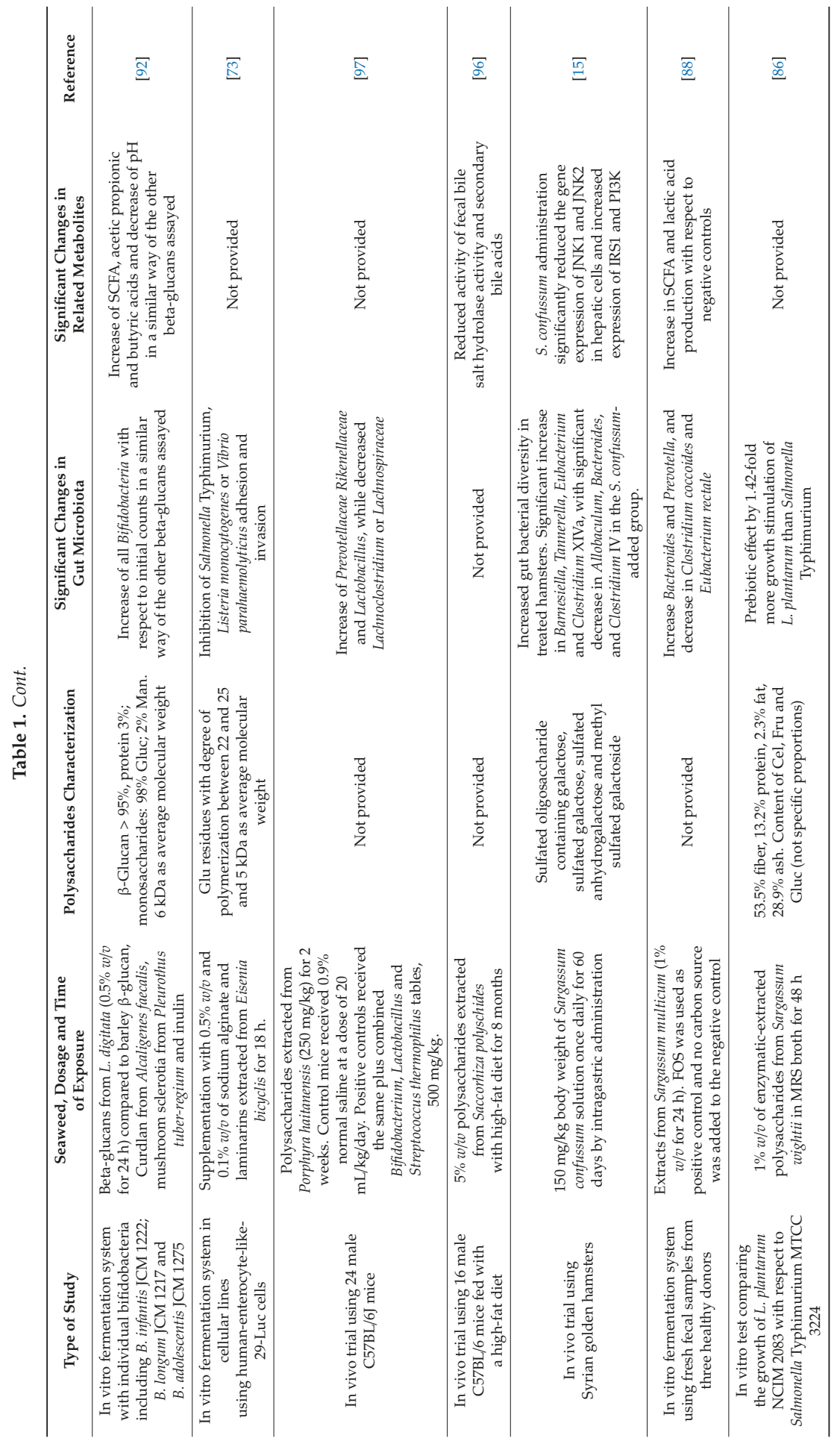


Molecules 2020, 25, 1004

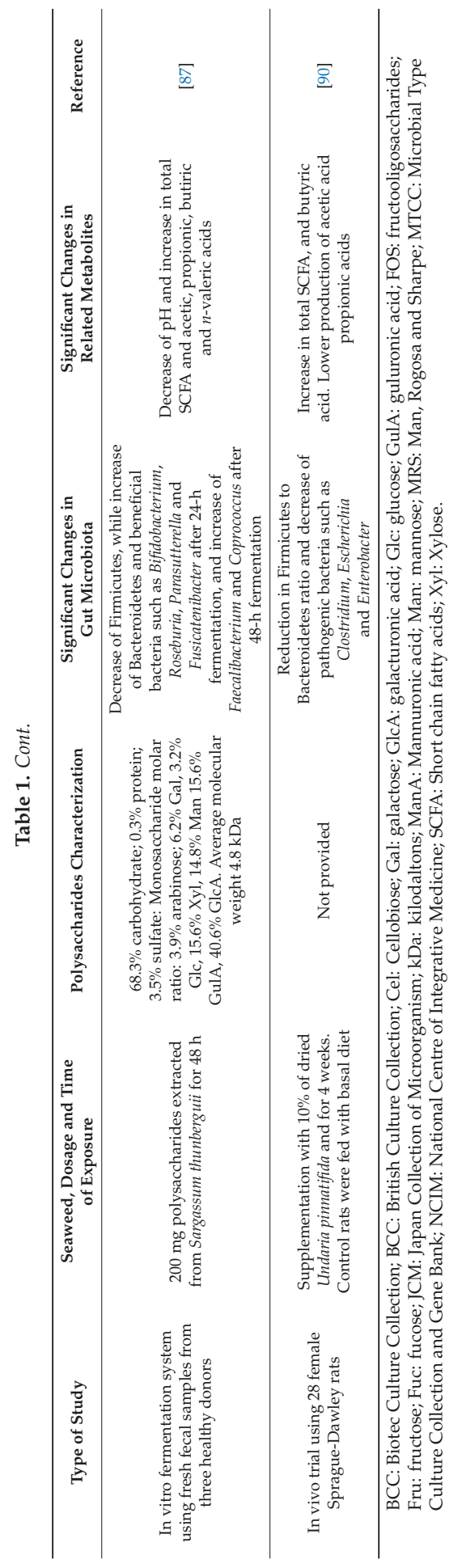


Evidence that probiotic bacteria in the gastrointestinal tract utilize dietary alginate was reviewed by Shang et al. [38]. Among the studies, Kuda et al. [73] found that supplementation with sodium alginate and laminarin of brown algae inhibited the adhesion and invasion of pathogens, such as S. Typhimurium, Listeria monocytogenes or Vibrio parahaemolyticus. Other authors reported an increase in Lactobacillus and Ruminococcus in the intestine of mice fed fucoidans from A. nodosum, besides a reduction in the opportunistic Peptococcus bacteria [95].

In vitro fermentation experiments conducted by Charoensiddhi et al. [85] demonstrated the growth-promoting effect of E. radiata extracts on beneficial bacteria, such as Bifidobacterium, Lactobacillus and Clostridium coccoides, and SCFAs production was stimulated as well. Later, the same authors [7] found increased levels of beneficial bacteria, such as Bifidobacterium, Lactobacillus and C. coccoides associated with the phlorotannin-enriched fermentation of E. radiata. Higher numbers of Lactobacillus, Faecalibacterium prausnitzii, C. coccoides, Firmicutes and E. coli were observed for phlorotannin-supplemented fermentation compared with inulin fermentation [7]. In contrast, the number of Enterococcus in both fermentations decreased approximately ten-fold relative to the initial counts.

Other authors tested the effects of supplementation of two brown algae ( $U$. pinnatifida and L. japonica) on the GM and body status of laboratory rats [90]. In both instances, the animals' body weight was reduced, which was thought to be mediated by the influence of the seaweed on the composition of the intestinal microbial communities associated with obesity, reducing the proportion of Firmicutes with respect to Bacteroidetes, and the populations of pathogenic bacteria, such as Clostridium, Escherichia and Enterobacter [90]. Similarly, L. japonica increased beneficial bacteria and SCFA, and decreased the $\mathrm{pH}$ level [82], while $\beta$-glucans extracted from $L$. digitata increased Bifidobacterium and propionic and butyric acids in vitro, in addition to lowering $\mathrm{pH}$ [92].

$\beta$-Glucans obtained from another Laminaria species (L. digitata) were able in an in vitro test [92] to increase Bifidobacterium and propionic and butyric acids, in addition to lowering $\mathrm{pH}$. A study by Strain et al. [91] in vitro investigated the effect of a polysaccharide-rich raw extract obtained from L. digitata. A significant alteration of the relative abundance of several families, including Lachnospiraceae and genera such as Streptococcus, Ruminococcus and Parabacteroides of human faecal bacterial populations was seen. Concentrations of acetic acid, propionic acid, butyric acid and total SCFA were significantly higher.

Finally, Huebbe et al. [96] conducted a study on mice that were administered polysaccharides from S. polyschides with a high-fat diet. A metabolic improvement was seen including normalization of blood glucose, reduction of plasma leptin, reduction of fecal bile salt hydrolase activity and secondary bile acids in these mice.

\subsection{Polysaccharides from Red Seaweeds}

The most relevant results obtained from the investigation of red seaweeds effect on GM can be found in Table 2. In this table, results about the prebiotic effect of red seaweed species from genus Acanthopora [86], Gracilaria [105,106], Kappaphycus [107], Euchema and Grateloupia [10], Chondrus [57], Gelidium [94], or Osmundea [88] were included.

As can be seem in Table 2, as was described previously for brown seaweeds, administration of red seaweeds or seaweed-extracted polysaccharides resulted in an increase of SCFA production, stimulating of beneficial bacteria grown such as Lactobacillus [86] or Bifidobacterium $[57,94,107]$, whereas inhibited the growth of potentially pathogen bacteria $[57,86]$. It was also reported red seaweeds activity on the prevention of naproxen-induced gastrointestinal damage [106].

Agarose stands out among the polysaccharides isolated from red algae that cannot be digested by human intestinal enzymes. When seaweed is consumed, whether as an edible food or food additive, agarose reaches the most distal portions of the gastrointestinal tract, where it is fermented and metabolized by the GM $[108,109]$. As described by Ramnani et al. [94], low-molecular-weight agarose exerted a prebiotic effect in vitro by promoting the growth of Bifidobacterium and increasing SCFA concentrations in the medium. 


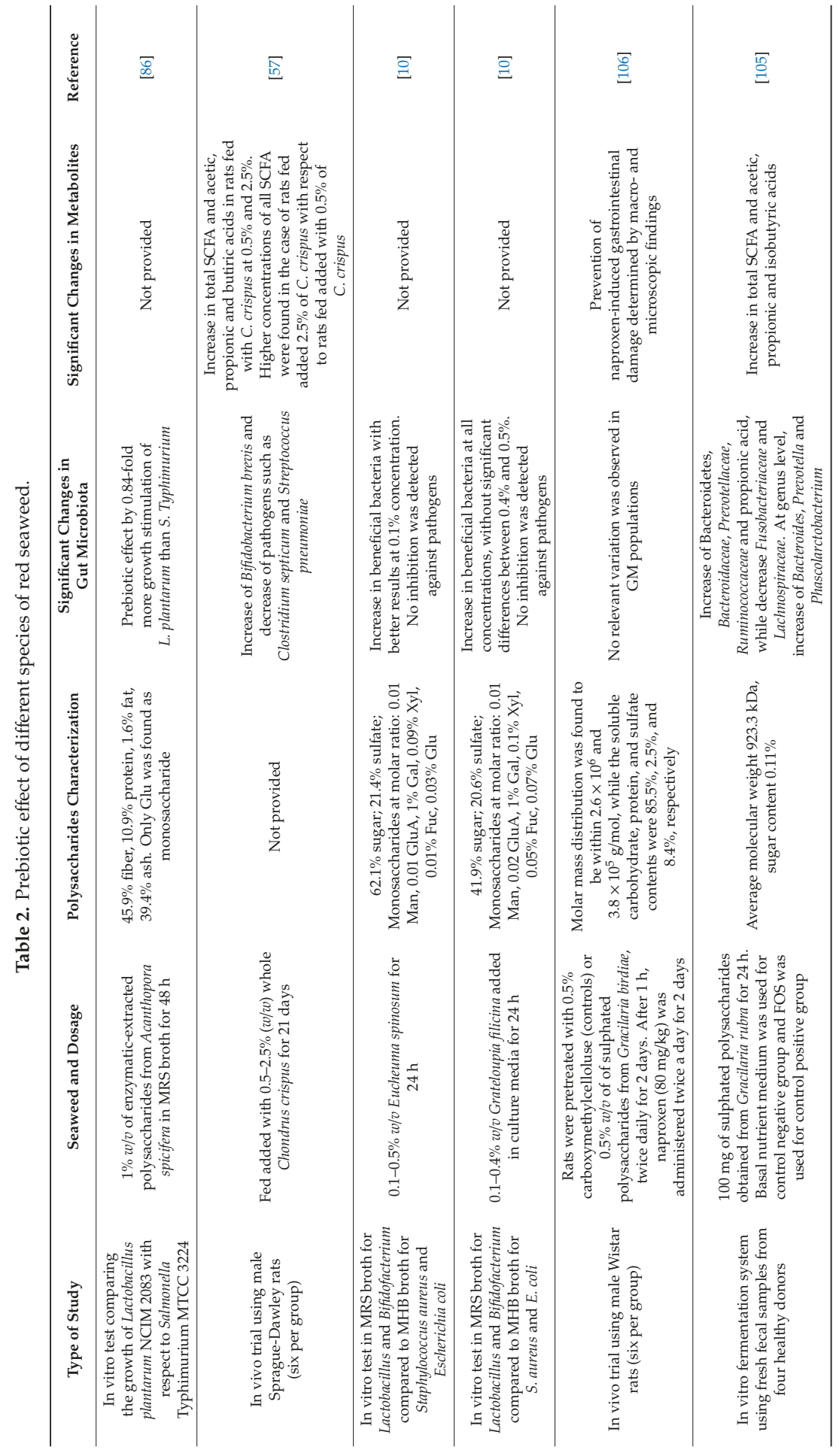


Molecules 2020, 25, 1004

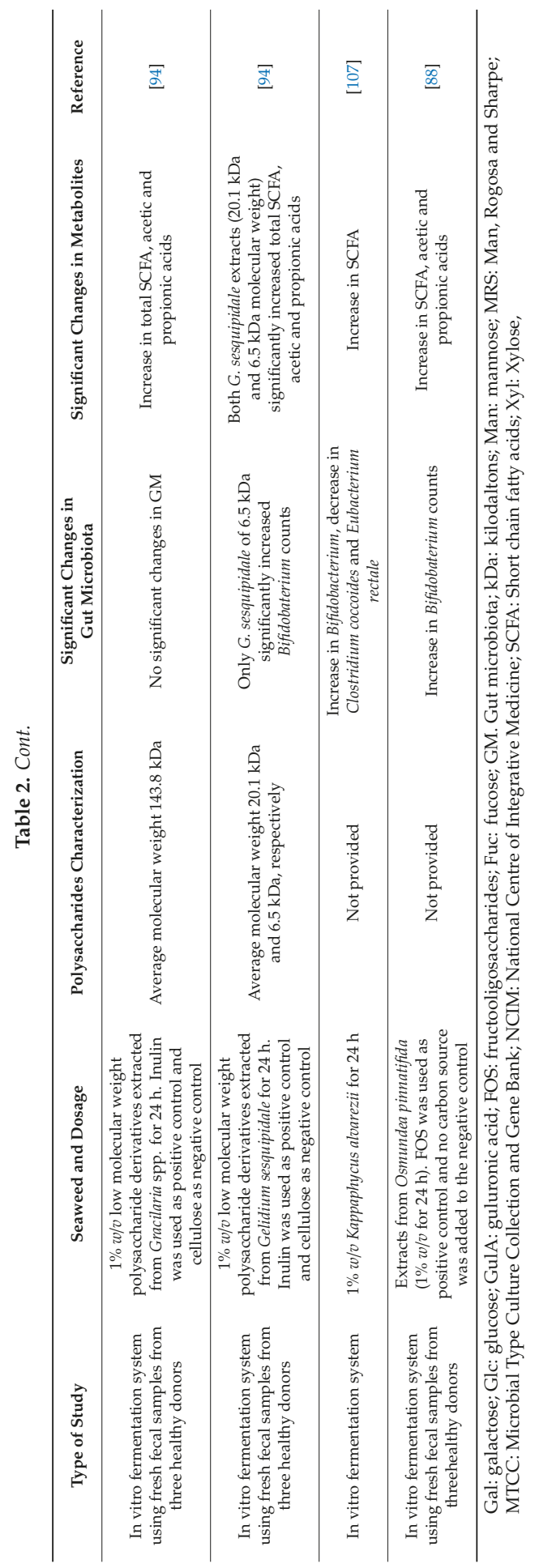


Bajury et al. [107] conducted an in vitro colon model in which they evaluated the prebiotic capacity of $K$. alvarezii. This study showed an increase in SCFA (particularly acetate and propionate) and Bifidobacterium. In the other hand, decrease in C. coccoides and E. rectale. These results suggested that K. alvarezii might have the potential as a prebiotic ingredient. A study published by Zhang et al. [110] focused on the beneficial effect of low-melting-point agarose (in the form of neoagaro-oligosaccharides) on the GM during the relief of intense exercise-induced fatigue in mice. Results showed the abundance of Bacteroidetes and Proteobacteria increased and decreased, respectively, during the attenuation of fatigue and its associated gastrointestinal problems. Ladirat et al. [111] found that mice fed $2.5 \%(w / v)$ neoagaro-oligosaccharides for seven consecutive days achieved a much more pronounced increase in the population of Lactobacillus spp. and Bifidobacterium spp. in their GM relative to those fed 5\% $(w / v)$ FOS for 14 consecutive days. Likewise, it was demonstrated that agaro-oligosaccharides could be used as a prebiotic to encourage the growth of beneficial strains of bacteria, such as B. adolescentis ATCC 15703 and B. infantis ATCC 15697. Low-molecular-weight agar has demonstrated a bifidogenic effect, along with an increase in SCFA acetate and propionate concentrations, after $24 \mathrm{~h}$ of in vitro fermentation with human faeces inoculant [94].

Another type of polysaccharide with prebiotic function found in red algae are the group of carrageenans, which are derived from D-galactose, and approved as food additives [79]. In rats fed $2.5 \%$ C. crispus, of which carrageenan is a major polysaccharide, B. brevis, as well as SCFA, increased considerably, while pathogens Clostridium septicum and Streptococcus pneumonia noticeably decreased compared with the basal diet [57]. Elevation of plasma immunoglobulin levels was also found in rats fed with C. crispus, resulting in improved host immunity. Consistent with the prebiotic activity of carrageenan, carrageenans isolated from red algae G. filicina and E-spinosum promoted the growth of Bifidobacterium [10].

Research led by Di et al. [105] found that the polysaccharides of Gracilaria rubra increased the relative abundances of Bacteroides, Prevotella and Phascolarctobacterium in vitro compared with the control group. Bacteroides spp. assists the host with degrading polysaccharides and contains codifying genes of glucosidase enzymes [39]. Prevotella is another beneficial genus with the potential to participate in the metabolism and utilization of plant polysaccharides. The genus Phascolarctobacterium is associated with the production of SCFA [110].

Many other bacterial genera, such as Legionella, Sutterella, Blautia, Holdemania, Shewanella and Agarivorans, were decreased as a consequence of intake of C. crispus supplements in rats [57]. Decreases in the presence of Streptococcus were also observed. In conclusion, carrageenans from C. crispus could act as a fermentable substrate for probiotic bacteria present in the gastrointestinal tract, thereby promoting the growth of probiotic groups, while inhibiting certain groups of pathogenic bacteria [57]. Another study in chickens described an overall impact of administering whole red algae (Sarcodiotheca gaudichaudii and C. crispus) on the intestinal mucosa, increasing the height and surface of the villi in these animals [112]. Moreover, the abundance of beneficial bacteria, such as B. longum and Streptococcus salivarius increased, while some harmful bacteria species, such as C. perfringens, decreased [112] Rodrigues et al. [88] used extracts from the red algae O. pinnatifida and S. muticum in an in vitro fermentation system, which increased the production of acetate and propionate, and the population of Bifidobacterium. In work published by Silva et al. [106], in which extracts of sulphated polysaccharides from G. birdiae were administered to laboratory rats, gastrointestinal damage induced by naproxen was prevented, although it did not produce notable variations in the GM of these rats.

An in vitro study using A. spicifera in MRS broth evaluated their antioxidant activity and prebiotic score with L. plantarum and S. Typhimurium. The study showed that the prebiotic activity score was positive, promoting the growth of L. plantarum and suppressing the growth of the pathogen S. Typhimurium. Specifically, a prebiotic effect by 0.84 -fold more growth stimulation of $L$. plantarum than S. Typhymurium [86]. 


\subsection{Polysaccharides from Green Seaweeds}

Unlike brown and red algae, the current evidence for the fermentation capacity of green algae and their polysaccharides is scarce, partly because their fermentation requires a specific activity of $\alpha$-L-rhamnosidase in the gastrointestinal tract, which is infrequent [113]. The most relevant results obtained from the investigation of green seaweeds effect on GM can be found in Table 3. In this table, results about the prebiotic effect of green seaweed species from genus Enteromorpha [38,82,86,113-115] and Ulva [115] were included. Administration of green seaweeds or seaweed-extracted polysaccharides also resulted in an increase of SCFA production, stimulating of beneficial bacteria grown such as Lactobacillus [38,86,115], Bifidobacterium [38], or Akkermansia [38] whereas inhibited the growth of potentially pathogen bacteria $[81,114]$. Other beneficial actions were reported such as decrease lipopolysaccharide-binding protein in female mice [38], diminished histopathological lesions of inflammatory infiltrations in distal colon [114], or modulating diabetes-related genes expression in diabetic mice [22].

Ulvans are one of the most frequent polysaccharides in green algae. This polysaccharide is a water-soluble sulphated heteropolysaccharide [79]. Ulvans contains sulphate and uronic acids, and so produce undigestible ionic colloids, has ion-exchange capacity and can bind to bile acids, consequently increasing the excretion of bile acids with cholesterol-lowering or antihyperlipidemic effects $[2,79]$. Antioxidant and immunomodulatory properties are other beneficial actions elicited by ulvans [116,117].

Ulvans has also been studied for its possible prebiotic potential. Kong et al. [82] performed an in vitro assay using Enteromorpha with a high content of ulvans, but there were no noticeable variations in the populations of Enterococcus, Lactobacillus and Bifidobacterium compared with controls. In contrast, in a recent in vitro faecal fermentation analysis, ulvans stimulated the growth of Bifidobacterium and Lactobacillus populations and promoted the production of SCFA, such as lactic and acetic acids [42]. In a previous study by Ren et al. [114], both whole Enteromorpha and polysaccharides extracted from Enteromorpha improved inflammation associated with loperamide-induced constipation in mice. In those mice, the GM showed an increase in Firmicutes and Actinobacteria compared with the control mice, whereas the relative amounts of Bacteroidetes and Proteobacteria decreased.

In work by Shang et al. [38], an extract of E. clathrata was administered to mice, resulting in marked decreased concentrations of genera, such as Enterobacter, Staphylococcus and Streptococcus. Surprisingly, such supplementation also dramatically reduced the population of $A$. muciniphila in the intestine. These observations indicate a possible unfavorable effect of these polysaccharides on the GM. Contrarily, these polysaccharides were reported to increase the abundance of A. muciniphila, Bacteroides, Alloprevotella, Ruminococcaceae and Blautia in the intestinal tract of mice, and decrease the abundance of Peptococcus, Rikenellaceae and Alistipes [96,109].

An in vitro faecal fermentation of xylans derived from Palmaria palmata reported that xylose was fermented after $6 \mathrm{~h}$, and the SCFA content increased simultaneously [32]. This study did not determine the bacterial composition. Nonetheless, Xylans and xylo-oligosaccharides extracted from terrestrial plants, such as wheat husks and corn, are considered potential prebiotics due to evidence of bifidogenesis, improved plasma lipid profile and positive modulation of immune function markers in healthy adults [118]. 


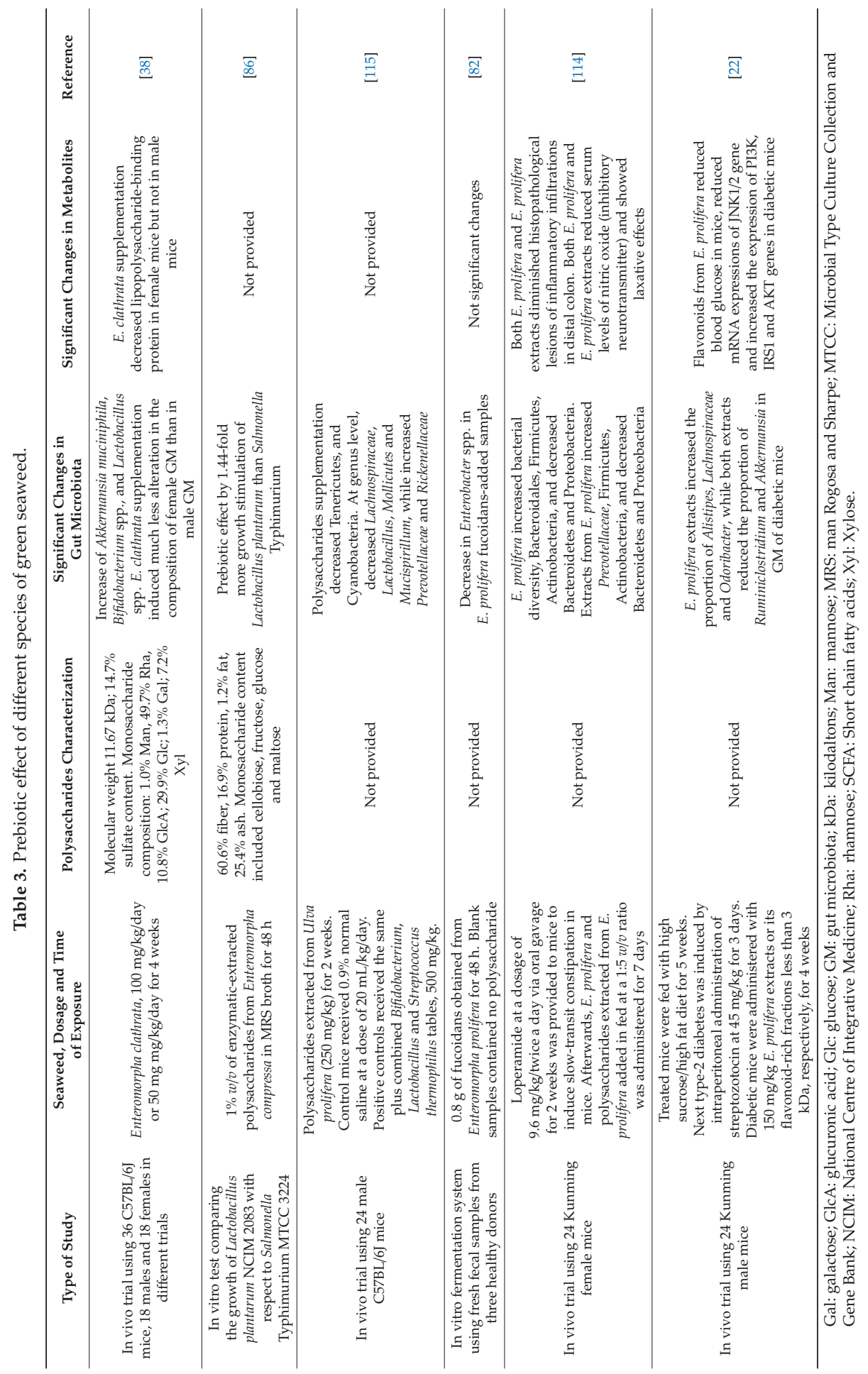


E. clathrata is an edible green seaweed possessing polysaccharides with numerous bioactivities, including anticoagulant, immunomodulatory, antioxidant, anticancer and anti-obesity effects [38]. It was reported that the polysaccharides of E. clathrata exerted diverse prebiotic effects on A. muciniphila, Bifidobacterium and Lactobacillus in male and female mice [38]. The results were most evident in the male mice because of a sex-specific effect on the GM, as sex hormones play a key role in determining the composition of intestinal microorganisms [109]. In other work from the same authors, male mice were supplemented with polysaccharides of E. clathrata in the diet, which increased the abundance of Bacteroides, Prevotella, Alloprevotella, Eubacterium and Peptococcus, and decreased the proportion of the cancer-related Helicobacter [109]. In the female counterparts, the abundance of Odoribacter, Clostridium IV, Oscillibacter and Alistipes spp. increased, and the proportions of beta-proteobacteria decreased [38].

An in vitro study using E. compressa in MRS broth evaluated their antioxidant activity and prebiotic score with L. plantarum and S. Typhimurium. The study showed that the prebiotic activity score was positive, promoting the growth of L. plantarum and suppressing the growth of the pathogen S. Typhimurium. This seaweed exhibited the highest score of prebiotic activity (1.44-fold), stimulating the growth of L. plantarum than S. typhimurium [86].

The natural products of marine macroalgae have shown notable antidiabetic potential by interfering with carbohydrate metabolism. For example, E. prolifera contains many bioactive compounds, such as sulphated polysaccharides, which could improve glucose metabolism, in addition to displaying anti-inflammatory, antiviral and anticoagulant functions [22].

\section{Conclusions}

Although substantial evidence of the prebiotic effect of seaweed and seaweed extracts has been published in recent years, these studies have been performed using in vitro digestion systems simulating the human colon, or in animal models. Animals, such as mice or rats, differ widely from humans in the GM composition, immune function, diets, metabolism and other key aspects, so extrapolating the results obtained from animal models to humans may not be valid. In vitro systems replicate more similarly the human intestinal microbiota, but are less-dynamic systems than the real human colonic environment. Additionally, other factors should be considered, such as the possible effect of other secondary compounds contained in seaweeds on the GM composition, or the potential to transfer genes from marine bacteria to human GM bacteria coding for enzymes that could degrade seaweed polysaccharides. Thus, not all people will respond equally after seaweed ingestion. The decrease in terrestrial agriculture and disposable water is likely to increase the consumption of algae by humans in the near future. Meanwhile, there is a profound need for more in-depth investigations into the potential prebiotic effects of marine seaweeds and their derived polysaccharides on the human GM.

Author Contributions: Conceptualization, J.M.M. and A.C. Literature data collection, A.C.A. and A.L.-S. Writing-original draft, A.L.-S. and A.d.C.-M. Writing-review and editing, A.C.-C., C.M.F., and A.L. Supervision: J.M.M. and A.C. All authors have read and agreed to the published version of the manuscript.

Funding: The authors thank the European Regional Development Funds (FEDER), grant ED431C 2018/05, and Programa Iberoamericano de Ciencia y Tecnología para el Desarrollo (CyTED), grant PCI2018-093245 for covering the cost of publication.

Conflicts of Interest: The authors declare no conflict of interest.

\section{References}

1. Cian, R.E.; Drago, S.R.; De Medina, F.S.; Martínez-Augustin, O. Proteins and carbohydrates from red seaweeds: Evidence for beneficial effects on gut function and microbiota. Mar. Drugs 2015, 13, 5358-5383. [CrossRef] [PubMed]

2. Gurpilhares, D.B.; Cinelli, L.P.; Simas, N.K.; Pessoa, A., Jr.; Sette, L.D. Marine prebiotics: Polysaccharides and oligosaccharides obtained by using microbial enzymes. Food Chem. 2019, 280, 175-186. [CrossRef] 
3. Brown, E.M.; Allsopp, P.J.; Magee, P.J.; Gill, C.I.; Nitecki, S.; Strain, C.R.; McSorley, E.M. Seaweed and human health. Nutr. Rev. 2014, 72, 205-216. [CrossRef] [PubMed]

4. Barba, F.J. Microalgae and seaweeds for food applications: Challenges and perspectives. Food Res. Int. 2017, 99, 969-970. [CrossRef] [PubMed]

5. Tiwari, B.K.; Troy, D.J. Seaweed sustainability-food and nonfood applications. In Seazeed Sustainability; Elsevier: Oxford, UK, 2015; pp. 1-6.

6. FAO. The Future of Food and Agriculture-Trends and Challenges; Food and Agriculture Organization of the United Nations: Rome, Italy, 2017.

7. Charoensiddhi, S.; Conlon, M.A.; Vuaran, M.S.; Franco, C.M.; Zhang, W. Polysaccharide and phlorotannin-enriched extracts of the brown seaweed Ecklonia radiata influence human gut microbiota and fermentation in vitro. J. Appl. Phycol. 2017, 29, 2407-2416. [CrossRef]

8. Charoensiddhi, S.; Conlon, M.A.; Franco, C.M.; Zhang, W. The development of seaweed-derived bioactive compounds for use as prebiotics and nutraceuticals using enzyme technologies. Trends Food Sci. Technol. 2017, 70, 20-33. [CrossRef]

9. Makkar, H.P.; Tran, G.; Heuzé, V.; Giger-Reverdin, S.; Lessire, M.; Lebas, F.; Ankers, P. Seaweeds for livestock diets: A review. Anim. Feed Sci. Technol. 2016, 212, 1-17. [CrossRef]

10. Chen, X.; Sun, Y.; Hu, L.; Liu, S.; Yu, H.; Li, R.; Wang, X.; Li, P. In vitro prebiotic effects of seaweed polysaccharides. J. Oceanol. Limnol. 2018, 36, 926-932. [CrossRef]

11. Cardoso, S.M.; Pereira, O.R.; Seca, A.M.L.; Pinto, D.C.G.A.; Silva, A.M.S. Seaweeds as preventive agents for cardiovascular diseases: From nutrients to functional foods. Mar. Drugs 2015, 13, 6838-6865. [CrossRef]

12. Kumar, S.A.; Magnusson, M.; Ward, L.C.; Paul, N.A.; Brown, L. Seaweed supplements normalize metabolic, cardiovascular and liver responses in high-carbohydrate, high-fat fed rats. Mar. Drugs 2015, 13, 788-805. [CrossRef]

13. Seca, A.M.L.; Pinto, D.C.G.A. Overview of the antihypertensive and anti-obesity effects of secondary metabolites from seaweeds. Mar. Drugs 2018, 16, 237. [CrossRef] [PubMed]

14. Wan-Loy, C.; Siew-Moi, P. Marine algae as a potential source for anti-obesity agents. Mar. Drugs 2016, 14, 222. [CrossRef] [PubMed]

15. Yang, C.F.; Lai, S.S.; Chen, Y.H.; Liu, D.; Liu, B.; Ai, C.; Wan, W.Z.; Gao, L.Y.; Chen, X.H.; Zhao, C. Anti-diabetic effect of oligosaccharides from seaweed Sargassum confusum via JNK-IRS1/PI3K signaling pathways and regulation of gut microbiota. Food Chem. Toxicol. 2019, 131, 110562. [CrossRef] [PubMed]

16. Zao, C.; Yang, C.; Liu, B.; Lin, L.; Sarker, S.D.; Nahar, L.; Yu, H.; Cao, H.; Xiao, J. Bioactive compounds from marine macroalgae and their hypoglycemic benefits. Trends Food Sci. Technol. 2018, 72, 1-12. [CrossRef]

17. Wang, H.M.D.; Li, X.C.; Lee, D.J.; Chang, J.S. Potential biomedical applications of marine algae. Bioresour. Technol. 2017, 244, 1407-1415. [CrossRef]

18. Xue, M.; Ji, X.; Liang, H.; Liu, Y.; Wang, B.; Sun, L.; Li, W. The effect of fucoidan on intestinal flora and intestinal barrier function in rats with breast cancer. Food Funct. 2018, 9, 1214-1223. [CrossRef]

19. Shin, T.; Ahn, M.; Hyun, J.W.; Kim, S.H.; Moon, C. Antioxidant marine algae phlorotannins and radioprotection: A review of experimental evidence. Acta Histochem. 2014, 116, 669-674. [CrossRef]

20. Chater, P.I.; Wilcox, M.; Cherry, P.; Herford, A.; Mustar, S.; Wheater, H.; Brownlee, I.; Seal, C.; Pearson, J. Inhibitory activity of extracts of Hebridean brown seaweeds on lipase activity. J. Appl. Phycol. 2016, 28, 1303-1313. [CrossRef]

21. You, L.; Gong, Y.; Li, L.; Hu, X.; Brennan, C.; Kulikouskaya, V. Beneficial effects of three brown seaweed polysaccharides on gut microbiota and their structural characteristics: An overview. Int. J. Food Sci. Technol. 2019. [CrossRef]

22. Yan, X.; Yang, C.; Chen, Y.; Miao, S.; Liu, B.; Zhao, C. Antidiabetic potential of green seaweed Enteromorpha prolifera flavonoids regulating insulin signaling pathway and gut microbiota in type 2 diabetic mice. J. Food Sci. 2019, 84, 165-173. [CrossRef]

23. Lean, Q.Y.; Eri, R.D.; Fitton, J.H.; Patel, R.P.; Gueven, N. Fucoidan extracts ameliorate acute colitis. PLoS ONE 2015, 10, e0128453. [CrossRef] [PubMed]

24. Zeid, A.A.; Aboutabl, E.A.; Sleem, A.; El-Rafie, H. Water soluble polysaccharides extracted from Pterocladia capillacea and Dictyopteris membranacea and their biological activities. Carbohydr. Polym. 2014, 113, 62-66. [CrossRef] [PubMed] 
25. Fedorov, S.N.; Ermakova, S.P.; Zvyagintseva, T.N.; Stonik, V.A. Anticancer and cancer preventive properties of marine polysaccharides: Some results and prospects. Mar. Drugs 2013, 11, 4876-4901. [CrossRef] [PubMed]

26. Wijesinghe, W.; Jeon, Y. Biological activities and potential industrial applications of fucose rich sulfated polysaccharides and fucoidans isolated from brown seaweeds: A review. Carbohydr. Polym. 2012, 88, 13-20. [CrossRef]

27. Qi, H.; Huang, L.; Liu, X.; Liu, D.; Zhang, Q.; Liu, S. Antihyperlipidemic activity of high sulfate content derivative of polysaccharide extracted from Ulva pertusa (Chlorophyta). Carbohydr. Polym. 2012, 87, 1637-1640. [CrossRef]

28. Fleita, D.; El-Sayed, M.; Rifaat, D. Evaluation of the antioxidant activity of enzymatically-hydrolyzed sulfated polysaccharides extracted from red algae; Pterocladia capillacea. LWT-Food Sci. Technol. 2015, 63, 1236-1244. [CrossRef]

29. Collins, K.G.; Fitzgerald, G.F.; Stanton, C.; Ross, R.P. Looking beyond the terrestrial: The potential of seaweed derived bioactives to treat non-communicable diseases. Mar. Drugs 2016, 14, 60. [CrossRef]

30. Torres, M.D.; Flórez-Fernández, N.; Domínguez, H. Integral utilization of red seaweed for bioactive production. Mar. Drugs 2019, 17, 314. [CrossRef]

31. Wells, M.L.; Potin, P.; Craigie, J.S.; Raven, J.A.; Merchant, S.S.; Helliwell, K.E.; Smith, A.G.; Camire, M.E.; Brawley, S.H. Algae as nutritional and functional food sources: Revisiting our understanding. J. Appl. Phycol. 2017, 29, 949-982. [CrossRef]

32. Cherry, P.; Yadav, S.; Strain, C.R.; Allsopp, P.J.; McSorley, E.M.; Ross, R.P.; Stanton, C. Prebiotics from seaweeds: An ocean of opportunity? Mar. Drugs 2019, 17, 327. [CrossRef]

33. O'Sullivan, L.; Murphy, B.; McLoughlin, P.; Duggan, P.; Lawlor, P.G.; Hughes, H.; Gardiner, G.E. Prebiotics from marine macroalgae for human and animal health applications. Mar. Drugs 2010, 8, 2038-2064. [CrossRef] [PubMed]

34. Jiao, G.; Yu, G.; Zhang, J.; Ewart, H.S. Chemical structures and bioactivities of sulfated polysaccharides from marine algae. Mar. Drugs 2011, 9, 196-223. [CrossRef] [PubMed]

35. Li, M.; Li, G.; Shang, Q.; Chen, X.; Liu, W.; Zhu, L.; Yin, Y.; Yu, G.; Wang, X. In vitro fermentation of alginate and its derivatives by human gut microbiota. Anaerobe 2016, 39, 19-25. [CrossRef] [PubMed]

36. Vera, J.; Castro, J.; Gonzalez, A.; Moenne, A. Seaweed polysaccharides and derived oligosaccharides stimulate defense responses and protection against pathogens in plants. Mar. Drugs 2011, 9, 2514-2525. [CrossRef]

37. Usov, A.I. Polysaccharides of the red algae. In Advances in Carbohydrate Chemistry and Biochemistry; Elsevier: San Diego, CA, USA, 2011; Volume 65, pp. 115-217.

38. Shang, Q.; Wang, Y.; Pan, L.; Niu, Q.; Li, C.; Jiang, H.; Cai, C.; Hao, J.; Li, G.; Yu, G. Dietary polysaccharide from Enteromorpha Clathrata modulates gut microbiota and promotes the growth of Akkermansia muciniphila, Bifidobacterium spp. and Lactobacillus spp. Mar. Drugs 2018, 16, 167. [CrossRef]

39. Hehemann, J.; Correc, G.; Barbeyron, T.; Helbert, W.; Czjzek, M.; Michel, G. Transfer of carbohydrate-active enzymes from marine bacteria to Japanese gut microbiota. Nature 2010, 464, 908. [CrossRef]

40. de Jesus Raposo, M.F.; De Morais, A.M.M.B.; De Morais, R.M.S.C. Emergent sources of prebiotics: Seaweeds and microalgae. Mar. Drugs 2016, 14, 27. [CrossRef]

41. Fehlbaum, S.; Prudence, K.; Kieboom, J.; Heerikhuisen, M.; van den Broek, T.; Schuren, F.H.J.; Steinert, R.E.; Raederstorff, D. In vitro fermentation of selected prebiotics and their effects on the composition and activity of the adult gut microbiota. Int. J. Mol. Sci. 2018, 19, 3097. [CrossRef]

42. Seong, H.; Bae, J.; Seo, J.S.; Kim, S.; Kim, T.; Han, N.S. Comparative analysis of prebiotic effects of seaweed polysaccharides laminaran, porphyran, and ulvan using in vitro human fecal fermentation. J. Funct. Foods 2019, 57, 408-416. [CrossRef]

43. Li, P.; Ying, J.; Chang, Q.; Zhu, W.; Yang, G.; Xu, T.; Yi, H.; Pan, R.; Zhang, E.; Zeng, X.; et al. Effects of phycoerythrin from Gracilaria lemaneiformis in proliferation and apoptosis of SW480 cells. Oncol. Rep. 2016, 36, 3536-3544. [CrossRef]

44. Nguyen, S.G.; Kim, J.; Guevarra, R.B.; Lee, J.; Kim, E.; Kim, S.; Unno, T. Laminarin favorably modulates gut microbiota in mice fed a high-fat diet. Food Funct. 2016, 7, 4193-4201. [CrossRef] [PubMed]

45. Gomez-Zavaglia, A.; Prieto Lage, M.A.; Jimenez-Lopez, C.; Mejuto, J.C.; Simal-Gandara, J. The potential of seaweeds as a source of functional ingredients of prebiotic and antioxidant value. Antioxidants 2019, 8, 406. [CrossRef] 
46. Okolie, C.L.; CK Rajendran, S.R.; Udenigwe, C.C.; Aryee, A.N.; Mason, B. Prospects of brown seaweed polysaccharides (BSP) as prebiotics and potential immunomodulators. J. Food Biochem. 2017, 41, e12392. [CrossRef]

47. Freitas, A.C.; Pereira, L.; Rodrigues, D.; Carvalho, A.P.; Panteleitchouk, T.; Gomes, A.M.; Duarte, A.C. Marine functional foods. In Springer Handbook of Marine Biotechnology; Springer: Heidelberg, Germany, 2015; pp. 969-994.

48. Rosa, G.P.; Tavares, W.R.; Sousa, P.M.C.; Pagès, A.K.; Seca, A.M.L.; Pinto, D.C.G.A. Seaweed secondary metabolites with beneficial health effects: An overview of successes in in vivo studies and clinical trials. Mar. Drugs 2019, 18, 8. [CrossRef] [PubMed]

49. Miranda, J.M.; Carrera, M.; Barros-Velázquez, J.; Aubourg, S.P. Impact of previous active dipping in Fucus spiralis extract on the quality enhancement of chilled lean fish. Food Control 2018, 90, 407-414. [CrossRef]

50. Miranda, J.M.; Trigo, M.; Barros-Velázquez, J.; Aubourg, S.P. Effect of an icing medium containing the alga Fucus spiralis on the microbiological activity and lipid oxidation in chilled megrim (Lepidorhombus whiffiagonis). Food Control 2016, 59, 290-297. [CrossRef]

51. Miranda, J.M.; Ortiz, J.; Barros-Velázquez, J.; Aubourg, S.P. Quality enhancement of chilled fish by including alga Bifurcaria bifurcata extract in the icing medium. Food Bioprocess Technol. 2016, 9, 387-395. [CrossRef]

52. Oucif, H.; Miranda, J.M.; Mehidi, S.A.; Abi-Ayad, S.E.; Barros-Velázquez, J.; Aubourg, S.P. Effectiveness of a combined ethanol-aqueous extract of alga Cystoseira compressa for the quality enhancement of a chilled fatty fish species. Eur. Food Res. Technol. 2018, 244, 291-299. [CrossRef]

53. Arulkumar, A.; Paramasivam, S.; Miranda, J.M. Combined effect of icing medium and red alga Gracilaria verrucosa on shelf life extension of Indian Mackerel (Rastrelliger kanagurta). Food Bioprocess Technol. 2018, 11, 1911-1922. [CrossRef]

54. Nwosu, F.; Morris, J.; Lund, V.A.; Stewart, D.; Ross, H.A.; McDougall, G.J. Anti-proliferative and potential anti-diabetic effects of phenolic-rich extracts from edible marine algae. Food Chem. 2011, 126, 1006-1012. [CrossRef]

55. Liu, M.; Zhang, W.; Wei, J.; Qiu, L.; Lin, X. Marine bromophenol bis (2,3-dibromo-4,5-dihydroxybenzyl) ether, induces mitochondrial apoptosis in K562 cells and inhibits topoisomerase I in vitro. Toxicol. Lett. 2012, 211, 126-134. [CrossRef] [PubMed]

56. Liu, F.; Wang, X.; Shi, H.; Wang, Y.; Xue, C.; Tang, Q. Polymannuronic acid ameliorated obesity and inflammation associated with a high-fat and high-sucrose diet by modulating the gut microbiome in a murine model. Br. J. Nutr. 2017, 117, 1332-1342. [CrossRef] [PubMed]

57. Liu, J.; Kandasamy, S.; Zhang, J.; Kirby, C.W.; Karakach, T.; Hafting, J.; Critchley, A.T.; Evans, F.; Prithiviraj, B. Prebiotic effects of diet supplemented with the cultivated red seaweed Chondrus crispus or with fructo-oligo-saccharide on host immunity, colonic microbiota and gut microbial metabolites. BMC Complement. Altern. Med. 2015, 15, 279. [CrossRef] [PubMed]

58. Chen, L.; Xu, W.; Chen, D.; Chen, G.; Liu, J.; Zeng, X.; Shao, R.; Zhu, H. Digestibility of sulfated polysaccharide from the brown seaweed Ascophyllum nodosum and its effect on the human gut microbiota in vitro. Int. J. Biol. Macromol. 2018, 112, 1055-1061. [CrossRef]

59. Kim, S.; Kim, S.R.; Oh, M.; Jung, S.; Kang, S.Y. In vitro antiviral activity of red alga, Polysiphonia morrowii extract and its bromophenols against fish pathogenic infectious hematopoietic necrosis virus and infectious pancreatic necrosis virus. J. Microbiol. 2011, 49, 102-106. [CrossRef]

60. Xu, X.; Piggott, A.M.; Yin, L.; Capon, R.J.; Song, F. Symphyocladins A-G: Bromophenol adducts from a Chinese marine red alga, Symphyocladia latiuscula. Tetrahedron Lett. 2012, 53, 2103-2106. [CrossRef]

61. Abou-El-Wafa, G.; Shaaban, M.; Shaaban, K.; El-Naggar, M.; Maier, A.; Fiebig, H.; Laatsch, H. Pachydictyols B and C: New diterpenes from Dictyota dichotoma Hudson. Mar. Drugs 2013, 11, 3109-3123. [CrossRef]

62. Rubiano-Buitrago, P.; Duque, F.; Puyana, M.; Ramos, F.; Castellanos, L. Bacterial biofilm inhibitor diterpenes from Dictyota pinnatifida collected from the Colombian Caribbean. Phytochem. Let. 2019, 30, 74-80. [CrossRef]

63. Tang, Z.; Gao, H.; Wang, S.; Wen, S.; Qin, S. Hypolipidemic and antioxidant properties of a polysaccharide fraction from Enteromorpha prolifera. Int. J. Biol. Macromol. 2013, 58, 186-189. [CrossRef]

64. Girard, L.; Birse, K.; Holm, J.B.; Gajer, P.; Humphrys, M.S.; Garber, D.; Guenthner, P.; Nël-Romas, L.; Abou, M.; McCorrister, S.; et al. Impact of the griffithsin anti-HIV microbiocide and placebo gels of the rectal mucose proteome and microbiome in non-human primates. Sci. Rep. 2018, 8, 8059. [CrossRef] 
65. Fitzgerald, C.; Aluko, R.E.; Hossain, M.; Rai, D.K.; Hayes, M. Potential of a renin inhibitory peptide from the red seaweed Palmaria palmata as a functional food ingredient following confirmation and characterization of a hypotensive effect in spontaneously hypertensive rats. J. Agric. Food Chem. 2014, 62, 8352-8356. [CrossRef]

66. Sato, M.; Hosokawa, T.; Yamaguchi, T.; nakano, T.; Muramoto, K.; Kahara, T.; Funayama, K.; Kobayashi, A.; Nakano, T. Angiotensin I-Conerting enzyme inhibitory peptides derived from Wakane (Undaria pinnatifida) and their antihypertensive effect in spontaneously hypertensive rats. J. Agric. Food Chem. 2002, 50, 6245-6252. [CrossRef] [PubMed]

67. Suárez, Y.; González, L.; Cuadrado, A.; Berciano, M.; Lafarga, M.; Muñoz, A. Kahalalide F, a new marine-derived compound, induces oncosis in human prostate and breast cancer cells. Mol. Cancer Ther. 2003, 2, 863-872.

68. Aryee, A.N.; Agyei, D.; Akanbi, T.O. Recovery and utilization of seaweed pigments in food processing. Curr. Opin. Food Sci. 2018, 19, 113-119. [CrossRef]

69. Fernández-Rojas, B.; Hernández-Juárez, J.; Pedraza-Chaverri, J. Nutraceutical properties of phycocyanin. J. Funct. Foods 2014, 11, 375-392. [CrossRef]

70. Hao, S.; Yan, Y.; Li, S.; Zhao, L.; Zhang, C.; Liu, L.; Wang, C. The in vitro anti-tumor activity of phycocyanin against non-small cell lung cancer cells. Mar. Drugs 2018, 16, 178. [CrossRef] [PubMed]

71. Jiang, L.; Wang, Y.; Yin, Q.; Liu, G.; Liu, H.; Huang, Y.; Li, B. Phycocyanin: A potential drug for cancer treatment. J. Cancer 2017, 8, 3416-3429. [CrossRef]

72. Manirafasha, E.; Ndikubwimana, T.; Zeng, X.; Lu, Y.; Jing, K. Phycobiliprotein: Potential microalgae derived pharmaceutical and biological reagent. Biochem. Eng. J. 2016, 109, 282-296. [CrossRef]

73. Kuda, T.; Kosaka, M.; Hirano, S.; Kawahara, M.; Sato, M.; Kaneshima, T.; Nishizawa, M.; Takahashi, H.; Kimura, B. Effect of sodium-alginate and laminaran on Salmonella Typhimurium infection in human enterocyte-like HT-29-Luc cells and BALB/c mice. Carbohydr. Polym. 2015, 125, 113-119. [CrossRef]

74. Han, Z.; Yang, M.; Fu, X.; Chen, M.; Su, Q.; Zhao, Y.; Mou, H. Evaluation of prebiotic potential of three marine algae oligosaccharides from enzymatic hydrolysis. Mar. Drugs 2019, 17, 173. [CrossRef]

75. Costa, L.; Fidelis, G.; Cordeiro, S.L.; Oliveira, R.; Sabry, D.D.A.; Câmara, R.; Nobre, L.; Costa, M.; Almeida-Lima, J.; Farias, E. Biological activities of sulfated polysaccharides from tropical seaweeds. Biomed. Pharmacother. 2010, 64, 21-28. [CrossRef] [PubMed]

76. Zaporozhets, T.; Besednova, N.; Kuznetsova, T.; Zvyagintseva, T.; Makarenkova, I.; Kryzhanovsky, S.; Melnikov, V. The prebiotic potential of polysaccharides and extracts of seaweeds. Russ. J. Mar. Biol. 2014, 40, 1-9. [CrossRef]

77. Hall, A.B.; Tolonen, A.C.; Xavier, R.J. Human genetic variation and the gut microbiome in disease. Nat. Rev. Genet. 2017, 18, 690. [CrossRef] [PubMed]

78. Roca-Saavedra, P.; Mendez-Vilabrille, V.; Miranda, J.M.; Nebot, C.; Cardelle-Cobas, A.; Franco, C.M.; Cepeda, A. Food additives, contaminants and other minor components: Effects on human gut microbiota-A review. J. Physiol. Biochem. 2018, 74, 69-83. [CrossRef] [PubMed]

79. Sardari, R.R.; Nordberg Karlsson, E. Marine poly-and oligosaccharides as prebiotics. J. Agric. Food Chem. 2018, 66, 11544-11549. [CrossRef]

80. Huttenhower, C.; Gevers, D.; Knight, R.; Abubucker, S.; Badger, J.H.; Chinwalla, A.T.; Creasy, H.H.; Earl, A.M.; Fitzgerald, M.G.; Fulton, R.S. Structure, function and diversity of the healthy human microbiome. Nature 2012, 486, 207.

81. Zmora, N.; Suez, J.; Elinav, E. You are what you eat: Diet, health and the gut microbiota. Nat. Rev. Gastroenterol. Hepatol. 2019, 16, 35-56. [CrossRef]

82. Kong, Q.; Dong, S.; Gao, J.; Jiang, C. In vitro fermentation of sulfated polysaccharides from E. prolifera and L. japonica by human fecal microbiota. Int. J. Biol. Macromol. 2016, 91, 867-871. [CrossRef]

83. Clemente, J.C.; Pehrsson, E.C.; Blaser, M.J.; Sandhu, K.; Gao, Z.; Wang, B.; Magris, M.; Hidalgo, G.; Contreras, M.; Noya-Alarcón, Ó. The microbiome of uncontacted Amerindians. Sci. Adv. 2015, 1, e1500183. [CrossRef]

84. Teng, Z.; Qian, L.; Zhou, Y. Hypolipidemic activity of the polysaccharides from Enteromorpha prolifera. Int. J. Biol. Macromol. 2013, 62, 254-256. [CrossRef]

85. Charoensiddhi, S.; Conlon, M.A.; Vuaran, M.S.; Franco, C.M.; Zhang, W. Impact of extraction processes on prebiotic potential of the brown seaweed Ecklonia radiata by in vitro human gut bacteria fermentation. J. Funct. Foods 2016, 24, 221-230. [CrossRef] 
86. Praveen, M.A.; Parvathy, K.K.; Jayabalan, R.; Balasubramanian, P. Dietary fiber from Indian edible seaweeds and its in-vitro prebiotic effect on the gut microbiota. Food Hydrocoll. 2019, 96, 343-353. [CrossRef]

87. Fu, X.; Cao, C.; Ren, B.; Zhang, B.; Huang, Q.; Li, C. Structural characterization and in vitro fermentation of a novel polysaccharide from Sargassum thunbergii and its impact on gut microbiota. Carbohydr. Polym. 2018, 183, 230-239. [CrossRef]

88. Rodrigues, D.; Walton, G.; Sousa, S.; Rocha-Santos, T.A.; Duarte, A.C.; Freitas, A.C.; Gomes, A.M. In vitro fermentation and prebiotic potential of selected extracts from seaweeds and mushrooms. LWT-Food Sci. Technol. 2016, 73, 131-139. [CrossRef]

89. Devillé, C.; Gharbi, M.; Dandrifosse, G.; Peulen, O. Study on the effects of laminarin, a polysaccharide from seaweed, on gut characteristics. J. Sci. Food Agric. 2007, 87, 1717-1725. [CrossRef]

90. Kim, J.; Yu, D.; Kim, J.; Choi, E.; Lee, C.; Hong, Y.; Kim, C.; Lee, S.; Choi, I.; Cho, K. Effects of Undaria linnatifida and Laminaria japonica on rat's intestinal microbiota and metabolite. J. Nutr. Food Sci. 2016, 6. [CrossRef]

91. Strain, C.R.; Collins, K.C.; Naughton, V.; McSorley, E.M.; Stanton, C.; Smyth, T.J.; Soler-Vila, A.; Rea, M.C.; Ross, P.R.; Cherry, P. Effects of a polysaccharide-rich extract derived from Irish-sourced Laminaria digitata on the composition and metabolic activity of the human gut microbiota using an in vitro colonic model. Eur. J. Nutr. 2019, 1-17. [CrossRef]

92. Zhao, J.; Cheung, P.C. Fermentation of $\beta$-glucans derived from different sources by bifidobacteria: Evaluation of their bifidogenic effect. J. Agric. Food Chem. 2011, 59, 5986-5992. [CrossRef]

93. Kaewmanee, W.; Suwannaporn, P.; Huang, T.C.; Al-Ghazzewi, F.; Tester, R.F. In vivo prebiotic properties of Ascophyllum nodosum polysaccharide hydrolysates from lactic acid fermentation. J. Appl. Phycol. 2019, 31, 3153-3162. [CrossRef]

94. Ramnani, P.; Chitarrari, R.; Tuohy, K.; Grant, J.; Hotchkiss, S.; Philp, K.; Campbell, R.; Gill, C.; Rowland, I. In vitro fermentation and prebiotic potential of novel low molecular weight polysaccharides derived from agar and alginate seaweeds. Anaerobe 2012, 18, 1-6. [CrossRef]

95. Shang, Q.; Shan, X.; Cai, C.; Hao, J.; Li, G.; Yu, G. Dietary fucoidan modulates the gut microbiota in mice by increasing the abundance of Lactobacillus and Ruminococcaceae. Food Funct. 2016, 7, 3224-3232. [CrossRef]

96. Huebbe, P.; Nikolai, S.; Schloesser, A.; Herebian, D.; Campbell, G.; Gluer, C.C.; Zeyner, A.; Demetrowitsch, T.; Schwarz, K.; Metges, C.C.; et al. An extract from the Atlantic brown algae Saccorhiza polyschides counteracts diet-induced obesity in mice via a gut related multi-factorial mechanisms. Oncotarget 2017, 8, 73501-73515. [CrossRef] [PubMed]

97. Berri, M.; Olivier, M.; Holbert, S.; Dupont, J.; Demais, H.; Le Goff, M.; Collen, P.N. Ulvan from Ulva armoricana (Chlorophyta) activates the PI3K/Akt signalling pathway via TLR4 to induce intestinal cytokine production. Algal Res. 2017, 28, 39-47. [CrossRef]

98. Shih, Y.L.; Hsueh, S.C.; Chen, Y.L.; Chou, J.S.; Chung, H.Y.; Liu, K.L.; Jair, H.W.; Chuang, Y.Y.; Lu, H.F.; Liu, J.Y; et al. Laminarin promotes immune responses and reduces lactate dehydrogenase but increases glutamic pyruvic transaminase in normal mice in vivo. In Vivo 2018, 32, 523-529. [PubMed]

99. Wang, X.; Wang, X.; Jiang, H.; Cai, C.; Li, G.; Hao, J.; Yu, G. Marine polysaccharides attenuate metabolic syndrome by fermentation products and altering gut microbiota: An overview. Carbohydr. Polym. 2018, 195, 601-612. [CrossRef]

100. Nakata, T.; Kyoui, D.; Takahashi, H.; Kimura, B.; Kuda, T. Inhibitory effects of laminaran and alginate on production of putrefactive compounds from soy protein by intestinal microbiota in vitro and in rats. Carbohydr. Polym. 2016, 143, 61-69. [CrossRef]

101. An, C.; Kuda, T.; Yazaki, T.; Takahashi, H.; Kimura, B. FLX pyrosequencing analysis of the effects of the brown-algal fermentable polysaccharides alginate and laminaran on rat cecal microbiotas. Appl. Environ. Microbiol. 2013, 79, 860-866. [CrossRef]

102. Xie, G.; Wang, X.; Liu, P.; Wei, R.; Chen, W.; Rajani, C.; Hernandez, B.Y.; Alegado, R.; Dong, B.; Li, D.; et al. Distinctly altered gut microbiota in the progression of liver disease. Oncotarget 2016, 7, 19355-19366. [CrossRef]

103. Scott, K.P.; Martin, J.C.; Duncan, S.H.; Flint, H.J. Prebiotic stimulation of human colonic butyrate-producing bacteria and bifidobacteria, in vitro. FEMS Microbiol. Ecol. 2014, 87, 30-40. [CrossRef]

104. Zheng, C.; Liu, R.; Xue, B.; Luo, J.; Gao, L.; Wang, Y.; Ou, S.; Li, S.; Peng, X. Impact and consequences of polyphenols and fructooligosaccharide interplay on gut microbiota in rats. Food Funct. 2017, 8, 1925-1932. [CrossRef] 
105. Di, T.; Chen, G.; Sun, Y.; Ou, S.; Zeng, X.; Ye, H. In vitro digestion by saliva, simulated gastric and small intestinal juices and fermentation by human fecal microbiota of sulfated polysaccharides from Gracilaria rubra. J. Funct. Foods 2018, 40, 18-27. [CrossRef]

106. Silva, R.; Santana, A.; Carvalho, N.; Bezerra, T.; Oliveira, C.; Damasceno, S.; Chaves, L.; Freitas, A.; Soares, P.; Souza, M. A sulfated-polysaccharide fraction from seaweed Gracilaria birdiae prevents naproxen-induced gastrointestinal damage in rats. Mar. Drugs 2012, 10, 2618-2633. [CrossRef] [PubMed]

107. Bajury, D.M.; Rawi, M.H.; Sazali, I.H.; Abdullah, A.; Sarbini, S.R. Prebiotic evaluation of red seaweed (Kappaphycus alvarezii) using in vitro colon model. Int. J. Food Sci. Nutr. 2017, 68, 821-828. [CrossRef] [PubMed]

108. Fu, X.T.; Kim, S.M. Agarase: Review of major sources, categories, purification method, enzyme characteristics and applications. Mar. Drugs 2010, 8, 200-218. [CrossRef] [PubMed]

109. Shang, Q.; Jiang, H.; Cai, C.; Hao, J.; Li, G.; Yu, G. Gut microbiota fermentation of marine polysaccharides and its effects on intestinal ecology: An overview. Carbohydr. Polym. 2018, 179, 173-185. [CrossRef]

110. Zhang, N.; Mao, X.; Li, R.W.; Hou, E.; Wang, Y.; Xue, C.; Tang, Q. Neoagarotetraose protects mice against intense exercise-induced fatigue damage by modulating gut microbial composition and function. Mol. Nutr. Food Res. 2017, 61, 1600585. [CrossRef]

111. Ladirat, S.; Schols, H.; Nauta, A.; Schoterman, M.; Schuren, F.; Gruppen, H. In vitro fermentation of galacto-oligosaccharides and its specific size-fractions using non-treated and amoxicillin-treated human inoculum. Bioact. Carbohydr. Diet. Fibre 2014, 3, 59-70. [CrossRef]

112. Kulshreshtha, G.; Rathgeber, B.; Stratton, G.; Thomas, N.; Evans, F.; Critchley, A.; Hafting, J.; Prithiviraj, B. Feed supplementation with red seaweeds, Chondrus crispus and Sarcodiotheca gaudichaudii, affects performance, egg quality, and gut microbiota of layer hens. Poult. Sci. 2014, 93, 2991-3001. [CrossRef]

113. Munoz-Munoz, J.; Cartmell, A.; Terrapon, N.; Henrissat, B.; Gilbert, H.J. Unusual active site location and catalytic apparatus in a glycoside hydrolase family. Proc. Natl. Acad. Sci. USA 2017, 114, 4936-4941. [CrossRef]

114. Ren, X.; Liu, L.; Gamallat, Y.; Zhang, B.; Xin, Y. Enteromorpha and polysaccharides from Enteromorpha ameliorate loperamide-induced constipation in mice. Biomed. Pharmacother. 2017, 96, 1075-1081. [CrossRef]

115. Zhang, Z.; Wang, X.; Han, S.; Liu, C.; Liu, F. Effect of two seaweed polysaccharides on intestinal microbiota in mice evaluated by illumina PE250 sequencing. Int. J. Biol. Macromol. 2018, 112, 796-802. [CrossRef] [PubMed]

116. Rahimi, F.; Tabarsa, M.; Rezaei, M. Ulvan from green algae Ulva intestinalis: Optimization of ultrasound-assisted extraction and antioxidant activity. J. Appl. Phycol. 2016, 28, 2979-2990. [CrossRef]

117. Lecerf, J.; Dépeint, F.; Clerc, E.; Dugenet, Y.; Niamba, C.N.; Rhazi, L.; Cayzeele, A.; Abdelnour, G.; Jaruga, A.; Younes, H. Xylo-oligosaccharide (XOS) in combination with inulin modulates both the intestinal environment and immune status in healthy subjects, while XOS alone only shows prebiotic properties. Br. J. Nutr. 2012, 108, 1847-1858. [CrossRef] [PubMed]

118. Lahaye, M.; Michel, C.; Barry, J.L. Chemical, physicochemical and in-vitro fermentation characteristics of dietary fibres from Palmaria palmata (L.) Kuntze. Food Chem. 1993, 47, 29-36. [CrossRef]

(C) 2020 by the authors. Licensee MDPI, Basel, Switzerland. This article is an open access article distributed under the terms and conditions of the Creative Commons Attribution (CC BY) license (http://creativecommons.org/licenses/by/4.0/). 
Review

\title{
Avocado Oil: Characteristics, Properties, and Applications
}

\author{
Marcos Flores ${ }^{1, *}$, Carolina Saravia ${ }^{2, *}$, Claudia E. Vergara ${ }^{1}$, Felipe Avila ${ }^{3}$, Hugo Valdés $^{4}$ and \\ Jaime Ortiz-Viedma ${ }^{5, *}$ \\ 1 Departamento de Ciencias Básicas, Facultad de Ciencias, Universidad Santo Tomás, Avenida Carlos Schorr \\ 255, Talca 3473620, Chile; claudiavergarava@santotomas.cl \\ 2 Escuela de Nutrición y Dietética, Facultad de Salud, Universidad Santo Tomás, Avenida Carlos Schorr 255, \\ Talca 3473620, Chile \\ 3 Escuela de Nutrición y Dietética, Facultad de Ciencias de la Salud, Universidad de Talca, Talca 3460000, \\ Chile; favilac@utalca.cl \\ 4 Centro de Innovación en Ingeniería Aplicada, Departamento de Computación e Industrias, \\ Universidad Catolica del Maule, Avenida San Miguel 3605, Talca 3480112, Chile; hvaldes@ucm.cl \\ 5 Department of Food Science and Chemical Technology, Faculty of Chemical and Pharmaceutical Sciences, \\ University of Chile, Santos Dumont 964, Santiago 8380494, Chile \\ * Correspondence: marcosflores@santotomas.cl (M.F.); csaraviam@santotomas.cl (C.S.); \\ jaortiz@uchile.cl (J.O.-V.); Tel.: +56-7123-424-18 (M.F.)
}

Academic Editor: Jose M. Miranda

Received: 9 May 2019; Accepted: 8 June 2019; Published: 10 June 2019

\begin{abstract}
Avocado oil has generated growing interest among consumers due to its nutritional and technological characteristics, which is evidenced by an increase in the number of scientific articles that have been published on it. The purpose of the present research was to discuss the extraction methods, chemical composition, and various applications of avocado oil in the food and medicine industries. Our research was carried out through a systematic search in scientific databases. Even though there are no international regulations concerning the quality of avocado oil, some authors refer to the parameters used for olive oil, as stated by the Codex Alimentarius or the International Olive Oil Council. They indicate that the quality of avocado oil will depend on the quality and maturity of the fruit and the extraction technique in relation to temperature, solvents, and conservation. While the avocado fruit has been widely studied, there is a lack of knowledge about avocado oil and the potential health effects of consuming it. On the basis of the available data, avocado oil has established itself as an oil that has a very good nutritional value at low and high temperatures, with multiple technological applications that can be exploited for the benefit of its producers.
\end{abstract}

Keywords: avocado oil; oil extraction; antioxidants compounds; fatty acid profile

\section{Introduction}

Avocado (Persea americana Mill.) is a fruit native to Central America, grown in warm temperate and subtropical climates throughout the world. The pulp of this fruit contains about $60 \%$ oil, $7 \%$ skin, and approximately $2 \%$ seed $[1,2]$. The main producers of avocado oil in the world are New Zealand, Mexico, the United States, South Africa, and Chile [3]. Avocado oil has sparked a growing interest in human nutrition, food industry, and cosmetics. The lipid content, mainly of monounsaturated fatty acids, is associated with cardiovascular system benefits and anti-inflammatory effects [4,5].

There are no internationally defined parameters for avocado oil. The values that are commonly used are those recommended for olive oil. The quality standard for olive oil is available in the Codex Alimentarius and the International Olive Oil Council (IOC) [6]. 
Woolf et al. [7] proposed a classification for avocado oil based on its extraction method and fruit quality. Avocado oil of a higher quality, "extra virgin", corresponds to that produced from high-quality fruit, extracted only with mechanical methods, using a temperature below $50{ }^{\circ} \mathrm{C}$ and without the use of chemical solvents. "Virgin" avocado oil is produced with fruit of a lower quality (with small areas of rot and physical alterations), extracted by mechanical methods, using a temperature below $50^{\circ} \mathrm{C}$ and without the use of chemical solvents. "Pure" avocado oil is a type of oil for the production of which the quality of the fruit is not important; it is a bleached and deodorized oil, infused with the natural flavor of herbs or fruits. Finally, "mixed" avocado oil is combined with olive, macadamia, and other oils. Therefore, it presents sensory and chemical characteristics that are variable.

The Mexican norm [8] states that the "crude oil of avocado" is a slightly amber-colored fatty liquid, obtained by physical extraction of the pulp and the seed of the fruit (Persea americana). "Pure" edible avocado oil is a product with at least $98.5 \%$ refined avocado oil.

In this work, a systematic review of the literature was carried out to collect, select, evaluate, and summarize all available evidence regarding the processes and properties of avocado oil. The research question was: What are the most published topics on avocado oil? The answer to this question allowed us to include topics, such as: extraction methods (i.e., cold pressed method, ultrasound-assisted aqueous extraction method, supercritical $\mathrm{CO}_{2}$ method, $\mathrm{CO}_{2}$ subcritical method, enzymatic extraction, and solvent extraction), procedures of conservation, contamination/adulteration, technological applications, composition (characteristics according to the variety and origin of the fruit, physicochemical characterization, avocado seed oil, and comparison with other oils), and biological effects (human health effects and experimental studies in animals). Figure 1 shows the exponential increase of scientific interest in avocado oil. On the topic, "avocado oil" (from 1980 to date), 180 and 224 articles have been published in the Web of Science (WoS) and Scopus, respectively.

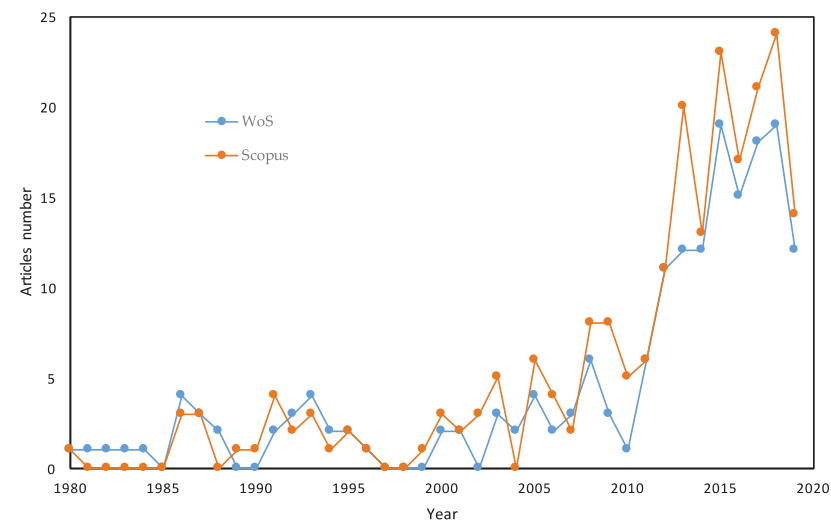

Figure 1. Graphic of articles (topic: "avocado oil") from 1980 to 2019 in the Web of Science (WoS) and Scopus.

The purpose of this research is to produce a complete profile on avocado oil, including extraction methods, physicochemical characteristics, nutritional properties, as well as various applications in the food and medicine industries. Avocado oil has proven to be a vegetable oil with a composition of major and minor components that are highly appreciated by the population, either at low or high temperatures, with multiple technological applications.

\section{Extraction Methods for Avocado Oil}

The information presented in this section focuses on the process efficiency, improvement of production performance, and product quality as well as applications in the food industry. 
Considering the high humidity percentage of avocado (around 70 to $80 \%$ ), the influence of the pulp drying method prior to oil extraction has been studied [9]. The quality parameters (peroxide value, iodine value, amount of oleic acid, refractive index, electrical conductivity, content of carotenoids, chlorophyll, phenolic compounds, and antioxidant activity) have shown better results when the pulp is dried at $60{ }^{\circ} \mathrm{C}$ under vacuum, and the extraction is performed by the Soxhlet method. Meanwhile, the bioactive compounds were best preserved when the avocado pulp was dried at $60{ }^{\circ} \mathrm{C}$ with air ventilation and mechanical pressing [10]. On the other hand, avocado pulp oil, pressed and dried in a microwave, presented a better quality—determined by the acidity index, peroxide index, and oxidative stability - when compared with oil obtained by extraction with ethanol. The composition of fatty acids did not differ significantly when analyzing oil obtained by drying under microwaves or in a drying oven with forced air circulation [11]. According to Chimsook and Assawarachan [12], the studied drying method of the avocado pulp, prior to the extraction of the oil, does not significantly influence the composition of fatty acids. However, changes were determined in the antioxidant activity and vitamin E content of cold-pressed avocado oil (from Thailand). Higher antioxidant activities and a higher vitamin E content were observed in oil, the pulp of which was dried with hot air, when compared to oils obtained by an air-dried and vacuum process. This study is consistent with the fact that oils from the fortune avocado variety, obtained by the pulp drying lyophilization method, resulted in lower concentrations of $\alpha$-tocopherol, squalene and $\beta$-sitosterol, as well as higher relative concentrations of campesterol and cycloartenol acetate, compared to oils obtained through hot air-drying processes [13].

\subsection{Cold Pressed Method}

According to the CODEX STAN 19-1981 [14], the method of extraction of edible vegetable oils is characterized by mechanical procedures, for example, extrusion or pressing, without the application of heat. In addition, the oil can only be purified by washing, sedimentation, filtration, and centrifugation.

In the cold pressing method, oil recovery is only obtained from the parenchyma cells of the pulp; its rupture begins in the first stages of grinding and it can be seen that the idioblastic cells (oil carriers) remain intact during the process of extraction. The extraction yield increases when the pulp is beaten at $45.5^{\circ} \mathrm{C}$ for $2 \mathrm{~h}$ [15]. In this method, a lower extraction yield is obtained, although with higher concentrations of $\alpha$-tocopherol and squalene, as well as lower contents of campesterol and cycloartenol acetate, compared to the Soxhlet method [13]. Drying by lyophilization and subsequent extraction by the Soxhlet method allows for a better extraction performance. However, when drying by lyophilization and extracting by cold pressing, oils with a greater concentration of antioxidants, and other bioactive compounds were obtained [13].

\subsection{Ultrasound-Assisted Aqueous Extraction Method (UAAE)}

This method uses the cavitation forces produced by acoustic waves to break down the cell walls of the oil-containing cells. This process allows for the generation of an emulsion, which facilitates oil extraction. This method can be carried out using an ultrasonic bath or an ultrasonic horn transducer [16]. The high frequency ultrasound conditioning $(0.4,0.6$, and $2 \mathrm{MHz}, 5 \mathrm{~min}, 90 \mathrm{~kJ} / \mathrm{kg}$ ) of the avocado puree can improve the oil separation and potentially reduce the beating time in industrial processes, without affecting the quality of the oil. If this treatment is applied after shaking, the extractability of the oil increases by between $2 \%$ and $5 \%$. The oils obtained from sonicated purees showed free fatty acids (FFA) and peroxide values below the levels of industrial specification (peroxide less than $20 \mathrm{meqO}_{2} / \mathrm{kg}$ ) and an increase in total phenolic compounds after a $2 \mathrm{MHz}$ treatment [17]. The ultrasound-assisted aqueous extraction (UAAE) of low virgin avocado oil in FFA, considered as virgin avocado oil, is that obtained by mechanical or natural means at low temperatures $\left(<50^{\circ} \mathrm{C}\right)$ and without chemical refining [7]. The optimal UAAE parameters to produce the highest extraction of virgin avocado oil was $6 \mathrm{~mL} / \mathrm{g}$ water-dried pulp powder, $30 \mathrm{~min}$ of sonication time at $35^{\circ} \mathrm{C}$. The sonicated virgin avocado oil was lighter and had a higher level of unsaturated fatty acids, compared to the avocado oil extracted by the Soxhlet method [16]. 


\subsection{Supercritical $\mathrm{CO}_{2}$ Method}

This method of extraction is based on the use of supercritical fluids, substances that are, in certain circumstances, in a state in which they have intermediate properties between liquid and gas. Supercritical $\mathrm{CO}_{2}\left(\mathrm{scCO}_{2}\right)$ is a totally innocuous gas, which becomes a powerful solvent under conditions of pressure and at a temperature above its critical point [18].

Extraction with $\mathrm{scCO}_{2}$ presents a higher performance at a pressure of 400 bar. The use of ethanol as a co-solvent favors the extraction of residual oil, benefiting the extraction of a fraction enriched in tocopherols [19].

Some authors [20,21] proposed the combined extraction of avocado oil and active compounds present in peppers (capsanthin) and tomatoes (lycopene) using $\mathrm{scCO}_{2}$ in order to enrich the avocado oil. For this, a fixed bed extractor was used, where the lipids and the desired active ingredient were subjected to the extraction process, simultaneously with $\mathrm{scCO}_{2}$. First, both the $\mathrm{scCO}_{2}$ and the oil extracted from the avocado passed through the avocado bed and then through the second bed, where the plant component to be co-extracted was found. The lipids obtained in the first chamber served as a co-solvent with $\mathrm{scCO}_{2}$ for extraction in the second chamber. In the case of the simultaneous extraction of edible avocado oil and the capsanthin (carotenoid) of red pepper, the higher concentration of oil improved the extraction yield of capsanthin. However, a less concentrated extract was obtained, since the carotenoid was diluted in the product. In the case of the extraction of avocado oil rich in lycopene, the extraction yield of lycopene increased as the proportion of avocado in the first extraction chamber increased, being the best condition for the extraction of lycopene present in tomato pomace at $400 \mathrm{bar}$ and $50^{\circ} \mathrm{C}$.

Restrepo et al. [22] evaluated the quality of avocado oil extracted by Soxhlet, cold pressed, and $\mathrm{scCO}_{2}$ methods, determining the quality of the oil in terms of free fatty acid titration, peroxide index, iodine index, saponification, and specific gravity, according to the American Oil Chemists' Society (AOCS) standards. Extraction with supercritical fluids was the technique by which the highest yields and quality were obtained. Oils extracted by $\mathrm{scCO}_{2}$ were characterized as possessing a lower acidity index $(0.48 \%)$, low oxidation of unsaturated fatty acids $\left(16.87 \mathrm{meqO}_{2} / \mathrm{kg}\right)$ and higher iodine index $(80.18 \mathrm{cgI} / \mathrm{g})$, when compared with the other methods. In addition, extraction by cold pressing showed better results in terms of vitamin $\mathrm{E}$ content.

Regarding extraction by pressurized fluids, the extraction with the liquefied gas of compressed oil (LPG), constituted by a mixture of propane, n-butane, isobutane, ethane, and other hydrocarbons, showed a higher oil extraction performance in less time and with a lower solvent consumption than the $\mathrm{scCO}_{2}$ method. On the other hand, the oil obtained by compressed LPG presented higher concentrations of Stigmasterol, licopersene, palmitic acid, oleic acid, and linoleic acid. However, $\mathrm{scCO}_{2}$ provided a higher yield in terms of antioxidant activity, which was determined by means of the 2,2-Diphenyl-1-picrylhydrazyl (DPPH) radical assay [23].

\section{4. $\mathrm{CO}_{2}$ Subcritical Method}

Extraction with $\mathrm{sCO}_{2}$ operates under the same principle as the $\mathrm{scCO}_{2}$ extraction, but with a temperature below $31.1^{\circ} \mathrm{C}$ and $\mathrm{CO}_{2}$ pressure of 72.9 bar [24].

In this part of the review, a comparison of the physicochemical properties of avocado oil, extracted through $\mathrm{sCO}_{2}, \mathrm{UAAE}$, and conventional solvent (AOAC 920.39 [25]) will be analyzed. Extraction with $\mathrm{sCO}_{2}$ was performed at $27^{\circ} \mathrm{C}$ and 68 bar $\mathrm{CO}_{2}$, UAAE was performed with $60 \mathrm{~mL}$ of distilled water, an ultrasonic power of $240 \mathrm{~W}$ and a frequency of $40 \mathrm{kHz}$ for $30 \mathrm{~min}$ at $35^{\circ} \mathrm{C}$, followed by a final pressing. Compared to solvent extraction, oils extracted using $\mathrm{sCO}_{2}$ and $\mathrm{UAAE}$ had higher iodine index values but lower melting points, determined by slip, free fatty acid content, and saponification index values. The oils extracted by $\mathrm{sCO}_{2}$ and UAAE have a clear color and higher levels of unsaturated fatty acids than the oil extracted with hexane. Regardless of the extraction method, the main fatty acids in avocado oils were oleic and palmitic acids, while the main triacylglycerols in avocado oils were palmitoyl-dioleoyl-glycerol (POO; 22.48-23.01\%) and palmitoyl- Oleoyl-linoleoyl-glycerol (POL; 17.64-18.23\%) [24]. 


\subsection{Enzymatic Extraction}

In order to improve the performance of extraction by centrifugation, the incorporation of enzymes, such as pectinases, $\alpha$-amylase, proteases, and cellulase, to avocado paste have been considered. The yield varies depending on the concentration and type of enzyme used and the reaction time and percentage of water used. It is emphasized that this method improves oil by up to 25 times, in comparison with the performance of a non-enzymatic centrifugation [26].

\subsection{Solvent Extraction}

Reddy et al. [27] compared four extraction methods to produce avocado oil (Hass and Fuerte variety). They analyzed: (1) the extraction with traditional solvent using Soxhlet (5.0 $\mathrm{g}$ of dried avocado sample with $250 \mathrm{~mL}$ of hexane for $24 \mathrm{~h}$ ); (2) Ultrasonic Soxhlet extraction (5.0 $\mathrm{g}$ of dry avocado sample, sonicated in a water bath at $60^{\circ} \mathrm{C}$, with hexane as the solvent, for $1 \mathrm{~h}$ ); (3) Soxhlet extraction, combined with a microwave treatment (avocado paste $5 \mathrm{~mm}$ thick, extended in the rotating plate of a domestic microwave oven, heated to the maximum power for $11 \mathrm{~min}$, with $5 \mathrm{~g}$ of the resulting mass subsequently extracted by means of the Soxhlet method with hexane); and (4) extraction with supercritical fluid (Argon and scCO $\mathrm{CO}_{2}$ used as extraction fluids, extractions performed for $2 \mathrm{~h}$, with a fluid flow rate of $2.8-3.5 \mathrm{~mL} / \mathrm{min}$ ). The traditional Soxhlet extraction method yields the most reproducible results, whereas the microwave extraction showed a higher extraction yield and higher fatty acid content (69.94\%).

Meyer and Terry [28] performed a sequential extraction and quantification of fatty acids and avocado sugars. The average oil yield using Soxhlet extraction, with ethanol as the solvent, was significantly higher than the oil obtained by homogenization with hexane, and the fatty acid profiles for the two methods were similar. As the maturity of the fruit increases, the extraction of oil is improved. After lipid removal, methanolic extraction was superior in terms of the sucrose and perseitol obtained, compared to extraction with $80 \%$ ethanol $(v / v)$. The extraction of mannoheptulose was not affected by any of the solvents used.

The yield of avocado oil extraction has been assessed, comparing four extraction methods using solvents of different polarities. The extraction was performed using the Soxhlet method, with (1) petroleum ether, (2) homogenization with petroleum ether, (3) homogenization with a mixture of chloroform/methanol (2:1 v/v), and finally (4) extraction with chlorine-naphthalene and ball milling. It was determined that methods that only use petroleum ether as an extraction medium presented lower yields (6-9\% less) than the last two methods. Saponifiable residues were lower when the method using the chloroform/methanol mixture was employed. However, this method did not completely eliminate the residual oil from the fruit [29].

Ortiz-Moreno et al. [30] analyzed the effect of four extraction methods on the chemical-physical quality of avocado oil, namely, (1) the method of microwave extraction and manual pressing, (2) extraction with hexane using the Soxhlet methodology, (3) microwave extraction, combined with the Soxhlet methodology, using hexane as the solvent, and (4) extraction with acetone. The method with the highest oil extraction performance was the third method. The amount of trans fatty acids produced by the first method was the lowest and the latter method is also the one that generates the least physicochemical alterations.

When analyzing the effect of the drying method and avocado oil extraction process, ripe fruit, independent of the drying method, presents a higher extraction performance than immature fruit. This is influenced by the enzymatic degradation of the cell wall of the parenchyma during maturation. Freeze drying improves the amount of oil extracted for the $\mathrm{scCO}_{2}$ extracts and, to a lesser extent, for the hexane extracts. Extraction with hexane has been shown to have a higher oil extraction yield than $\mathrm{scCO}_{2}$ due to the lower degree of selectivity of this solvent, which completely penetrates the plant material [31].

Regarding the performance of the avocado oil extraction process, methodologies have been proposed for developing countries. One is carried out with boiling petroleum ether $\left(30-60^{\circ} \mathrm{C}\right)$ and another extraction with distilled water (avocado paste, diluted at a ratio of 3:1 and 5:1 (w/w), heated in a water bath of 75 to $98^{\circ} \mathrm{C}$, with subsequent centrifugation. In the extraction methods, calcium chloride, sodium chloride, 
calcium carbonate and calcium sulfate were used as extraction aids. The presence of inorganic salts at a low concentration improves the extraction performance, provided that it does not exceed $5 \%$; otherwise, it has an adverse effect. The most efficient extractions were obtained with a water/avocado ratio of 5:1, $\mathrm{pH}$ of 5.5 and centrifugal force of $12,300 \times g$, with the addition of $5 \%$ calcium carbonate or calcium sulfate. At higher heating temperatures $\left(75-98^{\circ} \mathrm{C}\right)$, the oil release time decrease. In addition, the gravity sedimentation for four days at $37^{\circ} \mathrm{C}$, followed by centrifugation, improves the oil extraction performance [32].

Considering the use of organic solvents in avocado oil extraction processes could alter the quality of fatty acids by inducing the formation of trans isomers. Ariza-Ortega et al. [33] proposed the application of infrared spectroscopy by Fourier transform (FTIR) to study trans fatty acids in the avocado oils of the Hass, Fuerte, and Criollo varieties. For this, oil extraction was performed by centrifugation at $40^{\circ} \mathrm{C}$ and extraction with hexane at $70{ }^{\circ} \mathrm{C}$ for $4 \mathrm{~h}$. The method using centrifugation did not increase the deterioration of fatty acids. A strong band at $723 \mathrm{~cm}^{-1}$ was documented, which is attributable to the cis functional groups, where the green color was maintained. On the other hand, the infrared spectroscopy with Fourier transform (FTIR) analysis identified an absorption band, located at $968 \mathrm{~cm}^{-1}$, which is associated with fatty acids, with trans isomerism for the Fuerte variety extracted with hexane.

\section{Procedures for the Conservation of Avocado Oil}

The conservation of oils is a necessary issue to address, since it allows for increasing the useful life of the products. One of the efforts made to improve the conservation of avocado oil has been the use of physical techniques, such as the electric field.

The electric field (voltage $9 \mathrm{kV} \mathrm{cm}^{-1}$, frequency $720 \mathrm{~Hz}$, time of 5 and $25 \mathrm{~min}$ ) allows the polyphenol oxidase enzyme present in the avocado pulp to be inactivated, preserving the components present in the avocado oil. The modifications in the quality of the refined oil (established according to the acidity index, peroxides, and iodine) are minimal, considering the electric field method as an alternative for the addition of synthetic antioxidants [34].

The oxidative stability (determined by finding the antioxidant activity reducing ferric ion, FRAP), during the storage of cold-extracted avocado oil in the presence of the oleoresins of Capsicum annuum L. (vegetable material rich in carotenoids), was assessed. It was determined that the optimal extraction of carotenoids was at a concentration of 1:3 (w/v: Capsicum annuum L/avocado oil) for $48 \mathrm{~h}$ in darkness at room temperature. The behavior of the oil under stronger conditions $\left(45^{\circ} \mathrm{C}, 30\right.$ days $)$ showed the following characteristics: (1) the extracts were stable to lipid oxidation, with a Totox index total value of 27.34 , (2) $85.6 \%$ of carotenoids were conserved, (3) $80.66 \%$ of the antioxidant activity was retained, and (4) there was a color change $(\Delta \mathrm{E})$ of 1.783 . The oleoresins obtained by extraction with avocado oil can be considered as an economic and sustainable alternative for the extraction of carotenoids, with a good oxidative stability, compared with organic solvents [35].

\section{Use of Analytical Techniques in the Quantification, Adulteration, and Contamination of Avocado Oil}

There is growing interest among consumers in accessing quality and authentic products. Vegetable oils can suffer from contamination and/or adulteration, which causes the product to have components not specific to the oil. It is here that the development, implementation, and application of analytical technologies are very useful.

The components present in avocado oil, such as fatty acids and phytosterols, have been quantified, mainly by gas chromatography, coupled with a flame ionization detector (GC-FID). In addition, techniques, such as ultra-high-performance liquid chromatography (UHPLC), coupled with mass spectrometry (UHPLC-MS) or a photodiode array detector (UHPLC-PDA), as well as Inductively Coupled Plasma Mass Spectrometry (ICP-MS), have been used for the identification and/or quantification of analytes, such as polyphenols, squalene and minerals, respectively [36,37]. Other analytical techniques have been used for the qualitative determination of the components present in avocado oil, including ${ }^{13} \mathrm{C}$ nuclear magnetic resonance spectroscopy (NMR), which has been used for the identification of its major components, including fatty acids [38]. At the same time, ${ }^{1} \mathrm{H}$ Nuclear 
magnetic resonance spectroscopy $\left({ }^{1} \mathrm{H}-\mathrm{NMR}\right)$ has been used for the detection of the minor components present in other vegetable oils [39]. Therefore, the development of new analytical methodologies for quantifying the analytes present in avocado oil represents a major challenge.

Rohman et al. [40] studied the purity of avocado oil, adulterated with palm oil and canola oil, through FTIR, combined with chemometric techniques. FTIR combined with multivariate calibrations can be used to detect and quantify the adulteration of avocado oil in binary mixtures with palm oil and canola oil.

The adulteration of avocado oil with soybean oil or grape seed oil can be determined using mid-infrared spectroscopy, combined with the statistical method of partial least squares discriminant analysis. This methodology allows for a simple and fast discrimination of avocado oil in binary mixtures and Tertiary oils. The frequency selected for the authentication of avocado oil was $1500-750 \mathrm{~cm}^{-1}$, with a precision of $100 \%$ for the analysis of the mixture of two oils and $93.3 \%$ for the mixture of three oils [41].

Organophosphorus pesticides in samples of commercial avocado oil were determined using atmospheric pressure microwave-assisted liquid-liquid extraction (APMAE), with solid-phase extraction or low-temperature precipitation, as the clean-up step. The analysis was carried out by gas chromatography-flame photometric detection and gas chromatography-tandem mass spectrometry. Chlorpyrifos residues were detected in one of four samples of commercially packaged avocado oil, produced in Chile [42]. While spectroscopic techniques have focused on determining the adulteration of avocado oil with the presence of other types of vegetable oil, according to the literature reviewed here, there is a research deficiency related to the modification of the composition of avocado oil, including the study of its major components, such as triacylglycerides and/or fatty acids, in addition to its minority components, such as phytosterols, alkanes, aliphatic alcohols, polyphenols, and others. This could provide information for detecting the contamination of avocado oil with other oils of a different quality.

\section{Technological Applications of Avocado Oil}

At the industrial level, there is a constant demand for the production of healthy foods that can maintain their nutritional properties over time, as well as environmentally friendly technological solutions. Avocado oil is mainly sold for direct consumption due to its interesting contribution of fatty acids, vitamins, antioxidants, among other compounds. Efforts have been made to develop products based on avocado oil. Arancibia et al. [43] propose the development of O/W nanoemulsions using the natural emulsifiers, lecithin and synthetic tween 80 , systems that improve the characteristics with respect to traditional emulsions, such as (i) increased dispersibility of water in the encapsulated oils, which generates slightly turbid emulsions and an easy production, and (ii) a good physical and chemical stability, as well as a high bioavailability of its lipid components.

Another interesting technological application for avocado oil has been the production of structured lipids. Caballero et al. [44] propose the elaboration of triacylglycerides of the MLM type, using regio-specific immobilized commercial lipases $s n-1.3$, where $\mathrm{M}$ corresponds to saturated medium-chain fatty acids (6-12 carbon atoms) at positions $s n 1$ and $s n 3$ of glycerol. L corresponds to saturated or unsaturated long-chain fatty acids (14-24 carbon atoms) in the sn2 position. The increased interest in this type of lipids is due to the low caloric intake (average caloric density for this family of lipids $5 \mathrm{kcal} / \mathrm{g}$ ). According to the literature, there are no negative effects associated with the ingestion of MLM lipids for both animals and humans.

Finally, avocado oil has also been used in the production of biodegradable polymers. Polyhydroxyalkanoates (PHAs) are linear polyesters, produced by a large number of bacteria under stress conditions, with different thermal and mechanical properties, which depend on their molecular structure. Flores-Sanchez et al. [45] prepared PHAs through a fermentative process using the bacterium C. necator H-16 with avocado oil and fructose, as a carbon source. The highest yield in obtaining polymers was obtained when the addition of avocado oil was $20 \% v / v$, which demonstrates the feasibility of using this oil as a renewable carbon source for the PHA production process. 


\section{Composition of Avocado Oil}

There is a growing interest in avocado oil, including the determination of the composition of major and minor components. Therefore, for a total understanding of the nutritional and functional properties that this oil presents, it is important to consider the different varieties and parts of the fruit.

\subsection{Characteristics According to the Variety and Origin of the Fruit}

Avocado is a fruit grown mainly in warm temperate and subtropical climates throughout the world, so it is interesting to study how the climate and country of origin can affect the fruit quality and therefore, the oil. Thus, the oil from the fruit of the Hass variety, originating from crops from Mexico, Australia, the United States, and New Zealand, was characterized by a high content of $62 \%$ lipids, of which oleic ( $42-51 \%$ ) and palmitic $(20-25 \%)$ lipids were present in a greater proportion. Among the predominant triacylglycerols were OOO (21-34\%) and OOP (19-24\%), where $\mathrm{O}$ and $\mathrm{P}$ denote oleic and palmitic acids, respectively. On the other hand, Hass avocado oil from New Zealand contained a significant amount of natural pigments and unsaturated compounds, compared to oils from Mexico, Australia, and the United States [1].

Studies carried out in South America on the analysis and characterization of avocado oil showed a high content of monounsaturated fatty acids $(69.4 \%)$ and a lower amount of polyunsaturated and saturated fatty acids, which were $16.6 \%$ and $14 \%$, respectively. These studies indicate that avocado oil has a thermal stability close to $176^{\circ} \mathrm{C}$ and has a lower concentration of total phenolic compounds than olive oil. Despite this, the antioxidant activity of avocado oil is similar to that of olive oil. Olive oil has a high concentration of polyphenols, such as tyrosol and hydroxytyrosol [46].

Galvão et al. [47] analyzed the fatty acid composition of the pulp, seed, and skin oil of the Fortuna, Collinson, and Barker varieties, indicating that there was a small variation in the composition of monounsaturated fatty acids in the skin oil among the cultivars. However, the seed oil of the Collinson variety was the best due to the lower SFA content. The SFA content for pulp oil corresponded to 22.3, 29.4 and $41.3 \%$ in the Fortuna, Collinson, and Barker varieties, respectively. In this sense, it was possible to affirm that the pulp oil of the Fortuna and Collinson varieties presented a better quality, in terms of fatty acid profile, than the Barker variety.

In Mexico, avocado oil from six local creole varieties (BTancitaro, Irapuato, Orgánico, Puerto, San José, and STancitaro) were analyzed and compared with oil from the Hass variety. It was observed that the Mexican creole genotypes had a greater thermal stability, properties resistant to oxidation, and a greater phenolic content, in comparison with the commercial oil from the Hass variety. In addition, these varieties showed intense fluorescent peaks at 675 and $720 \mathrm{~nm}$, as well as broad absorption bands centered at 465 and $510 \mathrm{~nm}$, which can be used as an identification parameter for these oils [48].

Yanty et al. [49] indicated that the avocado oil originating from three Malaysian varieties was found in a significantly lower proportion than in the Australian Hass variety. In addition to being in a semi-solid form, all these oils had a higher proportion of oleic acid, although they also had different proportions of palmitic and linoleic acids. Regarding the composition of TAG for local varieties, the highest was POO, followed by POL, OOO, and PPO, while in the Hass variety, the distribution was OOO, followed by PPO, OOL, and POL. As a result of these different compositions in TAG, differences were found in the iodine index, melting point by slip and melting and solidification characteristics.

\subsection{Physicochemical Characterization}

Table 1 shows the composition of the common fatty acids of the oils from different varieties and origin of avocados, discussed in this work. However, only some varieties have the C6:0, C7:0, C8:0, C9:0, C10:0, C11:0, C12:0, C13:0, C14: 0, C14:1, C15:0, C15:1, C16:1, C17:0, C17:1, C19:0, C20:0, C20:1, C20:3, C20:4, C22:0, C22:1, C22:2, C23:0, and C24:0 fatty acids in a low proportion, ranging from traces $(<0.06 \%)-3.58 \%$. Dreher and Davenport [50] refer to the fact that the oil coming from the Hass variety can contain up to $71 \%$ of monounsaturated fatty acids (MUFA), $13 \%$ of polyunsaturated fatty acids (PUFA), and $16 \%$ of saturated fatty acids (SFA). 


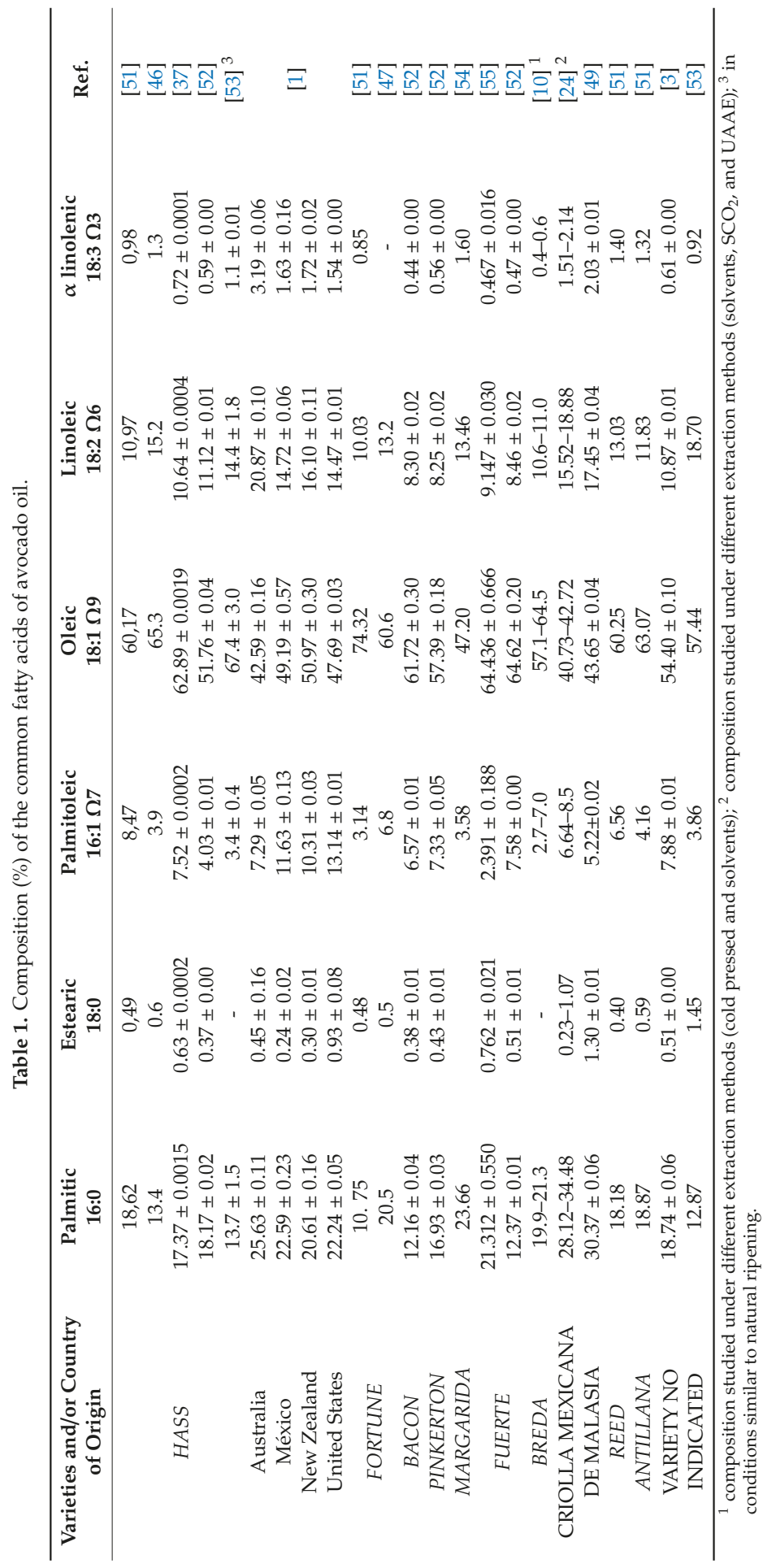


In order to study the fatty acid profile of the avocado oil from the fruits harvested and artificially ripened, the avocado oil was extracted from preserved fruit at $5{ }^{\circ} \mathrm{C}$ in a controlled atmosphere and was analyzed $\left(4 \%\right.$ of $\mathrm{O}_{2}$ and $6 \%$ of $\left.\mathrm{CO}_{2}\right)$. Postharvest ripening was stimulated in the presence of exogenous ethylene ( 0 or $100 \mathrm{ppm}$ ) at a temperature of $18^{\circ} \mathrm{C}$ for $24 \mathrm{~h}$ and then preserved at 15 and $20^{\circ} \mathrm{C}$. It was concluded that post-harvest conservation and ripening by means of a controlled atmosphere did not have a detrimental effect on the fatty acid profile or the amount of oil obtained, when compared with the one commonly applied in the ready-to-eat market [53]. This information is very important for the fresh product industry, where avocados move long distances at low temperatures.

When carrying out the physicochemical evaluation of two Hass avocado oils sold in Chile and labeled as extra virgin, it was demonstrated that both oils presented significant differences in the content of tocopherols, total phenols, oil stability, measured as the induction time, UV absorption coefficients, peroxide index, free acidity, total chlorophyll, total carotenoids, and polar compounds. In addition, the presence of 3,5-stigmastadiene in one of the samples, a compound that has been associated with a high degree of refining or exposure to high temperatures of oils, indicated a disparity in the quality parameters and a lack of regulation of avocado oil in the local market [37].

On the other hand, monovarietal oils from the Bacon, Fuerte, Hass, and Pinkerton varieties, obtained in Spain, were compared with commercial oils originating in Brazil, Chile, Ecuador and New Zealand. The content of triacylglycerols, fatty acids, aliphatic, and terpene alcohols, desmethylmethyl, methyl and dimethyl sterols, squalene and tocopherols were determined. The main triacylglycerols were those with ECN48 (48 equivalents of carbon atoms). The oleic, palmitic, and linoleic fatty acids were the most abundant fatty acids, and the desmethyl sterols were the main quantified minor compounds. Small amounts of aliphatic and terpene alcohols were observed. The concentrations of squalene were higher in the oils of the Bacon, Fuerte, and Pinkerton varieties than in the other varieties. The most abundant tocopherol was $\alpha$-tocopherol [52].

While the fruit reaches a minimum of $8 \%$ fat at the time of its extraction from the tree, during vegetative ripening, values of $20 \%$ or more are reached, depending on the variety. In this sense, it is recommended that the avocado oil industry ripen the fruit on the tree, since climacteric ripening, in comparison with commercial ripening, influences not only the increase in oil content, but also the profile of the fatty acids, increasing the amount of unsaturated fatty acids, such as oleic acid, and decreasing the amount of saturated fatty acids, such as palmitic and palmitoleic acids [56]. This situation seems controversial with respect to the previously discussed studies. However, it is well known that the composition of fruits depends on environmental and growth conditions. In addition, the quantification of the different analytes depends on the conditions of extraction, processing, and detection limits of the analytical equipment.

Martinez-Nieto and Moreno-Romero [57] have analyzed the sterol composition of the unsaponifiable matter of avocado oil in 4 varieties (Reed, Bacon, Fuerte, and Hass) by means of gas chromatography. The results showed that the Fuerte and Reed varieties contained $2 \%$ more of $\beta$-sitosterol than the Bacon and Hass varieties. In relation to the cholesterol content, the smallest amount was present in the Fuerte variety and the largest in the Hass variety. In this sense, the unsaponifiable sterol composition can be a guiding tool to determine the authenticity of oil.

Martínez-Nieto et al. [51] analyzed the composition of different fractions in an industrial extraction process using a continuous method, under conditions similar to those used in the extraction of olive oil, for ripe avocados of the Fuerte, Reed, Hass, and Antillana varieties. They concluded that it is possible to obtain a good net oil yield with the industrial equipment used prior to specific modifications in the grinding stage and in the decanter, as well as good quality parameters, such as the acidity index, peroxide index, and absorbance coefficients, for both virgin oil and refined avocado oil.

When evaluating the physicochemical characteristics of the avocado oil obtained from the Bantul, Purwokerto, and Garut varieties, originating in Indonesia, by extraction with solvents, the Garut variety presented a better quality in terms of the iodine index, which is associated with a greater amount of unsaturated fatty acids. The conjugated dienes and trienes were significantly different 
between the samples. The p-anisidine index did not have significant differences between the samples. The saponification index was higher in the Purwokerto variety, and the peroxide index was higher in the Bantul variety. In addition, the analysis using differential scanning calorimetry (DSC) showed that the three samples had different melting and crystallization profiles [58].

\subsection{Avocado Seed Oil}

In relation to avocado seed oil, Barrera-López and Arrubia-Vélez [59] pointed out that the Lorena variety contained about $8.47 \%$ oil, and the unsaponifiable matter was $76.9 \%$. The phytosterols quantified in a greater proportion were ergosterol, $5 \alpha$-cholestane and stigmasterol.

Avocado seed presents, in its composition, a large number of extractable polyphenols, which have attracted attention due to their high antioxidant capacity. It was determined that, with a higher power of the ultrasound $(0-104 \mathrm{~W})$ and increase of the temperature $\left(20-60^{\circ} \mathrm{C}\right)$, the polyphenol content and antioxidant capacity was increased [60].

When performing a physicochemical analysis of the seed oil of the Hass variety, cultivated in Peru and obtained by the Soxhlet method, it was found that it had a high fatty acid profile in linoleic acid $(48.77 \%)$ and linolenic acid (12.17\%). While the antioxidant activity, determined by the DPPH method, was low, it was higher in the saponifiable fraction than in the unsaponifiable fraction, which was attributable to the presence of polyphenols and steroids. In addition, it was determined that the quality parameters, such as acidity, peroxide, saponification, iodine, and specific gravity indexes, were similar to those for extra virgin olive oil [61].

When comparing the composition of oil from the pulp and seed of the Fuerte variety, cultivated in the region of Northeastern Brazil, a great difference in the lipid content between the pulp and the seed can be seen (15.39\% v.s. $1.87 \%$, dry base). It was determined that the parameters of oil quality, refractive index, gravity, and peroxide index were similar for both oils, but the iodine, acid index, and saponification index were higher in seed oil than in pulp oil. Gas chromatography showed that seed oil had a greater variety of fatty acids than pulp oil. Additionally, the fatty acid profile of the pulp was much more concentrated in monounsaturated fatty acids than that of seed, and conversely, the seed oil is much more concentrated in polyunsaturated fatty acids than pulp oil [55].

\subsection{Comparison with Other Oils}

Dubois et al. (2007) [62] compared 80 varieties of vegetable oils, including avocado oil, indicating that it was composed of more than $60 \%$ of monounsaturated fatty acids, a characteristic shared with olive oil, hazelnut, and macadamia nut profiles. In comparison with olive oil, avocado oil possessed a higher proportion of saturated fatty acids $(16.4 \%)$, with a predominance of palmitic acid $(15.7 \%)$, a lower proportion of monounsaturated fatty acids $(67.8 \%)$, with a predominance of oleic acid $60.3 \%$ and a higher proportion of polyunsaturated fatty acids (15.2\%), the most important of which was linoleic acid at $13.7 \%$.

Additionally, similar fatty acid profiles have been published by Berasategi et al. [3], who also showed that avocado oil had a higher PUFA/SFA and higher omega-6/omega-3 ratios than olive oil.

Berasategi et al. [3] showed that the phytosterol content was higher in avocado oil (3.3 $\mathrm{g}$ to $4.5 \mathrm{mg} / \mathrm{g}$ of oil) than in olive oil, of which the most abundant was $\beta$-sitosterol, followed by sitostanol, cycloartenol, cycloeucalenol and D7-avenasterol. The number of sterols in the avocado oil was higher, 4-demethyl-sterols being the most abundant, reaching $80 \%$ of the total fraction of sterols. This greater proportion was even maintained under drastic conditions of deterioration $\left(180^{\circ} \mathrm{C}\right)$. Moreover, avocado oil has a lower proportion of vitamin E, compared to olive oil. This study indicates that the thermal stability of avocado oil is similar to that of olive oil. From Table 2, it is possible to appreciate a summary of the different antioxidant components present in the avocado oils of the different varieties shown in this work. 


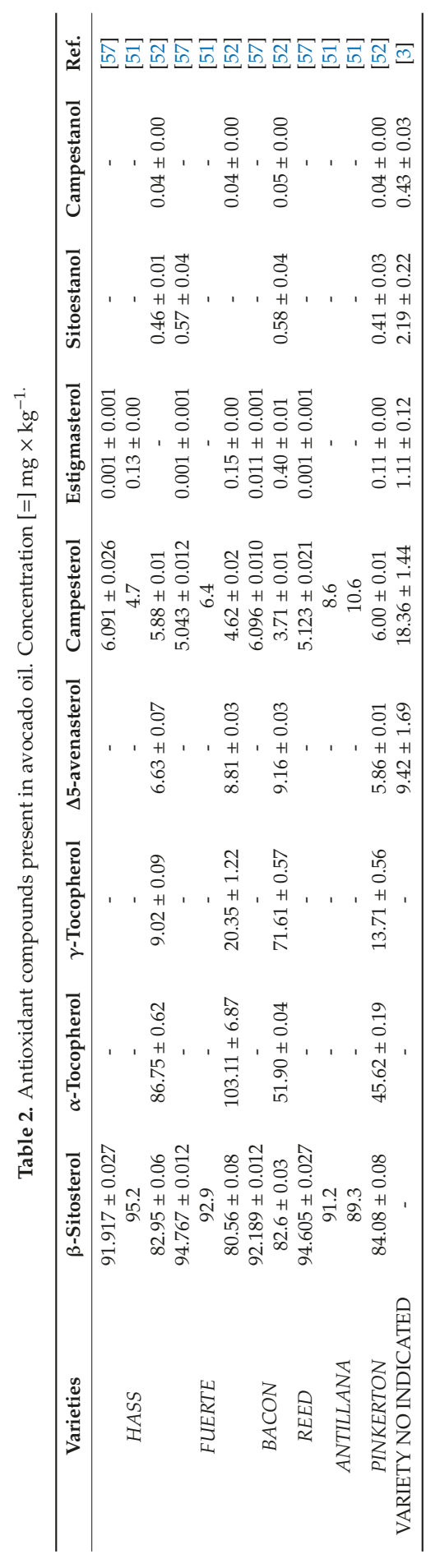




\section{Biological Effects}

The presence of compounds with nutritional interest, such as unsaturated fatty acids (MUFA and PUFA), as well as compounds with biological activity, such as tocopherols, tocotrienols, phytosterols, carotenoids, and polyphenols, have made avocado oil of growing interest for research on the possible biological effects of avocado oil, with the aim of preventing and treating diseases through the diet of the population.

\subsection{Human Health Effects}

A study in 13 healthy adults with a habitual hypercaloric and hyperlipidic diet, where butter was replaced by avocado oil extracted at $35^{\circ} \mathrm{C}$ from the pulp alone, was conducted. The incorporation of avocado oil for a period of six days reflected an improvement in the postprandial profile of insulin, glycemia, total cholesterol, low-density lipoproteins, triglycerides, and inflammatory parameters, such as C-reactive protein (CRP) and interleukin-6 [63]. Avocado pulp oil (Mexican creole genotypes) has shown anti-inflammatory activity by inhibiting the enzymes COX 1 and COX 2 in a similar way to the drug, ibuprofen, and extra virgin olive oil [48]. Additionally, when avocado oil was added to vitamin B12 skin cream preparation, it was well tolerated and had the potential for long-term topical therapy of psoriasis [64].

\subsection{Experimental Studies in Animals}

When administering avocado oil to Wistar diabetic rats for 90 days ( $1 \mathrm{gr} / 250 \mathrm{~g}$ weight), it was observed that it promoted an improvement in the functionality of the electron transport chain and decreased the generation of free radicals in the liver, attenuating the harmful effects of oxidative stress [65].

In the brain, an improvement in mitochondrial function has been observed, as well as a decrease in free radical levels, lipid peroxidation, and an improvement in the reduced/oxidized glutathione ratio. These results demonstrate that supplementation with avocado oil prevents mitochondrial dysfunction in the brain and liver of diabetic rats [66].

Ortiz-Avila et al. [67] demonstrated that supplementation with avocado oil in Wistar rats led to a reduction of the alterations in the electron transport chain at the renal level, attenuating the oxidative damage, although a protective effect on lipid peroxidation was not evidenced.

Some authors [68-70] studied the relationship between avocado oil and collagen metabolism in both the skin and liver, finding that oil obtained from intact fruit (pulp and seed), refined with hexane, was associated with fibrosis in the liver, an increase in liver enzymes and consequently hepatotoxicity.

In addition to an increase in the solubility of collagen, behavior that is attributed to a decrease in the activity of lysyl oxidase was observed [66]. A similar conclusion was proposed by Lamaud et al. [71], stating that the mixture of soybean and avocado oils decreased the degree of collagen cross-linking, a process that has been associated with a delay in wound healing. However, Oliveira et al. [53] indicated that the healing activity of a semi-solid formulation of avocado oil (50/50 Vaseline) and avocado pulp oil promoted the increase of collagen synthesis and decreased the number of inflammatory cells during the process of wound healing. 
Regarding the effects on cardiovascular health, it is possible to point out that the atherogenic power of avocado oil could be similar to that of olive oil and lower than that of corn and coconut oil [72]. On the other hand, an avocado oil-rich diet modifies the fatty acid content in cardiac and renal membranes in a tissue-specific manner in Wistar rats. The rise in renal arachidonic acid suggests that diet content can be a key factor in vascular responses [73].

Márquez-Ramírez et al. [74] studied the antihypertensive effect of avocado oil in rats with induced hypertension. They were subsequently treated with the administration of $1 \mathrm{~mL}$ of oil per $250 \mathrm{~g}$ of rat weight or $40 \mathrm{mg}$ of losartan potassium per $\mathrm{kg}$ of rat weight. Avocado oil significantly decreased both systolic and diastolic pressure in hypertensive rats, but not in controls. Avocado oil mimicked the effects of the drug, losartan, on blood pressure, vascular performance, and oxidative stress.

In rats fed with sucrose, it was observed that the addition of avocado oil in the diet reduced the levels of triglycerides, VLDL and LDL, without affecting the levels of HDL. It also reduced the level of ultrasensitive $\mathrm{CPR}$, indicating that the inflammatory processes associated with metabolic syndrome were partially re-established [4]. Additionally, a diet high in sucrose, which causes liver alteration in Sprague-Dawley Weaned rats, was partially reversible by the administration of avocado oil, obtained by centrifugation and extracted by solvents. This effect was similar to that of olive oil, but would not be extended to the pancreatic level [5]. In relation to insulin resistance induced by a diet high in sucrose in Wistar rats, it was possible to reduce it through the dietary addition of 5-20\% avocado oil [75]. In female Wistar rats exposed to prolonged androgenic stimulation, avocado oil improved triglyceride, VLDL and HDL levels, generating a direct regulatory effect on the lipid profile [76]. The influence of avocado oil on cell damage, induced by methyl methanesulfonate (MMS) and doxorubicin, can be carried out using in vitro (V79 cells) and in vivo models (Swiss mice). Avocado pulp oil had no genotoxic effects. The oil was effective in reducing the chromosomal damage induced by MMS and doxorubicin. However, an increase in liver tissue damage was observed when evaluating a high dose of avocado oil (measured as an increase in the hepatic enzyme aspartate aminotransferase), a phenomenon attributable to the high concentration of palmitic fatty acid [77]. Table 3 shows a summary of the biological effects presented in this study. 


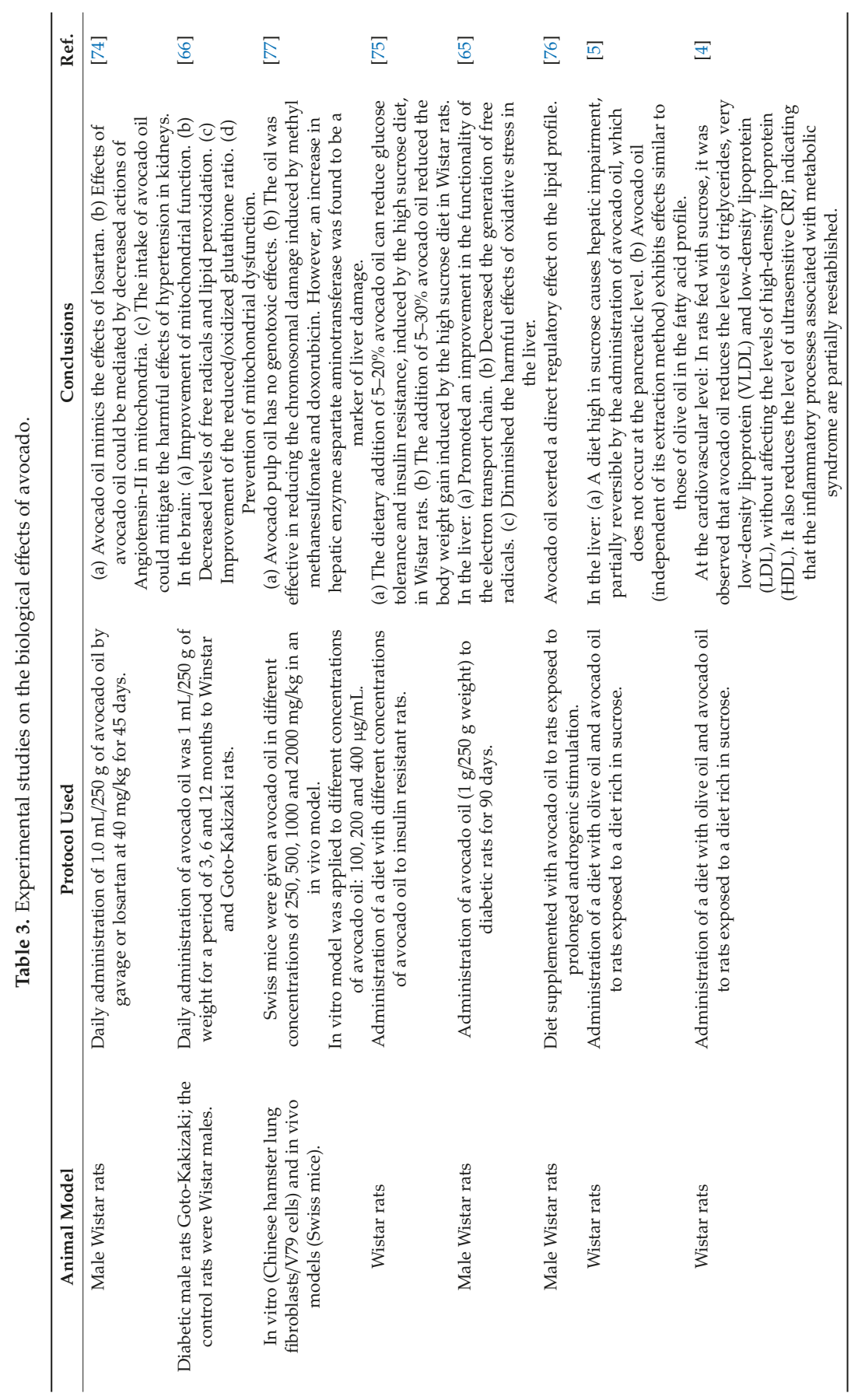




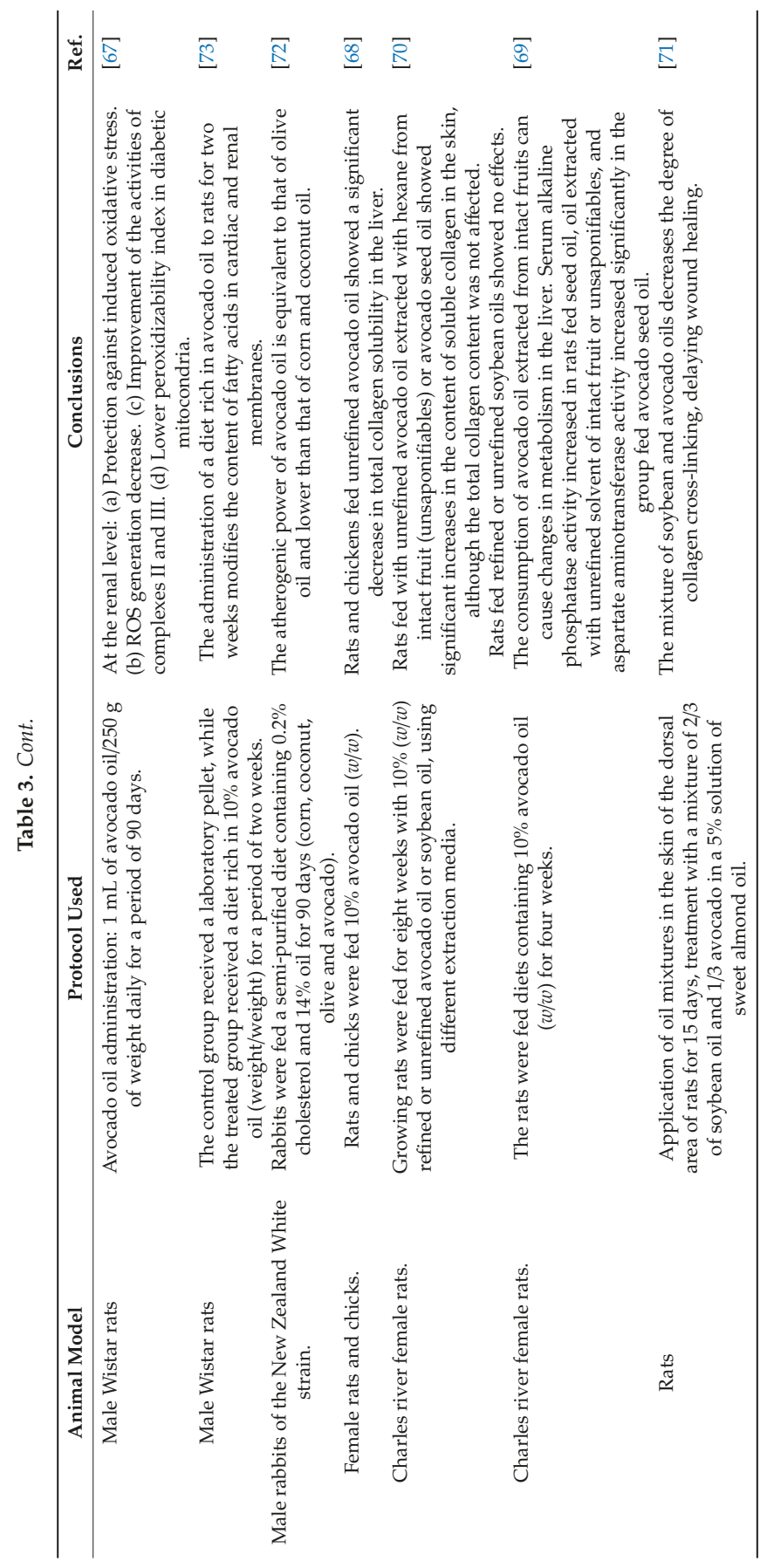




\section{Conclusions}

While the composition and quality of the avocado oil depends on the origin, weather conditions, variety, and extraction methods, it is characterized as a mainly monounsaturated oil, with an adequate proportion of polyunsaturated fatty acids, similar to olive oil. In addition, it contains other bioactive compounds, present in the unsaponifiable fraction, such as tocopherols, polyphenols, and a remarkable proportion of phytosterols. This oil has also been shown to perform well at high temperatures. All these characteristics indicate that avocado oil has nutritional properties that are greatly appreciated by the population, even for technological applications. This makes it a product of increasing exploitation interest for producers.

This growing interest also requires a greater development of studies on the adulteration and contamination of avocado oil, as well as the further assessment of the promising biological effects of the different components present in the oil, either in animals or humans. Furthermore, considering the presented information, it is necessary to inquire into the international regulations concerning the different qualities of this oil.

Author Contributions: Conceptualization, M.F. and J.O.-V.; methodology, C.E.V., C.S. and J.O.-V.; software, H.V.; validation, C.E.V., F.A., and H.V.; formal analysis, M.F. and F.A.; investigation, M.F., C.S. and J.O.-V.; resources, M.F.; data curation, C.S. and C.E.V.; writing-original draft preparation, C.S.; writing-review and editing, M.F., F.A., H.V. and J.O.-V.

Funding: This research received no external funding.

Conflicts of Interest: The authors declare no conflict of interest.

\section{Abbreviations}

$\begin{array}{ll}\text { UAAE } & \text { Ultrasound-assisted aqueous extraction } \\ \mathrm{SCO}_{2} & \text { Subcritical } \mathrm{CO}_{2} \\ \mathrm{ScCO}_{2} & \text { Supercritical } \mathrm{CO}_{2} \\ \mathrm{LPG} & \text { Liquefied gas of compressed oil } \\ \text { FFA } & \text { Free fatty acid } \\ \text { MUFA } & \text { Monounsaturated fatty acid } \\ \text { PUFA } & \text { Polyunsaturated fatty acid } \\ \text { SFA } & \text { Saturated fatty acid } \\ \text { TAG } & \text { Triacylglycerol } \\ \mathrm{O} & \text { Oleic acid } \\ \text { P } & \text { Palmitic acid } \\ \text { L } & \text { Linoleic acid } \\ \text { COX } & \text { Cyclooxygenase enzyme } \\ \text { PCR } & \text { C reactive protein } \\ \text { FTIR } & \text { Infrared spectroscopy with Fourier transform } \\ \text { IOC } & \text { International olive council } \\ \text { DPPH } & \text { 2,2-Diphenyl-1-picrylhydrazyl } \\ \text { APMAE } & \text { Atmospheric pressure microwave-assisted liquid-liquid extraction } \\ \text { PHAs } & \text { Polyhydroxyalkanoates } \\ \text { ECN48 } & \text { 48 equivalents of carbon atoms } \\ \text { VLDL } & \text { Very low-density lipoprotein } \\ \text { LDL } & \text { Low-density lipoprotein } \\ \text { HDL } & \text { High-density lipoprotein }\end{array}$

\section{References}

1. Tan, C.; Tan, S.; Tan, S. Influence of Geographical Origins on the Physicochemical Properties of Hass Avocado Oil. J. Am. Oil Chem. Soc. 2017, 94, 1431-1437. [CrossRef] 
2. Wong, M.; Requejo-Jackman, C.; Woolf, A. What is unrefined, extra virgin cold-pressed avocado oil? Inform 2010, 21, 189-260.

3. Berasategi, I.; Barriuso, B.; Ansorena, D.; Astiasarán, I. Stability of avocado oil during heating: Comparative study to olive oil. Food Chem. 2012, 1, 439-446. [CrossRef] [PubMed]

4. Carvajal-Zarrabal, O.; Nolasco-Hipolito, C.; Aguilar-Uscanga, M.; Melo-Santiesteban, G.; Hayward-Jones, P.; Barradas-Dermitz, D. Avocado oil supplementation modifies cardiovascular risk profile markers in a rat model of sucrose-induced metabolic changes. Dis. Markers 2014, 2014, 386-425. [CrossRef] [PubMed]

5. Carvajal-Zarrabal, O.; Nolasco-Hipolito, C.; Aguilar-Uscanga, M.; Melo-Santiesteban, G.; Hayward-Jones, P.; Barradas-Dermitz, D. Effect of dietary intake of avocado oil and olive oil on biochemical markers of liver function in sucrose-fed rats. Biomed Res. Int. 2014, 2014, 595479. [CrossRef] [PubMed]

6. Di Stefano, V.; Avellone, G.; Bongiorno, D.; Indelicato, S.; Massenti, R.; Lo Bianco, R. Quantitative evaluation of the phenolic profile in fruits of six avocado (Persea americana) cultivars by ultra-high-performance liquid chromatography-heated electrospray-mass spectrometry. Int. J. Food Prop. 2017, 20, 1302-1312. [CrossRef]

7. Woolf, A.; Wong, M.; Eyres, L.; McGhie, T.; Lund, C.; Olsson, S.; Wang, Y.; Bulley, C.; Wang, M.; Friel, E.; et al. Avocado oil. From cosmetic to culinary oil. In Gourmet and Health-Promoting Specialty Oils; Moreau, R., Kamal-Eldin, A., Eds.; AOCS Press: Urbana, IL, USA, 2009; pp. 73-125.

8. NM. 2008. Norma Mexicana NMX-F-052- SCFI-2008. Aceites y grasas-aceite de aguacate - especificaciones. Available online: http://aniame.com/mx/wp-content/uploads/Normatividad/CTNNIAGS/NMX-F-052-SCFI2008.pdf (accessed on 7 June 2019).

9. Costagli, G.; Betti, M. Avocado oil extraction processes: Method for cold-pressed high-quality edible oil production versus traditional production. J. Agric. Eng. 2015, 46, 115-122. [CrossRef]

10. Krumreich, F.D.; Borges, C.D.; Mendonça, C.R.B.; Jansen-Alves, C.; Zambiazi, R.C. Bioactive compounds and quality parameters of avocado oil obtained by different processes. Food Chem. 2018, 257, 376-381. [CrossRef]

11. Santana, I.; dos Reis, L.; Torres, A.; Cabral, L.; Freitas, S. Avocado (Persea americana Mill.) oil produced by microwave drying and expeller pressing exhibits low acidity and high oxidative stability. Eur. J. Lipid Sci. Technol. 2015, 117, 999-1007. [CrossRef]

12. Chimsook, T.; Assawarachan, R. Effect of Drying Methods on Yield and Quality of the Avocado Oil. Adv. Mater. Res. Key Eng. Mater. 2017, 735, 127-131. [CrossRef]

13. Dos Santos, M.; Alicieo, T.V.; Pereira, C.M.; Ramis-Ramos, G.; Mendonça, C.R. Profile of bioactive compounds in avocado pulp oil: Influence of the drying processes and extraction methods. J. Am. Oil Chem. Soc. 2014, 91, 19-27. [CrossRef]

14. Norma para grasas y aceites comestibles no regulados por normas individuales. Available online: http: //URLwww.fao.org/input/download/standards/74/CXS_019s_2015.pdf (accessed on 16 April 2019).

15. Yang, S.; Hallett, I.; Rebstock, R.; Oh, H.; Kam, R.; Woolf, A.; Wong, M. Cellular Changes in "Hass" Avocado Mesocarp During Cold-Pressed Oil Extraction. J. Am. Oil Chem. Soc. 2018, 95, 229-238. [CrossRef]

16. Xuan, T.; Hean, C.; Hamzah, H.; Ghazali, H. Optimization of ultrasound-assisted aqueous extraction to produce virgin avocado oil with low free fatty acids. J. Food Process Eng. 2017, 12656, 1-9.

17. Martínez-Padilla, L.P.; Franke, L.; Xu, X.Q.; Juliano, P. Improved extraction of avocado oil by application of sono-physical processes. Ultrason. Sonochemistry 2018, 40, 720-726. [CrossRef] [PubMed]

18. Valdés, H.; Unda, K.; Saavedra, A. Numerical Simulation on Supercritical $\mathrm{CO}_{2}$ Fluid Dynamics in a Hollow Fiber Membrane Contactor. Computation 2019, 7, 8. [CrossRef]

19. Corzzini, S.; Barros, H.; Grimaldi, R.; Cabral, F. Extraction of edible avocado oil using supercritical $\mathrm{CO}_{2}$ and a CO 2 /ethanol mixture as solvents. J. Food Eng. 2017, 194, 40-45. [CrossRef]

20. Barros, H.D.; Coutinho, J.P.; Grimaldi, R.; Godoy, H.T.; Cabral, F.A. Simultaneous extraction of edible oil from avocado and capsanthin from red bell pepper using supercritical carbon dioxide as solvent. J. Supercrit. Fluids 2016, 107, 315-320. [CrossRef]

21. Barros, H.; Grimaldi, R.; Cabral, F. Lycopene-rich avocado oil obtained by simultaneous supercritical extraction from avocado pulp and tomato pomace. J. Supercrit. Fluids 2017, 120, 1-6. [CrossRef]

22. Restrepo, A.M.; Londoño, J.; González, D.; Benavides, Y.; Cardona, B.L. Comparación del aceite de aguacate variedad Hass cultivado en Colombia, obtenido por fluidos supercríticos y métodos convencionales: Una perspectiva desde la calidad. Rev. Lasallista Investig. 2012, 9, 151-161. 
23. Abaide, E.; Zabot, G.; Tres, M.; Martins, R.; Fagundez, J.; Nunes, L.; Druzian, S.; Soares, J.; Dal Prá, V.; Silva, J.; et al. Yield composition, and antioxidant activity of avocado pulp oil extracted by pressurized fluids. Food Bioprod. Process. 2017, 102, 289-298. [CrossRef]

24. Xuan, T.; Hean, C.; Hamzah, $\mathrm{H}$;; Ghazali, $\mathrm{H}$. Comparison of subcritical $\mathrm{CO}_{2}$ and ultrasound-assisted aqueous methods with the conventional solvent method in the extraction of avocado oil. J. Supercrit. Fluids 2018, 135, 45-51.

25. AOAC. Official Methods of Analysis of AOAC International, 18th ed.; Horwitz, W., Latimer, G., Eds.; AOAC International: Maryland, MD, USA, 2007.

26. Buenrostro, M.; López-Munguia, A.C. Enzymatic extraction of avocado oil. Biotechnol. Lett. 1986, 8, 505-506. [CrossRef]

27. Reddy, M.; Moodley, R.; Jonnalagadda, S.B. Fatty acid profile and elemental content of avocado (Persea americana Mill.) oil-effect of extraction methods. J. Environ. Sci. Health B 2012, 47, 529-537. [CrossRef] [PubMed]

28. Meyer, M.D.; Terry, L.A. Development of a rapid method for the sequential extraction and subsequent quantification of fatty acids and sugars from avocado mesocarp tissue. J. Agric. Food Chem. 2008, 56, 7439-7445. [CrossRef] [PubMed]

29. Lewis, C.E.; Morris, R.; O'Brien, K. The oil content of avocado mesocarp. J. Sci. Food Agric. 1978, 29, 943-949. [CrossRef] [PubMed]

30. Ortiz-Moreno, A.; Dorantes, L.; Galíndez, J.; Guzmán, R.I. Effect of different extraction methods on fatty acids, volatile compounds, and physical and chemical properties of avocado (Persea americana Mill.) oil. J. Agric. Food Chem. 2003, 51, 2216-2221. [CrossRef] [PubMed]

31. Mostert, M.E.; Botha, B.M.; Du Plessis, L.M.; Duodu, K.G. Effect of fruit ripeness and method of fruit drying on the extractability of avocado oil with hexane and supercritical carbon dioxide. J. Sci. Food Agric. 2007, 87, 2880-2885. [CrossRef]

32. Bizimana, V.; Breene, W.M.; Csallany, A.S. Avocado oil extraction with appropriate technology for developing countries. J. Am. Oil Chem. Soc. 1993, 70, 821-822. [CrossRef]

33. Ariza-Ortega, J.A.; Cruz-Cansino, N.; Ramírez-Moreno, E.; Ramos-Cassellis, M.E.; Castañeda-Antonio, D.; Betanzos-Cabrera, G. Effect of electric field on the characteristics of crude avocado oil and virgin olive. J. Food Sci. Technol. 2017, 54, 2166-2170. [CrossRef] [PubMed]

34. Ariza-Ortega, J.; Mendez-Ramos, M.; Diaz-Reyes, J.; Delgado-Macuil, R.; De-la-Torre, R. Study by Fourier Transform Infrared Spectroscopy of the Avocado Oils of the Varieties Hass, Criollo and Fuerte. J. Mater. Sci. Eng. 2010, 4, 61-64.

35. Cerecedo-Cruz, L.; Azuara-Nieto, E.; Hernández-Álvarez, A.J.; González-González, C.R.; Melgar-Lalanne, G. Evaluation of the oxidative stability of Chipotle chili (Capsicum annuum L.) oleoresins in avocado oil. Grasas Aceites 2018, 69, 240. [CrossRef]

36. Cicero, N.; Albergamo, A.; Salvo, A.; Bua, G.; Bartolomeo, G.; Mangano, V.; Rotondo, A.; Di Stefano, V.; Di Bella, G.; Dugo, G. Chemical characterization of a variety of cold-pressed gourmet oils available on the Brazilian market. Food Res. Int. 2018, 109, 517-525. [CrossRef] [PubMed]

37. Retief, L.; McKenzieb, JM.; Koch, K. A novel approach to the rapid assignment of 13C NMR spectra of major components of vegetable oils such as avocado, mango kernel and macadamia nut oils. Magn. Reson. Chem. 2009, 47, 771-781. [CrossRef] [PubMed]

38. Fernándes, G.D.; Gómez-Coca, R.B.; Pérez-Camino, M.C.; Moreda, W.; Barrera-Arellano, D. Chemical characterization of commercial and single-variety avocado oils. Grasas Aceites 2018, 69, 256. [CrossRef]

39. Castejón, D.; Mateos-Aparicio, I.; Molero, M.D.; Cambero, MI.; Herrera, A. Evaluation and Optimization of the Analysis of Fatty Acid Types in Edible Oils by 1 H-NMR. Food Anal. Methods 2014, 7, 1285-1297. [CrossRef]

40. Rohman, A.; Windarsih, A.; Riyanto, S.; Sudjadi, S.A.S.A.; Rosman, A.S.; Yusoff, F.M. Fourier transform infrared spectroscopy combined with multivariate calibrations for the authentication of avocado oil. Int. J. Food Prop. 2016, 19, 680-687. [CrossRef]

41. Rohman, A.; Lumakso, F.A.; Riyanto, S. Use of partial least square-discriminant analysis combined with mid infrared spectroscopy for avocado oil authentication. J. Med. Plants Res. 2016, 10, 175-180. [CrossRef]

42. Fuentes, E.; Báez, M.E.; Díaz, J. Microwave-assisted extraction at atmospheric pressure coupled to different clean-up methods for the determination of organophosphorus pesticides in olive and avocado oil. J. Chromatogr. A 2009, 1216, 8859-8866. [CrossRef] 
43. Arancibia, C.; Riquelme, N.; Zúñiga, R.; Matiacevicha, S. Comparing the effectiveness of natural and synthetic emulsifiers on oxidative and physical stability of avocado oil-based nanoemulsions. Innov. Food Sci. Emerg. Technol. 2017, 44, 159-166. [CrossRef]

44. Caballero, E.; Soto, C.; Olivares, A.; Altamirano, C. Potential use of avocado oil on structured lipids MLM-type production catalysed by commercial immobilised lipases. PloS ONE 2014, 9, E107749. [CrossRef]

45. Flores-Sánchez, A.; López-Cuellar, M.; Pérez-Guevara, F.; Figueroa López, U.; Martín-Bufájer, J.M.; Vergara-Porras, B. Synthesis of Poly-(R-hydroxyalkanoates) by Cupriavidus necator ATCC 17699 Using Mexican Avocado (Persea americana) Oil as a Carbon Source. Int. J. Polym. Sci. 2017. [CrossRef]

46. Forero-Doria, O.; Flores, M.; Vergara, C.E.; Guzman, L. Thermal analysis and antioxidant activity of oil extracted from pulp of ripe avocados. J. Therm. Anal. Calorim. 2017, 130, 959-966. [CrossRef]

47. Galvão, M.D.S.; Narain, N.; Nigam, N. Influence of different cultivars on oil quality and chemical characteristics of avocado fruit. Food Sci. Technol. 2014, 34, 539-546. [CrossRef]

48. Espinosa-Alonso, L.G.; Paredes-López, O.; Valdez-Morales, M.; Oomah, B.D. Avocado oil characteristics of Mexican creole genotypes. Eur. J. Lipid Sci. Technol. 2017, 119, 1600406. [CrossRef]

49. Yanty, N.A.M.; Marikkar, J.M.N.; Long, K. Effect of varietal differences on composition and thermal characteristics of avocado oil. J. Am. Oil Chem. Soc. 2011, 88, 1997-2003. [CrossRef]

50. Dreher, M.; Davenport, A. Hass Avocado Composition and Potential Health Effects. Crit. Rev. Food Sci. Nutr. 2013, 53, 738-750. [CrossRef]

51. Martínez-Nieto, L.; Barranco-Barranco, R.; Moreno-Romero, M.V. Extracción de aceite de aguacate: Un experimento industrial. Grasas Aceites 1992, 43, 11-15. [CrossRef]

52. Flores, M.A.; Perez-Camino, M.C.; Troca, J. Preliminary Studies on Composition, Quality and Oxidative Stability of Commercial Avocado Oil Produced in Chile. J. Food Sci. Eng. 2014, 4, 21-26.

53. Pedreschi, R.; Hollak, S.; Harkema, H.; Otma, E.; Robledo, P.; Westra, E.; Defilippi, B.G. Impact of postharvest ripening strategies on 'Hass' avocado fatty acid profiles. South Afr. J. Bot. 2016, 103, 32-35. [CrossRef]

54. Oliveira, A.; De Souza, E.; Rodrigues, R.; Cordeiro, D.; Gonçalves, R.; Ferreira, C.; Rodrigues, A.; De Medeiros, P.; Gonçalves, T.; Da Silva, A.; et al. Effect of Semisolid Formulation of Persea Americana Mill (avocado) Oil on Wound Healing in Rats. Evid. -Based Complement. Altern. Med. 2013, 2013, 1-8. [CrossRef]

55. Bora, P.S.; Narain, N.; Rocha, R.V.; Paulo, M.Q. Characterization of the oils from the pulp and seeds of avocado (cultivar: Fuerte) fruits. Grasas Aceites 2001, 52, 171-174.

56. Martinez-Nieto, L.; Moreno-Romero, M.V. Evolución del contenido de ácidos grasos de aceite de aguacate durante la maduración. Grasas Aceites 1995, 46, 92-95. [CrossRef]

57. Martinez-Nieto, L.; Moreno-Romero, M.V. Sterolic composition of the unsaponifiable fraction of oil of avocado of several varieties. Grasas Aceites 1994, 45, 402-403.

58. Indriyani, L.; Rohman, A.; Riyanto, S. Physico-chemical characterization of avocado (Persea americana Mill.) oil from three Indonesian avocado cultivars. Res. J. Med. Plants 2016, 10, 67-78.

59. Barrera-López, R.E.; Arrubla-Vélez, J.P. Análisis de Fitoesteroles en la Semilla de Persea americana Miller (var. Lorena) por Cromatografía de Gases y Cromatografía Líquida de Alta Eficiencia. Rev. Fac. Cienc. Básicas 2017, 13, 35-41.

60. Segovia, F.J.; Corral-Pérez, J.J.; Almajano, M.P. Avocado seed: Modeling extraction of bioactive compounds. Ind. Crop. Prod. 2016, 85, 213-220. [CrossRef]

61. Rengifo, P.G.; Carhuapoma, M.; Artica, L.; Castro, A.J.; López, S. Caracterización y actividad antioxidante del aceite de semilla de palta Persea americana MILL. Cienc. E Investig. 2015, 18, 33-36.

62. Dubois, V.; Breton, S.; Linder, M.; Fanni, J.; Parmentier, M. Fatty acid profiles of 80 vegetable oils with regard to their nutritional potential. Eur. J. Lipid Sci. Technol. 2007, 109, 710-732. [CrossRef]

63. Furlan, C.P.B.; Valle, S.C.; Östman, E.; Maróstica, M.R.; Tovar, J. Inclusion of Hass avocado-oil improves postprandial metabolic responses to a hypercaloric-hyperlipidic meal in overweight subjects. J. Funct. Foods 2017, 38, 349-354. [CrossRef]

64. Stucker, M.; Memmel, U.; Hoffmann, M.; Hartung, J.; Altmeyer, P. Vitamin B12 cream containing avocado oil in the therapy of plaque psoriasis. Dermatology 2001, 203, 141-147. [CrossRef]

65. Ortiz-Avila, O.; Gallegos-Corona, M.; Sánchez-Briones, L.; Calderón-Cortés, E.; Montoya-Pérez, R.; Rodriguez-Orozco, A.; Campos-García, J.; Saavedra-Molina, A.; Mejía-Zepeda, R.; Cortés-Rojo, C. Protective effects of dietary avocado oil on impaired electron transport chain function and exacerbated oxidative stress in liver mitochondria from diabetic rats. J. Bioenerg. Biomembr. 2015, 47, 337-353. [CrossRef] [PubMed] 
66. Ortiz-Avila, O.; Esquivel-Martínez, M.; Olmos-Orizaba, B.; Saavedra-Molina, A.; Rodriguez-Orozco, A.; Cortés-Rojo, C. Avocado Oil Improves Mitochondrial Function and Decreases Oxidative Stress in Brain of Diabetic Rats. J. Diabetes Res. 2015, 2015, 485759. [CrossRef]

67. Ortiz-Ávila, O.; Sámano-García, C.; Calderón-Cortés, E.; Pérez-Hernández, I.; Mejía-Zepeda, R.; Rodríguez-Orozco, A.; Saavedra-Molina, A.; Cortés-Rojo, C. Dietary avocado oil supplementation attenuates the alterations induced by type I diabetes and oxidative stress in electron transfer at the complex II-complex III segment of the electron transport chain in rat kidney mitochondria. J. Bioenerg. Biomembr. 2013, 45, 271-287. [CrossRef] [PubMed]

68. Wermam, M.J.; Mokady, S.; Neeman, I. Effect of dietary avocado oils on hepatic collagen metabolism. Ann. Nutr. Metab. 1991, 35, 253-260. [CrossRef] [PubMed]

69. Werman, M.; Mokady, S.; Neeman, I.; Auslaender, L.; Zeidler, A. The effect of avocado oils on some liver characteristics in growing rats. Food Chem. Toxicol. 1989, 27, 279-282. [CrossRef]

70. Wermam, M.J.; Mokady, S.; Nimni, M.E.; Neeman, I. The effect of various avocado oils on skin collagen metabolism. Connect. Tissue Res. 1990, 26, 1-10. [CrossRef]

71. Lamaud, E.; Huc, A.; Wepierre, J. Effects of avocado and soya bean lipidic non-saponifiables on the components of skin connective tissue after topical application in the hairless rat: Biophysical and biomechanical determination. Int. J. Cosmet. Sci. 1982, 4, 143-152. [CrossRef]

72. Kritchevsky, D.; Tepper, S.; Wright, S.; Czarnecki, S.; Wilson, T.; Nicolosi, R. Cholesterol vehicle in experimental atherosclerosis 24: Avocado oil. J. Am. Coll. Nutr. 2003, 22, 52-55. [CrossRef]

73. Salazar, M.J.; El Hafidi, M.; Pastelin, G.; Ramírez-Ortega, M.C.; Sánchez-Mendoza, M.A. Effect of an avocado oil-rich diet over an angiotensin II-induced blood pressure response. J. Ethnopharmacol. 2005, 98, 335-338. [CrossRef]

74. Márquez-Ramírez, C.; Hernández de la Paz, J.; Ortiz-Avila, O.; Raya-Farias, A.; González-Hernández, J.; Rodríguez-Orozco, A.; Salgado-Garciglia, R.; Saavedra-Molina, A.; Godínez-Hernández, D.; Cortés-Rojo, C. Comparative effects of avocado oil and losartan on blood pressure, renal vascular function, and mitochondrial oxidative stress in hypertensive rats. Nutrition 2018, 54, 60-67.

75. Del Toro-Equihua, M.; Velasco-Rodríguez, R.; López-Ascencio, R.; Vásquez, C. Effect of an avocado oil-enhanced diet (Persea americana) on sucrose-induced insulin resistance in Wistar rats. J. Food Drug Anal. 2016, 24, 350-357. [CrossRef] [PubMed]

76. De Souza-Abboud, R.; Alves-Pereira, V.; Soares da Costa, C.A.; Teles-Boaventura, G.; Alves-Chagas, M. The action of avocado oil on the lipidogram of wistar rats submitted to prolonged androgenic stimulum. Nutr. Hosp. 2015, 32, 696-701.

77. Nicolella, H.D.; Neto, F.R.; Corrêa, M.B.; Lopes, D.H.; Rondon, E.N.; Dos Santos, L.F.; De Oliveira, P.F.; Damasceno, J.L.; Acésio, N.O.; Turatti, I.C.; et al. Toxicogenetic study of Persea americana fruit pulp oil and its effect on genomic instability. Food Chem. Toxicol. 2017, 101, 114-120. [CrossRef] [PubMed]

(C) 2019 by the authors. Licensee MDPI, Basel, Switzerland. This article is an open access article distributed under the terms and conditions of the Creative Commons Attribution (CC BY) license (http://creativecommons.org/licenses/by/4.0/). 

MDPI

St. Alban-Anlage 66

4052 Basel

Switzerland

Tel. +41616837734

Fax +41 613028918

www.mdpi.com

Molecules Editorial Office

E-mail: molecules@mdpi.com

www.mdpi.com/journal/molecules 

MDPI

St. Alban-Anlage 66

4052 Basel

Switzerland

Tel: +41 616837734

Fax: +41 613028918 